\section{Pacific Northwest}

National Laboratory

Operated by Battelle for the

U.S. Department of Energy

\title{
Radiation Damage Effects in Candidate Ceramics for Plutonium Immobilization: Final Report
}

\author{
D. M. Strachan \\ R. D. Scheele \\ A. E. Kozelisky \\ J. P. Icenhower \\ R. L. Sell \\ E. C. Buck \\ R. J. Elovich \\ W. C. Buckmiller
}

February 2004

Prepared for the U.S. Department of Energy under Contract DE-AC06-76RL01830 


\title{
DISCLAIMER
}

This report was prepared as an account of work sponsored by an agency of the United States Government. Neither the United States Government nor any agency thereof, nor Battelle Memorial Institute, nor any of their employees, makes any warranty, express or implied, or assumes any legal liability or responsibility for the accuracy, completeness, or usefulness of any information, apparatus, product, or process disclosed, or represents that its use would not infringe privately owned rights. Reference herein to any specific commercial product, process, or service by trade name, trademark, manufacturer, or otherwise does not necessarily constitute or imply its endorsement, recommendation, or favoring by the United States Government or any agency thereof, or Battelle Memorial Institute. The views and opinions of authors expressed herein do not necessarily state or reflect those of the United States Government or any agency thereof.

\author{
PACIFIC NORTHWEST NATIONAL LABORATORY \\ operated by \\ BATTELLE \\ for the \\ UNITED STATES DEPARTMENT OF ENERGY \\ under Contract DE-ACO6-76RLO183O
}

This document was printed on recycled paper. 


\title{
Radiation Damage Effects in Candidate Ceramics for Plutonium Immobilization: Final Report
}

\author{
D. M. Strachan \\ R. D. Scheele \\ J. P. Icenhower \\ E. C. Buck \\ A. E. Kozelisky \\ R. L. Sell \\ R. J. Elovich \\ W. C. Buckmiller
}

February 2004

Prepared for the U.S. Department of Energy

Under Contract DE-AC06-76RL01830

Pacific Northwest National Laboratory

Richland, Washington 99352 


\section{Summary}

In this document, we summarize our study of the effects of radiation induced damage to the titanate ceramics that were to be the immobilization form for surplus weapons-grade Pu. In this study, we made five ceramic materials: pure-phase pyrochlore, pure-phase zirconolite, pyrochlore-rich baseline, zirconolite-rich baseline, and impurity baseline. Two-hundred specimens were made of which 130 contained approximately 10 mass $\%{ }^{238} \mathrm{Pu}$ and 70 contained 10 mass $\%{ }^{239} \mathrm{Pu}$. The specimens containing ${ }^{239} \mathrm{Pu}$ served as materials against which the behavior of the ${ }^{238} \mathrm{Pu}$-bearing specimens could be compared. In our studies, we measured the "true" density (density exclusive of surface connected porosity), bulk density, crystalline-phase composition with X-ray diffraction (XRD), and dissolution rates as radiation induced damage accumulated in the ${ }^{238} \mathrm{Pu}$-bearing specimens. We routinely took photographs of the specimens during each characterization period.

From our studies, we determined that these materials swell less than $10 \%$ and generally less than 5\%. As the material swells, some open porosity can be converted to closed porosity, often causing the "true" density to decrease more rapidly than the bulk density. In general, $3 \cdot 10^{18} \alpha / \mathrm{g}$ of damage accumulation were required for the materials to become amorphous as determined with the XRD method. The order in which the phases became amorphous was brannerite, pyrochlore, and zirconolite with brannerite being the most susceptible to radiation induced damage. However, we also show that $\mathrm{Pu}$ is not evenly distributed amongst the phases when multiple phases are present. We were unsuccessful in making a pure brannerite to study. Therefore, the brannerite was always present with other phases. For a material containing about 10 mass $\%{ }^{239} \mathrm{Pu}, 3 \cdot 10^{18} \alpha / \mathrm{g}$ represent about 500 years in the geologic repository. At no time in our studies was there evidence for microcracking in these materials, even upon close examination in a scanningelectron microscope. Upon careful comparison between the dissolution behavior of non-radioactive, ${ }^{238} \mathrm{Pu}$-bearing, and ${ }^{239} \mathrm{Pu}$-bearing titanate ceramic specimens of the same composition, we see no difference in the dissolution rates of the three materials. Our results reported earlier suggested that the concentrations were affected by the radiolysis of the water in the dissolution tests with the ${ }^{238} \mathrm{Pu}$-bearing specimens, which have an intense local radiation field that does not exist for the ${ }^{239} \mathrm{Pu}$-bearing ceramics. This means that there is no effect of radiation induced damage on the forward dissolution rate of these ceramics.

The results from this study show that the titanate ceramic is a viable immobilization form for the disposition of surplus weapons-grade $\mathrm{Pu}$ in a geologic repository. As the material becomes amorphous over approximately 500 years, no change to its dissolution rate will take place nor will the surface area of

the ceramic increase from extensive microcracking. Therefore, the safety case that was used for the initial assessment of the performance of the titanate ceramic in the Yucca Mountain repository is valid. 


\section{Abbreviations and Acronyms}

$\begin{array}{ll}\text { ANSTO } & \text { Australian Science and Technology Organization } \\ \text { DOE } & \text { U.S. Department of Energy } \\ \text { EDS } & \text { energy-dispersive spectroscopy } \\ \text { EMPA } & \text { electron microprobe analysis } \\ \text { GEA } & \text { gamma energy analyses } \\ \text { HLW } & \text { high-level waste } \\ \text { ISIS } & \text { Internet-based information system } \\ \text { JAERI } & \text { Japan Atomic Energy Research Institute } \\ \text { MFFF } & \text { Mixed Oxide Fuel Fabrication Facility } \\ \text { PDCF } & \text { Pit Disassembly and Conversion Facility } \\ \text { PNNL } & \text { Pacific Northwest National Laboratory } \\ \text { REE } & \text { rare-earth elements } \\ \text { SEM } & \text { scanning electron microscope } \\ \text { SPFT } & \text { single-pass flow through } \\ \text { TEM } & \text { transmission electron microscope } \\ \text { XRD } & \text { X-ray diffraction } \\ & \end{array}$




\section{Acknowledgments}

The authors wish to acknowledge the contributions to this work of persons whose assistance was very much appreciated. Many helpful discussions were held with David McCready (Pacific Northwest National Laboratory [PNNL]) on the interpretation of the X-ray results and the use of the Rietveld program and with Bill Weber (PNNL), Linn Hobbs (MIT), and Greg Lumpkin (University of Cambridge) on the effects of radiation damage. Work with these quantities of ${ }^{238} \mathrm{Pu}$ would not have been possible without the assistance of the radiation protection and safety personnel at PNNL. While working within the guidelines for protection and safety, they made helpful suggestions as to how certain activities could take place. Todd Schaef played an important role in facilitating the use of an X-ray diffractometer with these highly radioactive materials. Gita Golcar played an important role in the reduction of data. We thank Elsa Rodriguez, Jackie Steele, Dawn Wellman, Rachel, and Michael Lindberg for assistance in setting up and running the dissolution kinetics experiments. We also thank Keith Geiszler and Steven Baum for analyzing the solution aliquots and Bruce Arey for the SEM analyses.

The financial assistance from the U.S. Department of Energy is gratefully acknowledged in the long-term programmatic support from Mr. William Danker ${ }^{(a)}$ and Andre Cygelman. Pacific Northwest National Laboratory is operated by Battelle for the U.S. Department of Energy under Contract DE-AC0676RL01830.

(a) Currently at the International Atomic Energy Agency, Vienna, Austria. 


\section{Quality Assurance}

The Pacific Northwest National Laboratory (PNNL) project that performed these studies was required by the U.S. Department of Energy (DOE) Office of Fissile Materials Disposition (MD) to develop and implement a Quality Assurance (QA) Program that addressed the requirements of DOE/RW-0333P, Office of Civilian Radioactive Waste Management (OCRWM) - Quality Assurance Requirements and Description (QARD), as applicable to the PNNL scope of work. In response to this requirement, the Nuclear Quality Assurance Requirements and Description (NQARD) QA Program was imposed upon the experimental studies described in this document.

The PNNL NQARD QA Program provided an effective management system for conducting and verifying quality-affecting activities in a planned, controlled, and traceable manner. The adequacy, effectiveness, and implementation of the NQARD QA Program have been verified by multiple DOE clients. The NQARD QA Program was audited and approved by the OCRWM Office of Quality Assurance in August 1998 as it related to PNNL work that supports OCRWM's Yucca Mountain Project. The OCRWM Office of Quality Assurance lists PNNL and the NQARD QA Program on their Qualified Supplier Listing. As a qualified supplier, OCRWM attests that the PNNL NQARD QA Program is adequate and effective. The PNNL NQARD QA Program was also audited and approved by the DOE Office of Fissile Materials Disposition in August of 2000.

Based on the acceptance of the PNNL NQARD QA Program by the OCRWM Office of Quality Assurance in August 1998, and the subsequent acceptance of this QA program by the DOE Office of Fissile Materials Disposition in August 2000, the data in this technical report are considered qualified and acceptable for use.

All QA records generated as a result of implementing the NQARD QA Program for the studies described in this technical report are maintained as permanent records within the DOE records management system. 


\section{Contents}

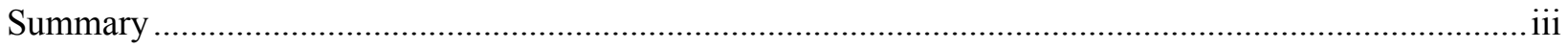

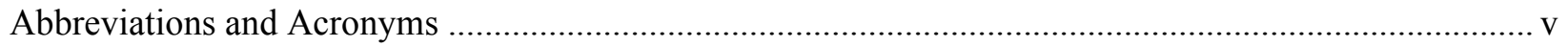

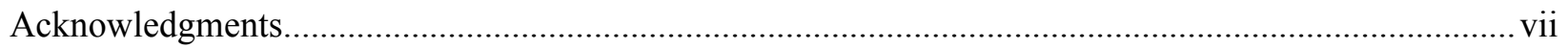

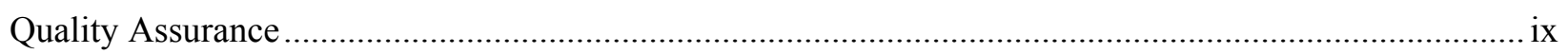

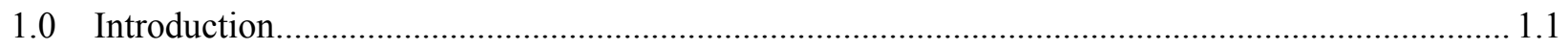

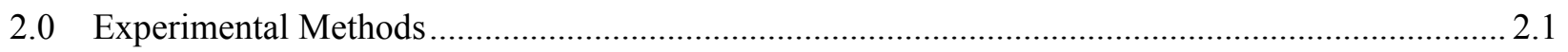

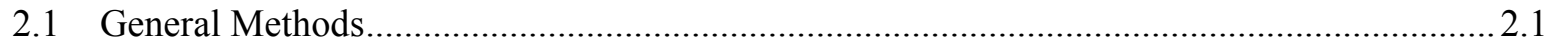

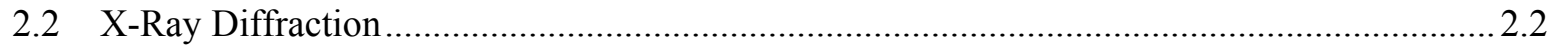

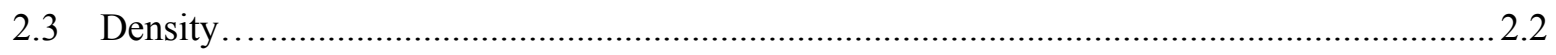

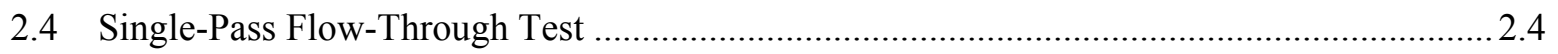

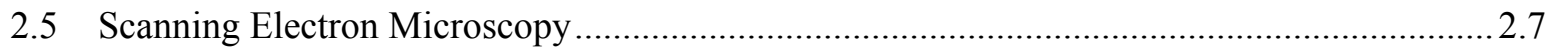

3.0 Radiation-Damage Effects in Pyrochlore ............................................................................... 3.1

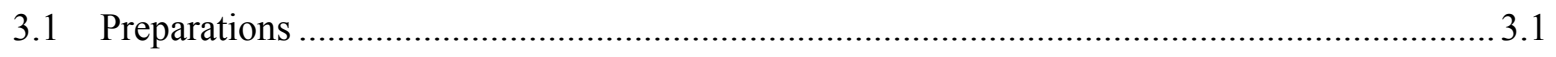

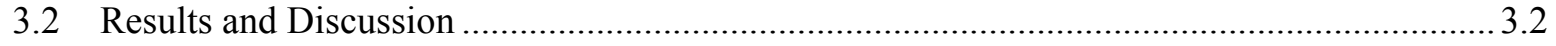

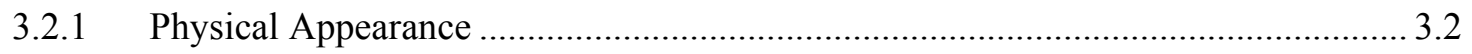

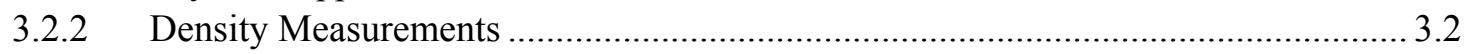

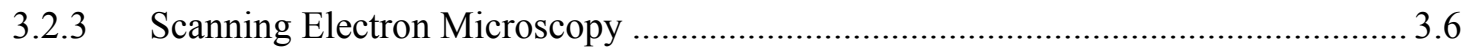

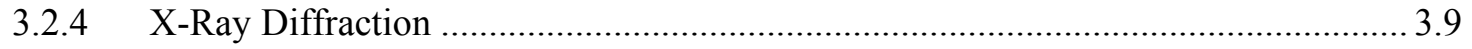

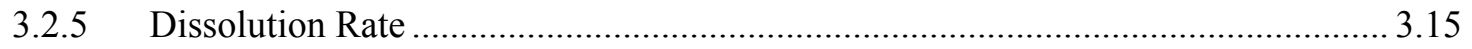

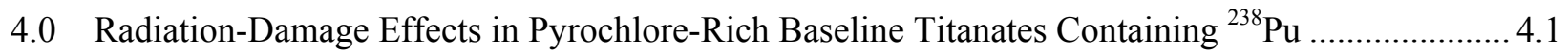

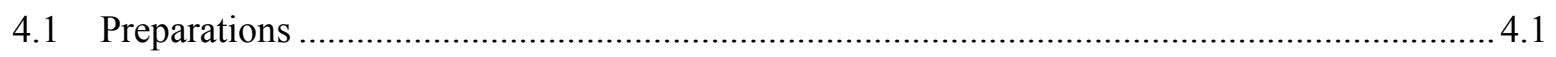

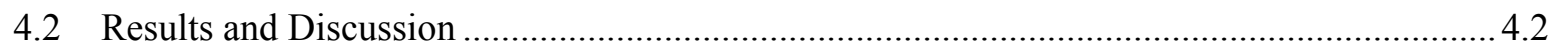

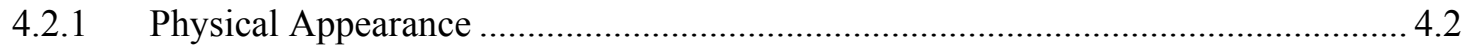

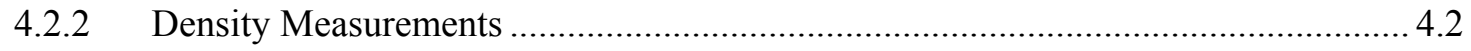

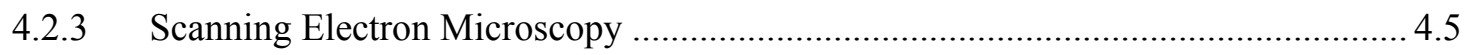

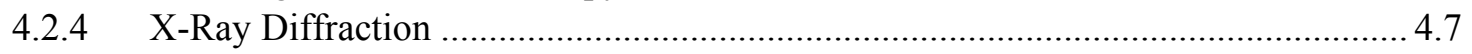

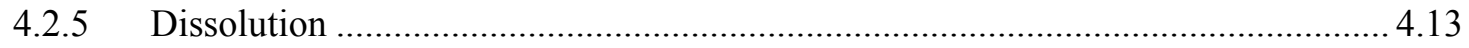


5.0 Radiation Damage Effects in ${ }^{238} \mathrm{Pu}$-Bearing Zirconolite....................................................... 5.1

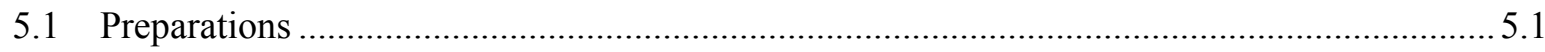

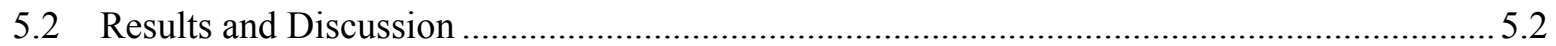

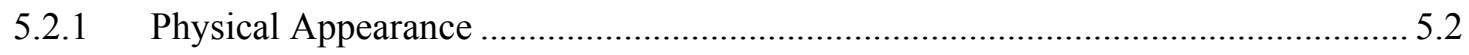

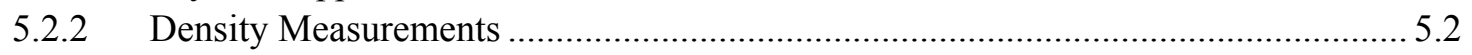

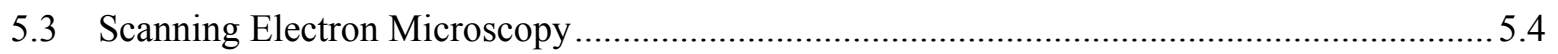

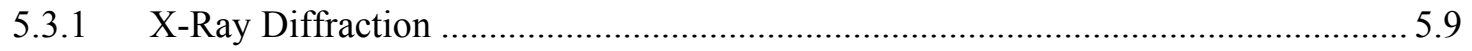

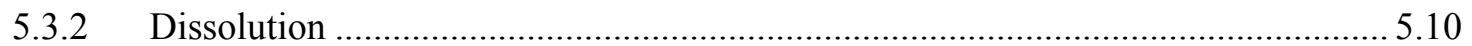

6.0 Radiation-Damage Effects of ${ }^{238} \mathrm{Pu}$-Bearing Zirconolite-Rich Baseline and Impurity Baseline

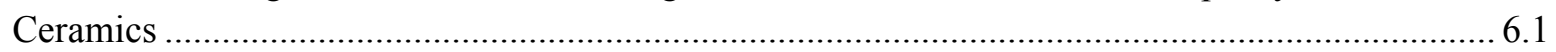

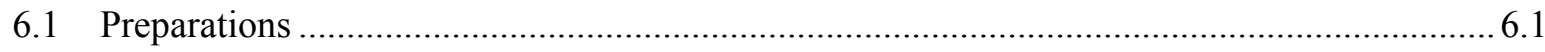

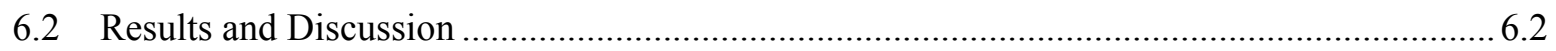

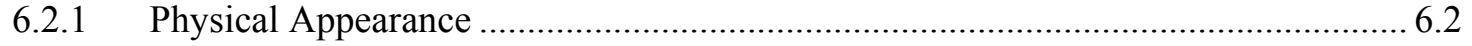

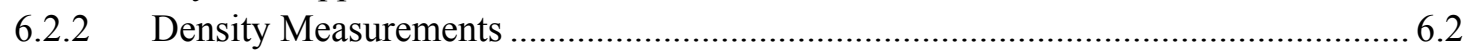

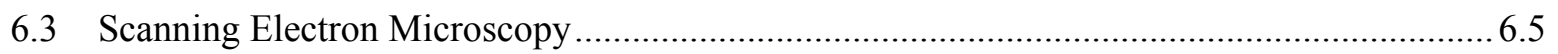

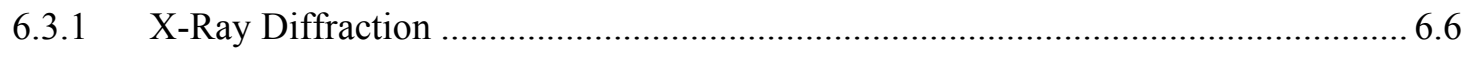

6.4 Transformations Induced by Radiation Damage ............................................................ 6.9

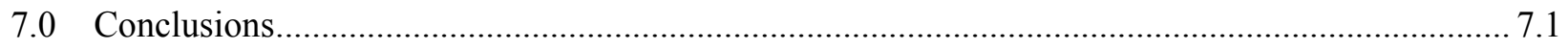

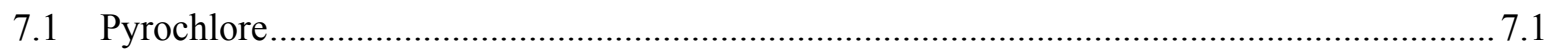

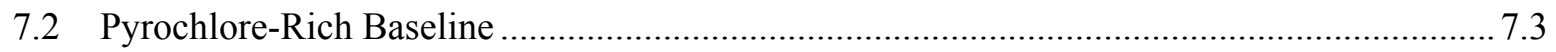

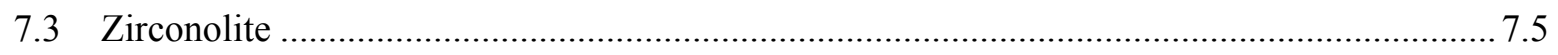

7.4 Zirconolite-Rich Baseline and Impurity Baseline ......................................................... 7.6

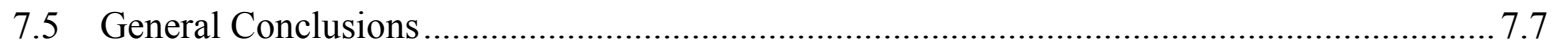

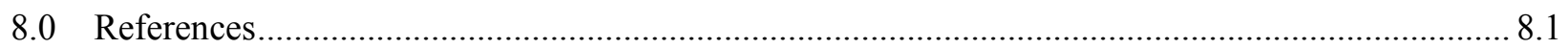




\section{Figures}

2.1. A 3-D Sketch of the XRD Specimen Holder for the Radioactive Specimens Studied

2.2. A Picture of the Laser-Based Specimen Measuring Instrument that Was Developed for Simultaneously Measuring the Diameter and Height of Pu-Bearing Specimens

2.3. Single-Pass Flow-Through Test Apparatus Schematic

3.1. A Picture of a Typical ${ }^{238} \mathrm{Pu}$-Bearing Pyrochlore Ceramic Specimen (color wheel in the background for true color rendition)

3.2. Effect of Time and Radiation Dose $\left({ }^{238} \mathrm{Pu}\right)$ on the "True" Density Measurements for the ${ }^{238} \mathrm{Pu}$ - and ${ }^{239} \mathrm{Pu}$-Bearing Pyrochlore Specimens Stored at $20^{\circ} \mathrm{C}$

3.3. Effect of Time and Radiation Dose $\left({ }^{238} \mathrm{Pu}\right)$ on the "True" Density of ${ }^{238} \mathrm{Pu}$-Bearing Pyrochlore for Specimens Stored at $125^{\circ} \mathrm{C}$

3.4. Effect of Time and Radiation Dose $\left({ }^{238} \mathrm{Pu}\right)$ on the "True" Density of ${ }^{238} \mathrm{Pu}$-Bearing Pyrochlore for Specimens Stored at $250^{\circ} \mathrm{C}$

3.5. Effect of Time and Dose $\left({ }^{238} \mathrm{Pu}\right)$ on the "True" Density of ${ }^{238} \mathrm{Pu}$ - and ${ }^{239} \mathrm{Pu}-\mathrm{B}$ earing Coarse Pyrochlore Specimens Stored at $20^{\circ} \mathrm{C}$.

3.6. Effect of Time and Radiation Dose $\left({ }^{238} \mathrm{Pu}\right)$ on the Diameters of ${ }^{238} \mathrm{Pu}$ - and ${ }^{239} \mathrm{Pu}$-Bearing Specimens Stored at $20^{\circ} \mathrm{C}, 125^{\circ} \mathrm{C}$, and $250^{\circ} \mathrm{C}$

3.7. Effect of Time and Radiation Dose $\left({ }^{238} \mathrm{Pu}\right)$ on the Diameters of ${ }^{238} \mathrm{Pu}$ - and ${ }^{239} \mathrm{Pu}$-Bearing Coarse Pyrochlore Specimens Stored at $20^{\circ} \mathrm{C}$

3.8. Effect of Time and Radiation Dose $\left({ }^{238} \mathrm{Pu}\right)$ on the Diameter of the ${ }^{238} \mathrm{Pu}$-Bearing Original (Open Symbols) and Resintered (Closed Symbols) Pyrochlore Specimens (Each Symbol Type Represents a Different Specimen)

3.9. (A) Backscattered Electron (BSE) Image of Grain Structure from the ${ }^{238} \mathrm{Pu}$-Bearing Pyrochlore Ceramic (Stored at $20^{\circ} \mathrm{C}$; Fully Damaged). The insert (B) shows a Hf-bearing rutile particle with an actinide-rich inclusion as evidenced from the EDS analyses of these particles $(\mathrm{C}$ and $\mathrm{D})$.

3.10. SEM Analysis of High $Z$ Regions Within the ${ }^{238} \mathrm{Pu}$-Bearing Pyrochlore Ceramic (Stored at $20^{\circ} \mathrm{C}$; Fully Damaged). (A) The backscattered electron (BSE) Image indicated the presence of a higher average $\mathrm{Z}$ intergrowth with the pyrochlore

3.11. Results from the XRD Analyses of the Original ${ }^{238} \mathrm{Pu}$-Bearing Pyrochlore Specimens ( $\mathrm{P}=$ Pyrochlore; $\mathrm{R}=$ Rutile; the patterns are in reverse order of the legend) 
3.12. Effect of Radiation Dose on the XRD Pattern from the Resintered ${ }^{238} \mathrm{Pu}$-Bearing Pyrochlore Specimen $(\mathrm{R}=$ Rutile)

3.13. The Effect of Time and Radiation Dose on the $\mathrm{a}_{0}$ Lattice Parameter for the Pyrochlore Phase in the Resintered ${ }^{238} \mathrm{Pu}$-bearing Specimen Stored at $20^{\circ} \mathrm{C}$

3.14. The Effect of Time and Radiation Dose on the $\mathrm{a}_{0}$ and $\mathrm{c}_{0}$ Lattice Parameters for the Rutile Phase in the Resintered ${ }^{238}$ Pu-bearing Specimen.....

3.15. Results from the XRD Analyses of the ${ }^{238} \mathrm{Pu}$-Bearing Pyrochlore Specimen Stored at $250^{\circ} \mathrm{C}$ Since Being Made

3.16. The Effect of Time (Dose) on the XRD Pattern from a ${ }^{238} \mathrm{Pu}$-Bearing Pyrochlore Specimen Originally Stored at $250^{\circ} \mathrm{C}$ and Stored at $250^{\circ} \mathrm{C}$ Since Resintering.

3.17. Results from XRD Analyses of ${ }^{238} \mathrm{Pu}$-Bearing Pyrochlore Ceramic that Had Been Stored at $250^{\circ} \mathrm{C}$ and, After Accumulating Damage, Was Sintered Again for 8 Hours Plus an Additional 24 Hours

3.18. Selected XRD Patterns Showing the Effects of Radiation Damage on the Pyrochlore and Two Zirconolite Phases in the ${ }^{238} \mathrm{Pu}$-Bearing Specimen Originally Stored at $250^{\circ} \mathrm{C}$ and Stored at $250^{\circ} \mathrm{C}$ Since Resintering

3.19. The Effect of Radiation Damage on the $\mathrm{a}_{0}$ Lattice Parameter for the Pyrochlore Phase in the ${ }^{238} \mathrm{Pu}$-Bearing Specimen Originally Stored at $250^{\circ} \mathrm{C}$ and Stored at $250^{\circ} \mathrm{C}$ Since Resintering ...... 3.16

3.20. The Effect of Radiation Damage on the $\mathrm{a}_{0}$ Lattice Parameter for the Pyrochlore Phase in the ${ }^{238} \mathrm{Pu}$-Bearing Specimen that Was Originally Stored at $250^{\circ} \mathrm{C}$ and Stored at Ambient Conditions Since Resintering

3.21. Plot of Gd Concentration ( $\mu \mathrm{g} / \mathrm{L})$ Versus Time for the ${ }^{238} \mathrm{Pu}$-Bearing Pyrochlore Tested with the Titanium Reactor System

3.23. Plot of Element Release Rates from the ${ }^{238} \mathrm{Pu}$-Bearing Pyrochlore Tested in the Titanium Flow Reactor System at $85^{\circ} \mathrm{C}$ and $\mathrm{pH}$ 2. (A) Plutonium Concentrations (GEA).

(B) Uranium Concentrations.

3.24. Plots of $\log _{10}($ Rate $)\left[\mathrm{g} /\left(\mathrm{m}^{2} \cdot \mathrm{d}\right)\right]$ Versus $\log _{10}(q / S)[\mathrm{m} / \mathrm{s}]$ for Pyrochlore Ceramics at $90^{\circ} \mathrm{C}$ and pH 2 (PY-17 is Ce-based and compositionally similar to PY-12 and -21).....

4.1. Pictures of Typical ${ }^{238} \mathrm{Pu}$-Bearing Pyrochlore-Rich Baseline Specimens

4.2. Results from the Measurement of the "True" Density of ${ }^{238} \mathrm{Pu}$-Bearing Pyrochlore-Rich Baseline Specimens Stored at $20^{\circ} \mathrm{C}, 125^{\circ} \mathrm{C}$, and $250^{\circ} \mathrm{C}$

4.3. The Variation of the "True" Density of the ${ }^{238} \mathrm{Pu}$-Bearing Pyrochlore-Rich Baseline Specimens that Were Resintered and Stored at $20^{\circ} \mathrm{C}$ and $250^{\circ} \mathrm{C}$ 
4.4. The Variation with Increasing Dose of the Specimen Diameters for the Original Specimens Stored at $20^{\circ} \mathrm{C}, 125^{\circ} \mathrm{C}$, and $250^{\circ} \mathrm{C}$

4.5. The Variation in the Diameters of the Individual ${ }^{238} \mathrm{Pu}$-Bearing Pyrochlore-Rich Baseline Specimens Originally Stored at $20^{\circ} \mathrm{C}$ and Stored at $20^{\circ} \mathrm{C}$ Since Resintering

4.6. The Variation in the Diameters of the Individual ${ }^{238} \mathrm{Pu}$-Bearing Pyrochlore-Rich Baseline Specimens Originally Stored at $250^{\circ} \mathrm{C}$ and Stored at $250^{\circ} \mathrm{C}$ Since Resintering

4.7. Secondary Electron (SE) Image of the ${ }^{238} \mathrm{Pu}$-Bearing Pyrochlore-Rich Baseline Ceramic (stored at $20^{\circ} \mathrm{C}$; fully damaged) Shows the Porosity and Holes (possibly due to polishing) in the Ceramic. 4.6

4.8. Backscattered Electron (BSE) Image of the ${ }^{238} \mathrm{Pu}$-Bearing Pyrochlore-Rich Baseline Ceramic (stored at $20^{\circ} \mathrm{C}$; fully damaged) Showing the Presence of High Z Crystals Within the Ceramic ... 4.6

4.9. Combination of SE and BSE Images to Discriminate Between Pores and the Rutile Phase. 4.6

4.10. From Area Shown in 4.8; Showing Evidence of Lamellae Structures Within the Pyrochlore Grains

4.11. Higher Magnification Image of Pyrochlore (grey; marked area in 4.10)

4.12. The Small Actinide Inclusion in the Pyrochlore Phase

4.13. Typical Pyrochlore Spectrum

4.14. Zirconolite-Type Composition

4.15. X-Ray Diffraction Patterns from the Original ${ }^{238} \mathrm{Pu}$-Bearing Pyrochlore-Rich Baseline Specimen Stored at $20^{\circ} \mathrm{C}$

4.16. A Comparison Between the XRD Patterns of the ${ }^{239} \mathrm{Pu}$-Bearing and the Resintered ${ }^{238} \mathrm{Pu}$-Bearing Pyrochlore-Rich Baseline Specimens.

4.17. A Set of XRD Patterns Showing the Effect of Radiation Damage on the Crystal Structures of the Phases Contained in the ${ }^{238} \mathrm{Pu}$-Bearing Pyrochlore-Rich Baseline Ceramic Specimen

4.18. The Change in the Lattice Parameter for the Pyrochlore Phase in the ${ }^{238} \mathrm{Pu}$-Bearing Pyrochlore-Rich Baseline Ceramic

4.19. A Graph Showing the Variation of the Lattice Parameters for the Brannerite Phase in the ${ }^{238} \mathrm{Pu}$-Bearing Pyrochlore-Rich Baseline Ceramic

4.20. A Graph Showing the Variation of the Cell Angle for the Brannerite Phase in the ${ }^{238} \mathrm{Pu}$-Bearing Pyrochlore-Rich Baseline Ceramic 
4.21. A Graph Showing the Variation of the Lattice Parameters for the Zirconolite Phase in the ${ }^{238} \mathrm{Pu}$-Bearing Pyrochlore-Rich Baseline Ceramic

4.22. A Graph Showing the Variation of the Cell Angle in the Zirconolite Phase in the ${ }^{238} \mathrm{Pu}$-Bearing Pyrochlore-Rich Baseline Ceramic

4.23. A Series of XRD Patterns Taken at Various Dates from ${ }^{238} \mathrm{Pu}$-Bearing Pyrochlore-Rich Baseline Ceramic Specimens Stored at $250^{\circ} \mathrm{C}$

4.24. An Expanded View of the XRD Patterns from the ${ }^{238} \mathrm{Pu}$-Bearing Pyrochlore-Rich Baseline Ceramic Stored at $250^{\circ} \mathrm{C}(\mathrm{P}=$ Pyrochlore, $\mathrm{R}=$ Rutile, $\mathrm{Z}=$ Zirconolite $)$

4.25. A Series of XRD Patterns from Resintered ${ }^{238} \mathrm{Pu}$-Bearing Pyrochlore-Rich Baseline Ceramic Stored at $250^{\circ} \mathrm{C}$

4.26. The Variation of the $\mathrm{a}_{0}$ Lattice Parameter for the Pyrochlore Phase in the ${ }^{238}$ Pu-Bearing Pyrochlore-Rich Baseline Ceramic

4.27. The Variation of $\mathrm{a}_{0}$ and $\mathrm{c}_{0}$ in the Brannerite Phase in the ${ }^{238} \mathrm{Pu}$-Bearing Pyrochlore-Rich Baseline Ceramic Stored at $250^{\circ} \mathrm{C}$

4.28. The Variation of the Cell Angle $(\beta)$ in the Brannerite Phase in ${ }^{238} \mathrm{Pu}$-Bearing Pyrochlore-Rich Baseline Ceramic Stored at $250^{\circ} \mathrm{C}$

4.29. The Variation of the $\mathrm{a}_{0}$ and $\mathrm{b}_{0}$ Lattice Parameters for the Zirconolite Phase in ${ }^{238} \mathrm{Pu}$-Bearing Pyrochlore-Rich Baseline Ceramic Stored at $250^{\circ} \mathrm{C}$

4.30. The Variation of the Cell Angle $(\beta)$ for the Zirconolite Phase in ${ }^{238} \mathrm{Pu}$-Bearing Pyrochlore-Rich Baseline Ceramic Stored at $250^{\circ} \mathrm{C}$

4.31. Plot of Gd Concentration ( $\mu \mathrm{g} / \mathrm{L})$ for the ${ }^{238} \mathrm{Pu}$-Bearing Pyrochlore-Baseline Tested in the Titanium Reactor System

4.32. Plot of Element Concentrations from the ${ }^{238} \mathrm{Pu}$-Bearing Pyrochlore-Baseline Tested in the Titanium Flow Reactor System at $85^{\circ} \mathrm{C}$ and $\mathrm{pH}$ 2. (A.) Plutonium Concentrations (GEA), and (B.) Uranium Concentrations.

4.33. Plot of $\log _{10}$ (Rate) $\left[\mathrm{g} /\left(\mathrm{m}^{2} \cdot \mathrm{d}\right)\right]$ Versus $\mathrm{pH}$ for the ${ }^{239} \mathrm{Pu}$-Bearing Pyrochlore-Rich Baseline Ceramic at $90^{\circ} \mathrm{C}$

4.34. Plot of $\log _{10}($ Rate $)\left[\mathrm{g} /\left(\mathrm{m}^{2} \cdot \mathrm{d}\right)\right]$ Versus Time for the ${ }^{239} \mathrm{Pu}$-Bearing Pyrochlore-Rich Baseline Ceramic at $90^{\circ} \mathrm{C}$ and $\mathrm{pH} 2$.

4.35. Plots of $\log _{10}($ Rate $)\left[\mathrm{g} /\left(\mathrm{m}^{2} \cdot \mathrm{d}\right)\right]$ Versus $\log _{10}(q / S)[\mathrm{m} / \mathrm{s}]$ for Pyrochlore-Baseline Ceramics at $90^{\circ} \mathrm{C}$ and $\mathrm{pH} 2$......

5.1. Top View of a Typical ${ }^{238} \mathrm{Pu}$-Bearing Zirconolite Specimen 
5.2. The Change in "True" Density with Increasing Radiation induced Damage for ${ }^{238} \mathrm{Pu}$ - and

${ }^{239} \mathrm{Pu}$-Bearing Zirconolite Specimens Stored at $20^{\circ} \mathrm{C}, 125^{\circ} \mathrm{C}$, and $250^{\circ} \mathrm{C}$

5.3. The Change in the Diameter of all Zirconolite Specimens with Increasing Alpha Dose

5.4. Secondary Electron Image of ${ }^{238} \mathrm{Pu}$ Zirconolite Ceramic (Stored at $20^{\circ} \mathrm{C}$; Fully Damaged) ......... 5.5

5.5. Backscattered Electron Image of ${ }^{238} \mathrm{Pu}$ Zirconolite Ceramic (Stored at $20^{\circ} \mathrm{C}$; Fully Damaged).... 5.5

5.6. Combined Backscattered Electron and Secondary Electron Images ............................................ 5.5

5.7. Scanning Electron Microscope Image of Microstructure from the ${ }^{239} \mathrm{Pu}$ Zirconolite Formulation

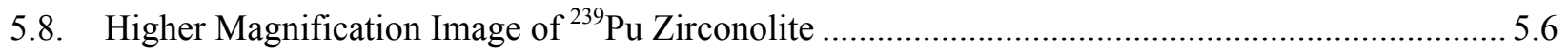

5.9. Low Magnification Image of ${ }^{238} \mathrm{Pu}$ Pyrochlore Ceramic .......................................................... 5.6

5.10. Higher Magnification Images of Region Highlighted in 5.4 .................................................. 5.6

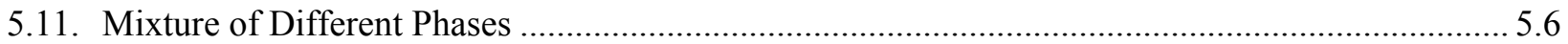

5.12. The Hf-Srilankite $\left(\mathrm{HfTiO}_{4}\right)$ Phase Has the Brightest Contrast in the Ceramic ............................. 5.7

5.13. Zirconolite-Composition Showing Higher Levels of Hf in the Phase than a Pyrochlore............... 5.7

5.14. Evidence for an Actinide Oxide Phase in the Ceramic............................................................. 5.7

5.15. A Summary of the XRD Patterns from the ${ }^{238} \mathrm{Pu}$-Bearing Zirconolite Specimens........................ 5.9

5.16. A Comparison of the XRD Patterns from ${ }^{238} \mathrm{Pu}$ - and ${ }^{239} \mathrm{Pu}$-Bearing Zirconolite Specimens........ 5.10

5.17. Plot of Element Concentrations Versus Time for the Zirconolite Ceramic at $90^{\circ} \mathrm{C}$. (A). Concentrations $(\mu \mathrm{g} / \mathrm{L})$ of $\mathrm{Ce}, \mathrm{Gd}$, and Ti, and (B) Mo concentrations $(\mu \mathrm{g} / \mathrm{L})$ at various $\mathrm{pH}$ values.

5.18. Plot of $\log _{10}($ Rate $)\left[\mathrm{g} /\left(\mathrm{m}^{2} \cdot \mathrm{d}\right)\right]$ Versus $\mathrm{pH}$ for a Zirconolite Ceramic at $90^{\circ} \mathrm{C}$

5.19. Plot of $\log _{10}($ Rate $)\left[\mathrm{g} /\left(\mathrm{m}^{2} \cdot \mathrm{d}\right)\right]$ Versus Time for ${ }^{239} \mathrm{Pu}$-Bearing Zirconolite Ceramic at $90^{\circ} \mathrm{C}$ and (A) $\mathrm{pH} 2$ for $\mathrm{Gd}, \mathrm{Pu}, \mathrm{Mo}$, and $\mathrm{U}$ and (B) $\mathrm{pH} 11$ for $\mathrm{U}, \mathrm{Mo}$, and Ti

5.20. Plot of $\log _{10}($ Rate $)\left[\mathrm{g} /\left(\mathrm{m}^{2} \cdot \mathrm{d}\right)\right]$ Versus $\mathrm{pH}$ for ${ }^{239} \mathrm{Pu}$-Bearing Zirconolite Ceramic at $90^{\circ} \mathrm{C}$

5.21. Plot of $\log _{10}($ Rate $)\left[\mathrm{g} /\left(\mathrm{m}^{2} \cdot \mathrm{d}\right)\right]$ Versus $\log _{10}(q / S)[\mathrm{m} / \mathrm{s}]$ at $90^{\circ} \mathrm{C}$ and $\mathrm{pH} 2$ for Brannerite and Zirconolite Specimens

6.1. Pictures of Typical ${ }^{238} \mathrm{Pu}$-Bearing Zirconolite-Rich Baseline (a-c) and Impurity Baseline (d-f) Ceramics 
6.2. The Change in "True" Density with Increasing Radiation induced Damage for ${ }^{238} \mathrm{Pu}$ - and ${ }^{239} \mathrm{Pu}$ Bearing Zirconolite-Rich Baseline Specimens Stored at $20^{\circ} \mathrm{C}, 125^{\circ} \mathrm{C}$, and $250^{\circ} \mathrm{C}$

6.3. A Graph Showing the Change in the "True" Density for the ${ }^{238} \mathrm{Pu}$ - and ${ }^{239} \mathrm{Pu}$-Bearing Impurity Baseline Specimens

6.4. The Change in the Diameter of all ${ }^{238} \mathrm{Pu}$-Bearing Zirconolite-Rich Baseline Specimens with Increasing Alpha Dose

6.5. The Variation in the Diameters of the ${ }^{238} \mathrm{Pu}$ - and ${ }^{239} \mathrm{Pu}$-Bearing Impurity Baseline Ceramic Specimens with Increasing Alpha Dose

6.6. Backscattered Electron Image of ${ }^{238} \mathrm{Pu}$-Bearing Zirconolite Baseline Ceramic (stored at $20^{\circ} \mathrm{C}$; fully damaged). (B) Higher Magnification Showing Three Major Phases.

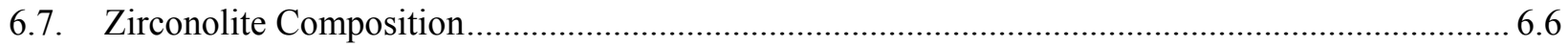

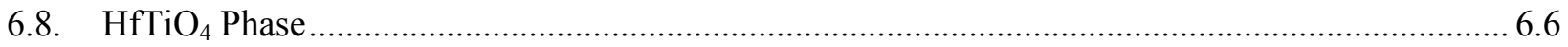

6.9. High Effective Atomic Number Particles in the Ceramic ........................................................ 6.6

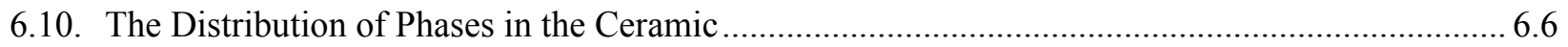

6.11. A Comparison of the XRD Patterns of the ${ }^{239} \mathrm{Pu}$-Bearing Zirconolite-Rich Baseline Ceramic Specimen from Early in the Study and at the End

6.12. A Summary of the XRD Patterns from the ${ }^{238}$ Pu-Bearing Zirconolite-Rich Baseline Specimens .. 6.8

6.13. A Comparison of the XRD Patterns from the ${ }^{239} \mathrm{Pu}$-Bearing Impurity Baseline Ceramic Specimen from Early and at the End of the Study....

6.14. A Comparison of the XRD Patterns from ${ }^{238} \mathrm{Pu}$-Bearing Impurity Baseline Specimens Showing the Progress from Crystalline to Amorphous Structure with Accumulating Radiation Damage (the order of the patterns is the same as the order in the legend)......

6.15. A Detail of the Three XRD Patterns from 6.13 Showing the Changes in the Zirconolite and Pyrochlore Phases in the ${ }^{238} \mathrm{Pu}$-Bearing Impurity Baseline Ceramic (the Order of the Patterns Is the Same as in the Legend)

6.16. Simulated Pyrochlore and Rutile Diffraction Patterns Showing the Effect of Crystallite Size on the Capbility to Differentiate Between Pyrochlore and Flourite 


\section{Tables}

2.1. Dates on Which the ${ }^{238} \mathrm{Pu}$ - and ${ }^{239} \mathrm{Pu}$-Bearing Specimens Were Made ......................................... 2.1

2.2. Compositions of Solutions Used in SPFT Experiments ......................................................... 2.6

3.1. The Target Oxide Composition of the Pyrochlore Ceramics Used in this Study .......................... 3.1

3.2. Compositions (mass\%) of the Ce-Bearing Pyrochlore Specimens Used in SPFT Tests ................. 3.2

4.1. The Target Oxide Composition of the Pyrochlore-Rich Baseline Ceramics Used in this Study ... 4.1

4.2. Target and Analyzed Compositions (mass\%) of the Pyrochlore-rich baseline Ceramics.............. 4.2

5.1. The Target Oxide Composition of the Zirconolite Ceramics Used in this Study .......................... 5.1

5.2. Plutonium Titanate Ceramic Compositions with an Estimation of the Backscattered Contrast

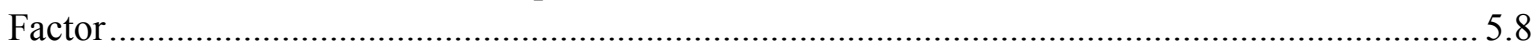

6.1. The Target Oxide Composition of the Impurity Baseline and Zirconolite-Rich Baseline Ceramics Used in this Study 6.1 


\subsection{Introduction}

In the 1990s, discussions were held between representatives of Russia and the United States on the disposition of surplus weapons-grade Pu (USA 2000; DOE 2002b). In parallel, the Department of Energy (DOE), after completion of a preliminary environmental impact statement, decided to build three plants at the Savannah River Site in west-central South Carolina to implement a program to provide for the safe and secure storage of $\mathrm{Pu}$. In the first of these plants, $\mathrm{Pu}$ from weapons declared to be excess will be converted to $\mathrm{PuO}_{2}$ at the Pit Disassembly and Conversion Facility (PDCF). The $\mathrm{PuO}_{2}$ will then be converted to a mixed oxide $\left(\mathrm{UO}_{2}\right.$ and $\left.\mathrm{PuO}_{2}\right)$ nuclear fuel at the Mixed Oxide Fuel Fabrication Facility (MFFF) and then "burned" in a commercial nuclear reactor. Some of the Pu declared to be excess was not in weapons, not in a form that was acceptable at the PDCF or directly acceptable at the MFFF, and was, therefore, destined for a third facility called the Plutonium Immobilization Plant. In 2002, at the request of the Administration, DOE undertook a review of the options to restructure the U. S. Pu disposition program to address the concerns by the Administration regarding the cost of both the Russian and U. S. programs. As a result of the review, the immobilization option was dropped (DOE 2002a). In the meantime, the development of a concept for the immobilization of some weapons-usable $\mathrm{Pu}$ was ongoing (Stokes et al. 1999; Myers et al. 1998; Cochran et al. 1997). In this program, a titanate ceramic containing approximately 10 mass\% Pu was developed (Ebbinghaus et al. 2000). The immobilized Pu ceramic would be placed in stainless steel cans that would be sealed and hung on a rack inside a large canister, approximately $0.6 \mathrm{~m}$ in diameter and $3 \mathrm{~m}$ tall, and the remaining volume filled with high-level nuclear waste glass (USA 2000). This package would provide secure interim storage for the Pu because the $\mathrm{Pu}$ is difficult to chemically separate from the titanate ceramic, and the HLW glass forms a radiation barrier that makes handling and retrieval difficult at any place other than a heavily shielded facility. This "can-in-canister" would be shipped to the national nuclear waste repository that is currently under development at Yucca Mountain located north of Las Vegas, Nevada.

Once this canister is placed in the repository, the main concern is the possibility of a future nuclear criticality event (TRW 1997). As produced, there are sufficient neutron absorbers in the titanate ceramic that it can be stacked safely in an infinite array and with full moderation from water. However, the canisters may begin to fail some 1000 to 10000 years after burial. The objective is to develop a system for storage that will allow the neutron absorbers and fissile products, either ${ }^{239} \mathrm{Pu}$ or its decay-product ${ }^{235} \mathrm{U}$, to stay together so that criticality cannot occur for the long-term (TRW 1997). A preliminary performance assessment suggested that a criticality event was very unlikely given certain assumptions about the behavior of the ceramic (TRW 1997). Assumptions had to be made concerning the swelling, chemical durability, and microcracking that might occur as the ${ }^{239} \mathrm{Pu}$ decays (Clinard and Rohr 1981; Clinard et al. 1982b). The assumptions that were made in this "safety case" needed to be verified through laboratory experiments, and those experiments are described in this report.

Even though the immobilization option was dropped and the development of the Pu-immobilization form was stopped, the possibility existed that a Pu-immobilization form could be needed in the future. Radiation damage experiments are very long term and, at the time of the decision to drop the immobilization form development, radiation damage experiments had been underway for four years. To stop the radiation damage experiments at that time would mean that, if there was a future need, the experiments would have be started from the beginning. The completion of the radiation damage studies was critical in validating the assumptions made in determining the acceptability of the ceramic in the 
proposed repository environment. If the ceramic in the fully damaged state were not to perform as predicted, the ceramic would probably prove not to be an acceptable form for immobilization. Thus, a decision was made at DOE to continue the radiation damage experiments so that a package of data was available to support any future decision on the use of a titanate-based immobilization form.

In this report, we describe the effects of radiation damage from self-irradiation with ${ }^{238} \mathrm{Pu}$ to the density and crystal structure of titanate ceramics. Five ceramic materials were studied: "phase pure" pyrochlore and zirconolite and three baseline compositions - pyrochlore, zirconolite, and impurity (Ebbinghaus and Krikorian 2001). In this study, the specimens contained approximately 10 mass $\%{ }^{238} \mathrm{Pu}$ so that we could determine the long-term effects of radiation induced damage from the $\alpha$ decay of ${ }^{239} \mathrm{Pu}$ in those titanate ceramics that would have been disposed of in the nuclear waste repository at Yucca Mountain.

As ${ }^{239} \mathrm{Pu}$ decays to ${ }^{235} \mathrm{U}$ with the emission of an alpha particle, the recoiling ${ }^{235} \mathrm{U}$ atom causes extensive damage to the surrounding chemical bonds, destroying about 1000 bonds before coming to rest (Weber et al. 1998). To study this effect in the laboratory, two techniques are typically used. The first is to place a specimen in an accelerator and bombard it with heavy ions such as gold or xenon. This causes rapid damage to a depth on the scale of 10 s of micrometers. While the effects on the crystal structure of the ceramic can be studied, bulk effects, such as swelling and cracking, are not manifest. In the second method, a short lived isotope, such as ${ }^{244} \mathrm{Cm}$ (half life of 18.1 years) and ${ }^{238} \mathrm{Pu}$ (half life of 87.7 years), is incorporated into the ceramic formulation, and damage occurs from the same process at an accelerated rate. We selected this second method because information was needed on the changes in bulk properties, such as dimensions, densities, and chemical durability. We selected ${ }^{238} \mathrm{Pu}$ because of its obvious chemical similarity to the ${ }^{239} \mathrm{Pu}$ that was to be immobilized.

One of the main phases in these ceramics is pyrochlore $\left(\mathrm{A}_{2} \mathrm{~B}_{2} \mathrm{O}_{7}\right)$ that has the cubic structure $(F d 3 m)$ and can take on many compositions through substitution with charge compensation between the $\mathrm{A}$ and $\mathrm{B}$ sites $\left(\mathrm{A}_{2}(\mathrm{III}) \mathrm{B}_{2}(\mathrm{IV}) \mathrm{O}_{7}\right.$ and $\mathrm{A}_{2}(\mathrm{II}) \mathrm{B}_{2}(\mathrm{~V}) \mathrm{O}_{7}$, as examples). In the case of $\mathrm{Pu}$ immobilization, the $\mathrm{B}$ site is occupied by Ti, principally, and the A site by Gd, Hf, U(IV), Pu(IV), and Ca (Ebbinghaus et al. 1999; Ebbinghaus and Krikorian 2001). Studies on ${ }^{244} \mathrm{Cm}$-substituted pyrochlores have shown that the pyrochlore structure becomes amorphous between $3 \cdot 10^{18}$ and $4 \cdot 10^{18} \alpha$ decays/g when Ti occupies the B site (Wald and Weber 1984; Weber et al. 1985; 1986; Weber and Matzke 1986; Weber et al. 1998; Wang et al. 1999c) and greater than $3 \cdot 10^{20} \alpha$ decays/g when $\mathrm{Zr}$ occupies the B site (Wang et al. 1999c). Pyrochlores with similar composition to that reported here have been reported to become amorphous between $1.5 \cdot 10^{18}$ and $2 \cdot 10^{18} \alpha$ decays/g (Burakov et al. 2002a; b; Lukinykh et al. 2002). These pyrochlore structures have been observed to swell between 3\% and 10\% during the process of becoming amorphous from radiation damage (Wald and Offerman 1982a; Weber et al. 1985; Weber et al. 1998; Burakov et al. 2002a; b; Lukinykh et al. 2002). Microcracking was not observed (Wald and Offerman 1982b). Wald and Offerman (1982b) found that the bulk dimensions of a 3 mass $\%{ }^{244} \mathrm{Cm}$-bearing $\mathrm{Gd}_{2} \mathrm{Ti}_{2} \mathrm{O}_{7}$ swelled $5.5 \%$-revised in (Weber and Ewing 2002) —when a dose of $3.2 \cdot 10^{18} \alpha / \mathrm{g}^{(\mathrm{a})}$ was accumulated. The lattice parameters swelled about the same amount when a dose of $3.1 \cdot 10^{18} \alpha / \mathrm{g}$ accumulated. A smooth transition between crystalline and amorphous states was observed; no fluorite phase was found. In other work,

(a) The density of the $\mathrm{Gd}_{2} \mathrm{Ti}_{2} \mathrm{O}_{7}$ was measured but not reported by Wald and Offerman (1982b). We used the theoretical density of $6.57 \cdot 10^{3} \mathrm{~kg} / \mathrm{m}^{3}\left(6.54 \cdot 10^{3} \mathrm{~kg} / \mathrm{m}^{3} / 0.996\right)$ reported by Begg et al. (2001b) less the porosity of $19 \%$ (Wald and Offerman 1982b) to give a value of $5.32 \cdot 10^{3} \mathrm{~kg} / \mathrm{m}^{3}$. This was used to convert from $\alpha / \mathrm{cm}^{3}$ to $\alpha / g$. 
principally with heavy ion bombardment, the authors report a transition from pyrochlore to disordered fluorite before the test specimen became amorphous (Chen et al. 2001; Wang et al. 2000; Meldrum et al. 2001; Wang et al. 1999c; Wang et al. 1999b). Aqueous dissolution rates have been observed to increase relative to specimens that are undamaged (Begg et al. 2000a; Weber et al. 1985; 1986; Wald and Offerman 1982b; Burakov et al. 2002b; a) and to increase in metamict natural samples (Lumpkin et al. 2001a; Eyal et al. 1987).

Studies of the radiation-damage effects in natural pyrochlores were summarized recently by Lumpkin (2001) in an extensive review article covering natural pyrochlore, zircon, zirconolite, brannerite, and perovskite. In his report, Lumkin (2001) reports that natural pyrochlores become metamict (amorphous) at $1 \cdot 10^{16} \alpha / \mathrm{mg}\left(1 \cdot 10^{19} \alpha / \mathrm{g}\right)$, and the residual diffuse maxima in the X-ray diffraction (XRD) patterns were observed at d-spacings of 0.350 to $0.363 \mathrm{~nm}$ and 0.206 to $0.222 \mathrm{~nm}$. These distances came from the metal-metal distance and the metal-to-oxygen distance, respectively. The saturation dose was reported to be $1.2 \cdot 10^{16} \alpha / \mathrm{mg}$.

Stability and metastability fields for relevant pyrochlores have recently been determined (Helean et al. 2002). The thermodynamic properties of the hafnium compound $\mathrm{CaHfTi}_{2} \mathrm{O}_{7}$ were corrected and found to be $32 \mathrm{~kJ} / \mathrm{mol}$ more endothermic than previously determined (Putnam et al. 1999b). These thermodynamic property determinations show that the formulation that was to be used in the immobilization of $\mathrm{Pu}$ was stable with respect to the constituent elements, constituent oxides, and perovskite. Depending on the composition of the pyrochlore, it might be metastable with respect to perovskite, metal oxide, and $\mathrm{TiO}_{2}$. Therefore, at low temperatures similar to those of the repository, some pyrochlores might be unstable thermodynamically with respect to a mixture of perovskite, metal oxide, and $\mathrm{TiO}_{2}$. However, the kinetics of decomposition is expected to be exceedingly slow at these low temperatures. Nevertheless, in the presence of radiation induced damage, the kinetics could be enhanced.

As part of some crystalline waste forms proposed for high-level waste (HLW) from reactor fuel reprocessing, zirconolite (ideally $\mathrm{CaZrTi}_{2} \mathrm{O}_{7}$ ) began to receive attention in the late 1970s as a phase in which actinides could be immobilized (Dosch et al. 1981; Morgan et al. 1984; Ringwood et al. 1980). In the latter case, Synroc received and continues to receive attention as a potential waste form, in particular for actinides. Most of the recent work on Synroc is by the scientists from the group at the Australian Science and Technology Organization (ANSTO) in Sydney. The Synroc waste form is based on phases that have existed in nature for millennia. The particular zirconolite structure being studied here is the $2 \mathrm{M}$ zirconolite polytype with the monoclinic structure $(\mathrm{C} 2 / \mathrm{c})$.

Natural zirconolites require doses of $1 \cdot 10^{19} \alpha / \mathrm{g}$ to become fully amorphous (Lumpkin 2001). In synthetic zirconolites, the dose at which swelling and other macroscopic properties cease to change is lower than in natural zirconolites and ranges from $4.3 \cdot 10^{18} \alpha / \mathrm{g}$ for $\mathrm{CaPuTi}_{2} \mathrm{O}_{7}$ - cubic zirconolite structure, (Clinard et al. 1982a; Clinard et al. 1984; Clinard 1986) — to $>9 \cdot 10^{17} \alpha / \mathrm{g}$ for monoclinic zirconolite (Clinard et al. 1982b). The dose at which the synthetic specimens become X-ray amorphous is substantially less than the dose at which swelling saturates. For example, Clinard et al. (1982a) report an X-ray amorphous dose of $8 \cdot 10^{17} \alpha / g$ and a dose of $4.3 \cdot 10^{18} \alpha / g$ for the saturation of swelling in cubic zirconolite. Weber and Matzke (1986) and Weber, Wald, and Matzke (1986) report that zirconolite with about 3 mass $\%{ }^{244} \mathrm{Cm}$ became X-ray amorphous at $2.1 \cdot 10^{25} \alpha / \mathrm{m}^{3}$ (about $4.2 \cdot 10^{18} \alpha / \mathrm{g}$ ) and amorphous to selected-area electron diffraction in a transmission electron microscope (TEM) at $2.3 \cdot 10^{25} \alpha / \mathrm{m}^{3}$ (about $4.6 \cdot 10^{18} \alpha / \mathrm{g}$ ) while the specimen was still swelling at $2.4 \cdot 10^{25} \alpha / \mathrm{m}^{3}\left(4.8 \cdot 10^{18} \alpha / \mathrm{g}\right)$. 
In his study, Gregg Lumpkin (2001) also extensively reviewed the alpha-decay damage in zirconoliteanother important phase in Pu immobilization ceramics. In zirconolite, many elements can be substituted on the $\mathrm{Ca}$ (rare-earth elements [REE], Th, U, Mn, and $\mathrm{Sr}$ ), $\mathrm{Zr}$ (Ti, REE, Hf, Pu, and U), and Ti (Mg, $\mathrm{Fe}(\mathrm{II}), \mathrm{Fe}(\mathrm{III}), \mathrm{Nb}, \mathrm{Pu}, \mathrm{Al}, \mathrm{Cr}, \mathrm{Mn}, \mathrm{Zn}, \mathrm{Ta}, \mathrm{W})$ sites. Many of these are also found in natural zirconolites. Zirconolites are chemically very durable, having survived in nature for over 600 million years. Ringwood, Oversby, and Sinclair (1980) showed that U in zirconolites that were over 500 million years old from Sri Lanka was still present, even though the samples were from stream-bed gravels that remained after the host rock had been completely altered, indicating extensive contact with water. These specimens were completely amorphous from alpha-decay damage. Significant chemical alteration in natural zirconolites is usually found in geologic sites where temperatures in excess of $500^{\circ} \mathrm{C}$ and hydrothermal conditions existed (Lumpkin 2001).

The effect of temperature on critical dose (dose needed for the sample to become amorphous) in natural zirconolite has been investigated by Lumpkin (1998). He calculated that an increase in storage temperature from $50^{\circ} \mathrm{C}$ to as much as $200^{\circ} \mathrm{C}$ increases the dose required to render a zirconolite amorphous by a factor of three. He also found that the change with temperature depends on the composition of the zirconolite. The temperatrue effect on critical dose in synthetic zirconolites has been measured by Clinard et al. (1984) with ${ }^{238} \mathrm{Pu}$-bearing cubic zirconolite and heavy ion bombardment. Many authors have verified this — for example, (Wang et al. 1999c; Smith et al. 1997).

Several investigators have studied the dissolution behavior of specimens that have been bombarded with heavy ions to produce an X-ray amorphous layer (Weber et al. 1985; 1986). These studies indicate that over a short period of time, there is an increase in the dissolution rate by a factor of 10 to 50 in heavy ionbombarded materials compared to undamaged materials (Begg et al. 2000b). While specimens that have a thin X-ray amorphous layer are useful for short duration dissolution tests, the bulk properties, such as radiation induced swelling, cannot be studied with these specimens. The authors of a Japan Atomic Energy Research Institute (JAERI)/ANSTO report (ANSTO 1999) documented release rates on the order of $10^{-5} \mathrm{~g} /\left(\mathrm{m}^{2} \cdot \mathrm{d}\right)$ for a Synroc composition containing $4 \cdot 10^{-4}$ mass $\%{ }^{244} \mathrm{Cm}$. Later experiments with samples containing $\sim 1$ mass $\%{ }^{244} \mathrm{Cm}$ indicated a release rate of $\sim 10^{-3} \mathrm{~g} /\left(\mathrm{m}^{2} \cdot \mathrm{d}\right)$, or a factor of $\sim 100 \mathrm{X}$ higher rate than the sample with lower $\mathrm{Cm}$ concentration (Mitamura et al. 1994). However, the relative release rates of other elements, such as $\mathrm{Sr}, \mathrm{Ca}$, and $\mathrm{Cs}$, were approximately the same between the two samples. This is potentially problematic because, without justification, there is no reason to accept one rate value over another. We reported dissolution rates for ${ }^{238} \mathrm{Pu}$-bearing specimens that were from 80 to 1000 times higher than for the corresponding specimens made with ${ }^{239} \mathrm{Pu}$ (Strachan et al. 2001). There were at least two possibilities for this difference in rate. The same possible explanations apply to the results from the JAERI/ANSTO study. The dissolution rate for the damaged material could be greater than the dissolution rate for the undamaged material, or radiolysis products could be building in the solution while in contact with the test specimen. Therefore, the purpose of the tests reported here is to determine the reason for the apparently high dissolution rate. To do this, we tested the corrosion resistance of surrogate ceramic waste forms over a wide span of experimental parameters. Both fully crystalline and X-ray amorphous materials were evaluated in an experimental apparatus in which experimental artifacts were either removed or minimized.

The results of tests obtained on Pu-bearing materials can then be compared to rate data determined on non-radioactive analog ceramics. Because the dissolution behavior of titanate ceramics at $90^{\circ} \mathrm{C}$ and $\mathrm{pH} 2$ 
are well known, we were able to allow fast flow-through rates that prevented radiolysis products from accumulating within the single-pass flow through (SPFT) system.

The last three materials are pyrochlore-, zirconolite-, and impurity-baseline ceramics. In these ceramics, the dominant crystalline phases result from the impurities that were projected to be in the sources of the $\mathrm{Pu}$ that was to be dispositioned. For the most part, the impurities determine the dominance of the two principal phases, pyrochlore and zirconolite, and the amount of brannerite (ideally, $\mathrm{UTi}_{2} \mathrm{O}_{6}$ ), rutile, and $\mathrm{HfTiO}_{4}$. At the $\mathrm{SiO}_{2}$ concentrations of the impurity baseline, there should also be a glass phase that contains trace quatities of $\mathrm{CaO}, \mathrm{Gd}_{2} \mathrm{O}_{3}, \mathrm{HfO}_{2}, \mathrm{PuO}_{2}$, and $\mathrm{UO}_{2}$ (Ebbinghaus et al. 1999) The composition that was selected for the baseline composition for the Plutonium Immobilization Plant was the pyrochlore-rich baseline composition (Ebbinghaus et al. 2000). 


\subsection{Experimental Methods}

\subsection{General Methods}

We prepared numerous samples from non-radioactive components, namely $\mathrm{Ce}, \mathrm{Hf}$, and $\mathrm{Gd}$, before preparing the test specimens containing Pu. Hafnium and $\mathrm{Gd}$ were also included in the actual formulations because they are neutron absorbers. The methods used to prepare the ${ }^{238} \mathrm{Pu}-$ and ${ }^{239} \mathrm{Pu}-$ bearing ceramic specimens are described; additional details may be found in Strachan et al. (2000). Reagent-grade constituent oxides and hydroxides, except $\mathrm{Pu}$, were mixed to the correct proportions. The $\mathrm{Pu}$ was added to the powder as a nitrate solution. About $100 \mathrm{~mL}$ of demineralized water were added, and the mixture was ball milled with zirconia grinding media for 16 hours. The resulting wet powder was quantitatively transferred to a beaker with demineralized water and, through various stages of drying, was subsequently dried in an oven at $110^{\circ} \mathrm{C}$. The resulting mixture was pressed into pellets $12.5 \mathrm{~mm}$ in diameter and 2 to $3 \mathrm{~mm}\left({ }^{238} \mathrm{Pu}\right.$-bearing powders) or 3 to $4 \mathrm{~mm}\left({ }^{239} \mathrm{Pu}\right.$-bearing powders $)$ in height. These pellets were then sintered at $1350^{\circ} \mathrm{C}$ under flowing Ar gas for 4 to 8 hours. We prepared the ${ }^{239} \mathrm{Pu}-$ bearing specimens first (19-May-1999) to make sure that the preparation procedures were correct. The dates on which the ${ }^{238} \mathrm{Pu}$ - and ${ }^{239} \mathrm{Pu}$-bearing specimens were made are shown in Table 2.1. After the specimens were sintered, at least one surface was polished to a 600-grit finish on $\mathrm{SiC}$ paper in a small polishing machine. Specimens that were to be tested in the dissolution test had both faces polished. The resulting ceramic specimens were not analyzed for composition. Trace concentrations of Mo were added to the formulation to indicate the behavior of the matrix in the dissolution experiments.

Table 2.1. Dates on Which the ${ }^{238} \mathrm{Pu}$ - and ${ }^{239} \mathrm{Pu}$-Bearing Specimens Were Made

\begin{tabular}{|l|l|l|}
\hline \multirow{2}{*}{\multicolumn{1}{|c|}{ Material }} & \multicolumn{2}{c|}{ Preparation Date } \\
\cline { 2 - 3 } & \multicolumn{1}{c|}{${ }^{\mathbf{2 3 8}} \mathbf{P u}$} & \multicolumn{1}{c|}{${ }^{\mathbf{2 3 9}} \mathbf{P u}$} \\
\hline \multirow{2}{*}{ Pyrochlore $^{(\mathrm{a})}$} & 25-May-1999 & 19-May-1999 \\
\cline { 2 - 3 } & 7-Jun-1999 & \\
\hline Zirconolite & 13-Jul-1999 & 11-Feb-1999 \\
\hline \multirow{2}{*}{ Pyrochlore-Rich baseline ${ }^{(\mathrm{a})}$} & 8-Oct-1999 & 10-June-1998 \\
\cline { 2 - 3 } & 19-Oct-1999 & \\
\hline Zirconolite-Rich baseline & 30-Sep-1999 & 23-Feb-1999 \\
\hline Impurity Baseline & 1-Jul-1999 & 29-May-1998 \\
\hline Coarse Pyrochlore & 16-Aug-1999 & 6-Aug-1999 \\
\hline Coarse Zirconolite & 23-Jul-1999 & 24-Jul-1999 \\
\hline (a) Two batches were made on separate dates. \\
\hline
\end{tabular}

It was anticipated that the effects of radiation damage would take a year or two to become manifest. Russian workers, however, saw radiation-damage effects within days of making their specimens (Burakov and Anderson 2001; Volkov et al. 2001; Lukinykh et al. 2002). By the time we obtained our first measurements, a substantial amount of radiation damage had occurred, which prevented us from determining the short- and long-term damage that was the objective of the experiments. Therefore, after approximately two years of characterization and testing, we resintered selected specimens at $1350^{\circ} \mathrm{C}$ for 2 hours under flowing argon to remove the damage that had occurred and establish the original crystallinity to the specimens. A set of pyrochlore specimens and all of the selected pyrochlore-rich 
baseline specimens were sintered on 29-April-2002, and the remaining selected pyrochlore specimens on 8-May-2002.

The specimens were housed in stainless-steel vessels in ovens between characterization and testing that occurred approximately semiannually for the original specimens and up to twice weekly for the resintered specimens. Each vessel contained either three or four specimens. Three storage temperatures were used: ambient $\left(\sim 20^{\circ} \mathrm{C}\right),{ }^{\text {(a) }} 125^{\circ} \mathrm{C}$, and $250^{\circ} \mathrm{C}$. These temperatures were selected so that some data would be available to estimate the critical temperature - the temperature at which the damage is annealed at the same rate as it occurs. Unfortunately, as will be seen in the results discussed below, no information on the critical temperature could be extracted from the data. The specimens were stacked face to face so that they had at least one face that would be a near representation of material far from the surface of the specimen. While the alpha particle and the recoiling atom do not travel great distances in the solid, these particles are lost at a free surface, resulting in a gradient in damage production from the free surface inward to the depth of the maximum range of the particles. For alpha particles, this range is $10 \mathrm{~s}$ of micrometres, while for the recoiling atom, the range is 10 s of nanometres. Since the damage effects at a free surface do not represent the damage effects in the bulk of the specimen, the specimens were stacked face-to-face so each surface received uniform damage and became more representative of the bulk.

\subsection{X-Ray Diffraction}

The specimens were characterized with XRD, dimension measurements, density measurements, photography, and SPFT tests. Because the specimens were highly radioactive and because we needed to control the spread of contamination, we developed a specimen holder to obtain the diffraction patterns from the polished surface of the specimens. This specimen holder is shown in Figure 2.1 and described in detail elsewhere (Strachan et al. 2003a). This specimen holder and a mounting jig allowed us to locate the specimen in exactly the same position each time it was mounted for examination. The rotational orientation varied each time. Because the specimen does not completely intercept the X-ray beam, there are some errors in obtaining the diffraction patterns, but these should remain the same from characterization to characterization. Relative changes were important to our results, so the absolute error did not affect our results. To facilitate the XRD characterization, a disk approximately $25 \mathrm{~mm}$ in diameter of the Standard Reference Material 1976 from the National Institute of Standards and Testing was permanently affixed to the post of a specimen holder. A diffraction pattern was obtained at the beginning and end of each day that patterns were being obtained from the test specimens. This allowed us to account for variations in instrument sensitivity, such as X-ray tube degradation and X-ray tube changes. The XRD unit was a Scintag PAD V (Scintag Corp., Cupertino, CA).

\subsection{Density}

We also developed a laser-based device for measuring the diameter and height of the specimens. Again, because these specimens are highly radioactive, we needed to minimize the time they were handled and the possibility of contamination spread. This device is shown in Figure 2.2 and consists of two orthogonal laser curtains and associated detectors (Keyence Corp, Woodcliff Lake, NJ, Model VG 036T

(a) An oven was used but with no power. The oven served as a cabinet to safely house the specimen storage devices. There was sufficient power generated in the specimens to raise the temperature of the 500-g stainlesssteel vessel by about $2^{\circ} \mathrm{C}$. 
and control Model VG 30). These lasers are capable of making 780 measurements each second. The specimen sits on a slowly rotating table $(5 \mathrm{rpm})$. During 45 seconds of measurement, over 3500 simultaneous measurements of the diameter and height are obtained and stored in a computer file. Each of these measurements is an average of four measurements. The current measurement parameters are obtaining a measurement (an average of four) for each $0.5^{\circ}$ of rotation. The advertised resolution of these laser devices is $10 \mu \mathrm{m}$. Since we are interested in the relative change in each specimen with time, we are not interested in the absolute accuracy of the instrument, but its long-term stability. Two "check pellets" were made from stainless steel to guarantee that the drift of the instrument is understood. Both of these pellets have nominal diameters of $10 \mathrm{~mm}$; one has a nominal height of $2.5 \mathrm{~mm}$ and the other $4.4 \mathrm{~mm}$. For the period of 664 days, the average diameter of the smaller "check pellet" was $10.063(6)^{(a)} \mathrm{mm}$, and the height was 2.487(7) $\mathrm{mm}$. This indicates excellent stability. Over the same time, the absolute accuracy was $0.30(7) \%$ and $0.5(3) \%$ for the diameter and height, respectively. We do not have many measurements on the 4.4-mm-high "check pellet" because it is only used for the checks when ${ }^{239} \mathrm{Pu}$-bearing specimens are characterized. We anticipated on the order of $1 \%$ swelling in the ${ }^{238} \mathrm{Pu}$-bearing specimens. The degree of stability and precision of our instrument indicates that we can reliably report $0.1 \%$ changes in specimen dimensions.

It should be noted that early in the use of the laser-based measurement device, the duration of the measurements was approximately 15 seconds. This length of time was insufficient to obtain good measurement statistics. The uncertainties in the measured dimensions were high and about the same as the uncertainty from the use of the handheld micrometer. Increasing the measurement time to 45 seconds decreased the uncertainty by about a factor of 4 .

From the dimension measurements and the mass of the specimen, we can calculate the bulk density. In reality, however, the table on which the specimens sat during the measurements had about a $20-\mu \mathrm{m}$ wobble up and down. While this wobble slightly degraded the accuracy of the overall height measurement, it, in combination with the chips on the edges of the specimens (see the discussion below), resulted in high uncertainty in the calculated bulk densities. Therefore, as discussed below, we do not report the changes in bulk density calculated from the observed changes in specimen dimensions. We do report the changes in the diameters of the specimens, which are unaffected by the wobble in the table, and, from those

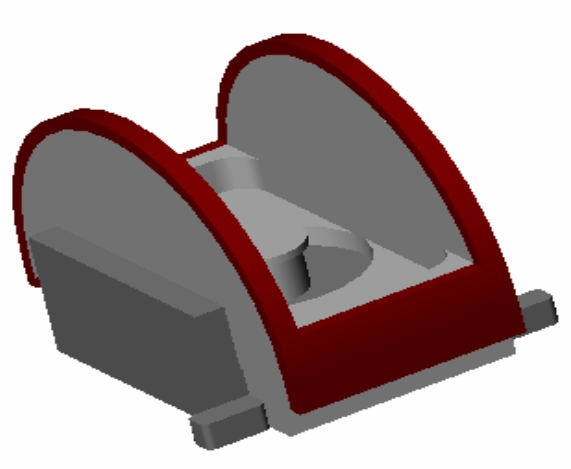

Figure 2.1. A 3-D Sketch of the XRD Specimen Holder for the Radioactive Specimens Studied

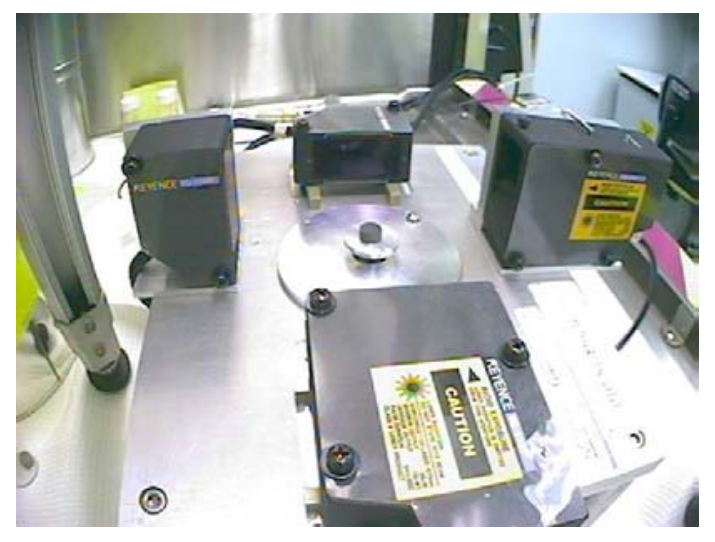

Figure 2.2. A Picture of the Laser-Based Specimen Measuring Instrument that Was Developed for Simultaneously Measuring the Diameter and Height of Pu-Bearing Specimens

(a) The number in ( ) represents the $1-\sigma$ standard deviation in the last place of the number reported. 
changes and the assumption of uniform swelling, we calculate the change in the bulk density.

Densities were also measured with a helium pycnometer (Micromeritics, Norcross, GA, Model AccuPyc 1330). This device measures the volume of a weighed specimen by displacement of He gas. The measurements reported here were obtained with an ultra-precise procedure in which a value for the density is not determined until five successive determinations agree within $0.05 \%$. The results are sent to a computer where they are automatically stored in a file. For the ${ }^{238} \mathrm{Pu}$-bearing specimens, three specimens are used in the density determination, two for the ${ }^{239} \mathrm{Pu}$-bearing specimens.

At each characterization, the specimens were photographed. This was done to document any visible changes to the specimens with storage time. At the start, we used an inexpensive video camera to obtain these pictures. The photographs were adequate, but we upgraded to a Tripix camera (ElectroImage, Inc., Great Neck, NY: standard RGB model) and a Navitar microscope (Rochester, NY: Model 1-60737). The latter allowed us to change the magnification with a control that was external to the fume hood. This minimized the chance for spreading contamination and allowed for hands-free adjustment of focus and magnification. The photographs shown in this report come from the Tripix camera.

\subsection{Single-Pass Flow-Through Test}

In our initial set of experiments with the ${ }^{238} \mathrm{Pu}$-bearing specimens, we used a modified SPFT apparatus in which Teflon ${ }^{\circledR}$ reaction vessels and fluid exchange lines were used. We added a platinum liner to shield the Teflon vessel from the alpha radiation with the hope of decreasing the release of the fluoride ion from Teflon reactor vessel as a result of the alpha dose from the test specimen. Damage to the Teflon reactor is possible since the powdered specimen rests directly on the bottom of the vessel. The insert was tall enough to protect the interior of the reactor so that the only Teflon in contact with the solution was that associated with the influent and effluent lines. Counter to our expectations, we found that significant (10 to $100 \mathrm{mg} / \mathrm{L}$ ) concentrations of fluoride were present in effluent solutions from experiments with ${ }^{238} \mathrm{Pu}-$ bearing materials. As yet, we are uncertain what the source of the fluoride was, but the high concentrations of fluoride in the effluent solution are inconsistent with what is known about the efficiency of alpha radiation on fluoride release from Teflon. Fluoride was not detected in any effluent solutions in experiments with ${ }^{239} \mathrm{Pu}$-bearing specimens or non-radioactive specimens. If allowed to stand, the presence of fluoride in the effluent specimens would always cloud the validity of any conclusions we would make about the dissolution of these ceramic materials.

Additionally, we were concerned about the low flow rates ( $\sim 2 \mathrm{~mL}$ per day) that could result in the buildup of radiolysis products that could affect the dissolution rate and make interpretation of the results difficult. Radiolysis products could form in a slowly flowing aqueous stream from the intense radiation field from the ${ }^{238} \mathrm{Pu}$ in the specimens. In sum, a new SPFT apparatus was needed in which the solution neither comes in contact with Teflon nor is in contact with the specimen long enough for significant radiolysis products to accumulate. Accordingly, for the experiments with ${ }^{238} \mathrm{Pu}$-bearing materials, we replaced the Teflon-based apparatus with one constructed of titanium.

In this new apparatus, the $\sim 20$ - $\mathrm{mL}$ reactor vessel consists of titanium top and bottom pieces that screw together. The volume of the reactor vessel is approximately one-third less than that of the Teflon reactors. This allows us to run high flow rates (ca $20 \mathrm{~mL} / \mathrm{d}$ ) that purge the solution rapidly and minimize the concentration of the radiolysis products and maintain the solution at or near dilute conditions. The top 
portion of the reactor contains ports for input and effluent lines. The fluid transport lines are constructed from small-bore titanium tubing to decrease the dead volume. A flat gold ring was used to seal the top and bottom halves of the reactor.

The experimental arrangement is shown in Figure 2.3 for the Teflon SPFT apparatus. The reactor apparatus differs from the Teflon apparatus in that an aluminum-block heater was used to heat the Ti vessels. Syringe pumps were programmed to yield constant flow rates of solution from the solution reservoir through the SPFT apparatus. A powdered sample lies on the bottom of the reactor. This configuration prevented air bubbles from nucleating in pore spaces between powder grains, thereby providing solution access to the entire specimen surface. However, even with insulating materials, the operating temperature was nearly constant at $85^{\circ} \mathrm{C}$, although the target temperature was $90^{\circ} \mathrm{C}$. Temperatures of the experiments were determined in situ with a calibrated thermocouple.

In our experiments with ${ }^{239} \mathrm{Pu}$-bearing and non-radioactive specimens, we used the standard SPFT apparatus fashioned from Teflon components. The salient features of the SPFT apparatus used in this study are illustrated in Figure 2.3. The temperature of the experiments with the Teflon-based apparatus was kept at $90^{\circ} \mathrm{C}$ in a laboratory convection oven. A digital thermocouple reader, accurate to $\pm 2^{\circ} \mathrm{C}$, was used to record oven temperature daily. Syringe pumps (Kloehn; model 50300) were used to transfer solution from the input reservoir bottles to the reaction vessels. Multiple fluid transfer lines are a key feature of these syringe pumps. Thus, one syringe pump can deliver solution to one to four reactors so

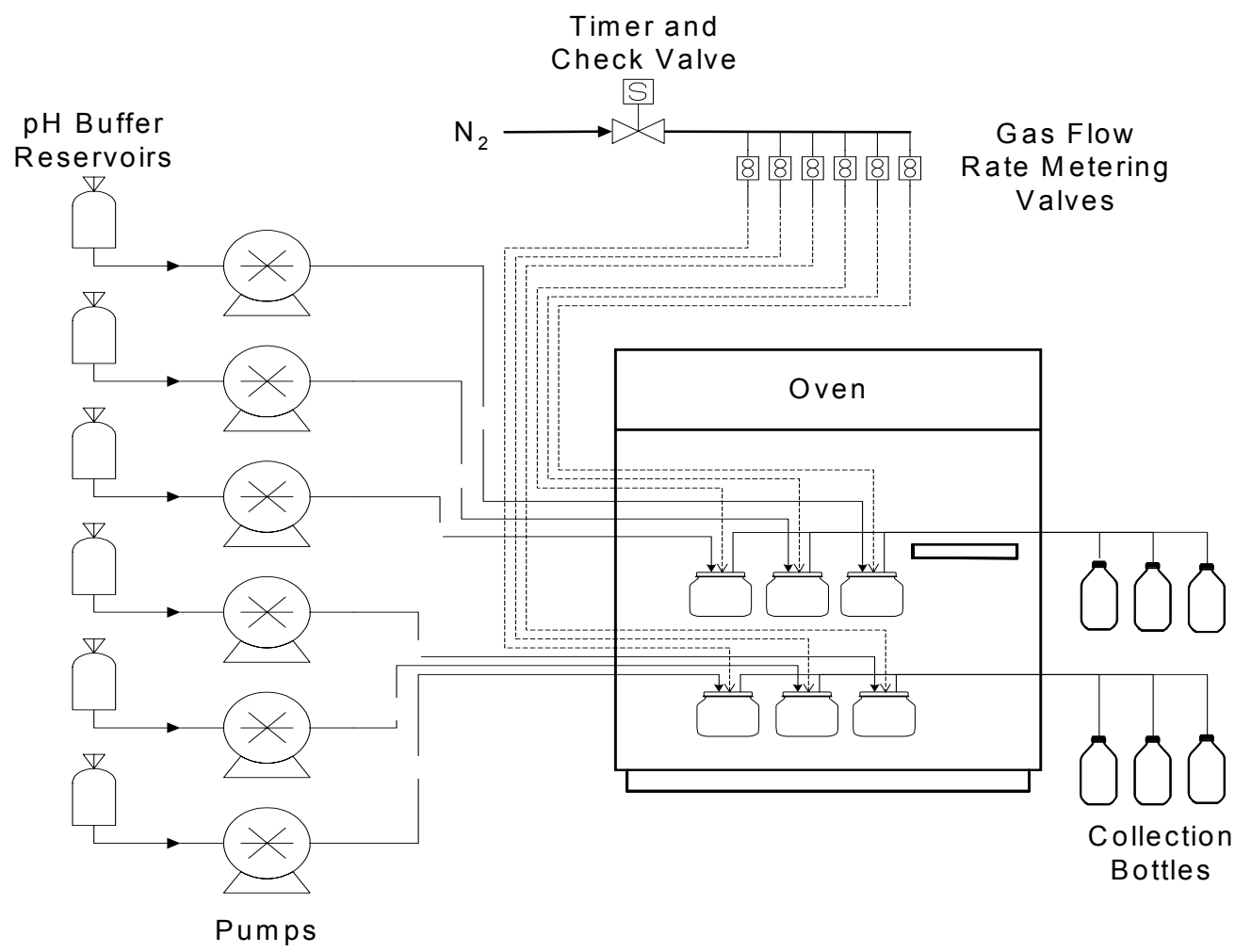

Figure 2.3. Single-Pass Flow-Through Test Apparatus Schematic 
that duplicate experiments and blanks can be run simultaneously. Nitrogen gas was used to purge the free space above the solution within the reservoir, thereby mitigating the effect of atmospheric $\mathrm{CO}_{2}$ on the solution $\mathrm{pH}$.

The chemical durability of the ${ }^{238} \mathrm{Pu}$-bearing ceramics were tested in $\mathrm{pH}=2$ solutions. Although acidic conditions will not prevail in prospective geologic repositories, $\mathrm{pH} 2$ solutions allow us to avoid solubility limitations for $\mathrm{Gd}, \mathrm{Ce}, \mathrm{Pu}$, and $\mathrm{U}$. Further, we show in this report, as we have in the past (Strachan et al. 2001), that there is a weak $\mathrm{pH}$-dependence of the dissolution rate. Therefore, at worst, the forward dissolution rate at $\mathrm{pH} 2$ is about a factor of 10 higher than the forward dissolution rate at neutral to slightly alkaline $\mathrm{pH}$ values.

Six solutions at $\mathrm{pH}$ values of $2,7,8,9,10$, and 11 were used for the experiments with ${ }^{239} \mathrm{Pu}$-bearing pyrochlore-rich baseline ceramics. Reagent grade nitric acid was mixed with deionized water to yield acidic solution $(\mathrm{pH}=2)$. Neutral to slightly basic solutions $(\mathrm{pH}=7,8,9$, and 10$)$ were made by mixing small amounts of the organic THAM (tris hydroxymethyl aminomethane) buffer to deionized water and then adding ultrapure $\mathrm{HNO}_{3}$ to bring the solution to the desired $\mathrm{pH}$ value. Alkaline solutions $(\mathrm{pH}=11)$ were prepared by adding $\mathrm{LiCl}$ and $\mathrm{LiOH}$ to deionized water. In Table 2.2 , the calculated $\mathrm{pH}$ at $90^{\circ} \mathrm{C}$ is also shown. This $\mathrm{pH}$ value was calculated with the EQ3NR computer code (Wolery 1992). As one can see from Table 2.2, the in-situ $\mathrm{pH}$ of the experiment can change by as much as $1.5 \mathrm{pH}$ units over the temperature interval of $23^{\circ}$ to $90^{\circ} \mathrm{C}$; about half of this change is due to the shift in the neutral $\mathrm{pH}$ of water.

Table 2.2. Compositions of Solutions Used in SPFT Experiments. Solution $\mathrm{pH}$ values at $90^{\circ} \mathrm{C}$ were calculated with EQ3NR code V7.2b database (Wolery 1992)

\begin{tabular}{|c|c|c|c|}
\hline Solution \# & $\begin{array}{c}\text { Target } \\
\text { pH }\left(25^{\circ} \mathrm{C}\right)\end{array}$ & $\begin{array}{l}\text { Estimated } \\
\text { pH }\left(90^{\circ} \mathrm{C}\right)\end{array}$ & Chemical Composition \\
\hline 1 & 2.0 & 2.0 & $0.01 \mathrm{M} \mathrm{HNO}_{3}$ \\
\hline 2 & 5.7 & 4.9 & De-ionized Water \\
\hline 3 & 7.0 & 5.5 & $0.01 \mathrm{THAM}^{(\mathrm{a})}+0.009 \mathrm{M} \mathrm{HNO}_{3}$ \\
\hline 4 & 8.0 & 6.5 & $0.01 \mathrm{THAM}+0.006 \mathrm{M} \mathrm{HNO}_{3}$ \\
\hline 5 & 9.0 & 7.3 & $0.01 \mathrm{THAM}+0.003 \mathrm{M} \mathrm{HNO}_{3}$ \\
\hline 6 & 10.0 & 9.2 & $0.01 \mathrm{THAM}+0.001 \mathrm{M} \mathrm{LiOH}$ \\
\hline 7 & 11.0 & 10.1 & $0.01 \mathrm{M} \mathrm{LiCl}+0.011 \mathrm{M} \mathrm{LiOH}$ \\
\hline
\end{tabular}

Aliquots of effluent solution, whether from the titanium or the Teflon SPFT apparatus, were routinely checked to assure that $\mathrm{pH}$ control was maintained during the experiment. Other aliquots were reserved for radiochemical assay with counting techniques. Gamma energy analysis (GEA) was used to analyze for ${ }^{239} \mathrm{Pu},{ }^{238} \mathrm{Pu},{ }^{240} \mathrm{Pu},{ }^{241} \mathrm{Pu}$, and ${ }^{241} \mathrm{Am}$ in aliquots of the effluent solution. The remainder of the periodically collected effluent was acidified $(\mathrm{pH}<2)$ with high-purity nitric acid and analyzed for Ce, $\mathrm{Gd}, \mathrm{Hf}, \mathrm{Mo},{ }^{239} \mathrm{Pu}, \mathrm{Ti}$, and mass-238 species concentrations with inductively coupled plasma-mass spectroscopy. "Mass-238" species include ${ }^{238} \mathrm{U}$ and ${ }^{238} \mathrm{Pu}$, which we assumed constituted the total of species of mass-238 (i.e., ${ }^{238} \mathrm{U}+{ }^{238} \mathrm{Pu}=$ mass-238). Concentrations of ${ }^{238} \mathrm{U}$ were determined by subtracting the concentration of ${ }^{238} \mathrm{Pu}$ determined with counting methods from the mass-238 species. Concentrations of $\mathrm{Ti}$ in effluent solutions from the titanium reactor experiments were not determined. Concentrations of $\mathrm{Al}$ and $\mathrm{Ca}$ in with the solutions from the tests with ${ }^{239} \mathrm{Pu}$-bearing ceramics were 
determined with optical emission spectroscopy methods. This technique was not used for solutions from tests with ${ }^{238} \mathrm{Pu}$ specimens because the optical emission spectrometer was not set up for the analysis of highly radioactive solutions.

Typically, three blank solutions were drawn before the specimen was added to the reactor. The blank solutions were analyzed for background concentrations of elements of interest and, together with analyses of starting solution aliquots, assured us that contamination from previous experiments was not a factor. Blanks, which were set up identically to the other reaction cells, but without a test specimen, were used to monitor the Mo in the starting $\mathrm{pH}$-buffered leach solutions. Through separate testing, we determined that one of the minor contaminants in the THAM was Mo. Analyses of the solutions from the blanks showed that the concentrations of Mo remained relatively low, but increased as water evaporated from the reservoir under flowing nitrogen. Some evaporation of the input solution was expected, especially as the reservoir reached empty. In most cases, reservoir bottles were exchanged before significant evaporation occurred. Any slight rise in background Mo concentrations was recorded. These concentrations dropped to near detection level $(\sim 0.10 \mu \mathrm{g} / \mathrm{L})$ after the solution was changed. The concentration of Mo from the blank was subtracted from the Mo concentration in the effluent solutions. Because a significant fraction of the dissolved Mo sorbs on the alteration product anatase at $\mathrm{pH}$ values below 5 (Saripalli et al. 2002), no Mo results are shown for the experiments in which the leachant has a $\mathrm{pH}$ of 2.

To assure that the dissolution rate we measured was the forward rate for each ceramic type, we varied the solution flow rate $(q)$ and the specimen surface area $(S)$ until the dissolution rate was independent of $q / S$. Values of $q / S$ were achieved by flow rate or surface area or both. We measured the dissolution rates of both monolithic and powdered specimens. The computation of dissolution rates and associated uncertainties has been discussed elsewhere (Icenhower et al. 2003) and will not be repeated here.

We were also concerned about the use of Ti vessels when testing titanate ceramics. With the Ti vessels, we are unable to report the Ti concentration in solution. Therefore, we tested one ${ }^{239} \mathrm{Pu}$-bearing specimen in both the Ti and Teflon apparatuses. Because the solubility of anatase is very low, the solutions were saturated with respect to anatase, irrespective of which vessel was used in the test. A comparison of these results in combination with the rest of the test results allows us to eliminate the vessel material as affecting the dissolution of these ceramic materials.

\subsection{Scanning Electron Microscopy}

At the start of the project, we did not have a scanning electron microscope (SEM) to examine specimens containing high concentrations of ${ }^{238} \mathrm{Pu}$. By the end of the project, we were able to examine these materials. Samples were examined on a JEOL JEM840 Scanning Electron Microscope equipped with a Gatan Inc., digital imaging system and a Robinson backscattered electron imaging system and an Oxford Instruments ISIS X-ray energy dispersive spectrometer. All collected spectra were saved as data text files. The background spectrum collected with the electron beam off was not considered to be interference in the collected X-ray data at lower energies $(<10 \mathrm{keV})$; however, the background spectra were subtracted from some collected spectra before analysis. Quantitative analysis was not possible because of the overlap of the $\mathrm{Pu}$ and $\mathrm{U} \mathrm{M}$ lines. The spectra were plotted using a graphing software program. Many of the X-ray energy-dispersive spectroscopy spectra were severely masked by X-rays from the decay of ${ }^{238} \mathrm{Pu}$ to ${ }^{234} \mathrm{U}$. This energetic event generates $\mathrm{U} X$-rays. The higher energy $\mathrm{L} \mathrm{X}$-rays were more apparent in the collected spectra as these X-rays are more penetrating than the M X-ray lines. 
In order to reduce this problem, the smallest possible ceramic sample was used that could still be observed and polished in a glovebox. 


\subsection{Radiation-Damage Effects in Pyrochlore}

This section describes the effects of radiation damage on the density, crystal structure, and dissolution of "phase-pure" pyrochlore specimens.

\subsection{Preparations}

Two batches containing ${ }^{238} \mathrm{Pu}$ were prepared, one on 25-May-1999 and the other on 7-June-1999 (Table 2.1). A number of these specimens were sintered at $1350^{\circ} \mathrm{C}$ for an additional 110 hours to coarsen the microstructure (16-August-1999). Ceramics with a coarse microstructure were thought to be more susceptible to microcracking than ones with a fine microstructure.

The target compositions for these batches are shown in Table 3.1. The $\mathrm{PuO}_{2}$ composition corresponds to 10.86 mass $\% \mathrm{Pu}$. This target composition suggests a formula $\mathrm{Ca}_{1.16} \mathrm{Gd}_{0.23} \mathrm{Hf}_{0.30} \mathrm{Pu}_{0.24} \mathrm{U}_{0.42} \mathrm{Ti}_{2} \mathrm{O}_{7}$. However, some Ti must appear as Hf-rutile, (Hf, Ti) $\mathrm{O}_{2}$, and some $\mathrm{Hf}$ must be on the pyrochlore $\mathrm{B}$ site in the pyrochlore structure. Thus, the approximate actual formula should be $\mathrm{Ca}_{1.13} \mathrm{Gd}_{0.22} \mathrm{Hf}_{0.12} \mathrm{Pu}_{0.24} \mathrm{U}_{0.40}\left(\mathrm{Ti}_{1.90} \mathrm{Hf}_{0.10}\right) \mathrm{O}_{7}$ and 20 mass $\% \mathrm{TiO}_{2}$ with $10 \%$ of the Ti replaced with Hf, i.e., $\mathrm{Hf}_{0.1} \mathrm{Ti}_{0.9} \mathrm{O}_{2}$ (Stewart et al. 2002). In this formulation, we assumed that $\mathrm{Pu}(\mathrm{IV})$ and $\mathrm{U}(\mathrm{IV})$ are the relevant oxidation states. Placing Hf on the B site in pyrochlore helped to minimize the residuals in the Rietveld fit to the XRD data (see below). Placing the Hf on the B site is also consistent with several studies of the Ti- and Zr-bearing pyrochlores ((Minervini et al. 2000; Begg et al. 2001; Hess et al. 2002; Gieré et al. 2002); and references within these publications). Although other authors report different oxidation states for some elements in these solids, notably U(V) and Pu(III) (Gieré et al. 2002; Stewart et al. 2002; Fortner et al. 2002; Conradson 1998), we did not attempt to design a formula with these oxidation states. Using this formulation for the pyrochlore specimens, we calculated a theoretical density of $6.008 \cdot 10^{3} \mathrm{~kg} / \mathrm{m}^{3}$ (see the XRD section below for the lattice parameter) in agreement with Stewart et al. (2002).

The compositions of the specimens used in the SPFT tests are shown in Table 3.2. Non-radioactive specimens were studied to obtain results that would aid in resolving the effect of radiolysis on the dissolution rates of these materials. In Table 3.2, "EMPA" means that the ceramic composition was determined with an electron microprobe. Because the other compositions are target compositions, no "total" is shown for these ceramics.

Table 3.1. The Target Oxide Composition of the Pyrochlore Ceramics Used in this Study

\begin{tabular}{|l|c|c|c|c||}
\hline \multirow{2}{*}{ Component } & \multicolumn{2}{|c|}{${ }^{\mathbf{2 3} \mathbf{P u} \text { Pyrochlrore }}$} & \multicolumn{2}{c|}{${ }^{239} \mathbf{P u}$-Pyrochlore } \\
\cline { 2 - 5 } & $\mathbf{M a s s \%}$ & $\mathbf{M o l e \%}$ & Mass\% & Mole\% \\
\hline $\mathrm{CaO}$ & 12.06 & 24.89 & 12.07 & 24.91 \\
\hline $\mathrm{Gd}_{2} \mathrm{O}_{3}$ & 7.65 & 2.44 & 7.64 & 2.44 \\
\hline $\mathrm{HfO}_{2}$ & 10.88 & 5.98 & 10.88 & 5.98 \\
\hline $\mathrm{MoO}_{3}$ & 0.10 & 0.09 & 0.10 & 0.09 \\
\hline $\mathrm{PuO}_{2}$ & 12.31 & 5.27 & 12.35 & 5.27 \\
\hline $\mathrm{TiO}_{2}$ & 36.17 & 52.39 & 36.15 & 52.38 \\
\hline $\mathrm{UO}_{2}$ & 20.82 & 8.93 & 20.82 & 8.92 \\
\hline
\end{tabular}


Table 3.2. Compositions (mass\%) of the Ce-Bearing Pyrochlore Specimens Used in SPFT Tests

\begin{tabular}{||l|r|r||}
\hline Oxide & $\begin{array}{r}\text { PY-12 } \\
\text { Target }\end{array}$ & $\begin{array}{r}\text { PY-21 } \\
\text { EMPA }\end{array}$ \\
\hline $\mathrm{CaO}$ & 8.23 & 7.58 \\
\hline $\mathrm{CeO}_{2}$ & 35.38 & 35.80 \\
\hline $\mathrm{Gd}_{2} \mathrm{O}_{3}$ & 13.31 & 13.06 \\
\hline $\mathrm{HfO}_{2}$ & 3.10 & 3.92 \\
\hline $\mathrm{MoO}_{3}$ & 0.08 & 0.08 \\
\hline $\mathrm{TiO}_{2}$ & 39.89 & 39.34 \\
\hline Total & & 99.78 \\
\hline
\end{tabular}

\subsection{Results and Discussion}

\subsubsection{Physical Appearance}

The specimens were produced as right circular cylinders. The pressing of these specimens was not optimized, so some edge chipping was observed. A picture of a typical specimen is shown in Figure 3.1. The defects shown in this specimen are typical for most of the ${ }^{238} \mathrm{Pu}$-bearing pyrochlore specimens.

\subsubsection{Density Measurements}

Helium Pycnometer Results. Two sets of results are discussed here. One set is from the original specimens that were made and placed in the storage vessels in the ovens and the other from the specimens that were resintered at $1350^{\circ} \mathrm{C}$. Results from the specimens stored at $20^{\circ} \mathrm{C}$ are shown in Figure 3.2. The "true" density of the ${ }^{239} \mathrm{Pu}$-bearing specimens is constant over approximately 1350 days; the measurement at 199 days is likely an outlier. A starting "true" density of $5.531 \cdot 10^{3} \mathrm{~kg} / \mathrm{m}^{3}$ is $92 \%$ of theoretical density $\left(6.008 \cdot 10^{3} \mathrm{~kg} / \mathrm{m}^{3}\right)$. Although the shape of the curves from the ${ }^{238} \mathrm{Pu}$-bearing specimens is similar, the density of the resintered specimens changed much more rapidly than the original. This is probably a result of the resintering process, which likely led to some restructuring of the microstructure. The density results were fit to the equation (Weber et al. 1986)

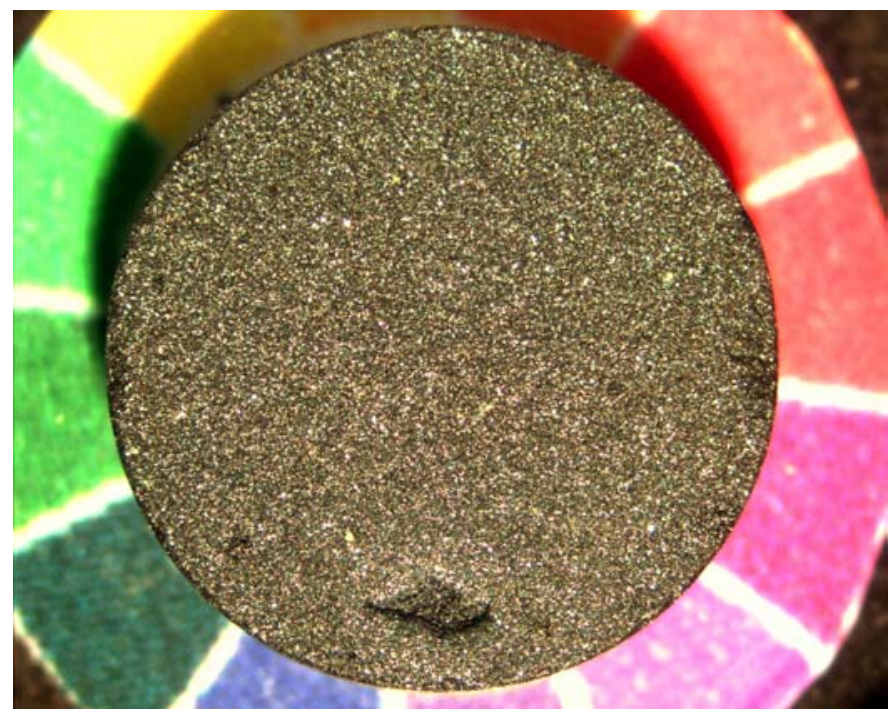

Figure 3.1. A Picture of a Typical ${ }^{238} \mathrm{Pu}$-Bearing Pyrochlore Ceramic Specimen (color wheel in the background for true color rendition) 


$$
\rho=\rho_{s}+b \exp (-c t)
$$

where $\rho=$ density

$\rho_{s}=$ density at saturation

$b=$ difference between the initial and the asymptotic (saturation) value of $\rho$

$c=$ a value related to the damage volume per alpha decay per unit time.

For this fit, the values are $\rho_{s}=5.156(9) \cdot 10^{3} \mathrm{~kg} / \mathrm{m}^{3}, \mathrm{~b}=0.37(1) \cdot 10^{3} \mathrm{~kg} / \mathrm{m}^{3}$, and $\mathrm{c}=0.0042(5) \mathrm{d}^{-1}$. More significant figures are shown in Figure 3.2 to allow the reader to reproduce our results more accurately. For the original specimens, the density changes appear to have saturated at a density of $5.16 \cdot 10^{3} \mathrm{~kg} / \mathrm{m}^{3}$ - a decrease of $6.8 \%$. The change in the density for the resintered specimens did not saturate or come sufficiently close for us to apply Equation 3.1 to the data. The density change for the resintered specimens is $-8.32(56) \cdot 10^{-4}$ $\mathrm{kg} /\left(\mathrm{m}^{3} \cdot \mathrm{d}\right)$ in the linear portion of the data in Figure 3.2. We surmise that the density would saturate between 5.0 and $5.1 \cdot 10^{3} \mathrm{~kg} / \mathrm{m}^{3}$ for an 8 to $10 \%$ decrease in the density.

Results from the density measurements of the specimens stored at $125^{\circ} \mathrm{C}$ are shown in Figure 3.3. No specimens that had been stored at $125^{\circ} \mathrm{C}$ were resintered. From these data, it is unclear if the density change has saturated. However, fitting the data to Equation 3.1 suggests that the density $\left(5.195(9) \cdot 10^{3} \mathrm{~kg} / \mathrm{m}^{3}\right.$ ) at saturation is the same within experimental uncertainty as the density at saturation of the original specimens stored at $20^{\circ} \mathrm{C}$ (Figure 3.2).

As has been reported previously (Strachan et al. 2002; Strachan et al. 2003b) there are changes to the pyrochlore specimens stored at $250^{\circ} \mathrm{C}$ that were not observed in the specimens stored at $20^{\circ} \mathrm{C}$. These changes appear to be manifest in the density changes as seen in Figure 3.4 and will be discussed in the section on the XRD results. While the density of the resintered specimens that were originally stored at $250^{\circ} \mathrm{C}$ has the same starting value of about $5.4 \cdot 10^{3} \mathrm{~kg} / \mathrm{m}^{3}$, the

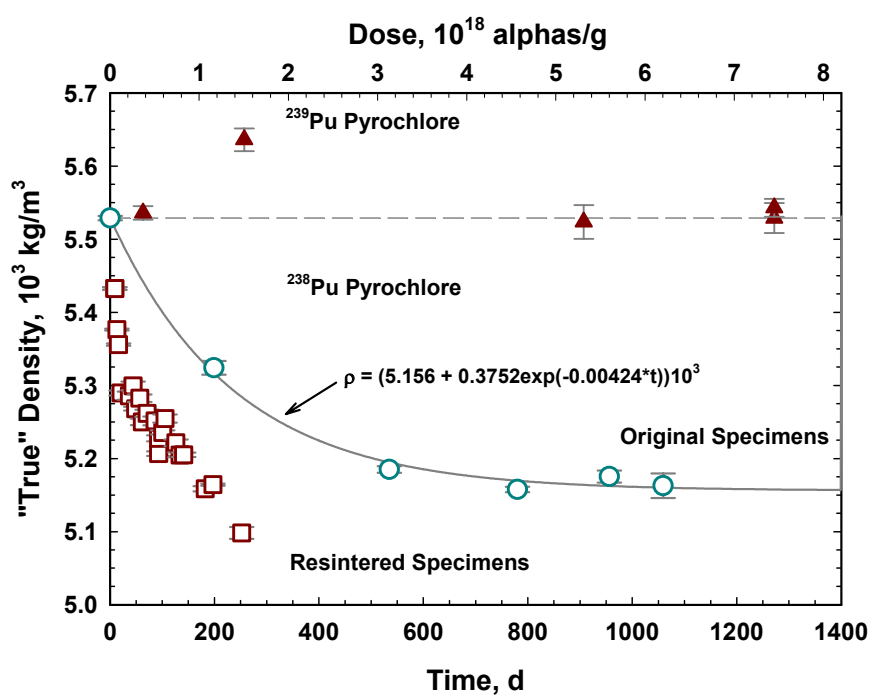

Figure 3.2. Effect of Time and Radiation Dose $\left({ }^{238} \mathrm{Pu}\right)$ on the "True" Density Measurements for the ${ }^{238} \mathrm{Pu}$ - and ${ }^{239} \mathrm{Pu}$-Bearing Pyrochlore Specimens Stored at $20^{\circ} \mathrm{C}$

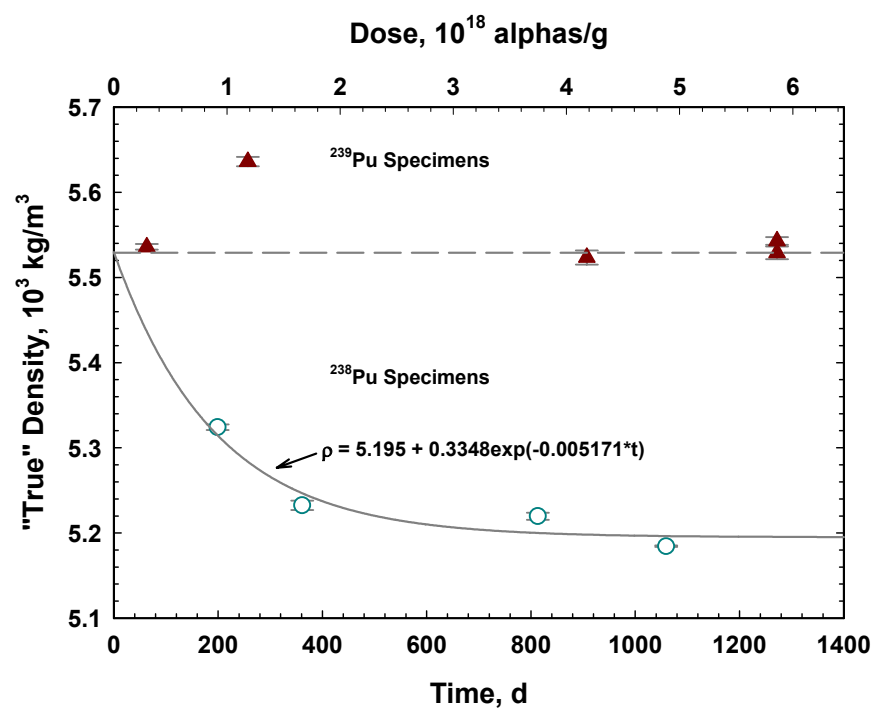

Figure 3.3. Effect of Time and Radiation Dose $\left({ }^{238} \mathrm{Pu}\right)$ on the "True" Density of ${ }^{238} \mathrm{Pu}$-Bearing Pyrochlore for Specimens Stored at $125^{\circ} \mathrm{C}$ 
densities change linearly with time and coincide with the densities of the original specimens (Figure 3.4). The rate of change in the density is $-3.88(28) \cdot 10^{-4} \mathrm{~kg} /\left(\mathrm{m}^{3} \cdot \mathrm{d}\right)$, which is slower by about a factor of two than the change shown in Figure 3.2 for the specimens stored at $20^{\circ} \mathrm{C}$. The coincidence of the data from the resintered specimens with the data from the original specimens suggests that the resintered density should decrease to about $5.1 \cdot 10^{3} \mathrm{~kg} / \mathrm{m}^{3}$ after about 800 days.

"True" densities were also measured for the coarsened microstructure pyrochlore specimens (Figure 3.5). The data from the ${ }^{238} \mathrm{Pu}$-bearing specimens were fit to Equation 3.1, while the data from the ${ }^{239} \mathrm{Pu}$-bearing specimens, except for the 225 day data, were averaged because of the low dose in the ${ }^{239} \mathrm{Pu}$-bearing specimens $\left[5.407(10) \cdot 10^{3} \mathrm{~kg} / \mathrm{m}^{3}\right]$. A $6.4 \%$ decrease in the "true" density of the ${ }^{238} \mathrm{Pu}$-bearing specimens is in excellent agreement with the $6.8 \%$ decrease noted for the normally sintered specimens also stored at $20^{\circ} \mathrm{C}$. Based on the total dose to the specimens, the change calculated for the ${ }^{238} \mathrm{Pu}$-bearing specimens from the change in the ${ }^{238} \mathrm{Pu}$-bearing specimens is also in excellent agreement.

Based on the calculated starting densities, prolonged sintering of these materials appears to reduce the "true" density, $2 \%$ for the ${ }^{239} \mathrm{Pu}$ bearing specimens and $13 \%$ for the ${ }^{238} \mathrm{Pu}$ bearing specimens.

The observed changes in the "true" densities of the ${ }^{238} \mathrm{Pu}$-bearing specimens stored at $250^{\circ} \mathrm{C}$ suggest that the critical temperature is higher than $250^{\circ} \mathrm{C}$. Unfortunately, there are insufficient data to allow us to make an estimate of the critical temperature.

Geometric Densities. The measured diameters of the original ${ }^{238} \mathrm{Pu}$ - and ${ }^{239} \mathrm{Pu}$-bearing specimens are shown in Figure 3.6. No significant temperature dependence is noted. Several data points appear to result from measurement error and do not fit the trend of the majority of data, e.g., the low data at 1072 days and at 1350 days. The majority of the ${ }^{238} \mathrm{Pu}$-bearing specimen data were fit to the equation

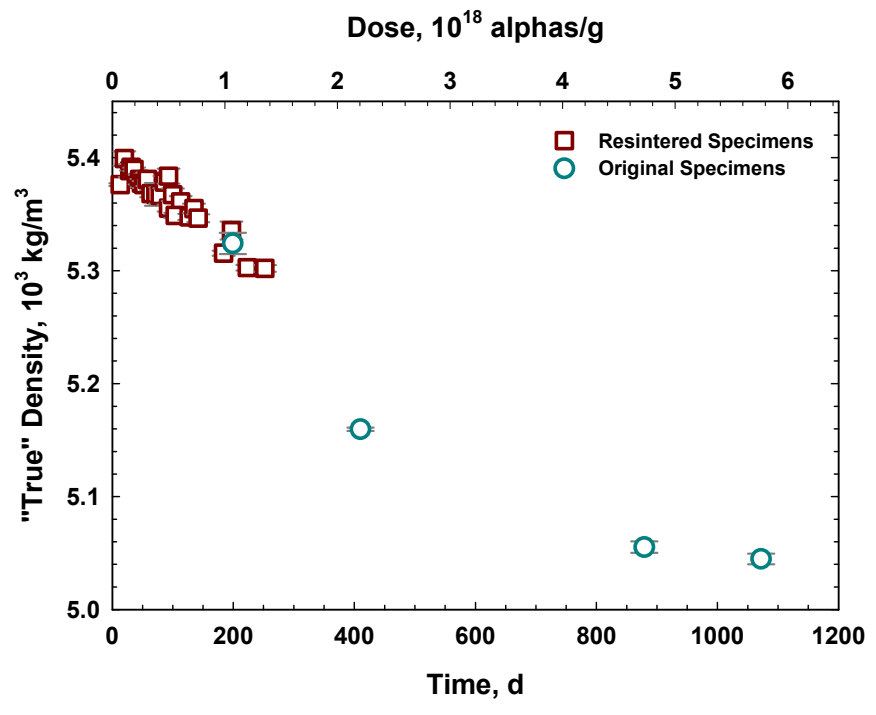

Figure 3.4. Effect of Time and Radiation Dose $\left({ }^{238} \mathrm{Pu}\right)$ on the "True" Density of ${ }^{238} \mathrm{Pu}$-Bearing Pyrochlore for Specimens Stored at $250^{\circ} \mathrm{C}$

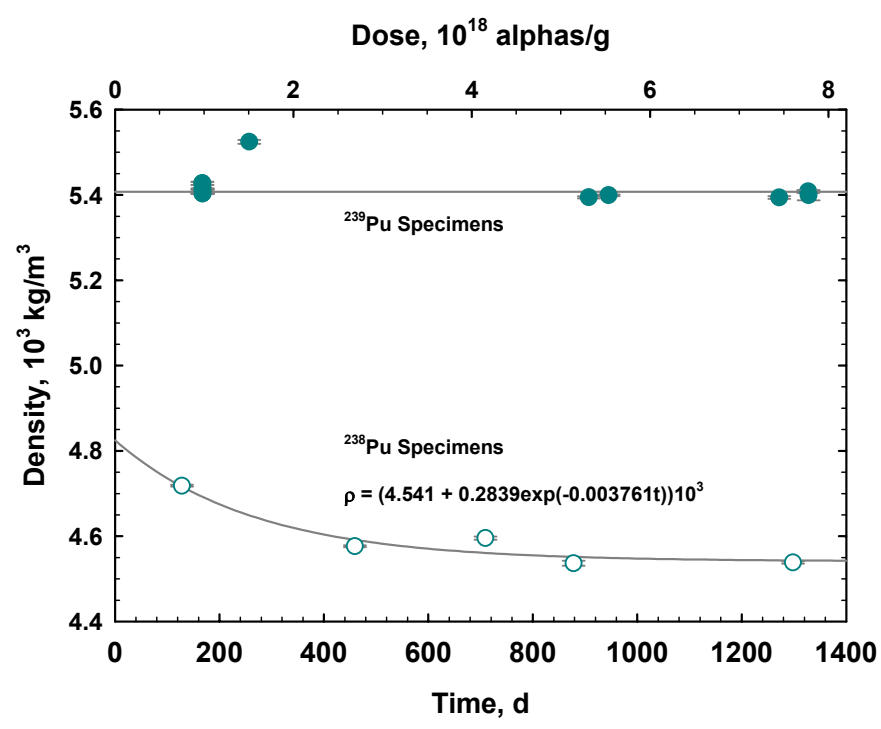

Figure 3.5. Effect of Time and Dose $\left({ }^{238} \mathrm{Pu}\right)$ on the "True" Density of ${ }^{238} \mathrm{Pu}$ - and ${ }^{239} \mathrm{Pu}-\mathrm{Bearing}$ Coarse Pyrochlore Specimens Stored at $20^{\circ} \mathrm{C}$ 


$$
d=d_{0}+a(1-\exp (-b t))
$$

where $d=$ specimen diameter

$d_{0}=$ diameter at zero dose

$a=$ difference between the initial and the asymptotic (saturation) value of $d$

$b=$ a value related to the damage volume per alpha decay (Weber et al. 1986) and the half-life of the active isotope.

From the least-squares fit to Equation 3.2, the measured diameters yielded values for the variables of $d_{0}=9.767(12) \mathrm{mm}$, $a=0.23(2) \cdot 10^{3} \mathrm{~mm}$, and $b=0.0030(7)$. More significant figures are shown for the variables in Figure 3.6 than are warranted by the uncertainties so that the reader can accurately reproduce the curves shown. Using the asymptotic value for the increase in the diameter, we calculate that the diameters swelled by $2.3 \%$ or a volume increase of $7.0 \%$. Thus, the bulk density is calculated to decrease by $6.6 \%$. This agrees well with the change in the density measured with the $\mathrm{He}$ pycnometer of $6.8 \%, 6.1 \%$, and $6.8 \%$ for the specimens stored at $20^{\circ} \mathrm{C}, 125^{\circ} \mathrm{C}$, and $250^{\circ} \mathrm{C}$, respectively (see discussion above).

We also show the change in the diameters of the ${ }^{238} \mathrm{Pu}$ - and ${ }^{239} \mathrm{Pu}$-bearing coarse pyrochlore specimens stored at $20^{\circ} \mathrm{C}$ with time in Figure 3.7. We used the results from the fit of Equation 3.2 to the data shown in Figure 3.6 to show the agreement between the original and coarse pyrochlore specimens. While the fit is good, it is not as good as the results of the least-squares fit of the data to Equation 3.2. Within experimental uncertainty, both values of $d_{0}$ and $a$ are the same while the value of $b$ is greater for the actual fit to the data than the value from the fit to the data in Figure 3.6. It is unlikely that the damage volume per alpha decay is different for the two materials where the only difference is the size of the pyrochlore grains. An increase in the diameter of $2.6 \%$ is noted, indicating an increase in the specimen volume of $8.0 \%$. Thus, the

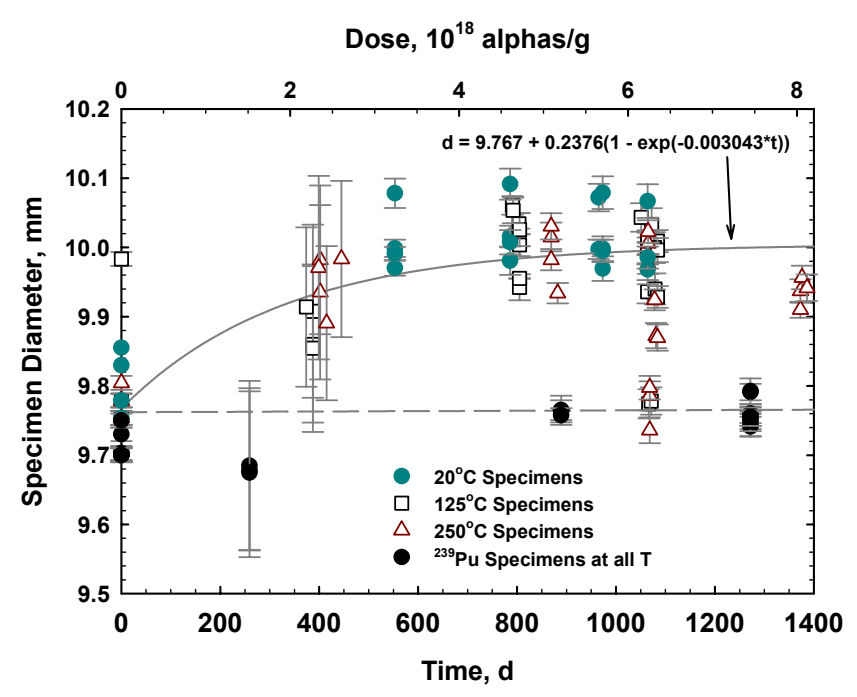

Figure 3.6. Effect of Time and Radiation Dose $\left({ }^{238} \mathrm{Pu}\right)$ on the Diameters of ${ }^{238} \mathrm{Pu}$ - and ${ }^{239} \mathrm{Pu}$-Bearing Specimens Stored at $20^{\circ} \mathrm{C}, 125^{\circ} \mathrm{C}$, and $250^{\circ} \mathrm{C}$

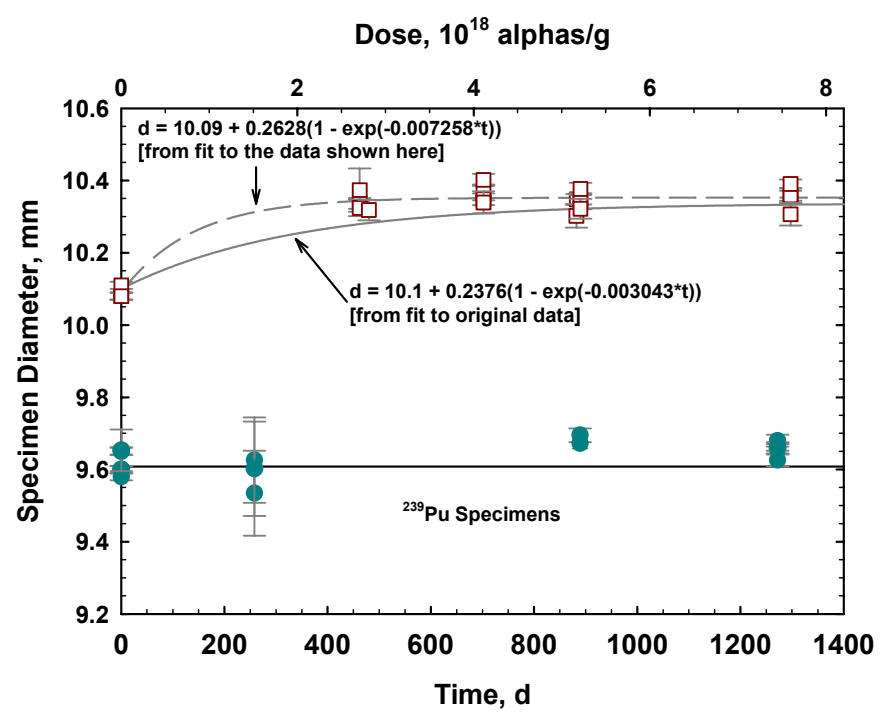

Figure 3.7. Effect of Time and Radiation Dose $\left({ }^{238} \mathrm{Pu}\right)$ on the Diameters of ${ }^{238} \mathrm{Pu}$ - and ${ }^{239} \mathrm{Pu}$-Bearing Coarse Pyrochlore Specimens Stored at $20^{\circ} \mathrm{C}$ 
geometric density decreases by $7.4 \%$ based on the dimension increase. This compares with the decrease in the "true" density (6.8\%) discussed above. Although there is a significant increase in the diameter of the specimens, the height of the specimens also changed about the same amount (data not shown). While the values for the swelling of these materials at saturation are similar to those reported in the literature (Burakov et al. 2002a; Wald and Offerman 1982b; Wald and Weber 1984; Weber et al. 1986) our calculated doses to saturation are larger by about a factor of two or more from those reported by these authors. Depending on the material and on the storage temperature, the dose to reach saturation of the change in diameter or "true" density is $7.3 \cdot 10^{18} \alpha / \mathrm{g}\left(20^{\circ} \mathrm{C}\right.$, diameter data [Figure 3.6]), $3.5 \cdot 10^{18} \mathrm{\alpha} / \mathrm{g}$ to 6.6 $10^{18} \alpha / \mathrm{g}$ (coarse grained at $20^{\circ} \mathrm{C}$, diameter data [Figure 3.7]), $8.9 \cdot 10^{18} \alpha / \mathrm{g}$ ("true" density at $20^{\circ} \mathrm{C}$ [Figure 3.2]), 6.7 $10^{18} \alpha / \mathrm{g}$ ("true" density at $125^{\circ} \mathrm{C}$ [Figure 3.3]), and $6.8 \cdot 10^{18} \alpha / \mathrm{g}$ (estimated from the "true" density at $250^{\circ} \mathrm{C}$ [Figure 3.4]). These data suggest marginal temperature dependence. Certainly, there is no evidence for temperature dependence in our dimensional data. The difference in dose between what is reported here and in the literature could be because we determined the saturation dose (leastsquares fit) differently than they did (measurement). It is also possible that composition played a role.

Resintering the ${ }^{238} \mathrm{Pu}$-bearing pyrochlore specimens did not return them to their original diameters (Figure 3.8). This implies an increase in the porosity of about 5\%. Over approximately 260 days, radiation induced swelling resulted in approximately $1 \%$ increase in the diameter or a decrease in density of about $3 \%$. This compares with an approximately $6 \%$ decrease in the "true" density (Figure 3.2 ) over the same time period. These results again suggest a closing of open porosity that results in a more rapid decrease in the "true" density when compared with the bulk density. The slope of the diameter change for the resintered specimens appears to match the initial slope of the original specimens (Figure 3.8).

\subsubsection{Scanning Electron Microscopy}

The SEM images of a sample from an original (fully damaged) ${ }^{238} \mathrm{Pu}$-bearing pyrochlore specimen stored at $20^{\circ} \mathrm{C}$ revealed two major phases but also a series of other minor phases within the ceramic. In the back-scattered images of the phases shown in Figure 3.9, the phase that appears dark is rutile, and the $\mathrm{Pu}-$ and U-bearing pyrochlore phase appears light. A spherical precipitate that appeared to contain a heavy element(s) was occasionally observed (Figure 3.10) within the rutile. Unfortunately, the analysis of these types of small precipitates was not possible because the beam penetration extends to too great a depth.

Hafnium that was present in the rutile component of the ceramic appeared to be at a relative level of about 5 to $10 \%$; however, based on the contrast variations within rutile grains, it is clear that there are either

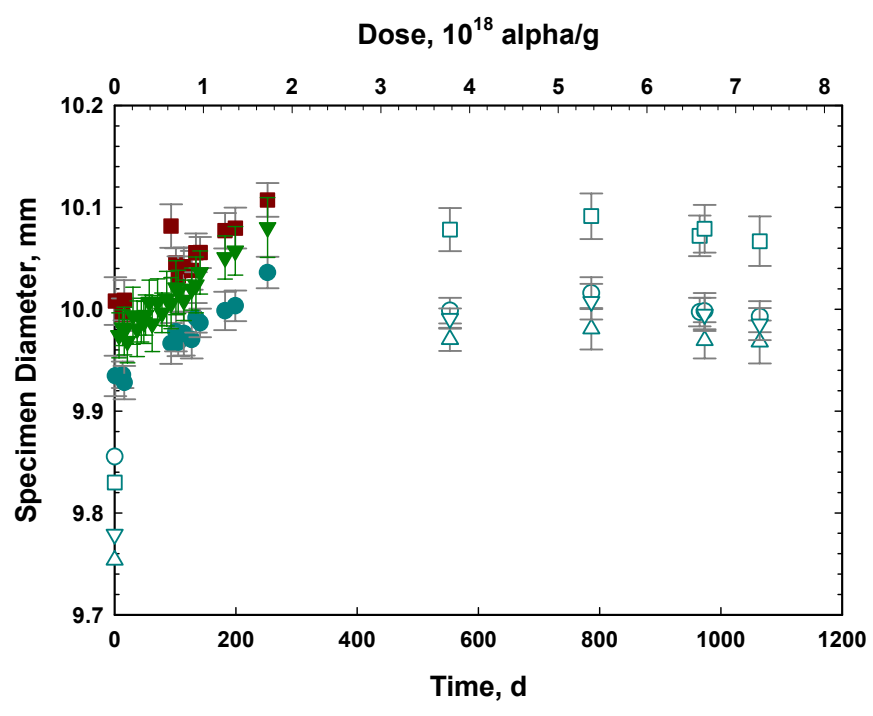

Figure 3.8. Effect of Time and Radiation Dose $\left({ }^{238} \mathrm{Pu}\right)$ on the Diameter of the ${ }^{238} \mathrm{Pu}$-Bearing Original (Open Symbols) and Resintered (Closed Symbols) Pyrochlore Specimens (Each Symbol Type Represents a Different Specimen) 

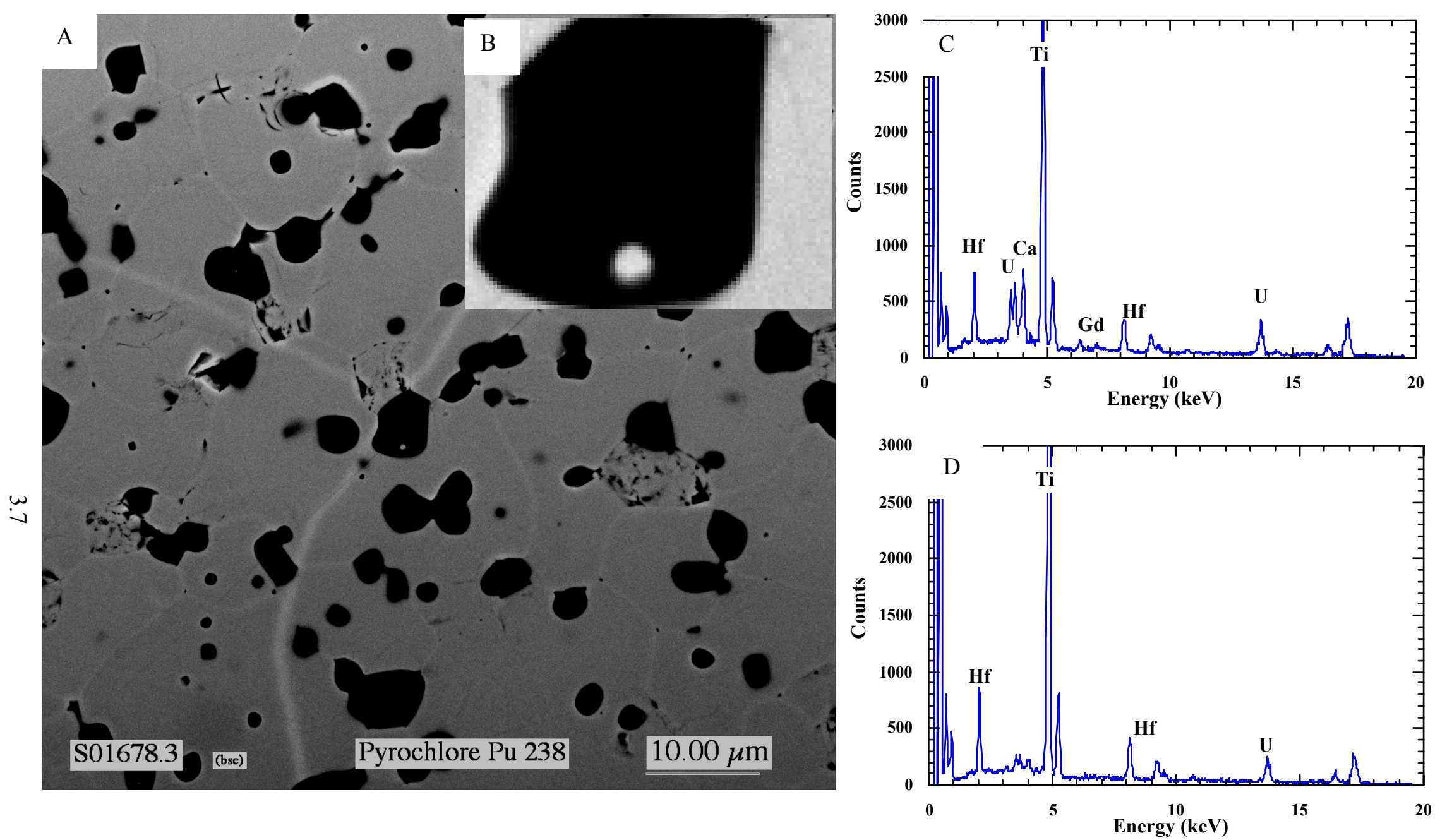

Figure 3.9. (A) Backscattered Electron (BSE) Image of Grain Structure from the ${ }^{238} \mathrm{Pu}$-Bearing Pyrochlore Ceramic (Stored at $20^{\circ} \mathrm{C}$; Fully Damaged). The insert (B) shows a Hf-bearing rutile particle with an actinide-rich inclusion as evidenced from the EDS analyses of these particles (C and D). 

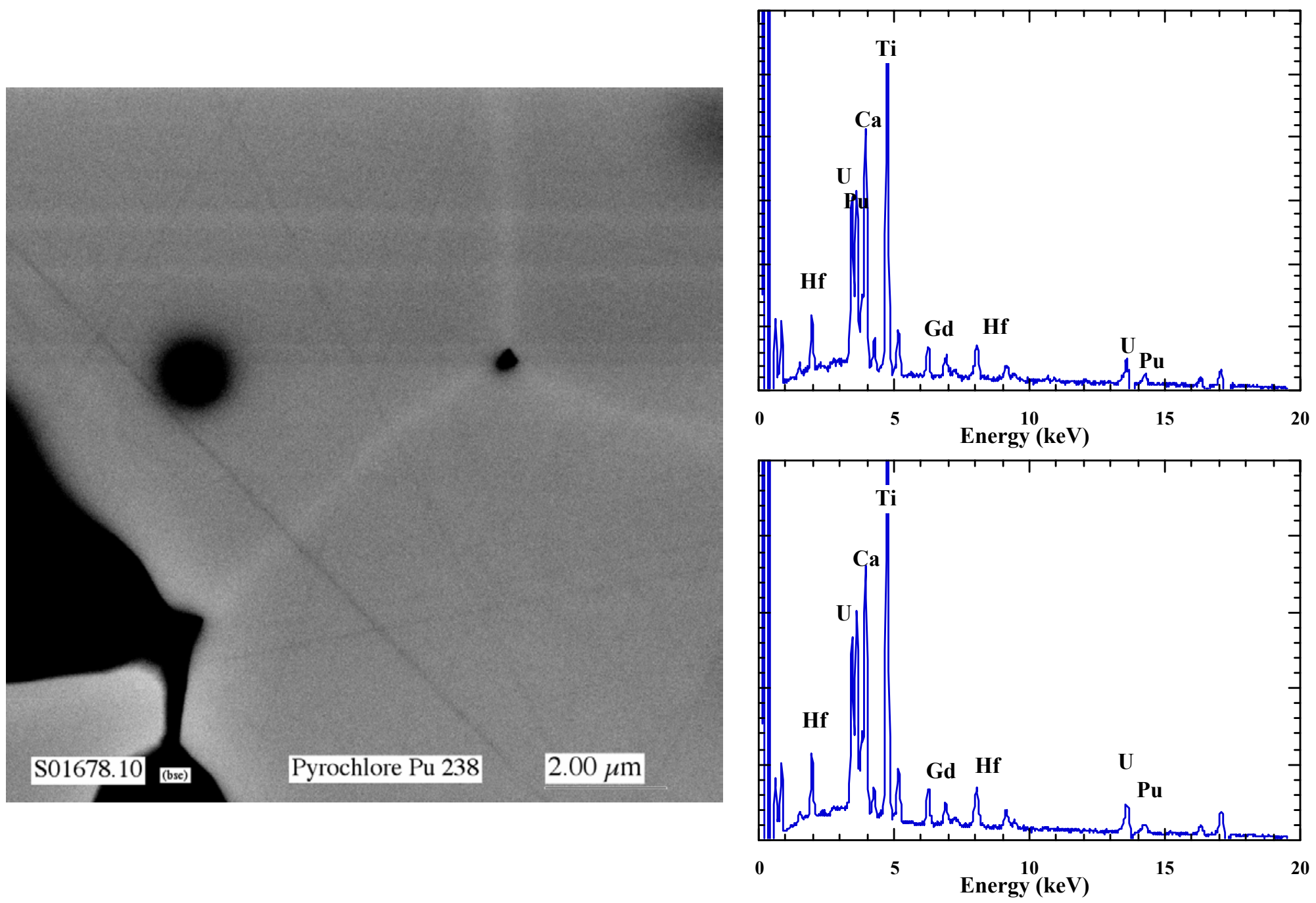

Figure 3.10. SEM Analysis of High Z Regions Within the ${ }^{238} \mathrm{Pu}$-Bearing Pyrochlore Ceramic (Stored at $20^{\circ} \mathrm{C}$; Fully Damaged). (A) The backscattered electron (BSE) Image indicated the presence of a higher average $\mathrm{Z}$ intergrowth with the pyrochlore. It was not possible to distinguish with $\mathrm{X}$-ray energy dispersive spectroscopy (EDS) analysis the reasons for this contrast variation; however, a slight oxygen deficiency and/or local densification of the phase could have produced the lightening effect. This effect was also observed delineating many of the pyrochlore grain boundaries. 
compositional variations within the rutile grains or overlying pyrochlore material. Although less likely in a single grain, electron channeling could also explain the variation. With the current analysis and techniques, it is not possible to distinguish between the two possibilities.

Images of the pyrochlore regions reveal subtle contrast changes across the ceramic. These features were not visible in the secondary imaging mode and are therefore most likely a result of electron channeling. The features were on too fine a scale to obtain accurate compositional data; however, the lighter regions appeared to be slightly enriched in $\mathrm{Pu}$. It was not possible to distinguish with $\mathrm{X}$-ray energy dispersive spectroscopy (EDS) analysis the reasons for this contrast variation; however, a slight oxygen deficiency and/or local densification of the phase could have produced the lightening effect. This effect was also observed delineating many of the pyrochlore grain boundaries. From the XRD results (see the next section), there is evidence that phase segregation occurred at a fine scale and that the phases have different compositions.

By maximizing contrast for the pyrochlore phase, the grain boundaries can be seen (Figure 3.10). The grain boundaries were marked by higher average atomic mass contrast. Again, the compositional variations were not apparent from the EDS. These variations could be from actual compositional variations in either an increase in the heavy elements $(\mathrm{Pu}$ and $\mathrm{U})$ or a decrease in the lighter elements $(\mathrm{Ca}$ and $\mathrm{O}$ ) or electron channeling. We could not distinguish between the possibilities.

\subsubsection{X-Ray Diffraction}

The results from the XRD studies are discussed in this section. As with the other measurements, there are results from the original and resintered specimens. The results from the original specimens stored at $20^{\circ} \mathrm{C}$ are shown in Figure 3.11. The diffraction patterns are not to scale; they have been scaled for display purposes. These results indicate that by the time the first measurement was made, a large amount of radiation induced phase transformation had taken place. Although the diffraction peaks are labeled "P" for pyrochlore $(\mathrm{Fd} 3 \mathrm{~m})$, many of the diffraction peaks that define pyrochlore symmetry were at low enough intensity that refinement of the parameters with the Riqas program (MDI, Livermore, CA) proved difficult at best. Somewhere between fully crystalline and completely amorphous, the diffraction peaks begin to represent diffuse scattering rather than true Bragg diffraction (Howard and Sabine 1974). However, we continued to analyze the diffraction patterns as if the diffraction represented the crystalline material that was present in the specimen. The diffraction patterns can be indexed a fluorite structure $(\mathrm{Fm} 3 \mathrm{~m})$ with half the unit cell size as the corresponding pyrochlore cell. Indexed as a fluorite, the unit cell is calculated to be $1.0238(4) \mathrm{nm}[2 \times 0.5119(2) \mathrm{nm}]$; indexed as a pyrochlore structure, the unit cell dimension is 1.015 to $1.021 \mathrm{~nm}$, depending on the amount of dose.

A compilation of the XRD patterns from the resintered specimens is shown in Figure 3.12 for the specimens that had been stored at ambient conditions before and after resintering. In Figure 3.12, the shift to larger unit cell sizes (smaller diffraction angle) and decrease in peak intensity can be seen. The intensity of the diffraction peaks drops rapidly over the 316 days that the data were collected. The weak diffraction peaks from the pyrochlore phase are the first to disappear, but this appears to be because we performed the scan too rapidly; had we scanned more slowly to obtain a better discrimination between signal and background, the weak peaks might have been detectable to much higher doses. As the pyrochlore becomes amorphous, it becomes more difficult to index the phase as a pyrochlore, although a characteristic (311) diffraction peak is still visible at the end of the experiment. The variation in the $\mathrm{a}_{0}$ 
lattice parameter for the pyrochlore phase is shown in Figure 3.13. For the data obtained after 140 days, the diffraction patterns were fit to the pyrochlore and fluorite cells. The fluorite cell parameter was doubled and plotted along with the cell parameters determined for the pyrochlore cell in Figure 3.13.

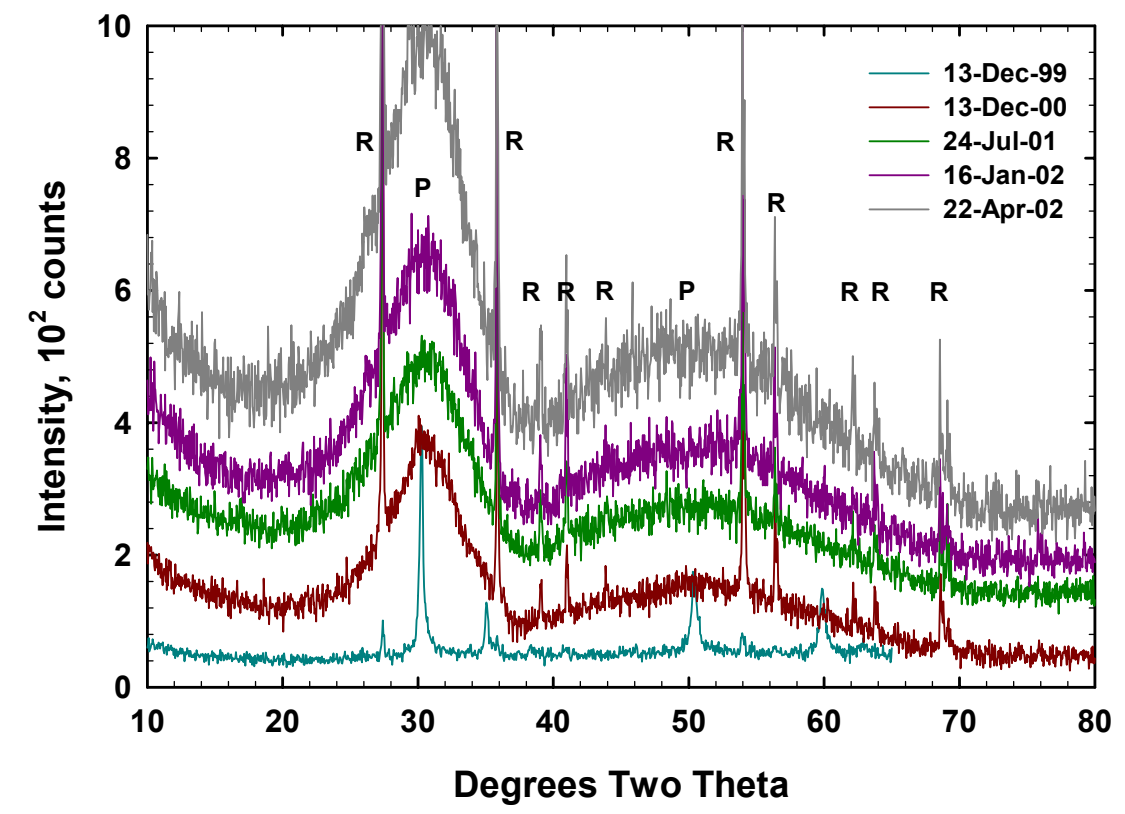

Figure 3.11. Results from the XRD Analyses of the Original ${ }^{238} \mathrm{Pu}$-Bearing Pyrochlore Specimens ( $\mathrm{P}=$ Pyrochlore; $\mathrm{R}=$ Rutile; the patterns are in reverse order of the legend)

The data were fit to the equation

$$
a=a_{0}+b(1-\exp (-c t))
$$

where $a=$ pyrochlore lattice parameter

$a_{0}=$ lattice parameter at zero dose

$\mathrm{b}=$ difference between the initial and the asymptotic value of $a$

$\mathrm{c}=$ a value related to the average damage volume per alpha decay per unit cell

(Weber et al. 1986).

The results of the least-squares fit to the data are a value of $a_{0}$ of $1.015 \pm 2.8 \cdot 10^{-4} \mathrm{~nm}$ and an asymptotic value of $1.027 \pm 9 \cdot 10^{-4} \mathrm{~nm}$ at approximately 390 to 440 days (a dose of $2.3 \cdot 10^{18}$ to $2.6 \cdot 10^{18} \mathrm{\alpha} / \mathrm{g}$ ). Based on the asymptotic value, the lattice parameter swells by $1.2 \%$ or the cell volume by $3.6 \%$. These results are consistent with the macroscopic swelling discussed above.

Based on the linear portion of the data in Figure 3.13, the rate of change of the lattice parameter is consistent with the rate of change in the diameter of the specimens, $4.03 \cdot 10^{-4} \mathrm{~mm} / \mathrm{d}$ obtained from the linear portion of the data shown in Figure 3.7. If one assumes a dense packing of unit cells that are perfectly aligned, there are $9.8 \cdot 10^{6}$ cells in a 10 -mm-diameter specimen; each cell has a dimension of $1.02 \mathrm{~nm}$. From the linear portion of the data in Figure 3.13, we calculate a rate of change for the unit cell of $4.8 \cdot 10^{-5} \mathrm{~nm} / \mathrm{d}$. Combining these data, we calculate a macroscopic rate of change in the diameter of a 
$10 \mathrm{~mm}$ specimen of $4.7 \cdot 10^{-4} \mathrm{~mm} / \mathrm{d}$. This is very good agreement, considering that the unit cells are not stacked perfectly, and the specimen has approximately $12 \%$ total porosity based on the theoretical density.

While the relative intensity of the rutile peaks increases because rutile is the only remaining crystalline phase, there is a small shift to larger unit cell sizes (Figure 3.14). Since there is no Pu in the rutile phase (Ebbinghaus et al. 1999), the small swelling probably comes from the alpha-particle damage and the small amount of recoil damage from the surrounding pyrochlore phase.

Specimens were also stored at $125^{\circ} \mathrm{C}$ and $250^{\circ} \mathrm{C}$ since being made. Although we do not discuss in detail the results from the specimens stored at $125^{\circ} \mathrm{C}$, there were minor differences between the results from these specimens and the results from the specimens stored at ambient conditions. Where appropriate, we will highlight the results. None of the specimens stored at $125^{\circ} \mathrm{C}$ was resintered.

As with the specimens stored at ambient temperatures, the specimens stored at $250^{\circ} \mathrm{C}$ rapidly became amorphous (Figure 3.15); also indicating that the critical temperature is higher than $250^{\circ} \mathrm{C}$. Although these specimens began as a mixture of pyrochlore and rutile, there was evidence for the ingrowth of a zirconolite phase (Figure 3.15). By the time the specimens were examined after approximately one year of damage accumulation, the XRD pattern showed them to be heavily damaged (Figure 3.15). In the specimen examined on 25-July-2000, we saw evidence for the presence of zirconolite that we did not see in the specimens stored at $20^{\circ} \mathrm{C}$ and $125^{\circ} \mathrm{C}$. The peaks labeled in Figure 3.15 appear to be from zirconolite - the split peak at $35^{\circ} 2 \theta$ and the high $2 \theta$ tails on the peaks at $50^{\circ}$ and $60^{\circ} 2 \theta$. These peaks disappeared by the next examination. Selected specimens that had been stored at $250^{\circ} \mathrm{C}$ for nearly two

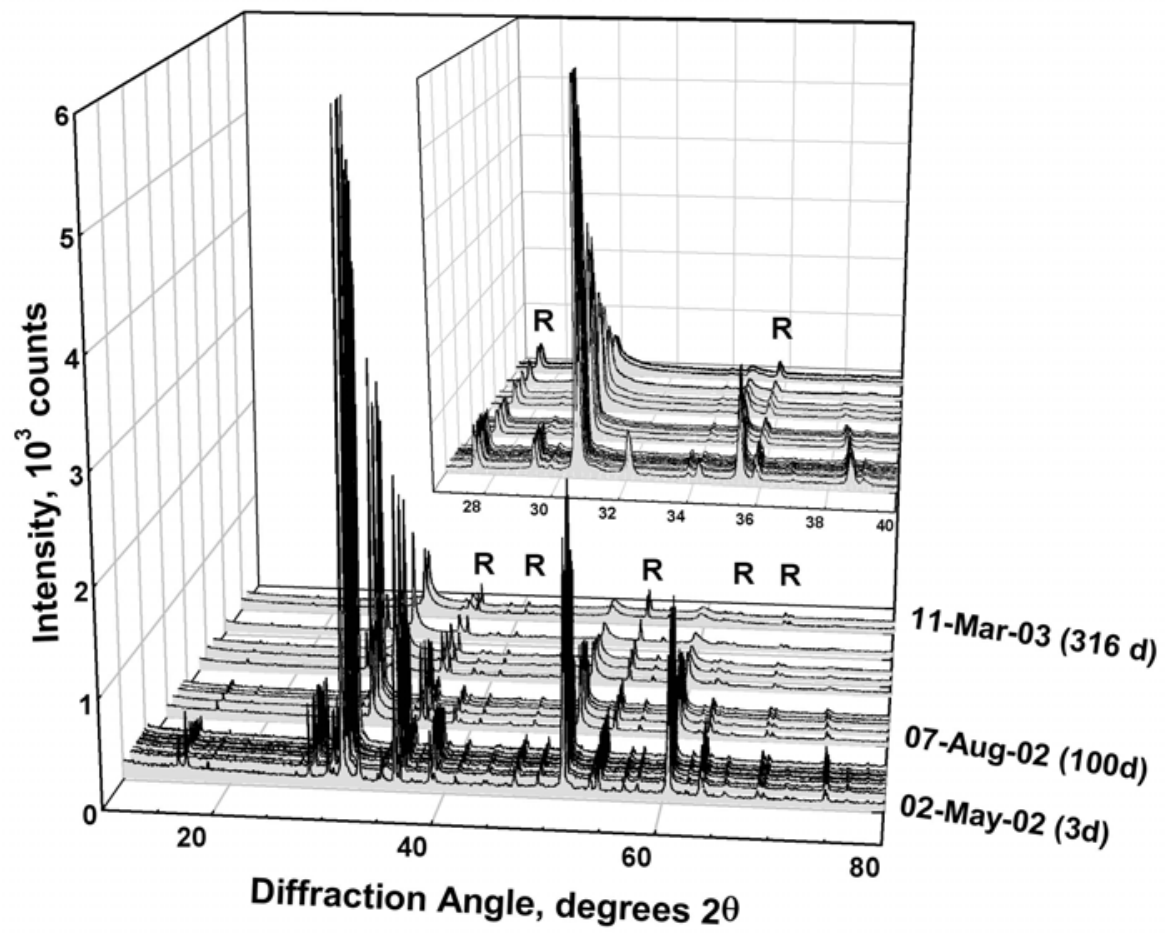

Figure 3.12. Effect of Radiation Dose on the XRD Pattern from the Resintered ${ }^{238} \mathrm{Pu}$-Bearing Pyrochlore Specimen $(\mathrm{R}=$ Rutile) 
years were resintered for 2 hours at $1350^{\circ} \mathrm{C}$. Surprisingly, this treatment yielded a phase assemblage of pyrochlore, minor rutile, and what appear to be two zirconolites, each with different lattice parameters (Figure 3.16). The two phases could be indexed as zirconolites, although there appeared to be substantial preferred orientation. Since the specimens stored at $250^{\circ} \mathrm{C}$ from the start showed evidence for ingrowth of zirconolite (Figure 3.15), it is possible that the sintering process was insufficient to return the phase assemblage to pyrochlore and rutile, but sufficient to develop the phases that formed during storage at $250^{\circ} \mathrm{C}$ with the accumulated radiation damage. Besides the possible zirconolite peaks at $31^{\circ}$ and $35^{\circ} 2 \theta$, the peaks at $50^{\circ}$ and $60^{\circ} 2 \theta$ are atypically broad and asymmetric to be only pyrochlore peaks. In the zirconolite diffraction pattern, there are groups of moderate to moderately intense peaks that occur at these diffraction angles. Therefore, the evidence is strong for the presence of zirconolite in this specimen. After these data were collected, we sintered one of these specimens at $1390^{\circ} \mathrm{C}$ for 8 hours under flowing Ar. The resulting material gave an XRD that was consistent with pyrochlore, rutile, and a single zirconolite with preferred orientation (Figure 3.17). An additional 24 hours of sintering at $1350^{\circ} \mathrm{C}$ resulted in a refinement of the crystalline phases, but preferred orientation remained for the zirconolite phase. These results suggest a change in the chemical makeup of the specimens, perhaps changes the oxidation state of the $\mathrm{Pu}, \mathrm{Ti}$, and $\mathrm{U}$. These oxidation states could be stabilized once in the zirconolite structure.

To more clearly illustrate the changes in the zirconolite and pyrochlore phases with increasing radiation induced damage, three XRD patterns from Figure 3.16 are shown expanded in Figure 3.18. In this graph, the rutile diffraction peaks are labeled. With increasing accumulated damage (time), the unit cells for the pyrochlore and zirconolite phases expand, and the diffraction peaks move to lower diffraction angles. The main peaks for pyrochlore $(h k l=(222))$ and zirconolite (221) overlap at about $30^{\circ} 2 \theta$. The telltale peak for pyrochlore in these diffraction patterns is the peak at about

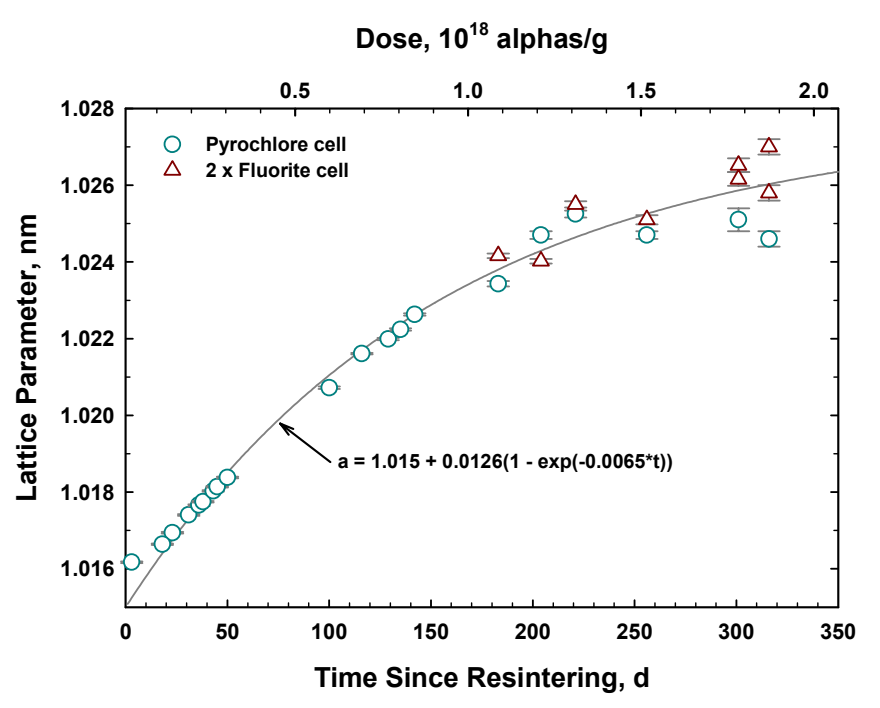

Figure 3.13. The Effect of Time and Radiation Dose on the $\mathrm{a}_{0}$ Lattice Parameter for the Pyrochlore Phase in the Resintered ${ }^{238} \mathrm{Pu}$-bearing Specimen Stored at $20^{\circ} \mathrm{C}$

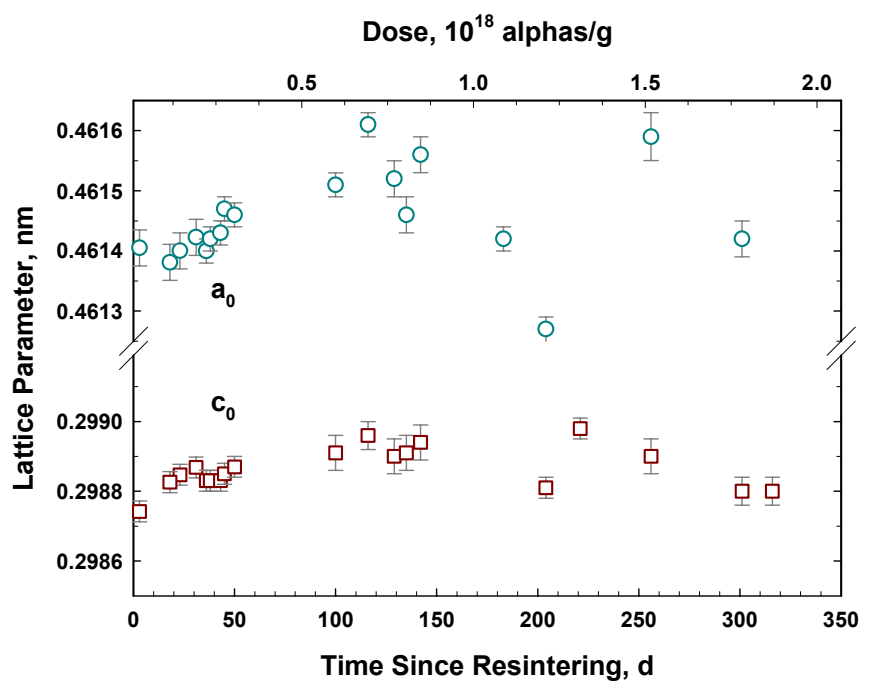

Figure 3.14. The Effect of Time and Radiation Dose on the $\mathrm{a}_{0}$ and $\mathrm{c}_{0}$ Lattice Parameters for the Rutile Phase in the Resintered ${ }^{238} \mathrm{Pu}$-bearing Specimen 
$29^{\circ} 2 \theta$ (311). This peak diminishes with time, but is still detectable at the end of the experiments. The ratio of the intensities, however, remains approximately the same until the (311) disappears into the background. Because this peak is so small, it was not possible throughout the duration of the experiments to index the pattern on the pyrochlore lattice, but at long time, the pattern could be indexed on the fluorite lattice. Doubling the lattice parameter determined for the fluorite lattice yielded the value for the pyrochlore lattice parameter. The change in the lattice parameter for the cubic cell is shown in Figure 3.19. Equation 3.3 was fit to the data. The values reported in the figure are again reported to more significant figures than are warranted to provide the reader with the ability to reproduce the curves. For this fit, the values are $a_{0}=1.016\left(5 \cdot 10^{-4}\right) \mathrm{nm}, b=0.016(1) \mathrm{nm}$, and $c=0.0071(14)$. The $c$ parameter probably relates to the damage per unit cell.

Changes in the zirconolite structures are evident from the patterns shown in Figure 3.16 and Figure 3.18. The two diffraction peaks in the range of $31^{\circ}$ to $32^{\circ} 2 \theta$ are assigned to the (004) reflection from the zirconolite phase. Both Wald and Offerman (1982b) and Strachan et al. (2002) have shown that the expansion of the unit cell in zirconolite is predominantly along the c-axis. Therefore, this diffraction peak shifts to lower values of $2 \theta$ more rapidly than the surrounding peaks. It is also apparent that the two zirconolites have different ${ }^{238} \mathrm{Pu}$ contents because the intensity of the peak at the lower $2 \theta$ decreases much more rapidly than the intensity of the peak at the higher $2 \theta$ (Figure 3.18).

Buck, Chamberlain, and Gieré (1999) found that zirconolite tends to exsolve from pyrochlore as lamellae. It is uncertain if these lamellae form in the materials in the work reported here. Putnam et al. (1999a) and Helean et al. (2002) report that $\mathrm{CaCeTi}_{2} \mathrm{O}_{7}$ is metastable with respect to $\mathrm{CaTiO}_{3}$ (perovskite), $\mathrm{CeO}_{2}$, and $\mathrm{TiO}_{2}$. The composition of the pyrochlore used in the work reported here is more complex, and evidence of low temperature instability was not seen. However, some radiation induced instability was noted for the pyrochlore specimens stored at $250^{\circ} \mathrm{C}$. The nature of this instability was not investigated further in the current work. A complete explanation of the formation of zirconolite in the specimens that were resintered after having been originally stored at $250^{\circ} \mathrm{C}$ would require additional investigation.

The results from the specimen stored at $250^{\circ} \mathrm{C}$ illustrate another problem with data interpretation. The alpha dose shown as the second $\mathrm{x}$-axis at the top of these graphs should be taken as an average for the entire solid. Because we do not have compositional information for each phase, we are unable to state what the alpha dose is to each phase. It is unfortunate that attempts to obtain compositional information on each phase have failed because the direct and induced X-rays generated from the radioactivity result in a high background in the SEM. Very small samples would have been needed, and a TEM was unavailable in which these highly

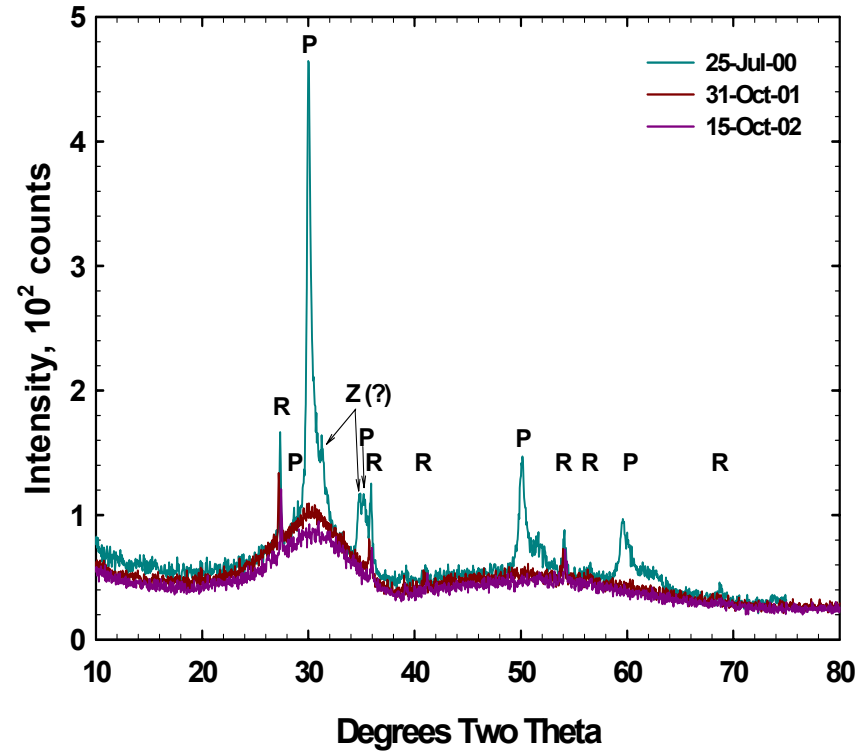

Figure 3.15. Results from the XRD Analyses of the ${ }^{238} \mathrm{Pu}$-Bearing Pyrochlore Specimen Stored at $250^{\circ} \mathrm{C}$ Since Being Made 
radioactive, alpha-bearing samples could have been examined.

Since the phase assemblage changed when the specimens that had been stored at $250^{\circ} \mathrm{C}$ were resintered, selected specimens were also stored at ambient conditions after resintering so that the data could be compared. The family of XRD patterns for one of these specimens looks similar to that shown in Figure 3.16 from the specimens that were stored at $250^{\circ} \mathrm{C}$ after resintering, so the data are not presented here. However, the details of the changes to the pyrochlore unit cell are different and are shown in Figure 3.20. These results indicate that the effects of radiation induced damage saturate at about $2 \cdot 10^{18}$ alphas/g based on the least-squares fit of Equation 3.3 to the data. This fit results in the values for $a_{0}=1.015\left(4 \cdot 10^{-4}\right), b=0.010(5) \mathrm{nm}$, and $c=0.0096(16)$. These specimens become amorphous more rapidly than the specimens stored at $250^{\circ} \mathrm{C}$. This is expected for the specimens of the same sample stored at $250^{\circ} \mathrm{C}$ after resintering because of the higher storage temperature after resintering. The rate may be higher than the rate for the specimens originally stored at $20^{\circ} \mathrm{C}$ and stored at $20^{\circ} \mathrm{C}$ after resintering because the ${ }^{238} \mathrm{Pu}$ content is higher in the pyrochlore phase relative to the zirconolite phases and relative to the "phase-pure" pyrochlore specimen discussed above (Figure 3.13). It may also be the result of a composition change that occurred with the phase separation between the pyrochlore and zirconolites. Interestingly, the value for $\mathrm{a}_{0}$ for all three pyrochlore phases immediately after sintering is the same, $1.015 \mathrm{~nm}$ (Figure 3.13), $1.016 \mathrm{~nm}$ (Figure 3.19), and $1.015 \mathrm{~nm}$ (Figure 3.20).

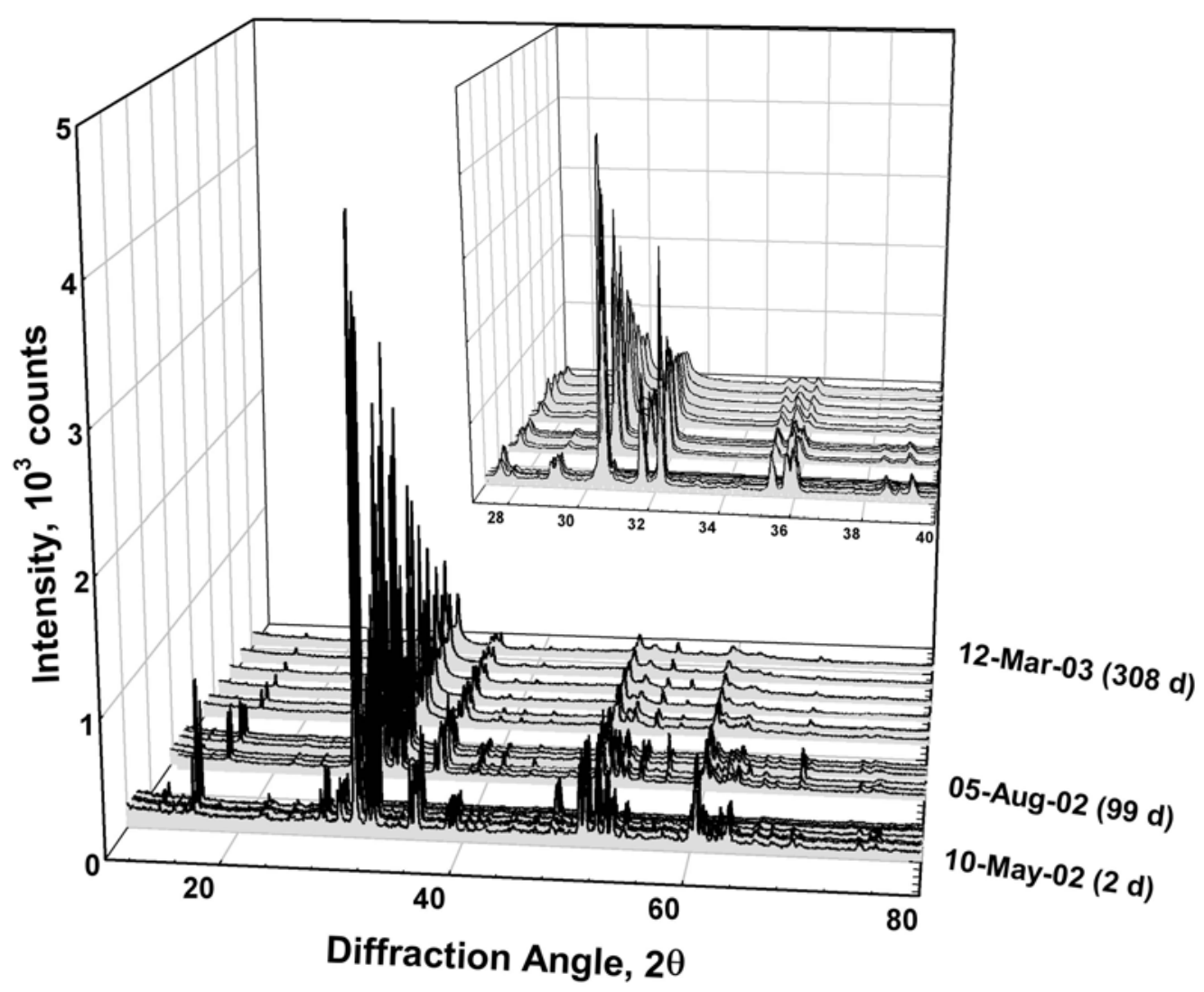

Figure 3.16. The Effect of Time (Dose) on the XRD Pattern from a ${ }^{238} \mathrm{Pu}$-Bearing Pyrochlore Specimen Originally Stored at $250^{\circ} \mathrm{C}$ and Stored at $250^{\circ} \mathrm{C}$ Since Resintering 
Average interatomic distances can be extracted from the XRD patterns from the original specimens. The maxima at about $30^{\circ}$ and $50^{\circ} 2 \theta$ result from the metal-metal and metal-oxygen distances, respectively. The Jade program (MDI, Livermore, CA) was used to fit these broad peaks and obtain the position of five pyrochlore amorphous maxima (four pyrochlore and one coarse pyrochlore). The average value for the metal-metal distance is $0.291(5) \mathrm{nm}$ and the metal-oxygen distance is $0.175(5) \mathrm{nm}$. These distances are similar to those found in natural pyrochlore by Lumpkin et al (2001b) with the TEM, but shorter than those reported in the $\mathrm{Gd}_{2}\left(\mathrm{Ti}_{1-}\right.$ $\left.{ }_{\mathrm{y}} \mathrm{Zr}_{\mathrm{y}}\right)_{2} \mathrm{O}_{7}$ system by Hess et al (2002), who used $\mathrm{X}$-ray absorption spectroscopy.

We used the Rietveld program Riqas to obtain all the lattice parameters for the phases discussed in this section. Of note was the need to substitute $\mathrm{Hf}$ for $\mathrm{Ti}$ in the pyrochlore structure. Without as much as $15 \%$ substitution, the residuals in the Rietveld fit to the pattern were high. Although this is outside the scope of the work presented here, mainly because we have insufficient data to support a firm conclusion, it is interesting to note that Rietveld results suggest that Hf substituted on the Ti sites in the pyrochlore lattice. As indicated above in the discussion of the chemical composition, placing $\mathrm{Hf}$ on the pyrochlore B site allows for better electrical balance without having to suggest significant non-stoichiometry. Hafnium substitution for Ti in rutile was already noted by Ebbinghaus and Krikorian (2001), but no indication was made that $\mathrm{Hf}$ substituted for Ti in pyrochlore or zirconolite. Substitution of $\mathrm{Hf}$ for $\mathrm{Ti}$ in pyrochlore may be the same as the substitution of $\mathrm{Zr}$ for $\mathrm{Ti}$ in pyrochlore (Hess et al. 2002) and (Wang et al. 1999a), which yields a material that is very resistant to radiation induced amorphization (Wang et al. 1999a).

\subsubsection{Dissolution Rate}

Figure 3.21 illustrates the release rate of Gd from the ${ }^{238} \mathrm{Pu}$-bearing pyrochlore specimen (as mentioned previously, all ${ }^{238} \mathrm{Pu}$-bearing specimens were tested in the SPFT apparatus constructed of Ti). After approximately 5 days, the release of Gd becomes constant with respect

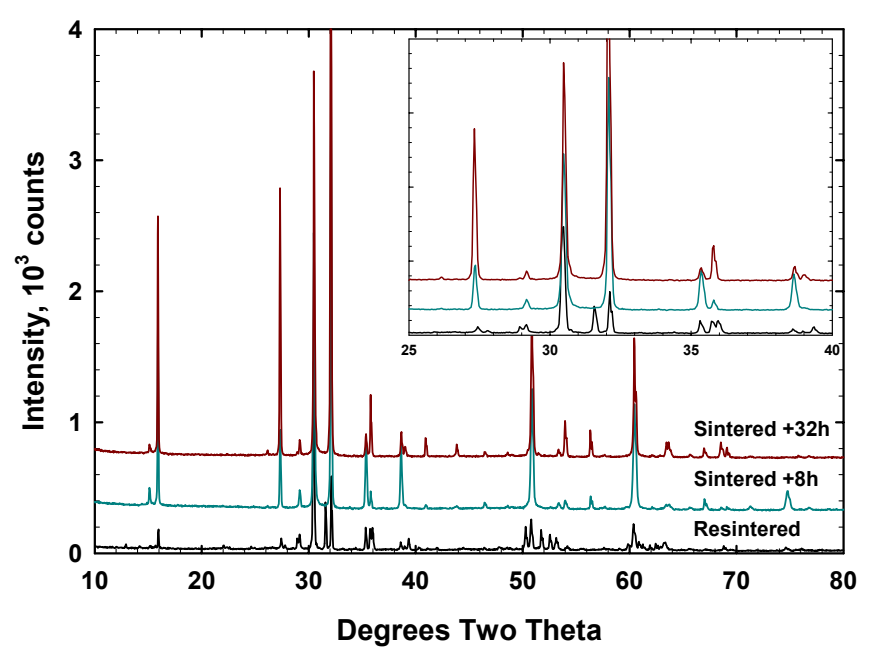

Figure 3.17. Results from XRD Analyses of ${ }^{238} \mathrm{Pu}$ Bearing Pyrochlore Ceramic that Had Been Stored at $250^{\circ} \mathrm{C}$ and, After Accumulating Damage, Was Sintered Again for 8 Hours Plus an Additional 24 Hours

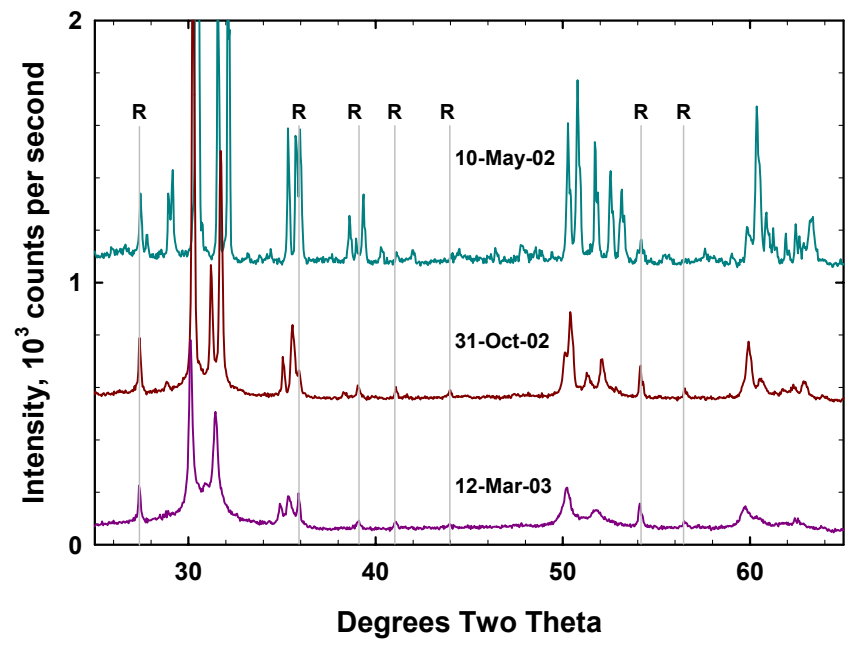

Figure 3.18. Selected XRD Patterns Showing the Effects of Radiation Damage on the Pyrochlore and Two Zirconolite Phases in the ${ }^{238} \mathrm{Pu}$-Bearing Specimen Originally Stored at $250^{\circ} \mathrm{C}$ and Stored at $250^{\circ} \mathrm{C}$ Since Resintering 
to time. At pH 2, Gd behaves as an indicator of the matrix dissolution, and these results yield a steadystate dissolution rate of $2.7(6) \cdot 10^{-4} \mathrm{~g} /\left(\mathrm{m}^{2} \cdot \mathrm{d}\right)$. Figure 3.22 displays the concentrations of ${ }^{238} \mathrm{Pu}$ and $\mathrm{U}$ over the duration of the experiment. While the release of ${ }^{238} \mathrm{Pu}$ reaches steady-state, the $\mathrm{U}$ concentrations do not. A reasonable dissolution rate can be extracted from the average concentration of ${ }^{238} \mathrm{Pu}$ from day 7 to 10 and is $8.2(6) \cdot 10^{-5} \mathrm{~g} /\left(\mathrm{m}^{2} \cdot \mathrm{d}\right)$. The release of $U$ appears to decrease linearly, although there is a lot of noise in the data. A rate of $8.9 \cdot 10^{-4}(20) \mathrm{g} /\left(\mathrm{m}^{2} \cdot \mathrm{d}\right)$ can be estimated from the last three data points. In summary, the release of $\mathrm{Gd}$ to solution best represents the dissolution rate of the pyrochlore specimen with the release of $\mathrm{Pu}$ a factor of 3 lower. Therefore, even at $\mathrm{pH}$ 2 and $85^{\circ} \mathrm{C}$, the release of $\mathrm{Pu}$ is very low.

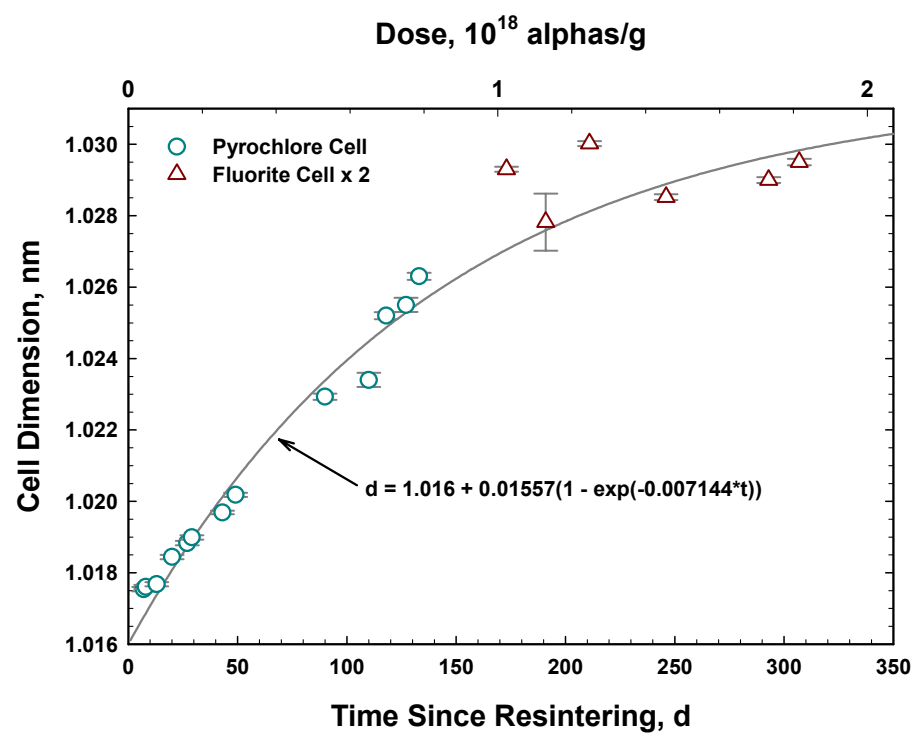

Figure 3.19. The Effect of Radiation Damage on the $a_{0}$ Lattice Parameter for the Pyrochlore Phase in the ${ }^{238} \mathrm{Pu}$ Bearing Specimen Originally Stored at $250^{\circ} \mathrm{C}$ and Stored at $250^{\circ} \mathrm{C}$ Since Resintering

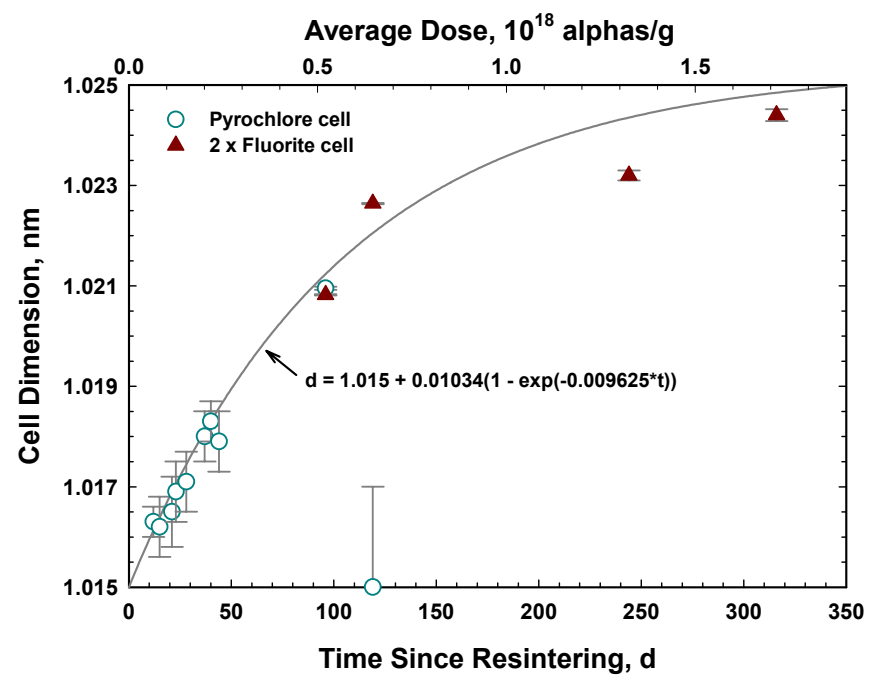

Figure 3.20. The Effect of Radiation Damage on the $\mathrm{a}_{0}$ Lattice Parameter for the Pyrochlore Phase in the ${ }^{238} \mathrm{Pu}-$ Bearing Specimen that Was Originally Stored at $250^{\circ} \mathrm{C}$ and Stored at Ambient Conditions Since Resintering 


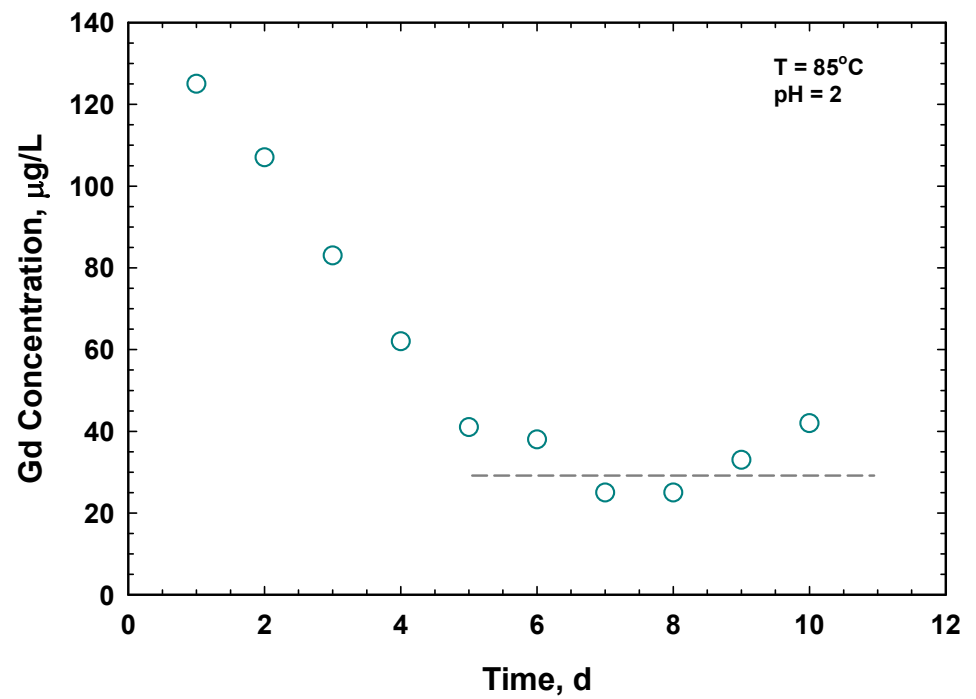

Figure 3.21. Plot of Gd Concentration $(\mu \mathrm{g} / \mathrm{L})$ Versus Time for the ${ }^{238} \mathrm{Pu}$-Bearing Pyrochlore Tested with the Titanium Reactor System 

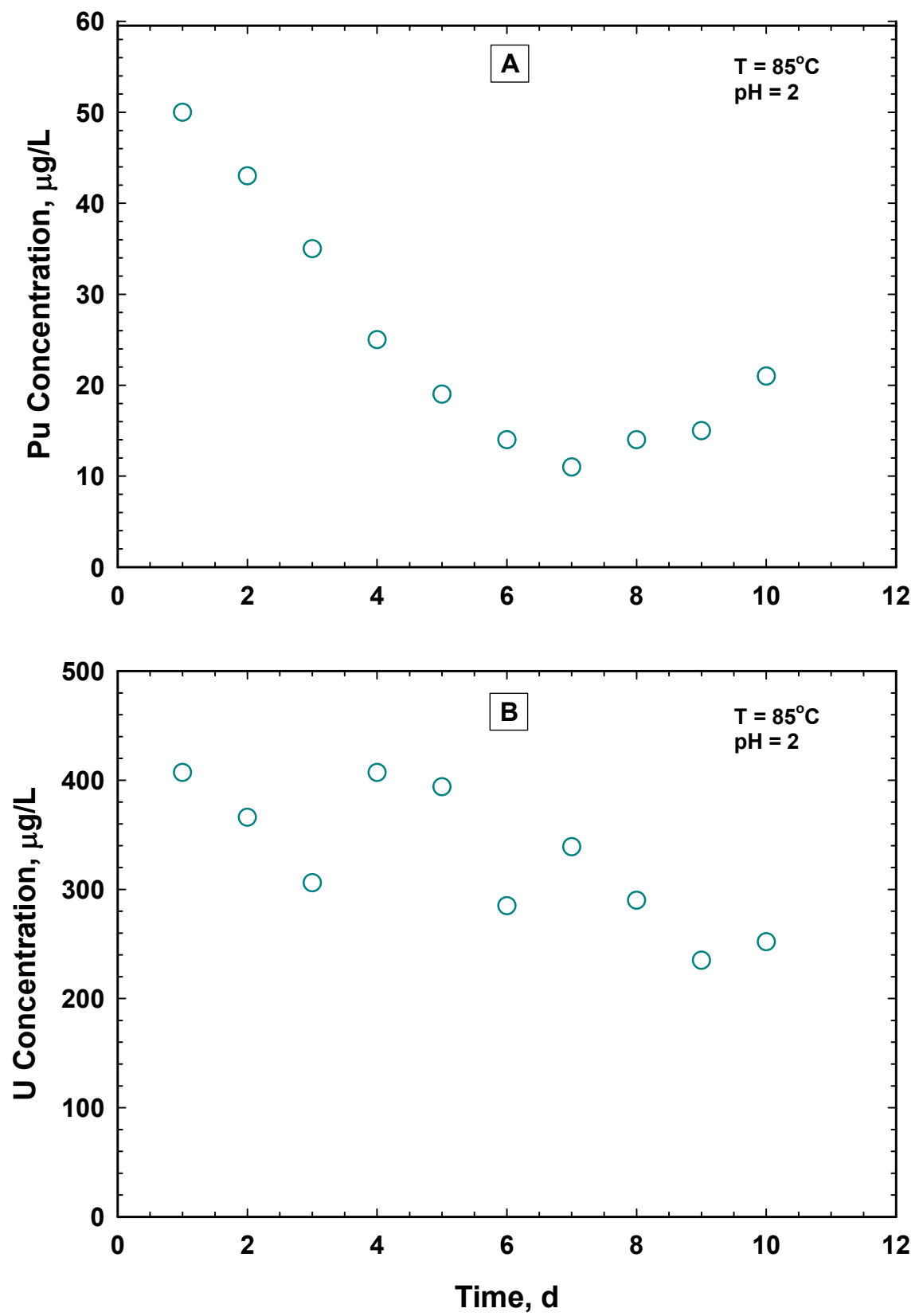

Figure 3.22. Plot of Element Release Rates from the ${ }^{238} \mathrm{Pu}$-Bearing Pyrochlore Tested in the Titanium Flow Reactor System at $85^{\circ} \mathrm{C}$ and $\mathrm{pH}$ 2. (A) Plutonium Concentrations (GEA). (B) Uranium Concentrations. 
The dissolution rate of the ${ }^{238} \mathrm{Pu}$-bearing pyrochlore specimen can be compared to that of non-radioactive specimens (Figure 3.23). These data indicate that forward dissolution rates (constant rate with increasing $q / S)$ appear to occur at $\log _{10}(q / S)$ values of $>-7$. The forward dissolution rate for the ${ }^{238} \mathrm{Pu}$-bearing pyrochlore specimen that had been resintered plots close to the forward dissolution rates of the nonradioactive specimens. Significantly, the data for all of the ${ }^{238} \mathrm{Pu}$-bearing specimens plot amongst the data for the non-radioactive specimens. These data suggest that radioactive and non-radioactive specimens dissolve at the same rate, once $q / S$ is taken into account. The data for the monolithic specimens are about a factor of 3 greater than the corresponding data from the powdered specimens. We believe this may be a result of the porosity of the specimen and the fact that we use geometric surface area in our calculations. Visually, the agreement looks worse than it is because the data are plotted on a log-log graph.

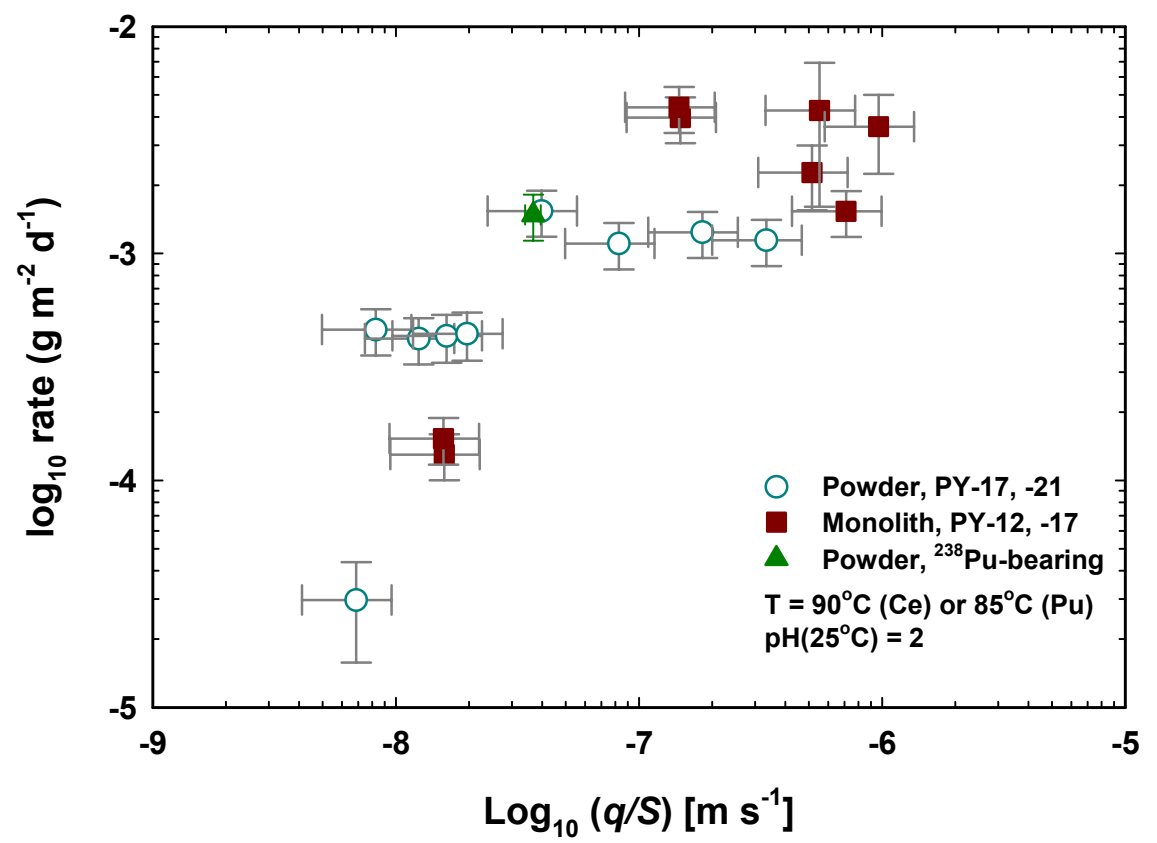

Figure 3.23. Plots of $\log _{10}($ Rate $)\left[\mathrm{g} /\left(\mathrm{m}^{2} \cdot \mathrm{d}\right)\right]$ Versus $\log _{10}(q / S)[\mathrm{m} / \mathrm{s}]$ for Pyrochlore Ceramics at $90^{\circ} \mathrm{C}$ and $\mathrm{pH} 2$ (PY-17 is Ce-based and compositionally similar to PY-12 and -21) 


\subsection{Radiation-Damage Effects in Pyrochlore-Rich Baseline Titanates Containing ${ }^{238} \mathrm{Pu}$}

This section describes the effects of radiation damage from self-irradiation with ${ }^{238} \mathrm{Pu}$ on the density, crystal structure, and dissolution rate of pyrochlore-rich baseline specimens.

\subsection{Preparations}

Two batches of ${ }^{238} \mathrm{Pu}$-bearing pyrochlore-rich baseline specimens were prepared, one on 8-Oct-1999 and the other on 19-Oct-1999. On 15-May-1999, a single batch of ${ }^{239} \mathrm{Pu}$-bearing specimens was made. Trace amounts of Mo were added to the formulation of all the specimens to serve as an indication of the behavior of the matrix in the dissolution experiments.

The target compositions are shown in Table 4.1. The $\mathrm{PuO}_{2}$ composition corresponds to 10.86 mass\% $\mathrm{Pu}$. The target composition was selected to provide a mixture of pyrochlore, zirconolite, and rutile.

For the SPFT, specimens with the compositions shown in Table 4.2 were used. These specimens were tested under the full range of $\mathrm{pH}$ that was discussed above. Both original and resintered pyrochlore-rich baseline specimens containing ${ }^{238} \mathrm{Pu}$ were tested. The specimen surface area in these tests was $0.064 \mathrm{~m}^{2}$; flow rates were typically in the range of $2 \cdot 10^{-11} \mathrm{~m}^{3} / \mathrm{s}$.

Table 4.1. The Target Oxide Composition of the Pyrochlore-Rich Baseline Ceramics Used in this Study

\begin{tabular}{|l|c|c|c|c|}
\hline \multirow{2}{*}{ Component } & \multicolumn{2}{|c|}{${ }^{\mathbf{2 3}} \mathbf{P u - P y r o c h l o r e - R i c h ~ B a s e l i n e}$} & ${ }^{239}$ Pu-Pyrochlore-Rich baseline \\
\cline { 2 - 5 } & $\mathbf{M a s s} \%$ & $\mathbf{M o l e} \%$ & Mass\% & Mole\% \\
\hline $\mathrm{CaO}$ & 9.91 & 21.13 & 9.94 & 21.15 \\
\hline $\mathrm{Gd}_{2} \mathrm{O}_{3}$ & 7.95 & 2.62 & 7.94 & 2.61 \\
\hline $\mathrm{HfO}_{2}$ & 9.61 & 5.46 & 9.63 & 5.46 \\
\hline $\mathrm{MoO}_{3}$ & 0.11 & 0.10 & 0.10 & 0.10 \\
\hline $\mathrm{PuO}_{2}$ & 11.84 & 5.24 & 11.88 & 5.23 \\
\hline $\mathrm{TiO}_{2}$ & 36.70 & 54.89 & 36.82 & 54.99 \\
\hline $\mathrm{UO}_{2}$ & 23.88 & 10.57 & 23.67 & 10.46 \\
\hline \hline
\end{tabular}


Table 4.2. Target and Analyzed Compositions (mass\%) of the Pyrochlore-rich baseline Ceramics.

\begin{tabular}{||l|c|c||}
\hline \multirow{2}{*}{ Oxide } & BSL-3 & BSL-3 \\
\cline { 2 - 3 } & Target & EMPA \\
\hline $\mathrm{CaO}$ & 11.47 & 10.71 \\
\hline $\mathrm{CeO}_{2}$ & 26.84 & 27.85 \\
\hline $\mathrm{Gd}_{2} \mathrm{O}_{3}$ & 9.16 & 9.23 \\
\hline $\mathrm{HfO}_{2}$ & 11.12 & 11.76 \\
\hline $\mathrm{MoO}_{3}$ & 0.08 & 0.08 \\
\hline $\mathrm{TiO}_{2}$ & 41.33 & 40.26 \\
\hline Total & & 99.89 \\
\hline
\end{tabular}

\subsection{Results and Discussion}

\subsubsection{Physical Appearance}

Shown in Figure 4.1 are photographs of the top and bottom of a typical specimen. This specimen contained chips, typically on the edges, and voids on the surfaces. These surface flaws lead to uncertainties in the geometric densities because they are detected with our measurement device, but register as noise.

\subsubsection{Density Measurements}

Helium Pycnometer Results. Results from

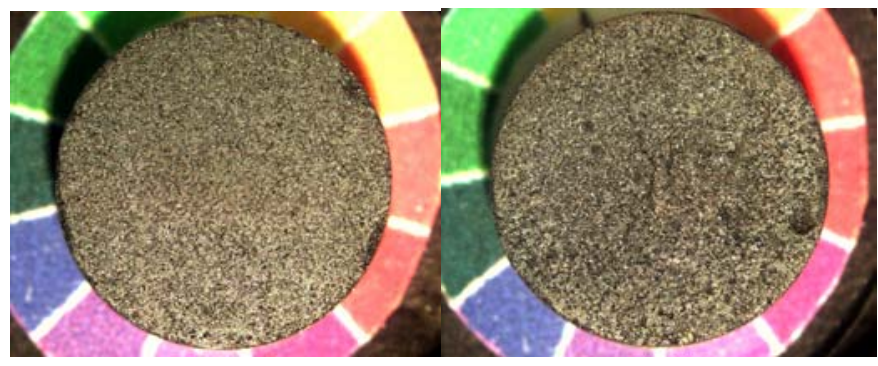

Figure 4.1. Pictures of Typical ${ }^{238} \mathrm{Pu}$-Bearing Pyrochlore-Rich Baseline Specimens. These photos are of a single specimen with the polished surface shown on the left and the unpolished surface shown on the right. the measurement of the "true" density of the original specimens are shown in Figure 4.2. At saturation, the densities are $5.04 \cdot 10^{3}, 5.12 \cdot 10^{3}$, and $5.26 \cdot 10^{3} \mathrm{~kg} / \mathrm{m}^{3}$ at $20^{\circ} \mathrm{C}, 125^{\circ} \mathrm{C}$, and $250^{\circ} \mathrm{C}$, respectively. The lines in Figure 4.2 are drawn to guide the eye, but are of the form of Equation 3.1.

The density of the ${ }^{239} \mathrm{Pu}$-bearing specimens is $5.76 \cdot 10^{3} \mathrm{~kg} / \mathrm{m}^{3}$, but we cannot reliably use this value as the starting value for the ${ }^{238} \mathrm{Pu}$-bearing specimens. There is no direct evidence that the starting density should be the same between the ${ }^{238} \mathrm{Pu}$ - and ${ }^{239} \mathrm{Pu}$-bearing specimens, except that the preparation conditions were as close as possible. Therefore, we extrapolated the data back to the start with the use of Equation 1 to obtain an average starting density of $5.67(1) \cdot 10^{3} \mathrm{~kg} / \mathrm{m}^{3}$. Relative to this extrapolated value, the densities at saturation represent decreases of $11 \%, 9.9 \%$, and $7.4 \%$ for the specimens stored at $20^{\circ} \mathrm{C}, 125^{\circ} \mathrm{C}$, and $250^{\circ} \mathrm{C}$, respectively. Although the experimental error is low, we feel that the low density determined at about 225 days for the specimens stored at $125^{\circ} \mathrm{C}$ is an outlier and should be ignored as are the data for the specimens stored at $250^{\circ} \mathrm{C}$ at about 275 days. Overall, the data seem to indicate that the radiation induced changes to the "true" density have saturated after 1000 days or $5.6 \cdot 10^{18} \mathrm{\alpha} / \mathrm{g}$. Saturation in the "phase pure" pyrochlore specimens occurred at the same dose (Section 3.2.2). At 280 days, the low 
values for the density of the specimens stored at $250^{\circ} \mathrm{C}$ and about 275 days suggest that we were having problems with the determination at that time. However, we did not know the measurements were in error until subsequent measurements were made.

In Figure 4.3, we show the results for the "true" densities of the resintered pyrochlore-rich baseline specimens stored at $20^{\circ} \mathrm{C}$ and $250^{\circ} \mathrm{C}$ after resintering. No resintered specimens were stored at $125^{\circ} \mathrm{C}$. After an apparent delay of about 10 days, the "true" density dropped exponentially as did the densities of the original specimens. If we take out the apparent 10-day delay and fit the resulting data to Equation 1, we project a value of $5.68(2) \cdot 10^{3} \mathrm{~kg} / \mathrm{m}^{3}$ as the starting density, which is similar to the density of the ${ }^{239} \mathrm{Pu}$-bearing specimens and the extrapolated starting density for the original specimens discussed above, $5.67(1) \cdot 10^{3} \mathrm{~kg} / \mathrm{m}^{3}$. Using the projected value and asymptotic value of $5.03 \cdot 10^{3} \mathrm{~kg} / \mathrm{m}^{3}$, we calculate an $11.4 \%$ decrease, the same as was found for the change in the "true" density of the original specimens at $20^{\circ} \mathrm{C}$. It is unclear from these data why there should be a 20-d induction period. Excluding the two data points at about 100 days, the slope of the straight line drawn through the "true" density data from the specimens stored at $250^{\circ} \mathrm{C}$ is $1.15(15) \mathrm{kg} /\left(\mathrm{m}^{3} \cdot \mathrm{d}\right)$. A slope similar to that one would calculate from the original specimens stored at $250^{\circ} \mathrm{C}$ (Figure 4.2). In fact, the two data sets (original and resintered) for the specimens stored at $250^{\circ} \mathrm{C}$ superimpose on one another, but the data sets for the specimens stored at $20^{\circ} \mathrm{C}$ do not. For the specimens stored at $250^{\circ} \mathrm{C}$, the slope is about three times greater than the slope observed for the "phase-pure" pyrochlore specimens stored at $250^{\circ} \mathrm{C}(-0.388(24)$ $\mathrm{kg} /\left(\mathrm{m}^{3} \cdot \mathrm{d}\right)$, Section 3.2.2).

Because there are changes in the "true" densities of the specimens stored at $250^{\circ} \mathrm{C}$, the data suggest that the critical temperature is higher than $250^{\circ} \mathrm{C}$. There are insufficient data for us to estimate the critical temperature.

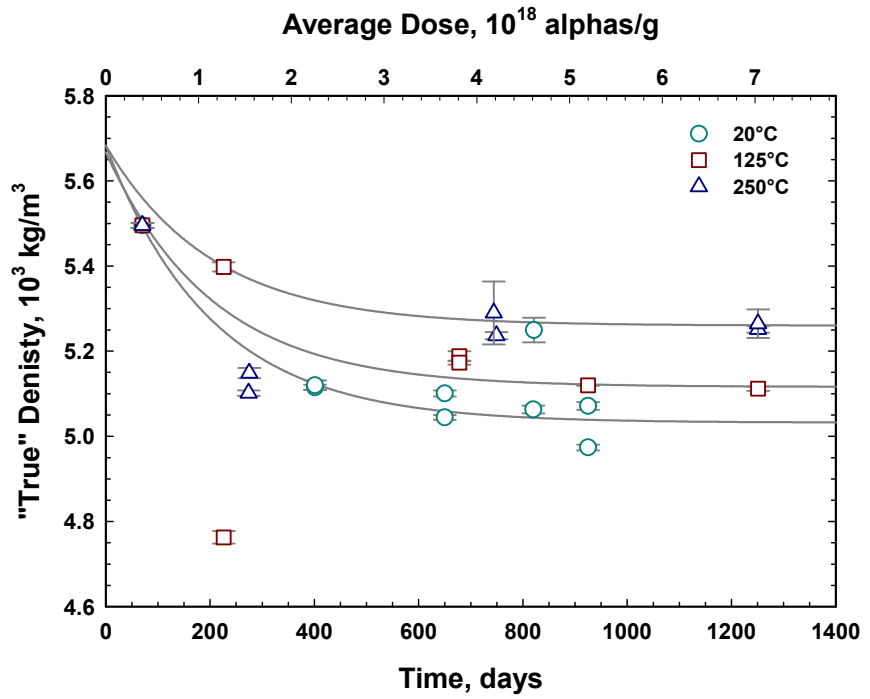

Figure 4.2. Results from the Measurement of the "True" Density of ${ }^{238} \mathrm{Pu}$-Bearing Pyrochlore-Rich Baseline Specimens Stored at $20^{\circ} \mathrm{C}, 125^{\circ} \mathrm{C}$, and $250^{\circ} \mathrm{C}$

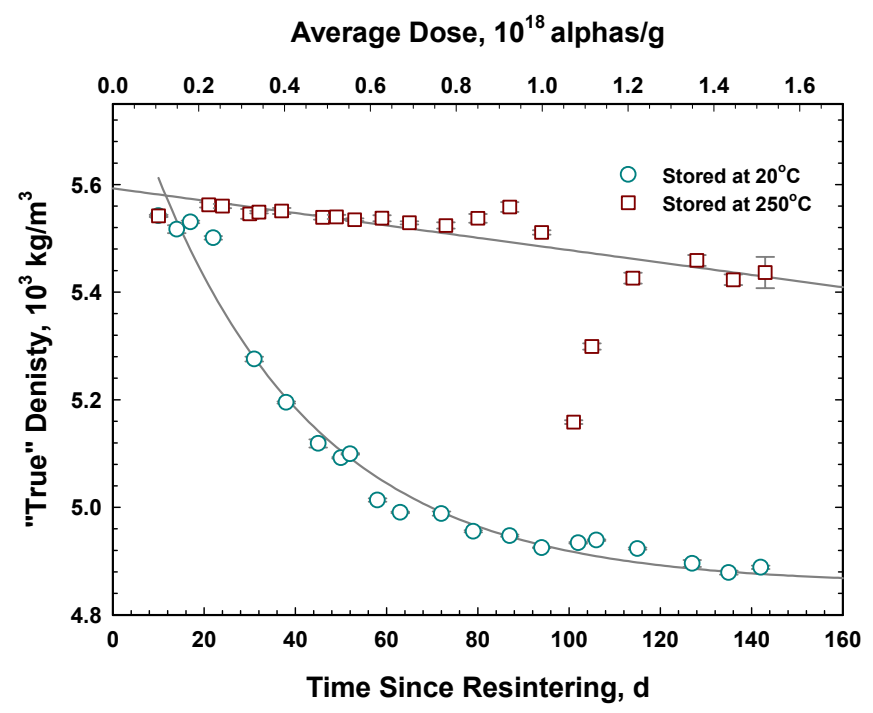

Figure 4.3. The Variation of the "True" Density of the ${ }^{238} \mathrm{Pu}$-Bearing Pyrochlore-Rich Baseline Specimens that Were Resintered and Stored at $20^{\circ} \mathrm{C}$ and $250^{\circ} \mathrm{C}$ 
Geometric Densities. Because of the wobble in the table on which the specimens were placed and the existence of edge chips, the height data varied significantly. Therefore, the variation in the diameter of the specimens is discussed here, as well as the density, which is calculated from the variation in the diameter, assuming uniform swelling of the specimen. The variation in the diameters of the specimens stored at $20^{\circ} \mathrm{C}, 125^{\circ} \mathrm{C}$, and $250^{\circ} \mathrm{C}$ is shown in Figure 4.4. When the specimens were made, all had the same diameter within experimental uncertainty $(10.3(1) \mathrm{mm})$. These diameters were measured with a hand-held micrometer, hence the higher uncertainty. The measurements between 200 and 300 days were

made with the shorter measurement time mentioned in Section 2. From the measurement of the diameters, there appears to be no temperature dependence in the radiation induced swelling of the specimens. That is, there is no systematic difference between the observed swelling of the specimens held at ambient conditions or at $250^{\circ} \mathrm{C}$. The data were fit to Equation 3.2.

These data suggest that the changes in the diameters saturate at about $4.6 \cdot 10^{18} \mathrm{\alpha} / \mathrm{g}$ (810 days) for a final diameter of 10.517(78) $\mathrm{mm}$. This suggests that the diameter expanded by $2.1 \%$ for a volume expansion of $6.5 \%$ or a $6.1 \%$ decrease in the bulk density, much less than the observed decrease in the "true" densities, which are sensitive to the amount of closed porosity. This indicates that open porosity was converted to closed porosity as the specimen swelled with increasing radiation induced damage.

Changes in the diameters of the resintered specimens are shown in Figure 4.5. These data indicate that the change is linear over the time of characterization for the specimens that were originally stored at $20^{\circ} \mathrm{C}$ and stored at $20^{\circ} \mathrm{C}$ after resintering. Taking the swelling of specimen $8 \mathrm{~PB} 1 \mathrm{~B}-7$ as representative of the behavior of all the specimens (Figure 4.5), we calculate a slope for the linear behavior of the diameter as $2.6(3) \cdot 10^{-4} \mathrm{~mm} / \mathrm{d}$. This rate of swelling is about half of what is needed to explain the swelling observed in the original specimens shown in Figure 4.4. This difference may be the uncertainty in the measurements of the original or resintered

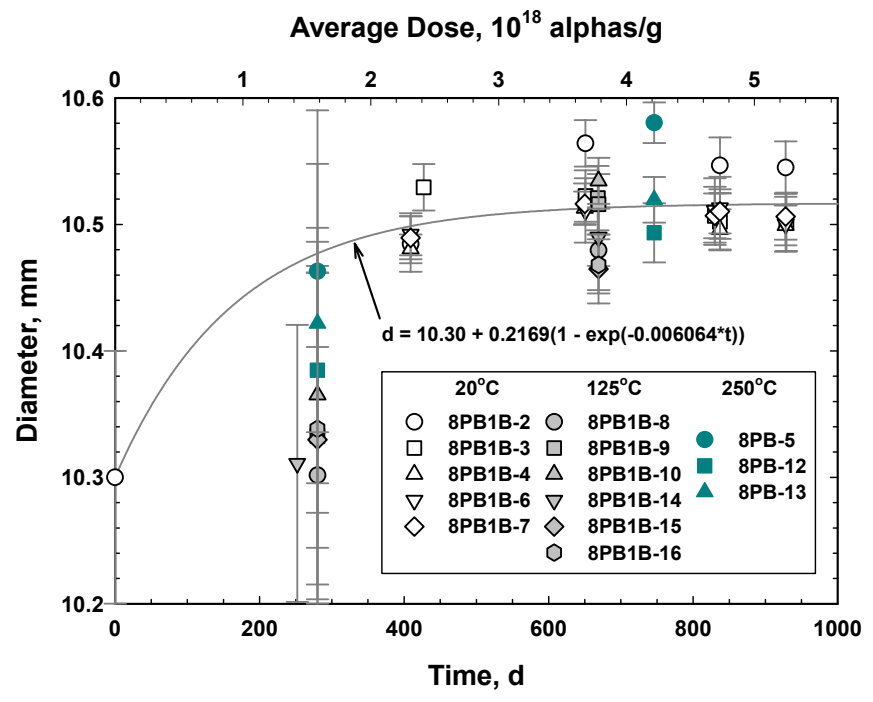

Figure 4.4. The Variation with Increasing Dose of the Specimen Diameters for the Original Specimens Stored at $20^{\circ} \mathrm{C}, 125^{\circ} \mathrm{C}$, and $250^{\circ} \mathrm{C}$

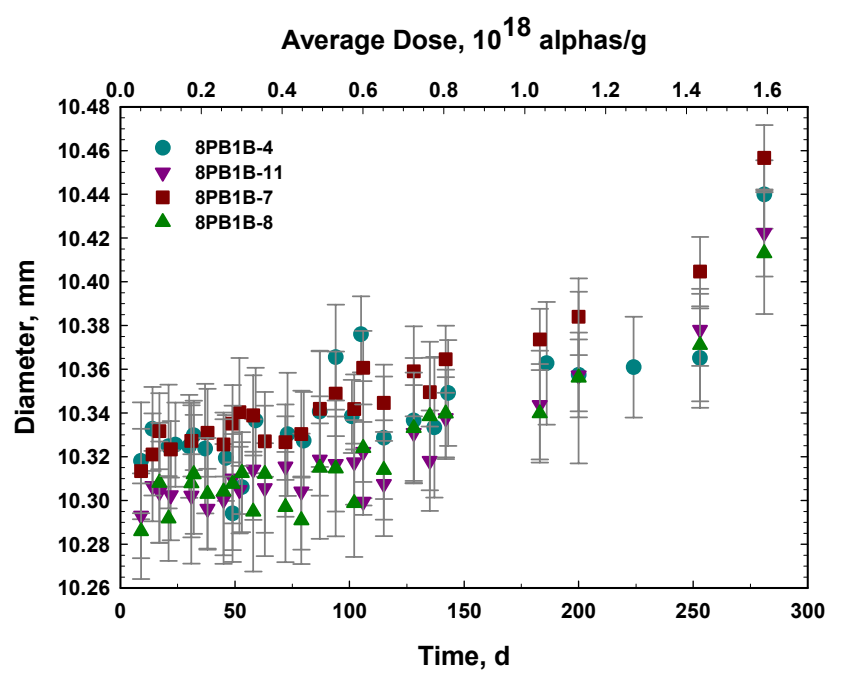

Figure 4.5. The Variation in the Diameters of the Individual ${ }^{238} \mathrm{Pu}$-Bearing Pyrochlore-Rich Baseline Specimens Originally Stored at $20^{\circ} \mathrm{C}$ and Stored at $20^{\circ} \mathrm{C}$ Since Resintering 
specimens, or it could reflect the changes that occurred in the pyrochlore-rich baseline specimens during resintering. Similarly, the diameters of the specimens that were originally stored at $250^{\circ} \mathrm{C}$ and later stored at $250^{\circ} \mathrm{C}$ since resintering also swelled linearly with a slope of $1.9(2) \cdot 10^{-4} \mathrm{~mm} / \mathrm{d}$ (Figure 4.6). As with the original specimens, there is no significant difference in the rate of swelling between the specimens stored at $20^{\circ} \mathrm{C}$ and $250^{\circ} \mathrm{C}$. These effects were not noted in either the pure-phase pyrochlore (Section 3.2.2) or pure-phase zirconolite specimens (Section 5.2.2). Over the 281 days $\left(20^{\circ} \mathrm{C}\right)$ or 325 $\left(250^{\circ} \mathrm{C}\right)$ days of the test, the specimens swelled about $0.7 \%$ for a calculated density change of $-2 \%$.. This value is inconsistent with the $4.5 \%$ decrease in density determined above for the original specimens and suggests that some densification occurred during resintering.

Because the "true" density for the specimens stored at $20^{\circ} \mathrm{C}$ changed by substantially more than what was observed from the diameters of the specimens and by more than the "true" densities of the specimens stored at $250^{\circ} \mathrm{C}$, we conclude that some open porosity became closed porosity as the specimen swelled. As open porosity was converted to closed porosity, there was less pore volume accessible to the He gas, so the specimen density appeared to decrease more rapidly. The effect of particle swelling might not be as important for the specimens stored at $250^{\circ} \mathrm{C}$. This would be consistent with the slightly lower swelling observed for the specimens stored at $250^{\circ} \mathrm{C}$. The microscopic swelling results (see the discussion below on the XRD results) show that the expansion of the unit cell(s) of the phases in the specimens stored at $250^{\circ} \mathrm{C}$ is slower than the swelling for the phases in the specimens stored at $20^{\circ} \mathrm{C}$.

\subsubsection{Scanning Electron Microscopy}

The ${ }^{238} \mathrm{Pu}$ pyrochlore-rich baseline ceramic sample, an original specimen stored at $125^{\circ} \mathrm{C}$, consisted of three major phases: pyrochlore, zirconolite, and rutile. Minor actinide oxide inclusions were also observed in the material (see Figure 4.7 through Figure 4.12). Figure 4.7 through Figure 4.9 show the presence of high $\mathrm{Z}$ crystals within the ceramic. The box area is shown in detail in Figure 4.10. By combining the secondary electron and backscattered electron images, it is possible to discriminate between pores and the rutile phase. The rutile phase exhibits low contrast in backscattered electron imaging mode. In Figure 4.8, black regions can not be readily identified as pores or phases, but in Figure 4.9, some of these black areas are clearly a phase. Figure 4.10 shows evidence of lamellae structures within the pyrochlore grains. The backscattered electron image shows microstructure consistent with zirconolite intergrowths within the pyrochlore phase, similar to that reported by Buck et al. (1999). The euhedral pyrochlore grains (grey and white) would have solidified before the anhedral rutile phase (black). The marks on the phase that appear white are polishing scratches on the ceramic surface. In Figure 4.12, a small actinide inclusion can be

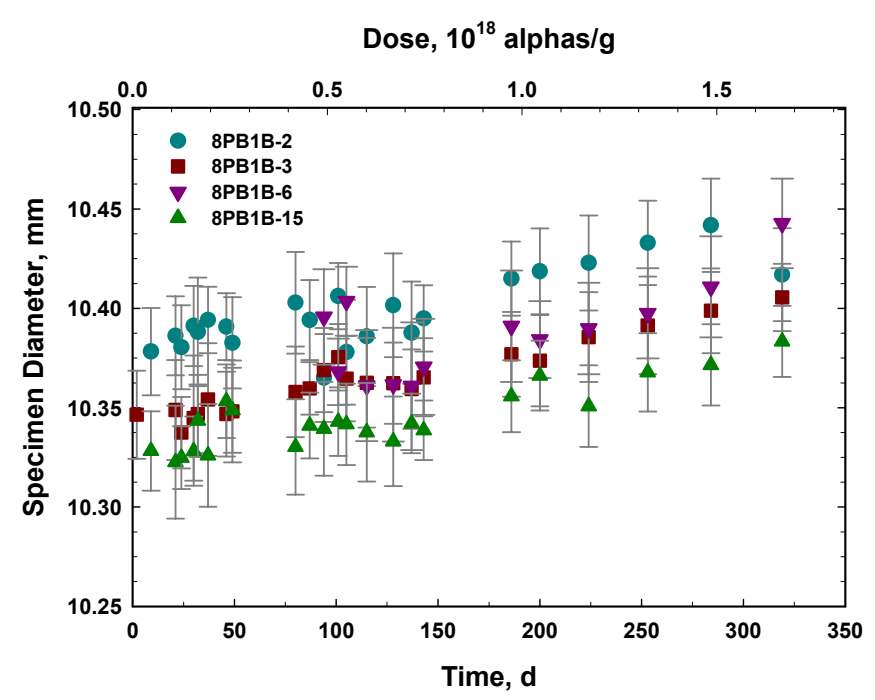

Figure 4.6. The Variation in the Diameters of the Individual ${ }^{238} \mathrm{Pu}$-Bearing Pyrochlore-Rich Baseline Specimens Originally Stored at $250^{\circ} \mathrm{C}$ and Stored at $250^{\circ} \mathrm{C}$ Since Resintering 
seen. This is marked by an arrow in the figure. This indicates that during cooling, not all the actinides could be incorporated into the main phase. The identification of the ceramic phases with EDS is not precise. In Figure 4.13 and Figure 4.14, spectra from pyrochlore and zirconolite, respectively, are shown. The zirconolite composition had a higher concentration of $\mathrm{Hf}$ and $\mathrm{Ca}$ compared to the pyrochlore phase.

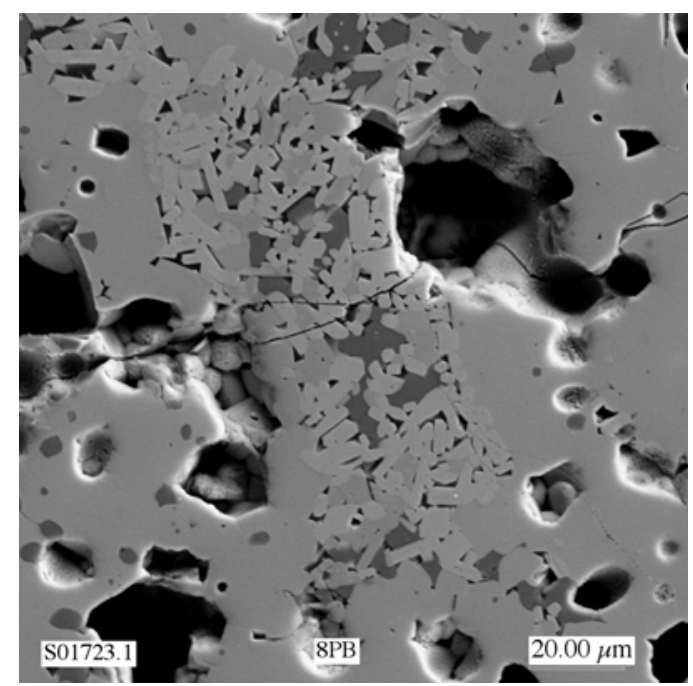

Figure 4.7. Secondary Electron (SE) Image of the ${ }^{238} \mathrm{Pu}$-Bearing Pyrochlore-Rich Baseline Ceramic (stored at $20^{\circ} \mathrm{C}$; fully damaged) Shows the Porosity and Holes (possibly due to polishing) in the Ceramic

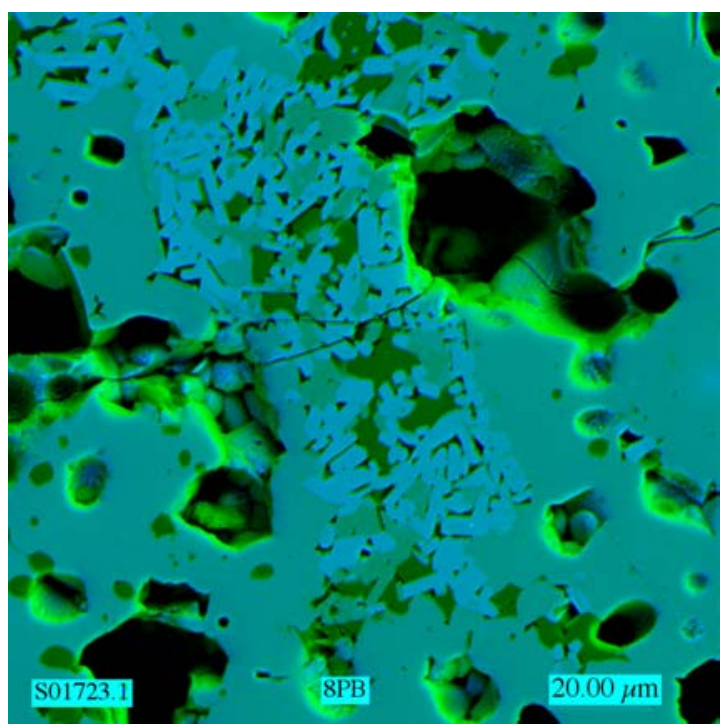

Figure 4.9. Combination of SE and BSE Images to Discriminate Between Pores and the Rutile Phase

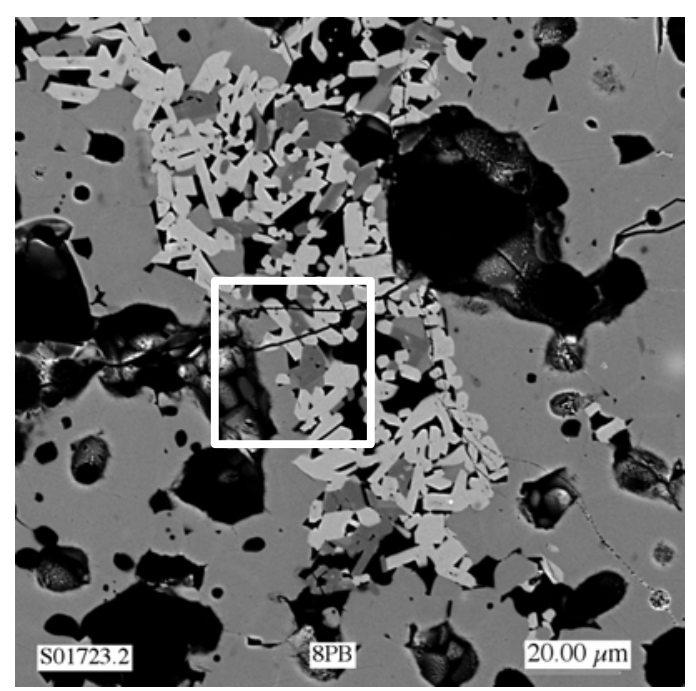

Figure 4.8. Backscattered Electron (BSE) Image of the ${ }^{238} \mathrm{Pu}$-Bearing Pyrochlore-Rich Baseline Ceramic (stored at $20^{\circ} \mathrm{C}$; fully damaged) Showing the Presence of High Z Crystals Within the Ceramic. Box area is shown in detail in Figure 4.10.

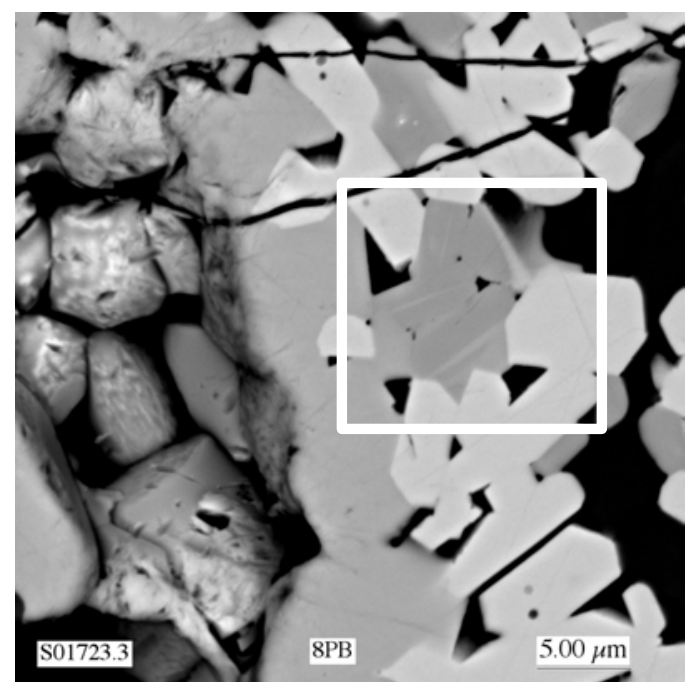

Figure 4.10. From Area Shown in Figure 4.8; Showing Evidence of Lamellae Structures Within the Pyrochlore Grains. The region to the left shows evidence of grain pull-out - a polishing artifact. 


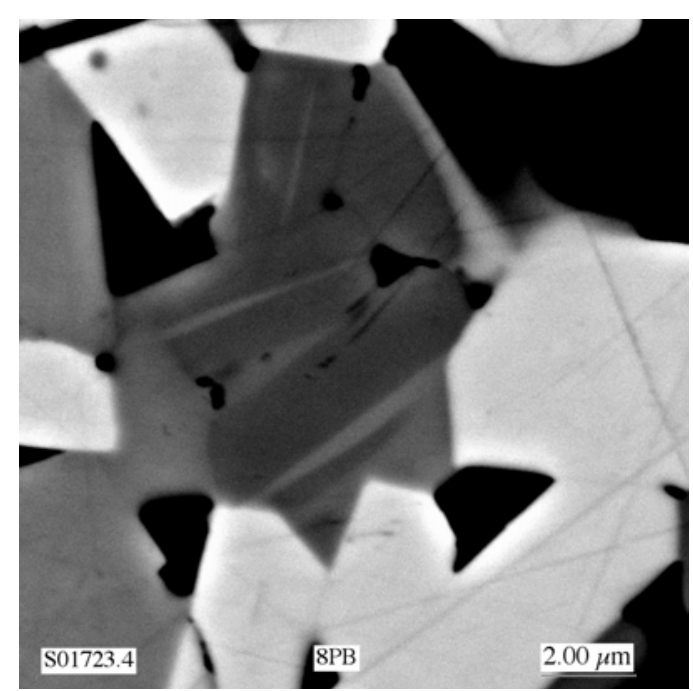

Figure 4.11. Higher Magnification Image of Pyrochlore (grey; marked area in Figure 4.10).



Figure 4.12. The Small Actinide Inclusion in the Pyrochlore Phase. This is marked by an arrow in the figure. This indicates that during cooling, not all the actinides could be incorporated into the main phase.

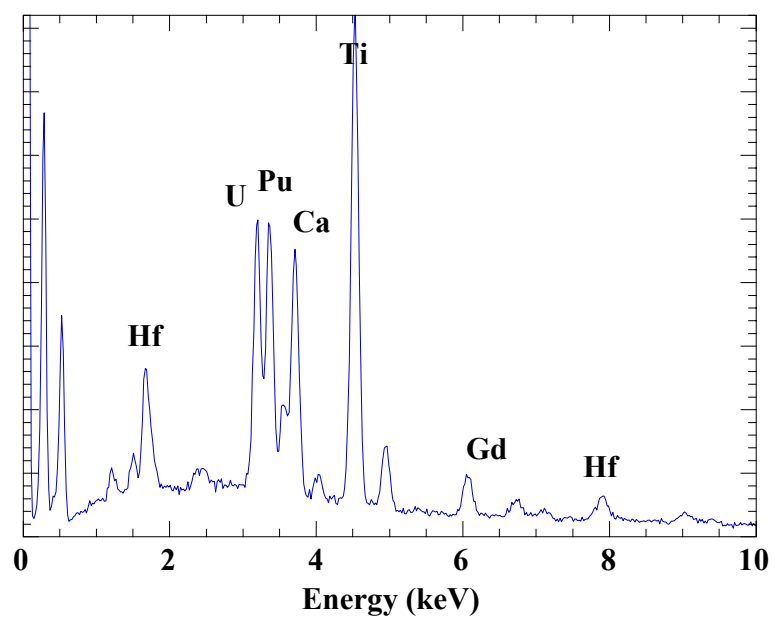

Figure 4.14. Zirconolite-Type Composition

Figure 4.13. Typical Pyrochlore Spectrum

\subsubsection{X-Ray Diffraction}

\subsubsection{Specimens Stored at $20^{\circ} \mathrm{C}$}

As in the other sections above, we discuss the results from original specimens and from the resintered specimens. In this section, we discuss the XRD results. The results from the original specimens stored at $20^{\circ} \mathrm{C}$ are shown in Figure 4.15. The XRD pattern is consistent with the presence of four phases - 
pyrochlore, brannerite, zirconolite, and rutile. The rutile phase remains crystalline as the other phases become amorphous and, hence, the relative intensities increase. As can be seen from the XRD patterns, the ceramic becomes amorphous quickly with the pyrochlore and brannerite peaks becoming broader and the intensities of most peaks becoming less than the background before the same happens to the zirconolite component.

After the specimens were resintered, the XRD patterns were compared and the results are shown in Figure 4.16. These patterns show that the phase assemblages were the same, but there is some preferred orientation in the ${ }^{239} \mathrm{Pu}$-bearing specimen or spurious diffraction from crystals in the specimen surface defects. This is evident in the different intensity of some peaks and the extra peak at about $16^{\circ} 2 \theta$.

Radiation induced changes to the crystal structures in the resintered ${ }^{238} \mathrm{Pu}$-bearing pyrochlore-rich baseline specimen are shown in Figure 4.17. As pointed out in the Experimental Methods section, a single specimen was used in obtaining these data. Although the pyrochlore, brannerite, and zirconolite phases undergo radiation induced changes, the changes are different than those observed in the materials discussed in the other sections of this report and other studies. The diffraction peak at $36^{\circ} 2 \theta(004)$ shows that the zirconolite phase, while becoming amorphous, does not exhibit lattice parameter changes, i.e. constant diffraction angle. There is a rutile peak that falls at the same diffraction angle, so the intensity of this peak is dominated by the rutile contribution at high alpha dose. At the same time, the pyrochlore phase (peak at $35^{\circ} 2 \theta$ ) becomes amorphous with a significant increase in the lattice parameter. This effect is also seen at $30^{\circ} 2 \theta$ where the diffraction peak from zirconolite and pyrochlore occur at nearly the same value. However with increasing dose, a separation develops between the two while both decrease in intensity and become broader. While other authors (Wald and Offerman 1982b) and we (Strachan et al. 2002) and Strachan et al 2003a,b) have shown that the predominant change to the zirconolite unit cell is along the c-axis, we do not see it in this material. The (004) diffraction peak at $32^{\circ} 2 \theta$ remains at the same value for the duration of the experiment, although the peak becomes broader and less intense. It has been noted that radiation induced changes to the crystal structure depend sometimes strongly on phase composition. Our results suggest that the zirconolite phase while still containing significant concentrations of ${ }^{238} \mathrm{Pu}$ (probably $>5$ mass \%) after resintering has a different composition than in the original specimen (Figure 4.15).

To further illustrate the changes in the crystal structures in this pyrochlore-rich baseline material, we show the changes to the lattice parameters with increasing time or damage. In Figure 4.18, we show the changes to the pyrochlore phase in the resintered specimen. As the pyrochlore becomes amorphous, it becomes more difficult to index the phase as a pyrochlore, although the characteristic diffraction peak with indices of (311) is still visible at the end of the experiment. For the data obtained after 140 days, the diffraction

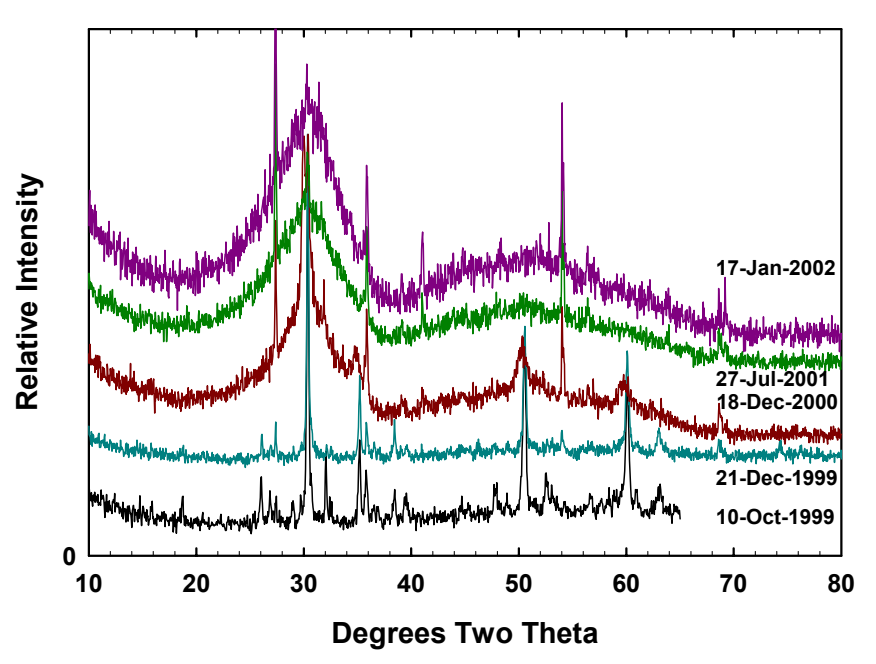

Figure 4.15. X-Ray Diffraction Patterns from the Original ${ }^{238} \mathrm{Pu}$-Bearing Pyrochlore-Rich Baseline Specimen Stored at $20^{\circ} \mathrm{C}$ 
patterns were fit to the pyrochlore and fluorite cells. The fluorite cell parameter was doubled and plotted along with the cell parameters determined for the pyrochlore cell in the XRD patterns (Figure 4.17). The data were fit to the Equation 3.3. The results of the least squares fit to the data are a value of $a_{0}$ of $1.016\left(6 \cdot 10^{-5}\right) \mathrm{nm}$ and an asymptotic value of $1.031\left(4 \cdot 10^{-4}\right) \mathrm{nm}$ at approximately 675 days (an average dose of 3.82.1 $0^{18} \mathrm{\alpha} / \mathrm{g}$ ) - approximately twice as long as the experiments with the resintered specimens. Based on the asymptotic value, the lattice parameter swells by $1.5 \%$ or the cell volume by $4.6 \%$. These results are consistent with the macroscopic swelling discussed above.

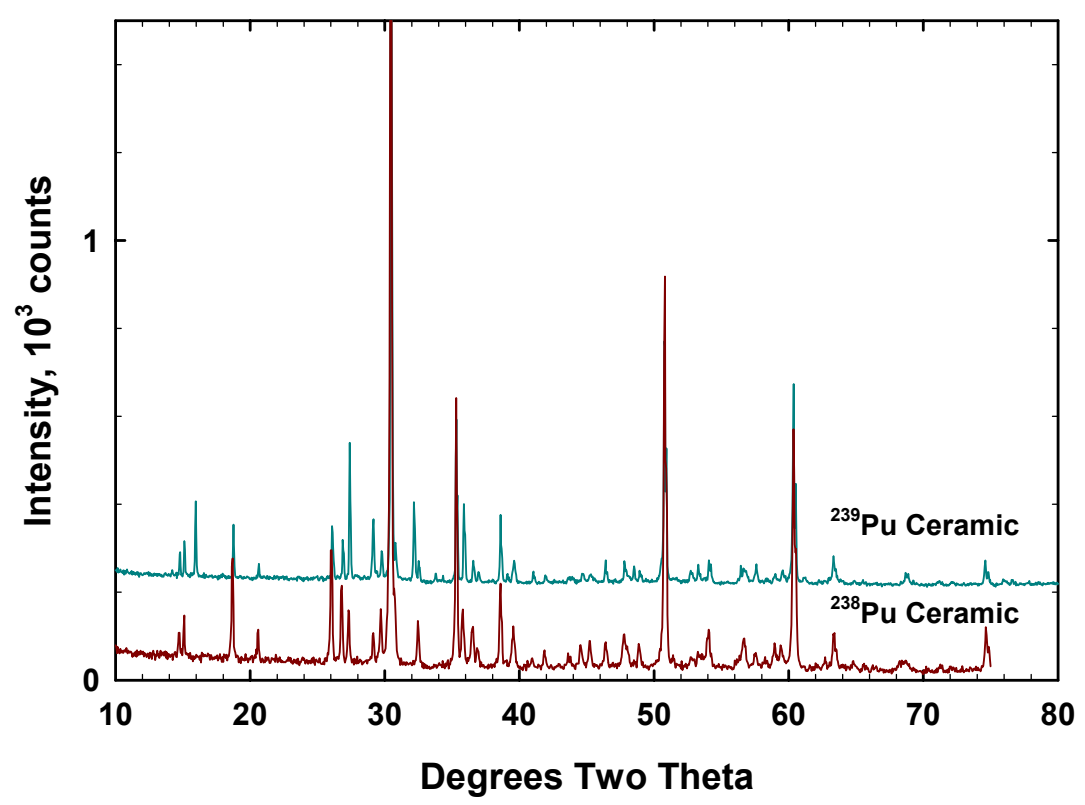

Figure 4.16. A Comparison Between the XRD Patterns of the ${ }^{239} \mathrm{Pu}$-Bearing and the Resintered ${ }^{238} \mathrm{Pu}$-Bearing Pyrochlore-Rich Baseline Specimens

Shown in Figure 4.19 are the variations of the lattice parameters for the brannerite phase in the ${ }^{238} \mathrm{Pu}-$ bearing pyrochlore-rich baseline ceramic; the variation in the cell angle is shown in Figure 4.20. Up to 100 days $\left(0.57 \cdot 10^{18} \alpha / g\right)$, there are slight increases in the $a_{0}$ and $b_{0}$ lattice parameters; decreases in the $c_{0}$ and $\beta$ parameters. After 100 days, the diffraction pattern becomes difficult to refine, hence the errors in the determinations increase (error bars). The significant changes in the lattice parameters beyond about 100 days, shown in Figure 4.18 and Figure 4.21, are probably not real and have more to do either with our inability to refine the parameters from the diffraction patterns or for the diffraction pattern to more represent diffuse scattering than true Bragg diffraction (Howard and Sabine 1974). Over the first 100 days, the volume of the brannerite cell swelled $0.2 \%$. This small amount of swelling may reflect the fact that little, if any $\mathrm{Pu}$ is in the brannerite. Pure Pu-brannerite has not been made in $100 \%$ yield (Vance et al. 2001) and has been found to be entropy stabilized at high temperature (Helean et al. 2003). Ebbinghaus et al (1995) determined that the presence of actinides in the titanate ceramic increased the yield of pyrochlore with brannerite as the major impurity. When no actinides were present, no brannerite formed. Helean et al. (2003) conclude that the presence of as much as 30 mass\% brannerite in the ceramic does not significantly decrease the thermodynamic stability of the ceramic. The marginal thermodynamic stability of brannerite-containing Pu may also explain its sensitivity to radiation induced damage. Hence, 
the small amount of observed swelling may be consistent with the observation that the brannerite phase becomes amorphous at quite low average radiation induced damage, whether it arises from a small amount of $\mathrm{Pu}$ in the phase or from radiation induced damage from the surrounding $\mathrm{Pu}$-bearing phases.

Zirconolite, the third phase in the pyrochlore-rich baseline ceramic, undergoes small changes in lattice parameters and cell angle (Figure 4.21 and Figure 4.22). However, the changes in the $\mathrm{a}_{0}$ and $\mathrm{b}_{0}$ axes are in opposition with $\mathrm{a}_{0}$ increasing $2.6 \%$ and $\mathrm{b}_{0}$ decreasing $0.75 \% ; \beta$ also decreased by $0.84 \%$. No significant change in $\mathrm{c}_{0}$ was observed.

The net result is an overall increase in the cell volume of $0.27 \%$. The insensitivity to radiation induced swelling along the c-axis is much different than what has been observed in the past for zirconolite (Wald and Offerman 1982b; Strachan et al. 2002). The volumetric swelling based on the unit cell is less than the values reported by Clinard et al (1982a; 1982b), suggesting that there is much less ${ }^{238} \mathrm{Pu}$ in this zirconolite than the pure phase $\mathrm{Ca}^{238} \mathrm{PuTi}_{2} \mathrm{O}_{7}$ used in Clinard's studies.

Although the transformation of zirconolite to an amorphous phase is reported to progress through pyrochlore (Wang et al. 1999c), there is little evidence of that progression in our data. Zirconolite is more resistant to damage than the pyrochlore in these materials. Thus, if zirconolite transforms to pyrochlore, one would expect the characteristic line at about $29.5^{\circ} 2 \theta$ (the (311)) should become stronger in the diffraction patterns. The data on the "pure phase" pyrochlore (Section 3.2.2) show that this characteristic line remains in the pattern until a substantial amount of radiation induced damage has occurred and

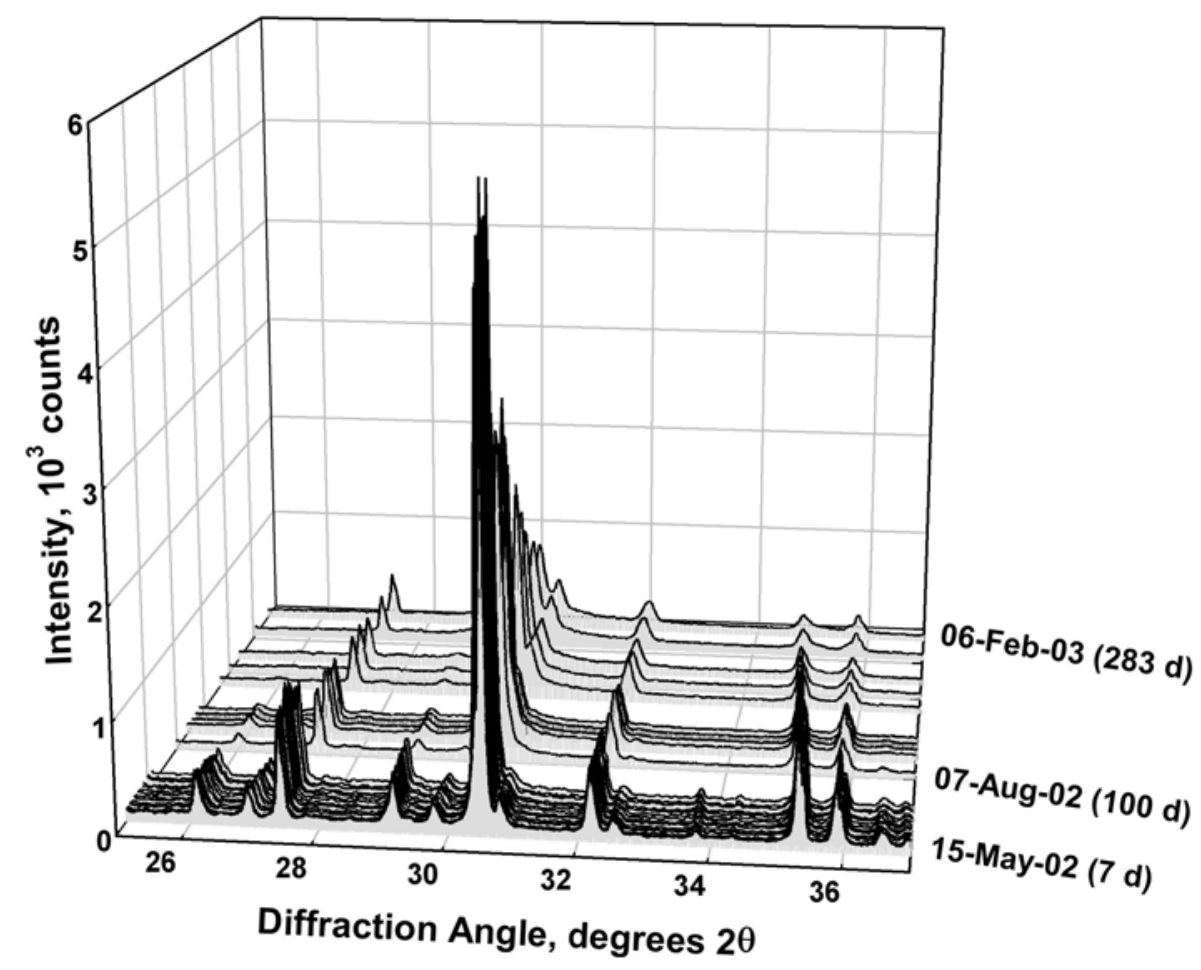

Figure 4.17. A Set of XRD Patterns Showing the Effect of Radiation Damage on the Crystal Structures of the Phases Contained in the ${ }^{238} \mathrm{Pu}$-Bearing Pyrochlore-Rich Baseline Ceramic Specimen 
appears to be at least as strong as it appears in the patterns from the pyrochlore-rich baseline studied here. Since the intensity of the (311) peak decreases similarly to intensity of the same peak in pure phase pyrochlore, the data presented in the patterns shown for both the specimen stored at $20^{\circ} \mathrm{C}$ and $250^{\circ} \mathrm{C}$ (see below) are inconsistent with zirconolite transforming to pyrochlore. We come to the same conclusion in Section 5 on pure phase zirconolite.

\subsubsection{Specimens Stored at $250^{\circ} \mathrm{C}$}

Results from the XRD studies of the original specimens stored at $250^{\circ} \mathrm{C}$ are shown in Figure 4.23. Although the specimens were made in October 1999, the first diffraction pattern of the specimens stored at $250^{\circ} \mathrm{C}$ was in July 2000. By this time, substantial radiation induced damage had occurred. Although the specimens produced for this study were produced as a single batch and, hence, should have contained four phases, by the time these specimens were characterized the brannerite phase appeared to have become amorphous. Contrary to what we saw with the specimens stored at $20^{\circ} \mathrm{C}$, the zirconolite in these specimens expands predominantly along the c-axis (Figure 4.24). In Figure 4.24, there is overlap between the rutile and zirconolite peaks. The (004) peak has a starting position of about $34^{\circ} 2 \theta$ and it shifts toward smaller $2 \theta$ values with increasing damage, eventually disappearing. As damage accumulates in the pyrochlore and zirconolite phases, the main peaks at $30^{\circ} 2 \theta$ separate (September 2000 in Figure 4.20). Both degrade to an amorphous maximum by November 2001 with only rutile as the remaining crystalline phase. This is consistent with the XRD patterns from the resintered specimens (Figure 4.23), where brannerite is observed to become amorphous after about 100 days (peak at $27.2^{\circ} ; 29^{\circ}$ to $30^{\circ}$, as examples).

The resintered specimens have four phases present: brannerite, pyrochlore, rutile, and zirconolite. A much different result was found for "phase pure" pyrochlore where two

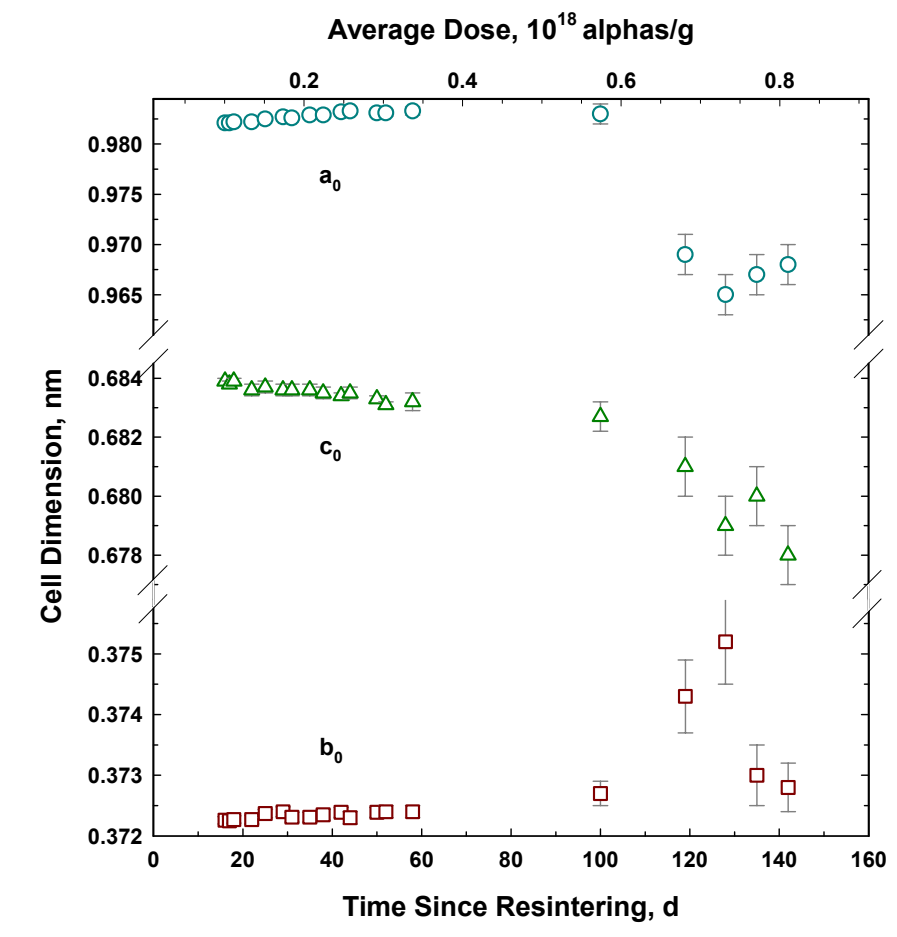

Figure 4.19. A Graph Showing the Variation of the Lattice Parameters for the Brannerite Phase in the ${ }^{238} \mathrm{Pu}$ Bearing Pyrochlore-Rich Baseline Ceramic 
zirconolite phases were found in the specimens that were originally stored at $250^{\circ} \mathrm{C}$ before resintering. As noted above, the brannerite appears to be very susceptible to radiation induced damage and becomes amorphous quickly (diffraction peaks at approximate positions of $26.8,29.8$, and $31^{\circ} 2 \theta$, as examples Figure 4.25). Pyrochlore and zirconolite remain crystalline for the duration of the experiment, although the ingrowth of damage is evident. The effect on the lattice parameter for the pyrochlore phase is shown in Figure 4.25. A least squares fit of the data to Equation 3.3 was used to draw the curve shown in Figure 4.26. The value for $\mathrm{a}_{0}$ is the same as for the specimens stored at $20^{\circ} \mathrm{C}$ even though these specimens had been stored at $250^{\circ} \mathrm{C}$ before resintering. The asymptotic value for $\mathrm{a}_{0}$ is $1.033 \mathrm{~nm}$, which is the same as the asymptotic value determined from the $20^{\circ} \mathrm{C}$ specimen. However, the time that it takes to approach the final value is 1200 days, 1.8 times longer than at $20^{\circ} \mathrm{C}$. Since the value for $\mathrm{c}$ in Equation 3.3 is related to the damage volume per decay event, these results suggest that the decay volume per event is about 1.6 times less than at $20^{\circ} \mathrm{C}$. A smaller decay volume is reasonable at the higher temperature since there is more chance for diffusion to 'repair' some of the damage in the collision cascade.

In Figure 4.27 and Figure 4.28, we show the variation of the lattice parameters $\mathrm{a}_{0}$ and $\mathrm{c}_{0}$ and the cell angle $\beta$ for the brannerite phase in the ${ }^{238} \mathrm{Pu}$-bearing pyrochlore-rich baseline ceramic stored at $250^{\circ} \mathrm{C}$. The $\mathrm{b}_{0}$ lattice parameter does not change significantly within the error of the determination. The error in the determinations increases after about 100 days and reflects the fact that the brannerite phase becomes amorphous rapidly. The changes beyond 100 days are unreliable and should not be used to make any conclusions about the quantitative changes to the phase.

Variations in the lattice parameters for the zirconolite phase in the baseline ceramic are summarized in Figure 4.29 and Figure 4.30;

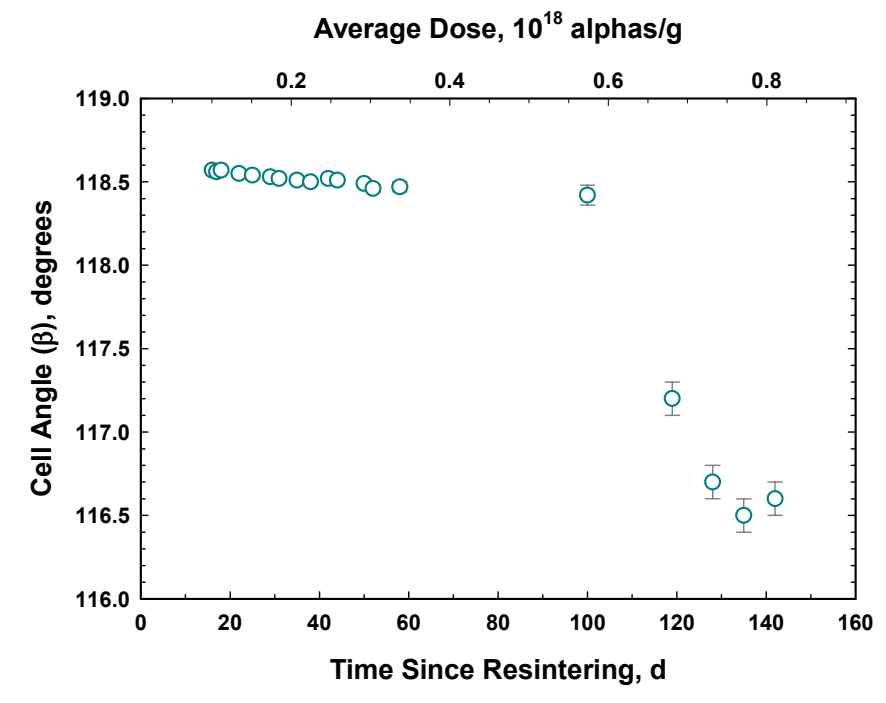

Figure 4.20. A Graph Showing the Variation of the Cell Angle for the Brannerite Phase in the ${ }^{238} \mathrm{Pu}$-Bearing Pyrochlore-Rich Baseline Ceramic

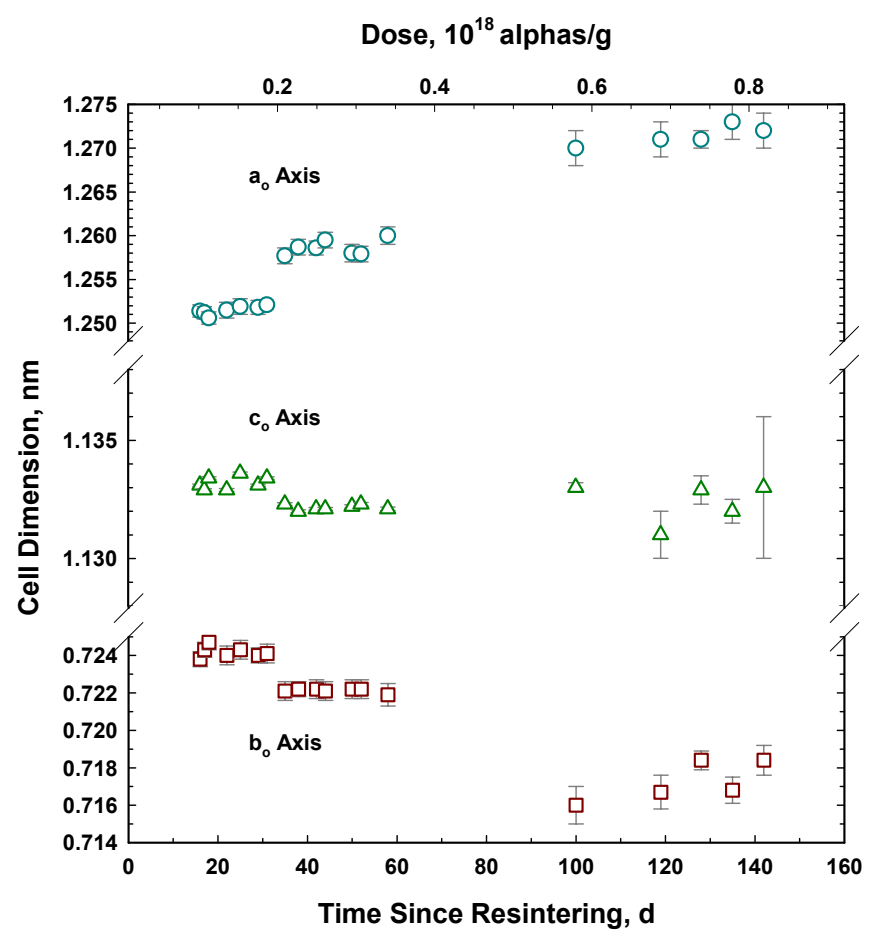

Figure 4.21. A Graph Showing the Variation of the Lattice Parameters for the Zirconolite Phase in the ${ }^{238} \mathrm{Pu}$ Bearing Pyrochlore-Rich Baseline Ceramic 
there was insignificant change in $\mathrm{c}_{0}$ (not shown). These data are consistent with the data from the specimen stored at $20^{\circ} \mathrm{C}$ discussed above, but inconsistent with earlier results where the major change to the zirconolite unit cell was swelling along the c-axis (Wald and Offerman 1982a; Strachan et al. 2002; Strachan et al. 2003b). Most of the variation in the zirconolite unit cell comes from the changes to $\mathrm{a}_{0}$ and $\beta$; there is almost no change in $b_{0}$ (Figure 4.29).

\subsubsection{Dissolution}

The release of Gd from the resintered and the fully radiation-damaged (original) ${ }^{238} \mathrm{Pu}$-bearing specimens is displayed in Figure 4.31.

Remarkably, the release of Gd from the two specimens is almost identical, and a reasonable steady-state concentration was achieved after 5 days. Dissolution rates calculated from steady-state Gd concentrations overlap for the two specimens and are $3.9(10) \cdot 10^{-4} \mathrm{~g} /\left(\mathrm{m}^{2} \cdot \mathrm{d}\right)$ for the radiationdamaged and resintered specimens.

Thus, based on the Gd concentrations, there is no difference between the dissolution of undamaged (resintered) and fully damaged (original) specimens. As in the case of the ${ }^{239} \mathrm{Pu}$-bearing pyrochlore, the release of $\mathrm{Pu}$ and $\mathrm{U}$ from the ${ }^{238} \mathrm{Pu}$-bearing specimens is difficult to interpret (Figure 4.32). Concentrations of ${ }^{238} \mathrm{Pu}$ in solution display a minimum at 2 days followed by a rise in concentration up to day 6 . Concentrations of ${ }^{238} \mathrm{Pu}$ become invariant with time for the resintered specimen. In contrast, ${ }^{238} \mathrm{Pu}$ concentrations from the experiment with a radiation-damaged specimen decline to the end of the experiment. Thus, we can only estimate the steady-state dissolution rate. Estimated release rates based on ${ }^{238} \mathrm{Pu}$ are $2.4(6) \cdot 10^{-4}$ and $3.7(8) \cdot 10^{-4} \mathrm{~g} /\left(\mathrm{m}^{2} \cdot \mathrm{d}\right)$

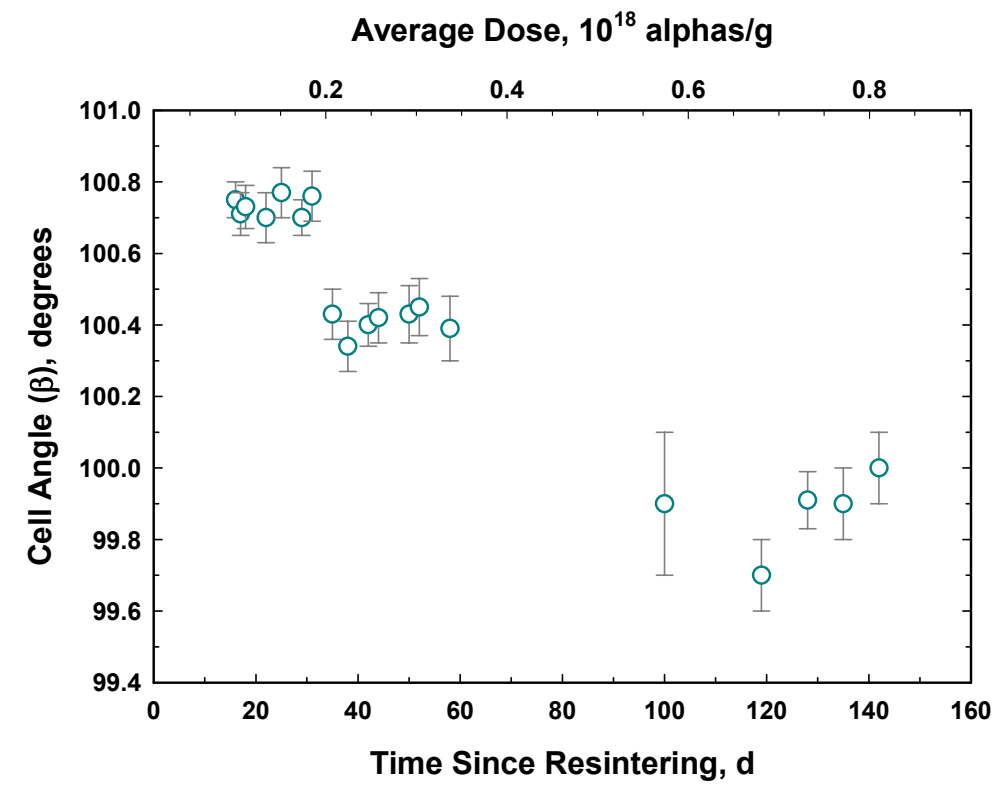

Figure 4.22. A Graph Showing the Variation of the Cell Angle in the Zirconolite Phase in the ${ }^{238} \mathrm{Pu}$-Bearing Pyrochlore-Rich Baseline Ceramic

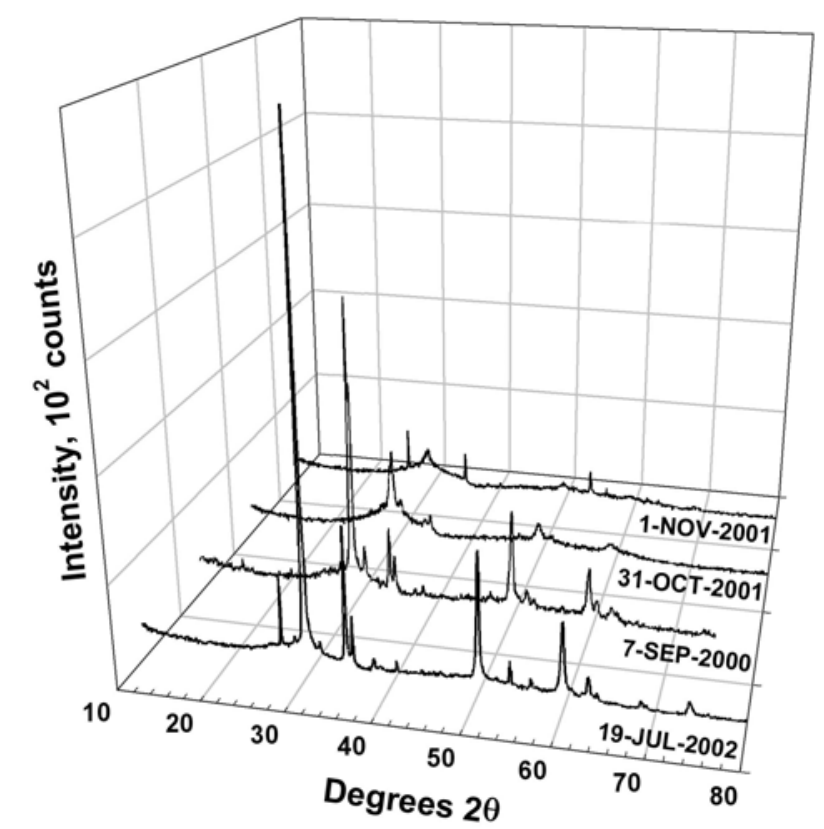

Figure 4.23. A Series of XRD Patterns Taken at Various Dates from ${ }^{238} \mathrm{Pu}$-Bearing Pyrochlore-Rich Baseline Ceramic Specimens Stored at $250^{\circ} \mathrm{C}$ 
for the radiation-damaged and resintered specimens, respectively. The release of $U$ to solution follows a pattern similar to that of ${ }^{238} \mathrm{Pu}$. Both ${ }^{238} \mathrm{Pu}$-bearing specimens show a minimum in $\mathrm{U}$ release at 3 days followed by an increase up to 6 days. The concentration of $U$ from the resintered specimen is variable over the last 4 days of the experiment, yet a reasonable steady-state dissolution rate based on the $\mathrm{U}$ concentrations can be estimated at $6.7(15) \cdot 10^{-4} \mathrm{~g} /\left(\mathrm{m}^{2} \cdot \mathrm{d}\right)$. In the case of the fully radiation-damaged (original) specimen, the concentration of $U$ decreases linearly after 6 days, so we can only estimate the dissolution rate based on $\mathrm{U}$ at $8.3(2) \cdot 10^{-4} \mathrm{~g} /\left(\mathrm{m}^{2} \cdot \mathrm{d}\right)$. These dissolution rates are slightly higher than the dissolution rate based on the $\mathrm{Gd}$ concentrations. Since the Gd concentration reached steady state and the $\mathrm{Pu}$ and $\mathrm{U}$ concentrations appear to be decreasing with time, the release of Gd to solution appears to be the most reliable index of dissolution, and the resintered and radiation-damaged specimens of ${ }^{238} \mathrm{Pu}$-bearing baseline materials dissolve at the same rate. Even though the $\mathrm{Pu}$ and U concentrations did not reach steady state, the behavior of both elements for undamaged and fully damaged specimens is the same.

Figure 4.33 shows the $\log _{10}$ (rate) $\left[\mathrm{g} /\left(\mathrm{m}^{2} \cdot \mathrm{d}\right)\right]$ calculated from release of $\mathrm{Ca}, \mathrm{Gd}, \mathrm{Mo}$, $\mathrm{Pu}$, and $\mathrm{U}$ versus solution $\mathrm{pH}$ (at $90^{\circ} \mathrm{C}$ ) for the experiments with ${ }^{239} \mathrm{Pu}$-bearing ceramics in Teflon vessels. In the leachant with $\mathrm{pH} 2$, the rates based on $\mathrm{Ca}, \mathrm{Gd}$, and $\mathrm{U}$ are identical within experimental uncertainty, but the rate based on Pu release is lower, probably reflecting some solubility effects. In leachants with higher $\mathrm{pH}$ values, $\mathrm{Pu}$ concentrations

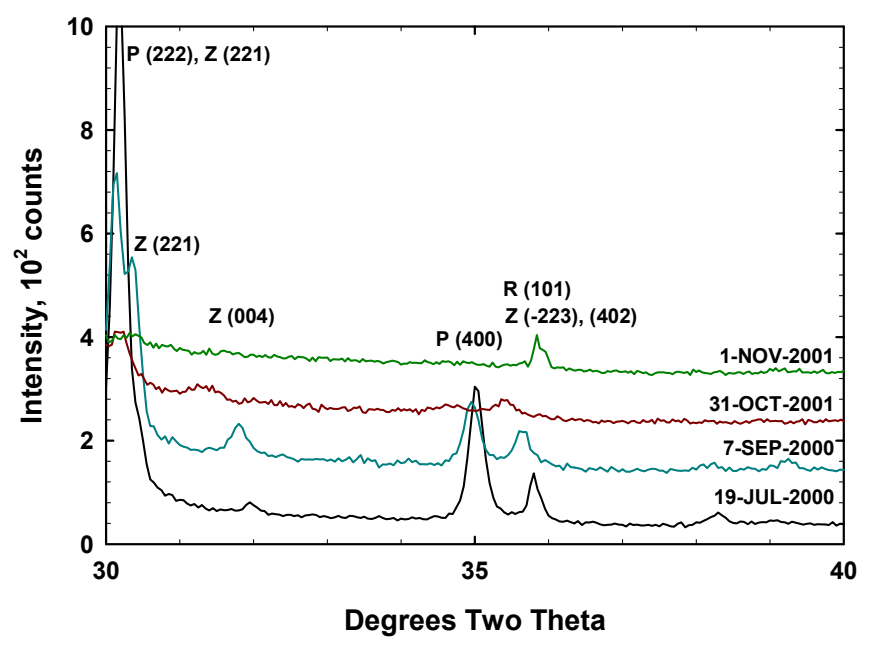

Figure 4.24. An Expanded View of the XRD Patterns from the ${ }^{238} \mathrm{Pu}$ Bearing Pyrochlore-Rich Baseline Ceramic Stored at $250^{\circ} \mathrm{C}(\mathrm{P}=$ Pyrochlore, $\mathrm{R}=$ Rutile, $\mathrm{Z}=$ Zirconolite)

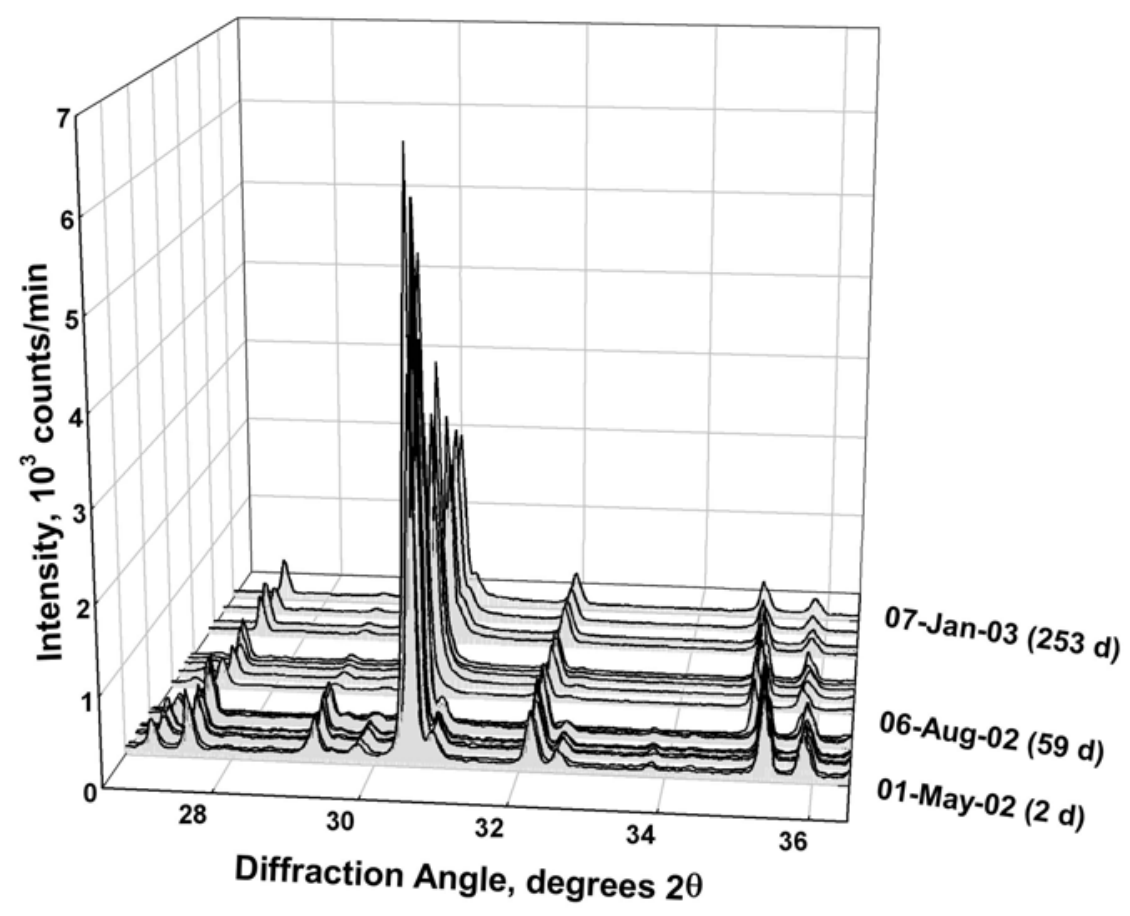

Figure 4.25. A Series of XRD Patterns from Resintered ${ }^{238} \mathrm{Pu}$-Bearing Pyrochlore-Rich Baseline Ceramic Stored at $250^{\circ} \mathrm{C}$ 
decrease to below the level of quantitation so that rates can not be reported. These results indicate that release of $\mathrm{Pu}$ is extremely slow at nearly every $\mathrm{pH}$ value, which may be an indication that $\mathrm{Pu}$ release is solubility controlled. Release rates based on $\mathrm{U}$ reach a broad minimum between $\mathrm{pH}$ values of $\sim 6$ to 9 , and then increase slightly. Release rates based on $\mathrm{Ca}$ in leachants with $\mathrm{pH}>2$ also show evidence for a broad minimum over the same $\mathrm{pH}$ interval, but the rates are about 10 times higher compared to the rates based on $\mathrm{U}$. The dissolution rates based on the Mo concentrations exhibit a maximum at a $\mathrm{pH}$ of approximately 7 .

In Figure 4.34, we show the release rates based on $\mathrm{Gd}, \mathrm{U}$, and ${ }^{239} \mathrm{Pu}$ from the specimen in the $\mathrm{pH} 2$ leachant. Note that elements achieve steady-state conditions after $\sim 200$ days and that the dissolution rates converge on a single value within the experimental uncertainty.

Figure 4.35 show the results for the flow rate dependence, expressed as $q / S$, of the dissolution rate for radioactive and nonradioactive specimens. The rates were computed from the Gd release. Data for the ${ }^{238} \mathrm{Pu}$-bearing specimens were determined from the experiments conducted with the titanium vessels. The figure shows that, at values of $\log _{10}(q / S)\left[\mathrm{m} \mathrm{s}^{-1}\right]<-8$, dissolution rates of the pyrochlore-rich baseline specimens decrease in a manner consistent with a reaction affinity mechanism. At $\log _{10}$ $(q / S)$ values of $>-9$ the dissolution rate becomes independent of $q / S$, signifying that release of $\mathrm{Gd}$ is at the forward rate of reaction. Note that the two ${ }^{238} \mathrm{Pu}$-bearing specimens plot on this diagram close to the forward rate of reaction. As with the comparison between the monolithic and the powdered specimens, some of this difference may be attributable to the differences in porosity. As with the "pure phase" pyrochlore specimens, the difference between the monolithic specimens and the powdered specimens is about a factor of 3 . Visually, however, the agreement looks better because this is a log-log graph, and the range of the respective data is about $7 \cdot 10^{-3} \mathrm{~g} /\left(\mathrm{m}^{2} \cdot \mathrm{d}\right)$ and $2 \cdot 10^{-2} \mathrm{~g} /\left(\mathrm{m}^{2} \cdot \mathrm{d}\right)$ for the powdered and monolithic specimens, respectively.

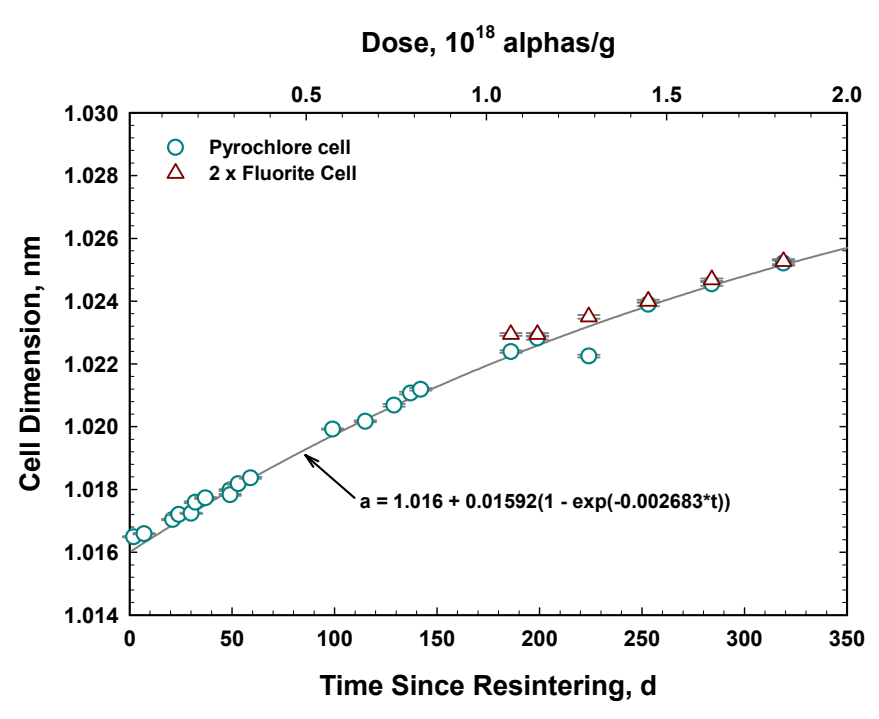

Figure 4.26. The Variation of the $\mathrm{a}_{0}$ Lattice Parameter for the Pyrochlore Phase in the ${ }^{238} \mathrm{Pu}$-Bearing Pyrochlore-Rich Baseline Ceramic

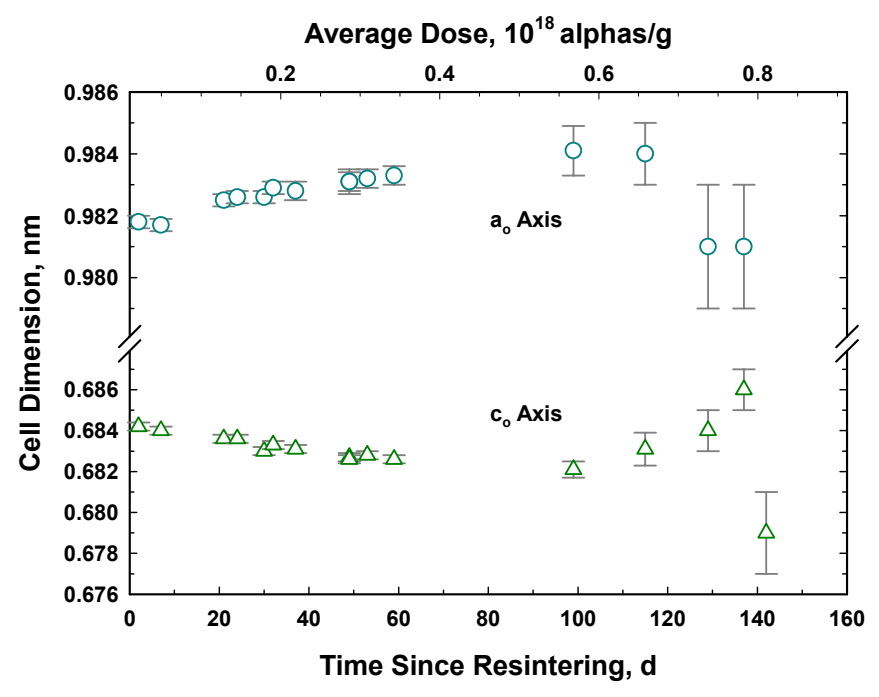

Figure 4.27. The Variation of $\mathrm{a}_{0}$ and $\mathrm{c}_{0}$ in the Brannerite Phase in the ${ }^{238} \mathrm{Pu}$-Bearing Pyrochlore-Rich Baseline Ceramic Stored at $250^{\circ} \mathrm{C}$ 
To summarize this section, the release of $\mathrm{Pu}$ is very slow, even at $\mathrm{pH} 2$ and $85^{\circ}$ to $90^{\circ} \mathrm{C}$. At higher $\mathrm{pH}$ values, concentrations of $\mathrm{Pu}$ are below the lower limit of quantification, which likely indicates that $\mathrm{Pu}$ is solubility-limited. Uranium release at $\mathrm{pH} 2$ is also very slow with rates identical to or slightly higher than those based on the $\mathrm{Pu}$ concentrations. At higher $\mathrm{pH}$ values, the release rate based on $\mathrm{U}$ is lower and may also indicate solubility control. The fact that the fully radiation-damaged (original) and resintered ${ }^{238} \mathrm{Pu}$-bearing specimens yield overlapping dissolution rates is significant. Further, these rates are nearly identical to the forward rate of reaction at $85^{\circ} \mathrm{C}$ to $90^{\circ} \mathrm{C}$ and $\mathrm{pH}=2$.

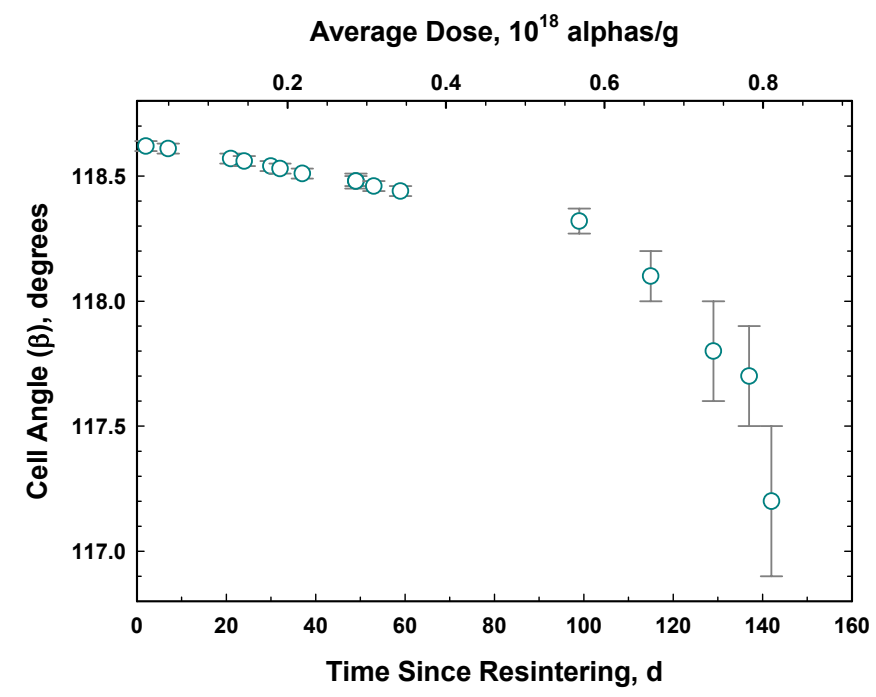

Figure 4.28. The Variation of the Cell Angle $(\beta)$ in the Brannerite Phase in ${ }^{238} \mathrm{Pu}$-Bearing Pyrochlore-Rich Baseline Ceramic Stored at $250^{\circ} \mathrm{C}$

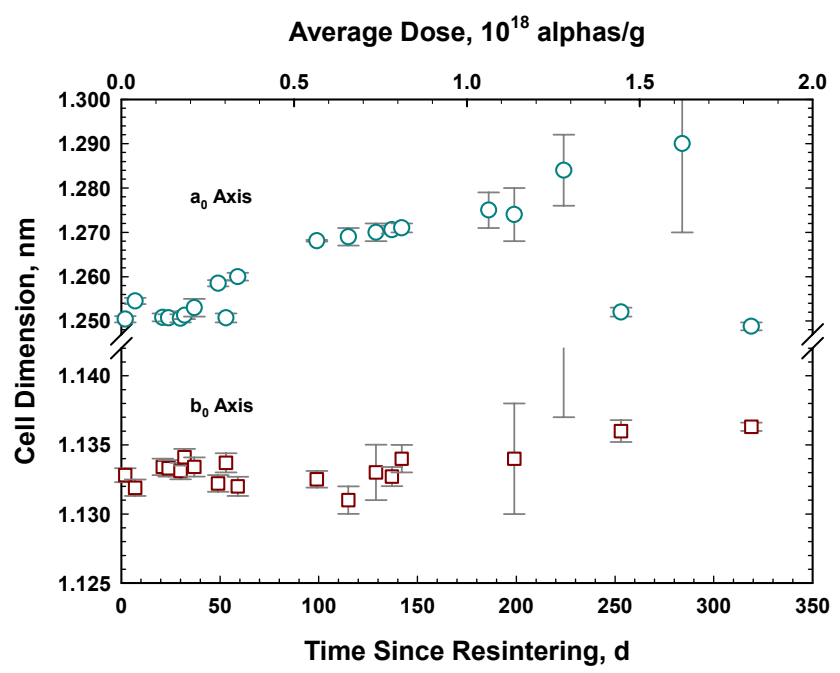

Figure 4.29. The Variation of the $\mathrm{a}_{0}$ and $\mathrm{b}_{0}$ Lattice Parameters for the Zirconolite Phase in ${ }^{238} \mathrm{Pu}$-Bearing Pyrochlore-Rich Baseline Ceramic Stored at $250^{\circ} \mathrm{C}$ 


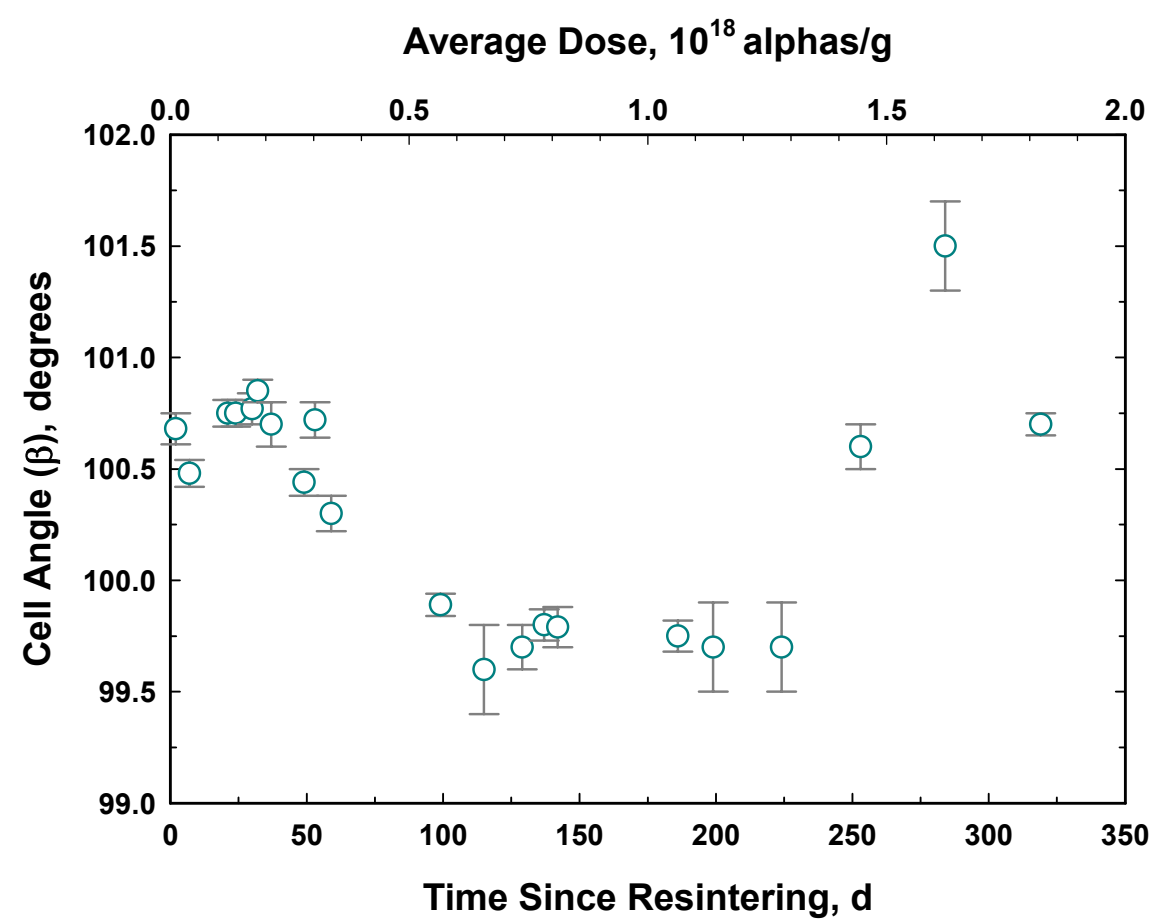

Figure 4.30. The Variation of the Cell Angle $(\beta)$ for the Zirconolite Phase in ${ }^{238} \mathrm{Pu}$-Bearing Pyrochlore-Rich Baseline Ceramic Stored at $250^{\circ} \mathrm{C}$

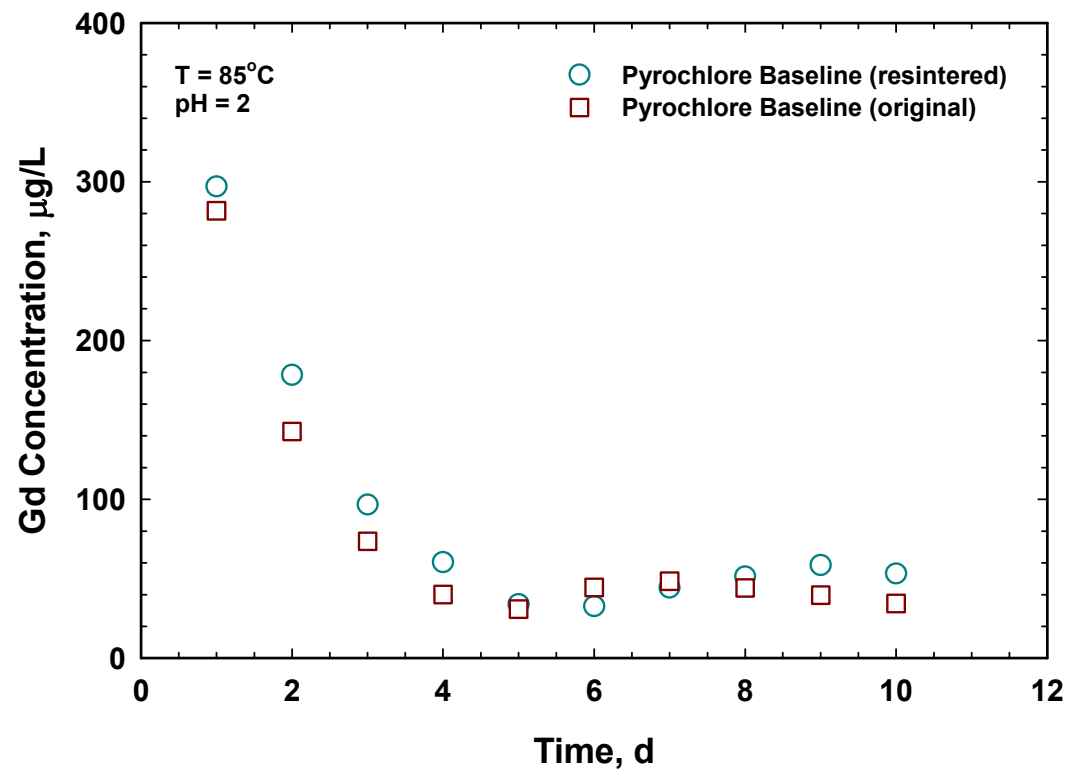

Figure 4.31. Plot of Gd Concentration $(\mu \mathrm{g} / \mathrm{L})$ for the ${ }^{238} \mathrm{Pu}$-Bearing Pyrochlore-Baseline Tested in the Titanium Reactor System 

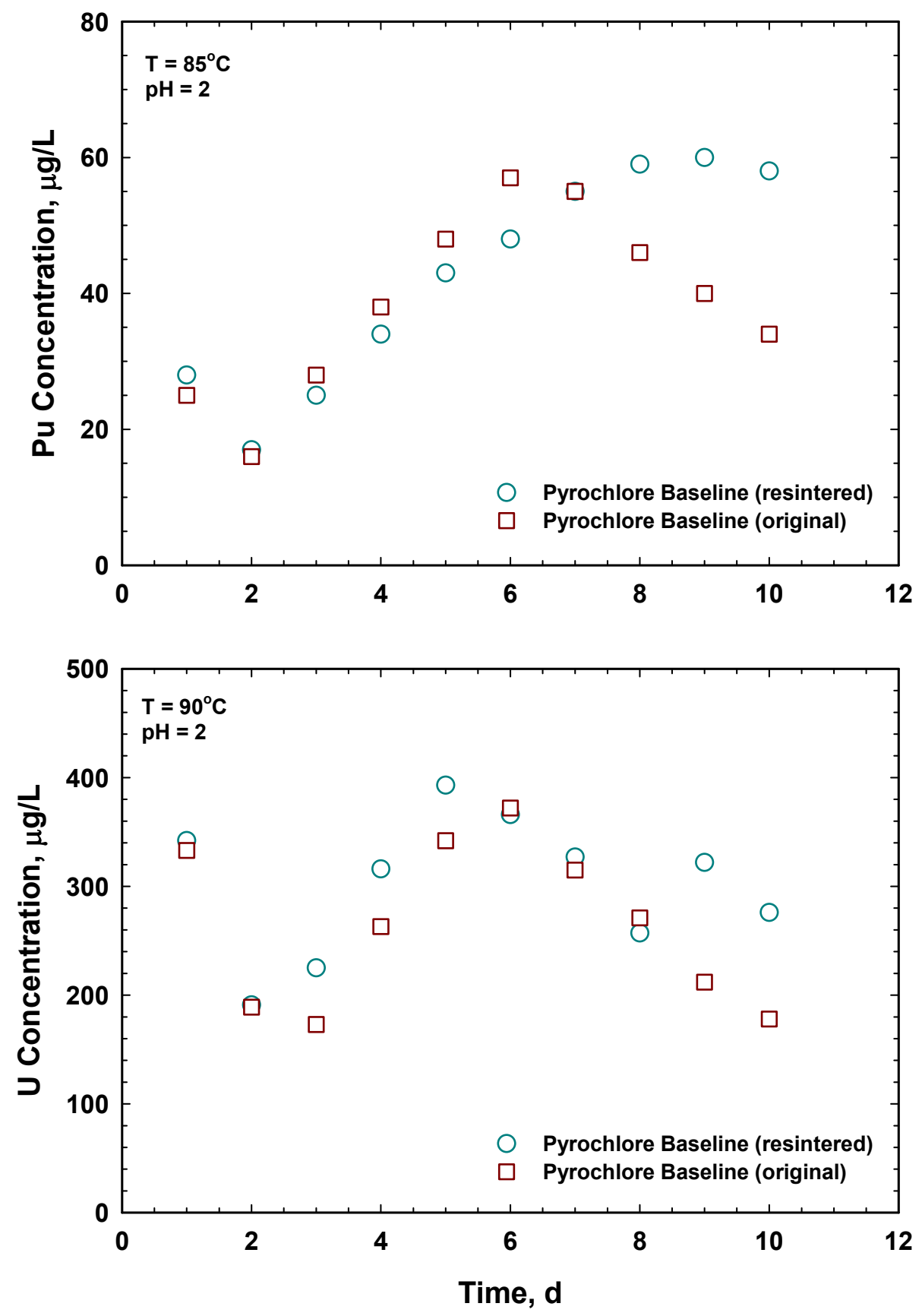

Figure 4.32. Plot of Element Concentrations from the ${ }^{238} \mathrm{Pu}$-Bearing PyrochloreBaseline Tested in the Titanium Flow Reactor System at $85^{\circ} \mathrm{C}$ and $\mathrm{pH}$ 2. (A.) Plutonium Concentrations (GEA), and (B.) Uranium Concentrations. 


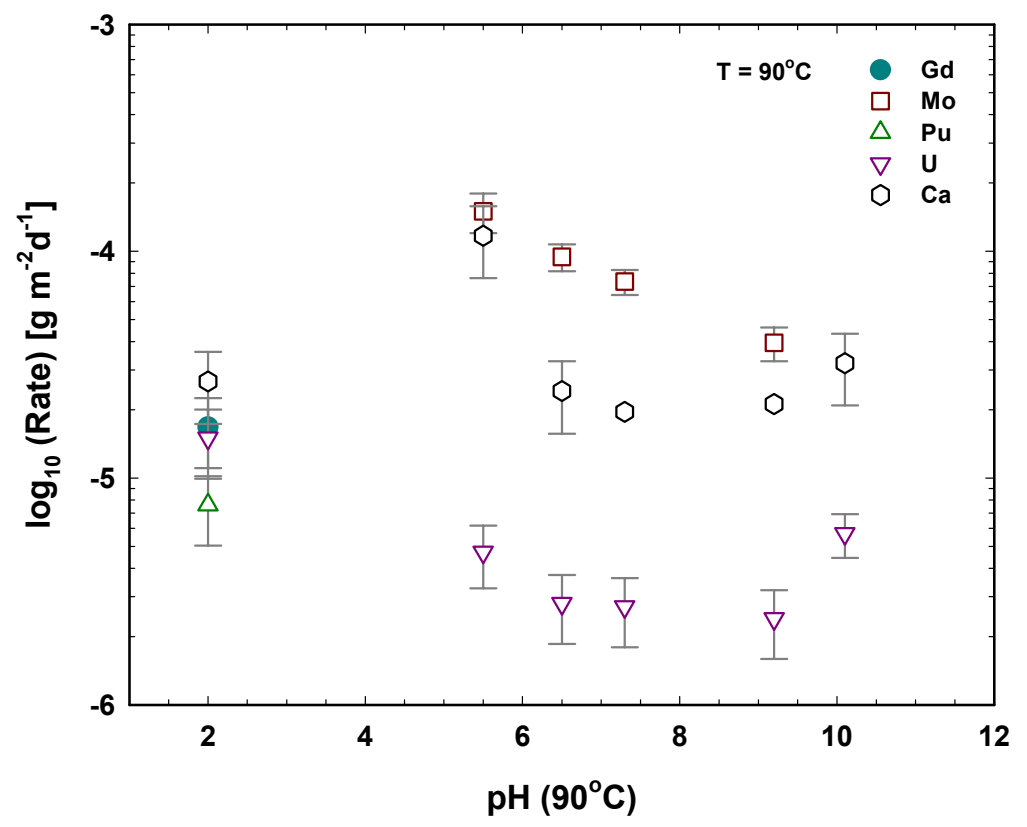

Figure 4.33. Plot of $\log _{10}$ (Rate) $\left[\mathrm{g} /\left(\mathrm{m}^{2} \cdot \mathrm{d}\right)\right]$ Versus $\mathrm{pH}$ for the ${ }^{239} \mathrm{Pu}-$ Bearing Pyrochlore-Rich Baseline Ceramic at $90^{\circ} \mathrm{C}$

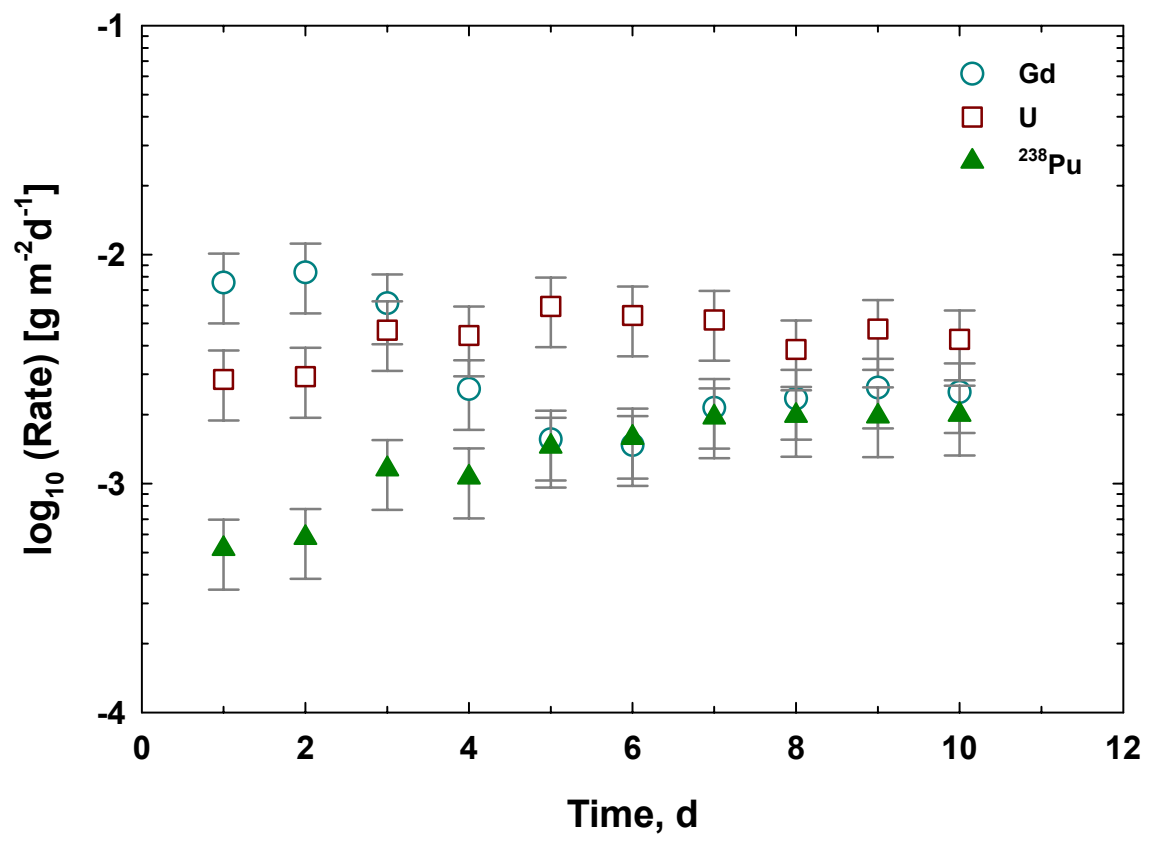

Figure 4.34. Plot of $\log _{10}($ Rate $)\left[\mathrm{g} /\left(\mathrm{m}^{2} \cdot \mathrm{d}\right)\right]$ Versus Time for the ${ }^{239} \mathrm{Pu}$-Bearing Pyrochlore-Rich Baseline Ceramic at $90^{\circ} \mathrm{C}$ and $\mathrm{pH} 2$ 


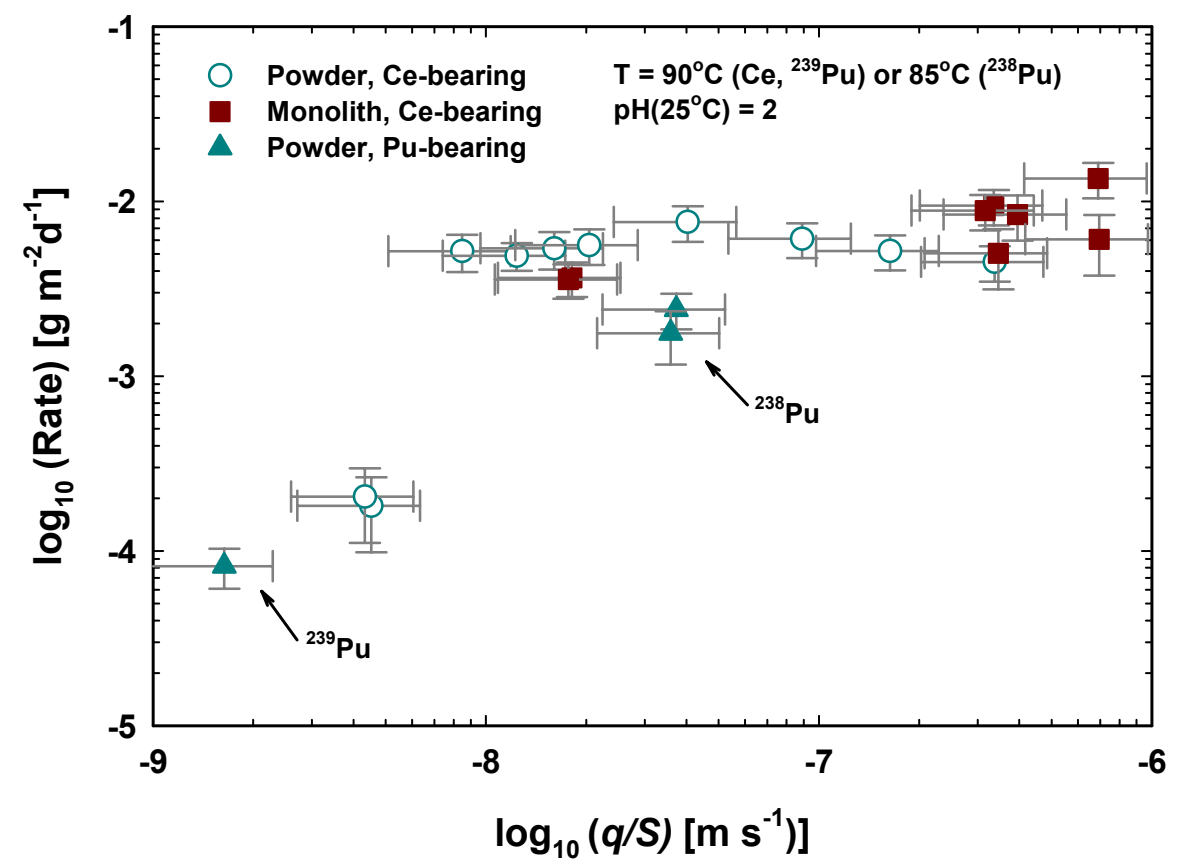

Figure 4.35. Plots of $\log _{10}($ Rate $)\left[\mathrm{g} /\left(\mathrm{m}^{2} \cdot \mathrm{d}\right)\right]$ Versus $\log _{10}(q / S)[\mathrm{m} / \mathrm{s}]$ for Pyrochlore-Baseline Ceramics at $90^{\circ} \mathrm{C}$ and $\mathrm{pH} 2$ 


\subsection{Radiation Damage Effects in ${ }^{238}$ Pu-Bearing Zirconolite}

The results from the studies of radiation damage on the density, crystal structure, and dissolution rate of "phase-pure" zirconolite specimens from self irradiation with ${ }^{238} \mathrm{Pu}$ are reported. We put "phase-pure" in quotation marks because the specimen actually contained more than single-phase zirconolite, despite our attempts to make a single-phase ceramic.

\subsection{Preparations}

A single batch was prepared on 13-July-1999. A number of these pellets were sintered at $1350^{\circ} \mathrm{C}$ for an additional 110 hours to coarsen the microstructure (23-July-1999). Ceramics with a coarse microstructure were thought to be more susceptible to microcracking than ones with a fine microstructure. The target compositions are shown in Table 5.1.

The $\mathrm{PuO}_{2}$ composition corresponds to 6.5 mass $\% \mathrm{Pu}$ - the lowest $\mathrm{Pu}$ content of the materials in this study. This target composition suggests a formula $\mathrm{Ca}_{0.85} \mathrm{Al}_{0.04} \mathrm{Gd}_{0.05} \mathrm{Hf}_{0.95} \mathrm{Pu}_{0.13} \mathrm{U}_{0.03} \mathrm{Ti}_{1.96} \mathrm{O}_{7.32}$. However, as will be seen below, there are at least three other phases in addition to zirconolite. Had the extra phases been just Hf-rutile $\left[(\mathrm{Hf}, \mathrm{Ti}) \mathrm{O}_{2}\right]$ and $\mathrm{Hf}$-srilankite $\left[\mathrm{HfTiO}_{4}\right]$, we might have attempted to derive a chemical formula for the zirconolite in these specimens, but the presence of significant quantities of brannerite confounds this derivation.

Table 5.1. The Target Oxide Composition of the Zirconolite Ceramics Used in this Study

\begin{tabular}{|l|c|c|}
\hline \multirow{2}{*}{ Component } & ${ }^{\mathbf{2 3 8}} \mathbf{P u - ~ a n d ~}{ }^{\mathbf{2 3 9}} \mathbf{P u}$-Zirconolite \\
\cline { 2 - 3 } & Mass\% & Mole\% \\
\hline $\mathrm{Al}(\mathrm{OH})_{3}$ & 1.74 & 1.97 \\
\hline $\mathrm{CaO}$ & 10.2 & 21.03 \\
\hline $\mathrm{Gd}_{2} \mathrm{O}_{3}$ & 2.06 & 0.66 \\
\hline $\mathrm{HfO}_{2}$ & 43.08 & 23.66 \\
\hline $\mathrm{MoO}_{3}$ & 0.1 & 0.09 \\
\hline $\mathrm{PuO}_{2}$ & 7.4 & 3.17 \\
\hline $\mathrm{TiO}_{2}$ & 33.61 & 48.63 \\
\hline $\mathrm{UO}_{2}$ & 1.81 & 0.79 \\
\hline
\end{tabular}




\subsection{Results and Discussion}

\subsubsection{Physical Appearance}

A photograph of a typical zirconolite specimen is shown in Figure 5.1. The specimens were produced as right circular cylinders. The typical surface flaws that occur in most of the zirconolite specimens are shown in the specimen (Figure 5.1). These surface flaws, which presumably occur throughout the bulk of the specimen, result in low measured bulk densities. The flaws shown on the surface may or may not be interconnected so that the densities measured with the He pycnometer may be affected.

\subsubsection{Density Measurements}

Helium Pycnometer Results. The results of the He pycnometer measurements of the "true" density of the ${ }^{238} \mathrm{Pu}$ - and ${ }^{239} \mathrm{Pu}$-bearing zirconolite specimens are shown in Figure 5.2. Although there is much scatter in the density data for the ${ }^{239} \mathrm{Pu}$-bearing specimens, we do not expect the density to change significantly over the course of the experiment. Thus, within the scatter of the data, the density is $5.610(75) \cdot 10^{3} \mathrm{~kg} / \mathrm{m}^{3}$ and appears to be temperature independent (dashed line in Figure 5.2). For the data from the ${ }^{238} \mathrm{Pu}$ bearing specimens, two least-squares fits were used. Equation 3.1 was used for the data from the specimens stored at $20^{\circ} \mathrm{C}$ and $125^{\circ} \mathrm{C}$. The values are $\rho_{s}=4.952(93) \cdot 10^{3} \mathrm{~kg} / \mathrm{m}^{3}$ and $5.300(69) \cdot 10^{3} \mathrm{~kg} / \mathrm{m}^{3}, b=0.92(11) \cdot 10^{3} \mathrm{~kg} / \mathrm{m}^{3}$ and $0.56(7) \cdot 10^{3} \mathrm{~kg} / \mathrm{m}^{3}$, and $c=0.0023(7)$ and 0.0017(5) for the $20^{\circ} \mathrm{C}$ and $125^{\circ} \mathrm{C}$ data, respectively. The intercept and slope of the straight line drawn through the two $250^{\circ} \mathrm{C}$ data are $5.89 \cdot 10^{3} \mathrm{~kg} / \mathrm{m}^{3}$ and $-0.23 \mathrm{~kg} /\left(\mathrm{m}^{3} \cdot \mathrm{d}\right)$, respectively. An extra data point was added to the $125^{\circ} \mathrm{C}$ data when the least-squares analysis

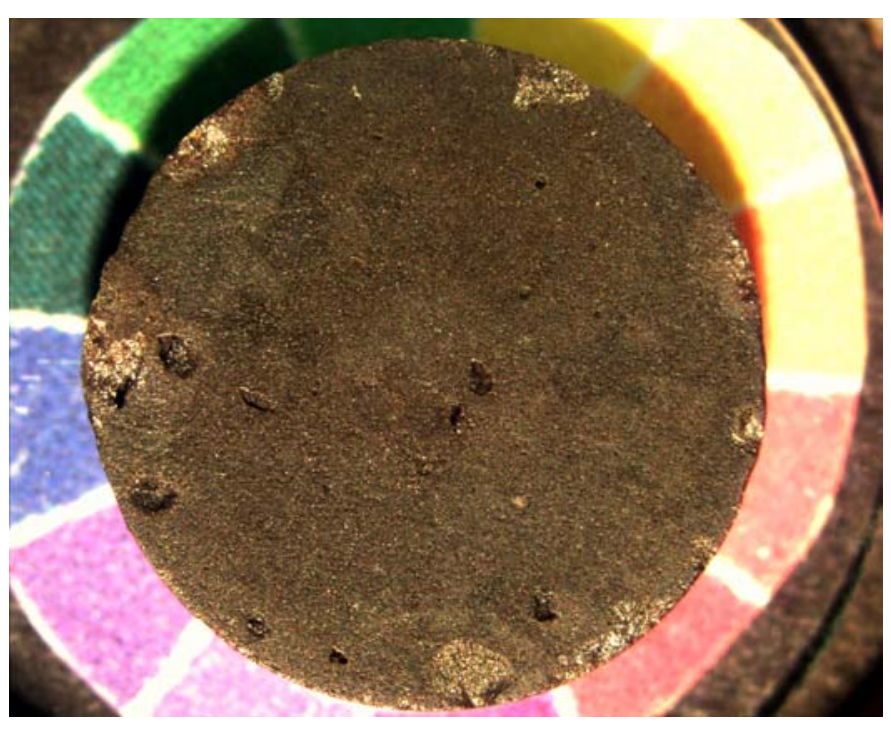

Figure 5.1. Top View of a Typical ${ }^{238} \mathrm{Pu}$-Bearing Zirconolite Specimen

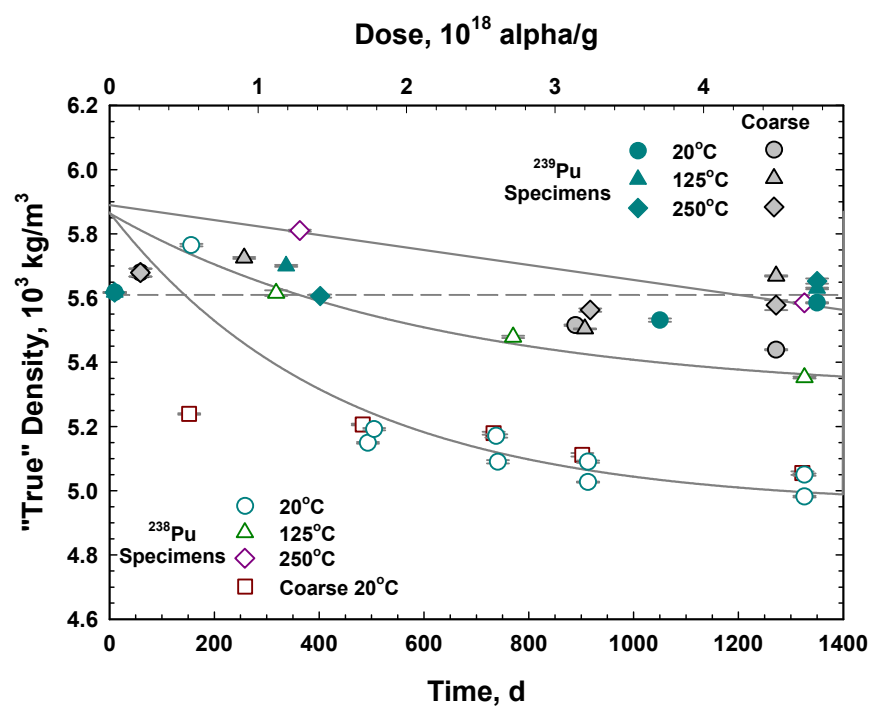

Figure 5.2. The Change in "True" Density with Increasing Radiation induced Damage for ${ }^{238} \mathrm{Pu}$ - and ${ }^{239} \mathrm{Pu}$-Bearing Zirconolite Specimens Stored at $20^{\circ} \mathrm{C}$, $125^{\circ} \mathrm{C}$, and $250^{\circ} \mathrm{C}$. The solid lines are least-squares fits to the ${ }^{238} \mathrm{Pu}$ data, and the dashed line is from a linear least-squares fit to the ${ }^{239} \mathrm{Pu}$ data. 
was performed so that the starting density was the same starting density as the $20^{\circ} \mathrm{C}$ specimens. This value, $5.869 \cdot 10^{3} \mathrm{~kg} / \mathrm{m}^{3}$ is similar to the intercept for the linear fit to the $250^{\circ} \mathrm{C}, 5.89 \cdot 10^{3} \mathrm{~kg} / \mathrm{m}^{3}$. These results also suggest that there is no difference between the specimens that were sintered for 8 hours and those for 100 hours (coarse zirconolite). From the extrapolated densities, the change in density from the start to saturation is $16 \%$ and $9.6 \%$ for the $20^{\circ} \mathrm{C}$ and $125^{\circ} \mathrm{C}$ data, respectively. There are insufficient data to determine the saturation value for the specimens that were held at $250^{\circ} \mathrm{C}$. The magnitude of the changes in the "true" densities is likely caused by the increase in closed porosity as the individual grains swell and close access to what was open porosity and accessible to the He gas. This conclusion will be strengthened by the results in the next section where the bulk swelling is incommensurate with the large changes in "true" density.

Geometric Densities. As seen in the picture of a typical specimen (Figure 5.1), there are chips on the edge of the specimen. This, combined with a $20-\mu \mathrm{m}$ wobble in the table, caused a significant variation in the measured height of the specimen and a concomitant uncertainty in the calculated geometric density of the specimen. Therefore, as a measure of the change in the geometric density, we show the change in diameter of the specimen with increasing dose (Figure 5.3). Here the diameters of all the specimens stored at all temperatures are shown. There is no discernable difference between specimens stored at any temperature. The initial (day zero) measurement of the diameter was done with a hand-held micrometer. This value, $10.94(6) \mathrm{mm}$, is an average of 25 specimens and agrees well with the extrapolated value of $10.88(4) \mathrm{mm}$ from a linear fit of the diameter measurements between 338 and 924 days. Using a value of $11.13 \mathrm{~mm}$ for the saturation value for the specimens and the starting value of $10.94 \mathrm{~mm}$, we calculate a $1.7 \%$ increase from radiation induced swelling or a $4.9 \%$ decrease in the density of the specimens when approximately $5 \cdot 10^{18} \alpha / \mathrm{g}$ have accumulated. Given this small increase in the diameter of the ${ }^{238} \mathrm{Pu}-$ bearing specimens, we did not expect a measurable change in the diameter of the ${ }^{239} \mathrm{Pu}$-bearing specimens from radiation induced swelling. This decrease in the geometric density of the ${ }^{238} \mathrm{Pu}$-bearing specimens is inconsistent with the "true" density changes discussed above. The most probable explanation for this is that as the individual grains swell, increasing amounts of internal and surface-connected porosity become sealed and cannot be accessed by the He gas in the pycnometer. This leads to a much more rapid change in the "true" density relative to the changes in the geometric density.

For the ${ }^{239} \mathrm{Pu}$-bearing specimens, the bulk density was calculated to be $5.14(2) \cdot 10^{3}$ $\mathrm{kg} / \mathrm{m}^{3}$; for the ${ }^{238} \mathrm{Pu}$-bearing specimens, $5.36(1) \cdot 10^{3} \mathrm{~kg} / \mathrm{m}^{3}$ after 179 days of damage accumulation. Using the chemical formula derived in Section 5.1 and the projected phase composition, we calculated a theoretical density of $6.2 \cdot 10^{3} \mathrm{~kg} / \mathrm{m}^{3}$ for these zirconolite specimens. If this value is accurate, then the specimens produced have $95 \%$ of the theoretical density based on the "true" densities, and the bulk densities are about $86 \%$ of theoretical. This implies $9 \%$ closed porosity.

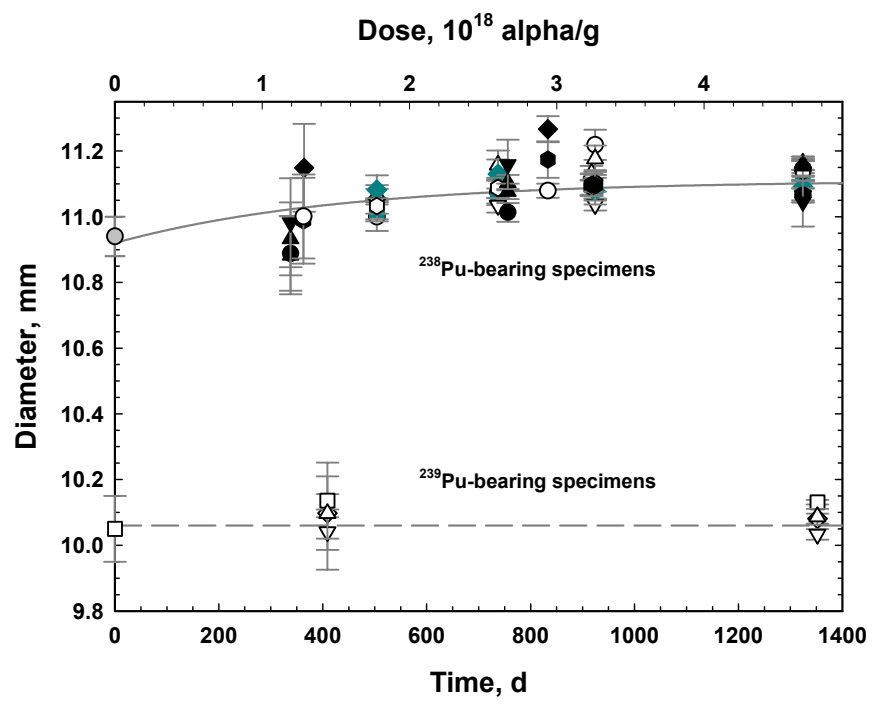

Figure 5.3. The Change in the Diameter of all Zirconolite Specimens with Increasing Alpha Dose 


\subsection{Scanning Electron Microscopy}

In this Section, we discuss the results from our SEM examination of original ${ }^{238} \mathrm{Pu}$ - and ${ }^{239} \mathrm{Pu}$-bearing zirconolite specimens that were stored at $20^{\circ} \mathrm{C}$. The results of the examination of the ${ }^{238} \mathrm{Pu}$ zirconolite ceramics are shown in Figure 5.4 through Figure 5.6. The secondary electron image shows the holes and pores in the material (Figure 5.4), whereas the backscattered electron image shows the difference in average atomic number more clearly (Figure 5.5). By combining these images, both the contrast (effective atomic number) and the surface defects can be observed (Figure 5.6). In Figure 5.6, the BSE and SE images have been combined and colorized to separate out the different phases: rutile (blue), pyrochlore (green), zirconolite (dark green), and brannerite (red). In the XRD patterns (see below), pyrochlore was not detected. It is possible that both phases are zirconolite (green and dark green) but with some compositional variation or the subtile variations result from electron channeling. The blue regions around the black have incorrect contrast as these are pores in the ceramic. The white box outlines the area of the sample that is examined more closely in the next sequence of images (see Figure 5.9 through Figure 5.11).

There were differences between the ${ }^{238} \mathrm{Pu}$ and ${ }^{239} \mathrm{Pu}$ ceramic microstructure. In particular, the distribution of rutile in the ${ }^{238} \mathrm{Pu}$ ceramics was intergranular, whereas the rutile tended to occur as discrete grains within the ${ }^{239} \mathrm{Pu}$ ceramic (Figure 5.7 and Figure 5.8). Figure 5.7 shows the lower magnifcation image of the ${ }^{239} \mathrm{Pu}$ analog sample that does not exhibit as much porosity. In Figure 5.9 and Figure 5.10, the SEM images show a concentric-spherulitic grain that possesses multiple shells with different contrast. The particle consists of three different compositions based on backscattered electron contrast. This is unlikely to be due to thickness variations or electron channeling; the sequence of light, darker, lighter indicates that this is an actual compositional profile. Again, actinide oxide inclusions are observed through the pyrochlore. The inclusions associated with the rutile (black contrast) are from skrilankite-like composition $\left(\mathrm{HfTiO}_{4}\right)$.

In Figure 5.11, rutile appears as the darkest and occurs as anhedral precipitates in the interstitial grannular regions. This indicates that this phase formed after the pyrochlore. Compared to the ${ }^{239} \mathrm{Pu}$ analog sample, the distribution of rutile is quite different. In some instances, the rutile itself appears to have undergone an exsolution, resulting in the precipitation of a $\mathrm{Hf}$ titanate (the white phase within the black in Figure 5.11). This phase may be a Hf-srilankite $\left(\mathrm{Hf}_{1-\mathrm{x}} \mathrm{Ti}_{\mathrm{x}} \mathrm{O}_{4}\right)$ related structure. The EDS of this phase is shown in Figure 5.12. Zirconium titanate ceramics similar to those observed in this study have been produced by solid-state reaction process using oxide $\mathrm{ZrO}_{2}$ and $\mathrm{TiO}_{2}$. By reacting in the presence of transition metal oxides and rare earth oxides, the formation temperature can be lowered to around $1100^{\circ} \mathrm{C}$. Kong et al. (2002) have reported solid solutions of $\left(\mathrm{Zr}_{1-x} \mathrm{Ti}_{x}\right) \mathrm{O}_{2}(x=0.44,0.48,0.52$ and 0.60$)$ with a srilankite structure that were produced ball-milling and sintering powders of $\mathrm{ZrO}_{2}$ and $\mathrm{TiO}_{2}$. natural srilankite is sometimes reported as $\mathrm{ZrTi}_{2} \mathrm{O}_{6}$. In Table 5.2, the backscattered contrast factors have been calculated based on the srilankite $\left(\mathrm{ZrTiO}_{4}\right)$ unit cell. The average $\mathrm{Z}$ contrast for a $\mathrm{Hf}$ srilankite would be predicted to be similar to a Pu-bearing pyrochlore. This illustrates that backscattered electron contrast can be deceptive for estimating actinide content. Figure 5.13 and Figure 5.14 show spectra from zirconolite and an actinide-rich phase. Although there is a large amount of zirconolite in the ceramic, this phase is not an effective immobilizing agent for Pu based on the EDS composition. The plutonium-rich actinide particle EDS analysis shown in Figure 5.14 is from a particle shown in Figure 5.10 as a small bright round inclusion within the zirconolite. 


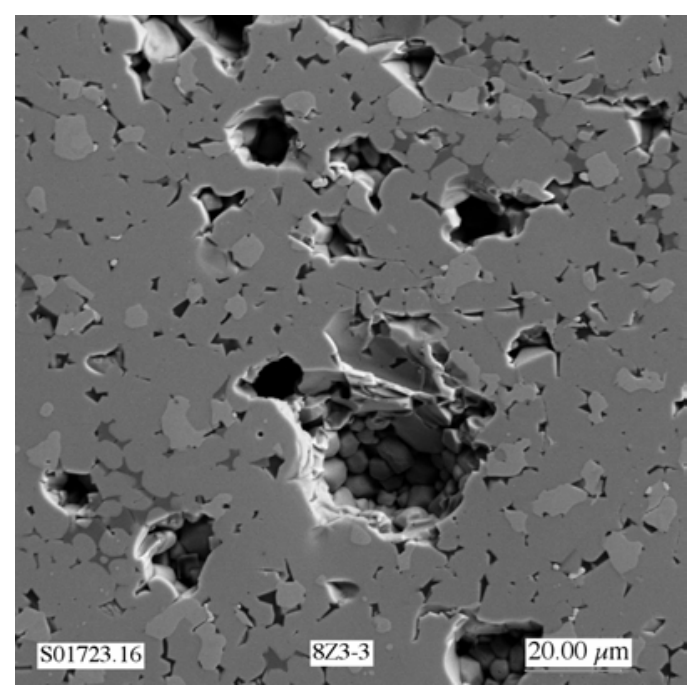

Figure 5.4. Secondary Electron Image of ${ }^{238} \mathrm{Pu}$ Zirconolite Ceramic (Stored at $20^{\circ} \mathrm{C}$; Fully Damaged)

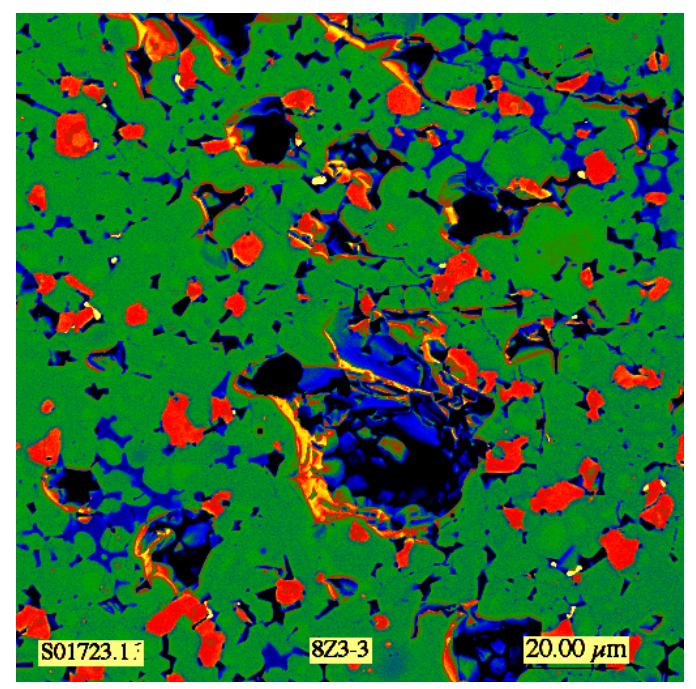

Figure 5.6. Combined Backscattered Electron and Secondary Electron Images

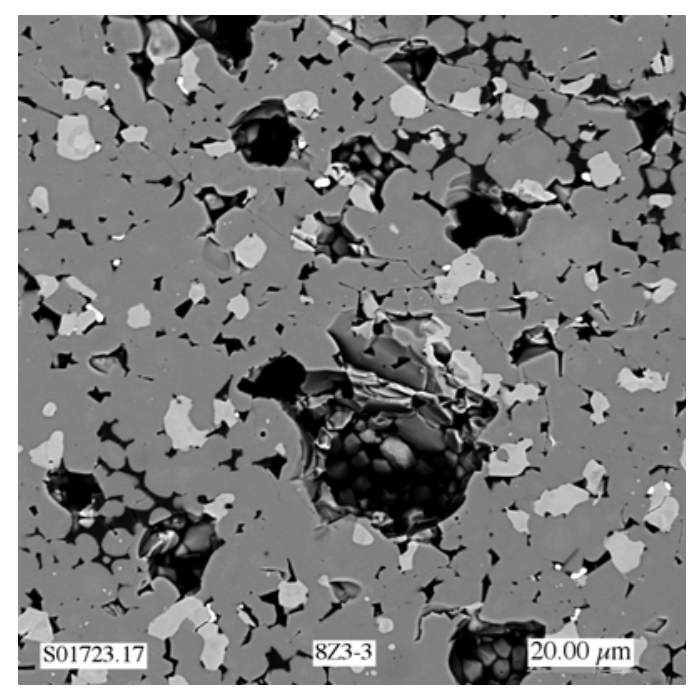

Figure 5.5. Backscattered Electron Image of ${ }^{238} \mathrm{Pu}$ Zirconolite Ceramic (Stored at $20^{\circ} \mathrm{C}$; Fully Damaged)

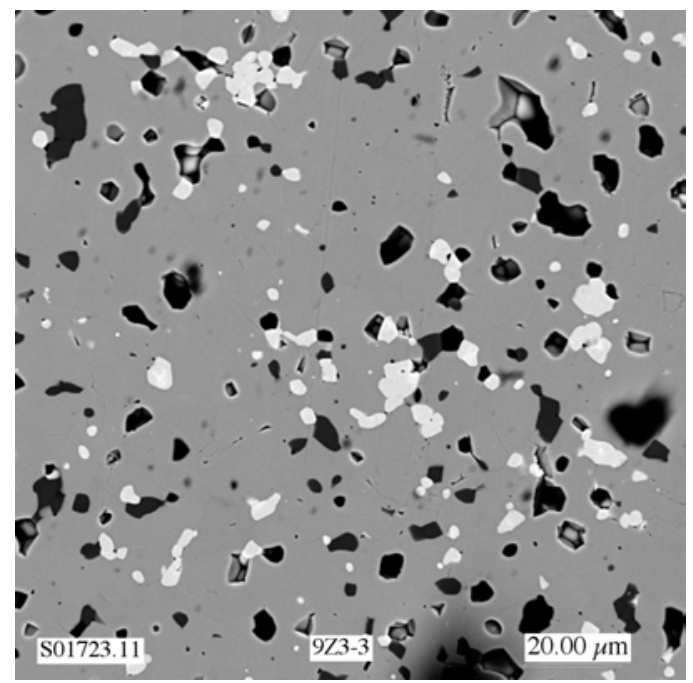

Figure 5.7. Scanning Electron Microscope Image of Microstructure from the ${ }^{239} \mathrm{Pu}$ Zirconolite Formulation 


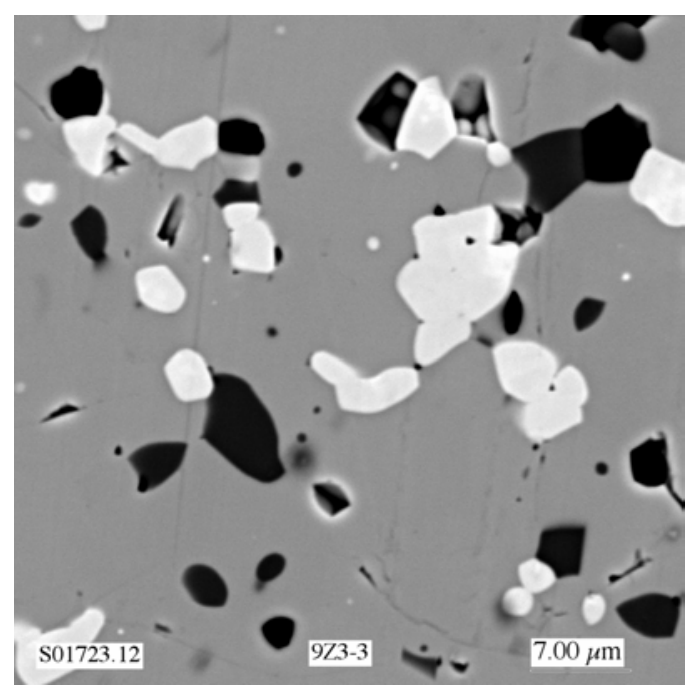

Figure 5.8. Higher Magnification Image of ${ }^{239} \mathrm{Pu}$ Zirconolite. The phase distribution in this ceramic appeared to be more uniform than the ${ }^{238} \mathrm{Pu}$ version.

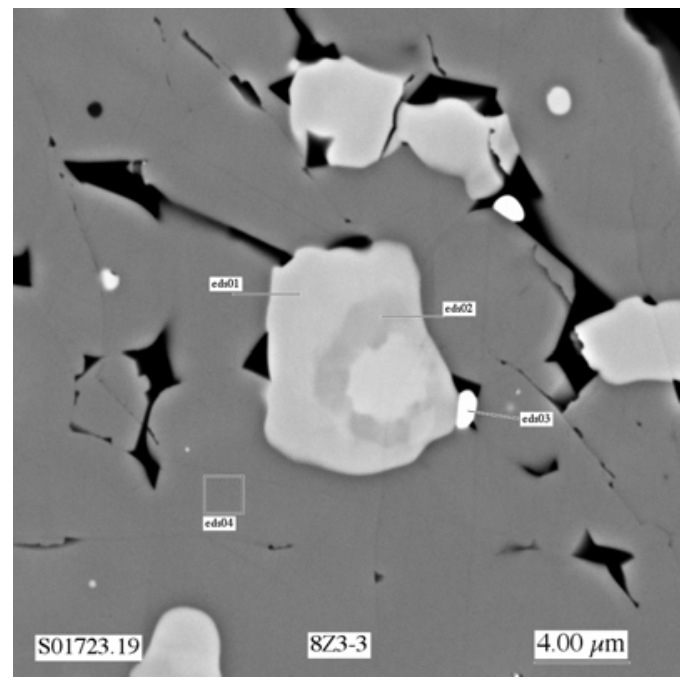

Figure 5.10. Higher Magnification Images of Region Highlighted in Figure 5.4

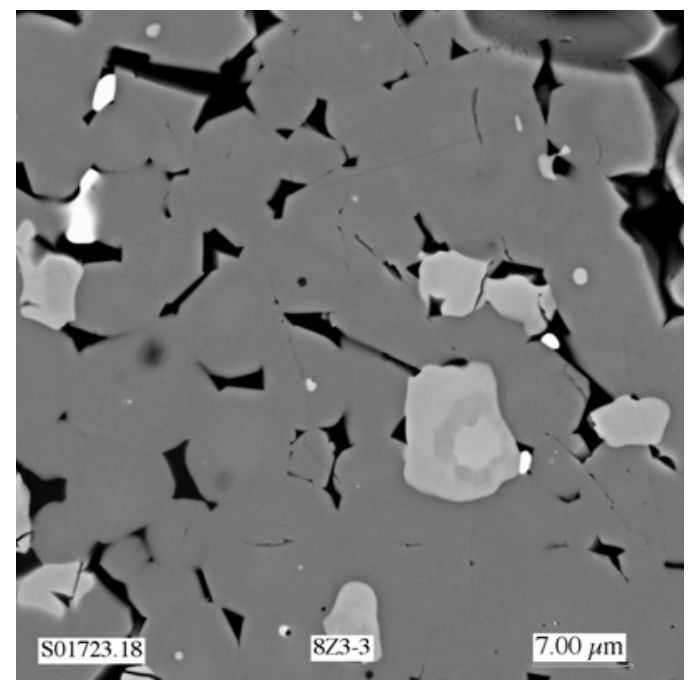

Figure 5.9. Low Magnification Image of ${ }^{238} \mathrm{Pu}$ Pyrochlore Ceramic

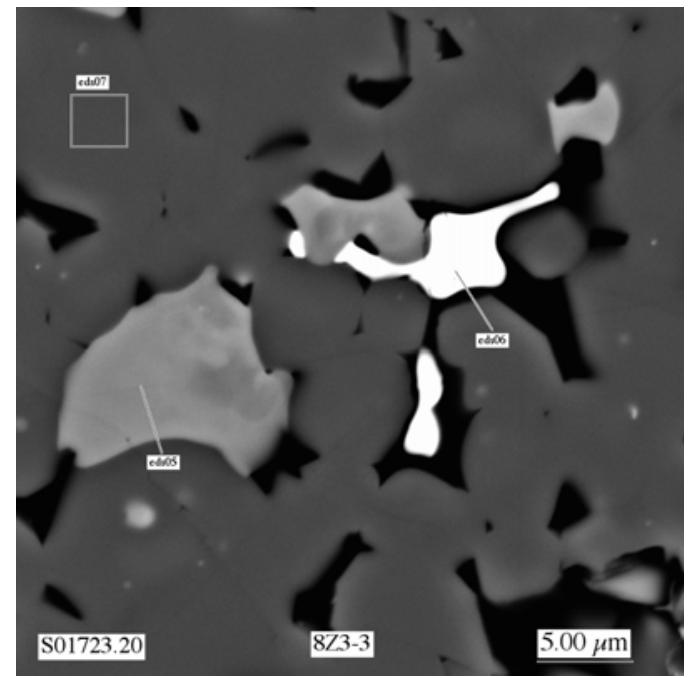

Figure 5.11. Mixture of Different Phases. Each phase has a rind of rutile. 


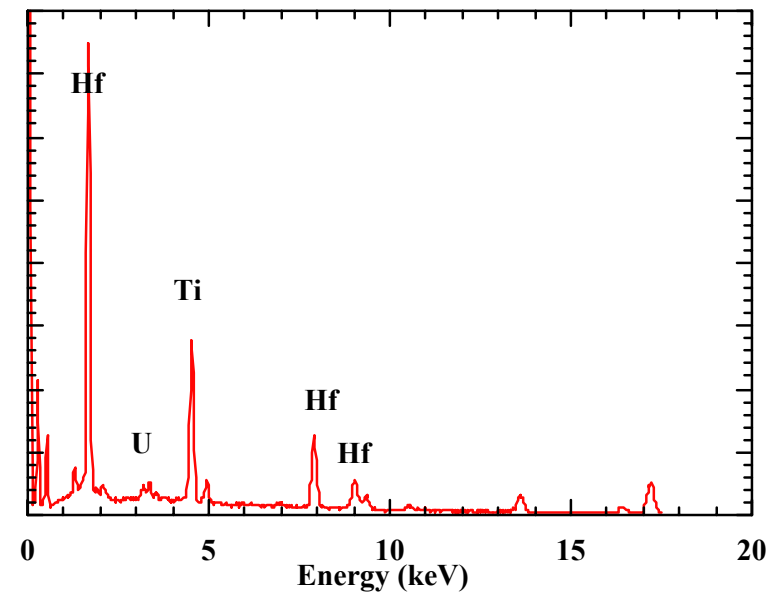

Figure 5.12. The Hf-Srilankite $\left(\mathrm{HfTiO}_{4}\right)$ Phase Has the Brightest Contrast in the Ceramic

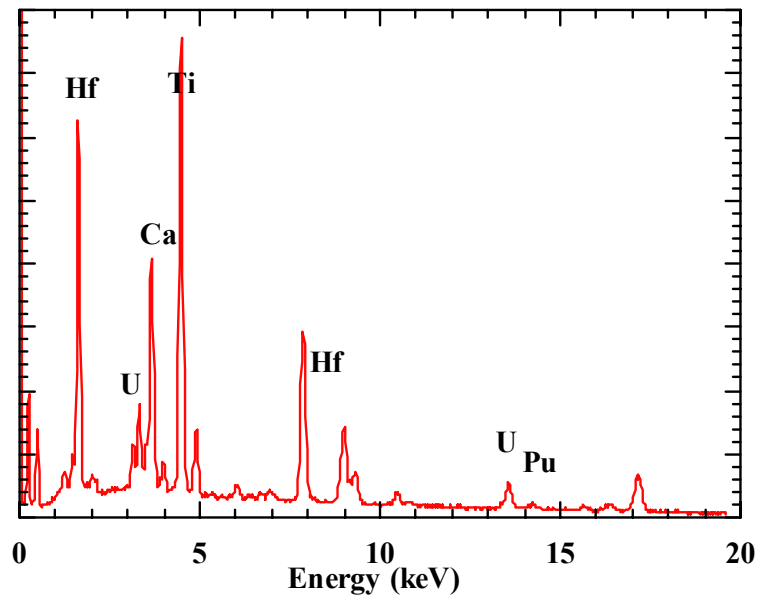

Figure 5.13. Zirconolite-Composition Showing Higher Levels of Hf in the Phase than a Pyrochlore

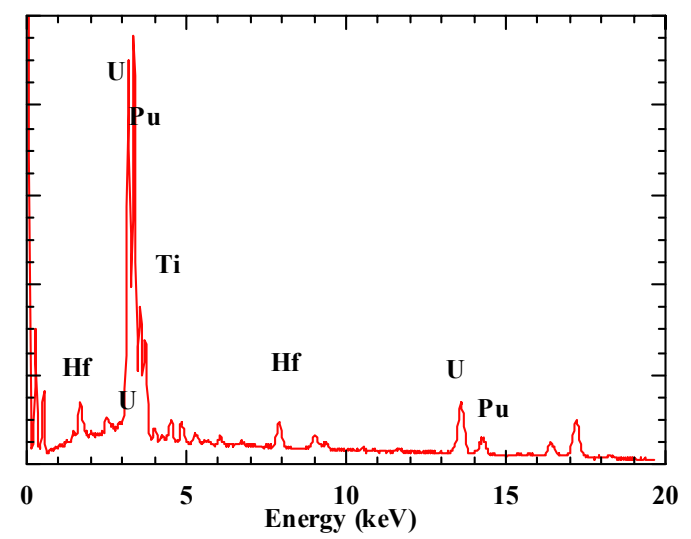

Figure 5.14. Evidence for an Actinide Oxide Phase in the Ceramic 
Table 5.2. Plutonium Titanate Ceramic Compositions with an Estimation of the Backscattered Contrast Factor

\begin{tabular}{|c|c|c|c|c|c|c|c|c|c|c|c|c|c|}
\hline & Al & $\mathrm{Ca}$ & Gd & Hf & $\mathbf{U}$ & $\mathbf{P u}$ & Ti & Metal & Average $\mathbf{Z}^{(\mathbf{a})}$ & Wt. & Density & Oxygens per Unit & Units per Cell \\
\hline Pyrochlore $^{(\mathrm{b})}$ & 0.10 & 0.85 & 0.22 & 0.27 & 0.44 & 0.22 & 1.90 & 4.00 & 49.76 & 479.80 & 7.14 & 7 & 10 \\
\hline Zirconolite $^{(\mathrm{b})}$ & 0.28 & 0.72 & 0.15 & 0.80 & 0.16 & 0.12 & 1.77 & 4.00 & 45.95 & 466.29 & 7.78 & 7 & 10 \\
\hline Brannerite & 0.05 & 0.06 & 0.10 & 0.12 & 0.53 & 0.24 & 1.90 & 3.00 & 54.40 & 411.41 & 5.98 & 6 & 2 \\
\hline Hf-Rutile & 0.01 & 0.00 & 0.00 & 0.09 & 0.01 & 0.00 & 0.89 & 1.00 & 27.56 & 93.35 & 4.96 & 2 & 2 \\
\hline $\mathrm{HfTiO}_{4}$ & 0.00 & 0.00 & 0.00 & 1.00 & 0.00 & 0.00 & 1.00 & 2.00 & 49.65 & 290.40 & 7.30 & 4 & 2 \\
\hline
\end{tabular}

Density (calculated) $=[\text { Aver. Wt. }]^{*}[$ Form.Units per cell] $) /\left([\text { Volume }]^{*} 0.60225\right)$ where the atomic weight is in $\mathrm{g} / \mathrm{mol}$, the volume in $\AA^{3}$, and 0.60225 is the

Avogadro constant.

(a) The average $\mathrm{Z}$ (mass fraction) provides a guideline for the expected backscattered contrast on the pyrochlore/zirconolite ceramic phases.

Brannerite should appear the brightest and rutile the darkest phase in the backscattered electron images. The $\mathrm{HfTiO}_{4}$ phase, although it contains no actinides, would also exhibit high $\mathrm{Z}$ contrast.

(b) The compositions of the zirconolite and pyrochlore phases have been estimated and are not the same as those observed in this study. 
The calculations in Table 5.2 indicate that backscattered electron contrast is not a good indicator for the presence of actinides in these ceramics. One of the brightest contrast phases in the ceramic is the Hfsrilankite phase.

\subsubsection{X-Ray Diffraction}

Results from the analyses of the XRD patterns from the zirconolite specimens indicated that the material was phase pure with lesser amounts of $\mathrm{TiO}_{2}$ and $\mathrm{HfTiO}_{4}$. The evolution of the XRD pattern with time (dose) is shown in Figure 5.15. Many of the peaks from the different phases overlap. As noted by Wald and Offerman (1982b) and Strachan et al (2002), the expansion of the monoclinic cell occurs predominantly along the c-axis with increasing radiation induced damage. This is most noticeable with the diffraction peak that occurs at $31^{\circ} 2 \theta$, which shifts to lower $2 \theta$ between December 1999 and December 2000 (Figure 5.15). By July 2001, this diffraction peak became a broad shoulder on the side of a growing maximum beneath the main zirconolite diffraction peak (Figure 5.15). Illustrated in Figure 5.16 are the XRD patterns from the first ${ }^{238} \mathrm{Pu}$-bearing zirconolite specimen in December 1999 (also shown in Figure 5.15) and a ${ }^{239} \mathrm{Pu}$-bearing specimen from March 2000. A significant amount of degradation of the diffraction pattern occurred over the 153 days since the ${ }^{238} \mathrm{Pu}$-bearing specimen was made; many of the less intense peaks became indistinguishable from background and some broadened noticeably. By 741 days (23-July-2001, 2.6 $10^{18} \alpha / \mathrm{g}$ ), the zirconolite had become X-ray amorphous. Insufficient XRD patterns with sufficient diffraction peaks were available for us to determine the change in lattice parameters with increasing dose. However, the lattice parameters for the ${ }^{239} \mathrm{Pu}$-bearing zirconolite are, in $\mathrm{nm}, \mathrm{a}_{0}=1.24566(12) ; \mathrm{b}_{0}=0.72621(6) ; \mathrm{c}_{0}=1.13535(12) ; \beta=100.656(7)^{\circ}$, volume $=$ $0.1281(72) \mathrm{nm}^{3}$ and from the ${ }^{238} \mathrm{Pu}$-bearing specimen $\mathrm{a}_{0}=1.25081(35) ; \mathrm{b}_{0}=0.72671(21) ; \mathrm{c}_{0}=$ $1.14276(36) ; \beta=100.714(20)^{\circ}$, volume $=0.1891(206) \mathrm{nm}^{3}$. It should be noted that the ${ }^{238} \mathrm{Pu}$-bearing specimen had accumulated $0.54 \cdot 10^{18} \alpha / \mathrm{g}$, a significant fraction of the dose needed to make the zirconolite

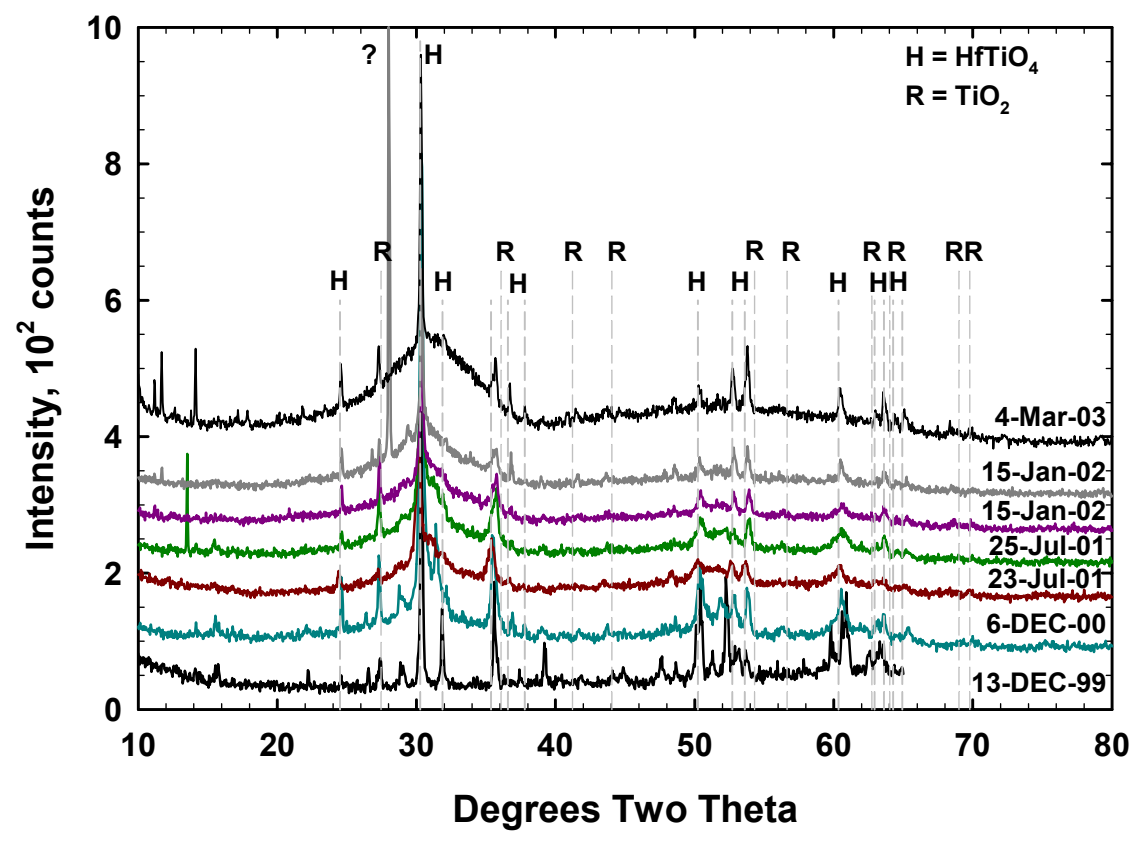

Figure 5.15. A Summary of the XRD Patterns from the ${ }^{238} \mathrm{Pu}$-Bearing Zirconolite Specimens. Only the peaks from phases other than zirconolite are marked. 
$\mathrm{X}$-ray amorphous. Therefore, a slightly larger unit cell with the dimensions having higher uncertainties was expected because of the accumulated dose and the less well defined diffraction peaks.

Although we did not obtain many XRD patterns over the time span during which most of the damage occurred, we saw no evidence for a transition from zirconolite to pyrochlore to fluorite before the specimens became X-ray amorphous. Disordered fluorite is reported as a phase through which these titanates transition before becoming amorphous (Wang et al. 1999c). We saw no evidence of this transition. We saw no evidence for the appearance of the characteristic (311) pyrochlore peak at $28^{\circ}$ to $29^{\circ} 2 \theta$. As the zirconolite peaks became broader and less intense, the diffraction from $\mathrm{TiO}_{2}$ and $\mathrm{HfTiO}_{4}$ became relatively more intense (Figure 5.15).

From the broad maxima that remain in the XRD pattern after the zirconolite has become amorphous, we obtained estimates of the metal-oxygen and metal-metal distances in the fully damaged material. These were obtained through the use of the JADE program after removing the background. The values that were determined are $0.177(2) \mathrm{nm}(\mathrm{M}-\mathrm{O})$ and $0.288(3) \mathrm{nm}(\mathrm{M}-\mathrm{M})$.

\subsubsection{Dissolution}

Concentrations of elements from the non-radioactive zirconolite specimens are shown in Figure 5.17. At $\mathrm{pH} 2$ and $90^{\circ} \mathrm{C}, \mathrm{Ce}, \mathrm{Gd}$, and $\mathrm{Ti}$ all achieve steady-state concentrations after 200 days. At higher $\mathrm{pH}$ values release of Mo over $\mathrm{pH}$ values 7 through 10 also realized steady-state values after 200 days. Note that the Mo steady-state concentrations all overlap, indicating that only a weak $\mathrm{pH}$ dependence of the dissolution rates. The lack of $\mathrm{pH}$ dependence is shown in Figure 5.18. At $\mathrm{pH}$ 2, the dissolution rates based on $\mathrm{Gd}$ and $\mathrm{Ca}$ overlap, but the release rates based on $\mathrm{Ce}$ and $\mathrm{Ti}$ are higher and lower, respectively. At higher $\mathrm{pH}$ values, the release of $\mathrm{Ca}$ and $\mathrm{Mo}$ are constant and overlapping, except at $\mathrm{pH} 7$ where the dissolution rates based on Mo are inexplicably higher compared to Ca. Taken together, these data

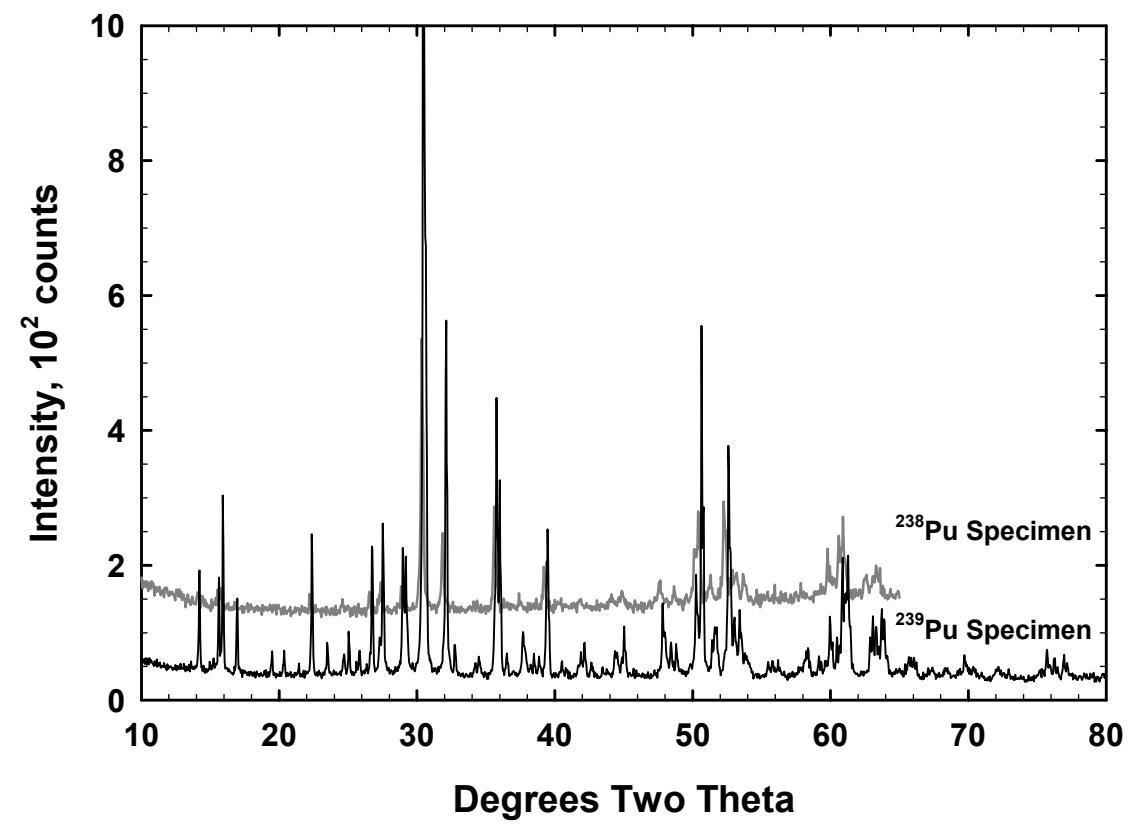

Figure 5.16. A Comparison of the XRD Patterns from ${ }^{238} \mathrm{Pu}$ - and ${ }^{239} \mathrm{Pu}$-Bearing Zirconolite Specimens 
indicate no rate dependence on solution $\mathrm{pH}$, which is similar to results for pyrochlore-containing specimens.

Results from the SPFT tests on ${ }^{239} \mathrm{Pu}$-bearing zirconolite at $\mathrm{pH} 2$ and 11 are shown in Figure 5.19. Calculated dissolution rates based on $\mathrm{Gd}, \mathrm{Pu}, \mathrm{Mo}$, and $\mathrm{U}$ are constant and overlapping after 150 days of testing. In contrast, the dissolution rates of $U$ and Mo are higher by at least a factor of 100 over Ti. Release rates of $U$ are constant over time, whereas Mo concentrations show no obvious steady-state
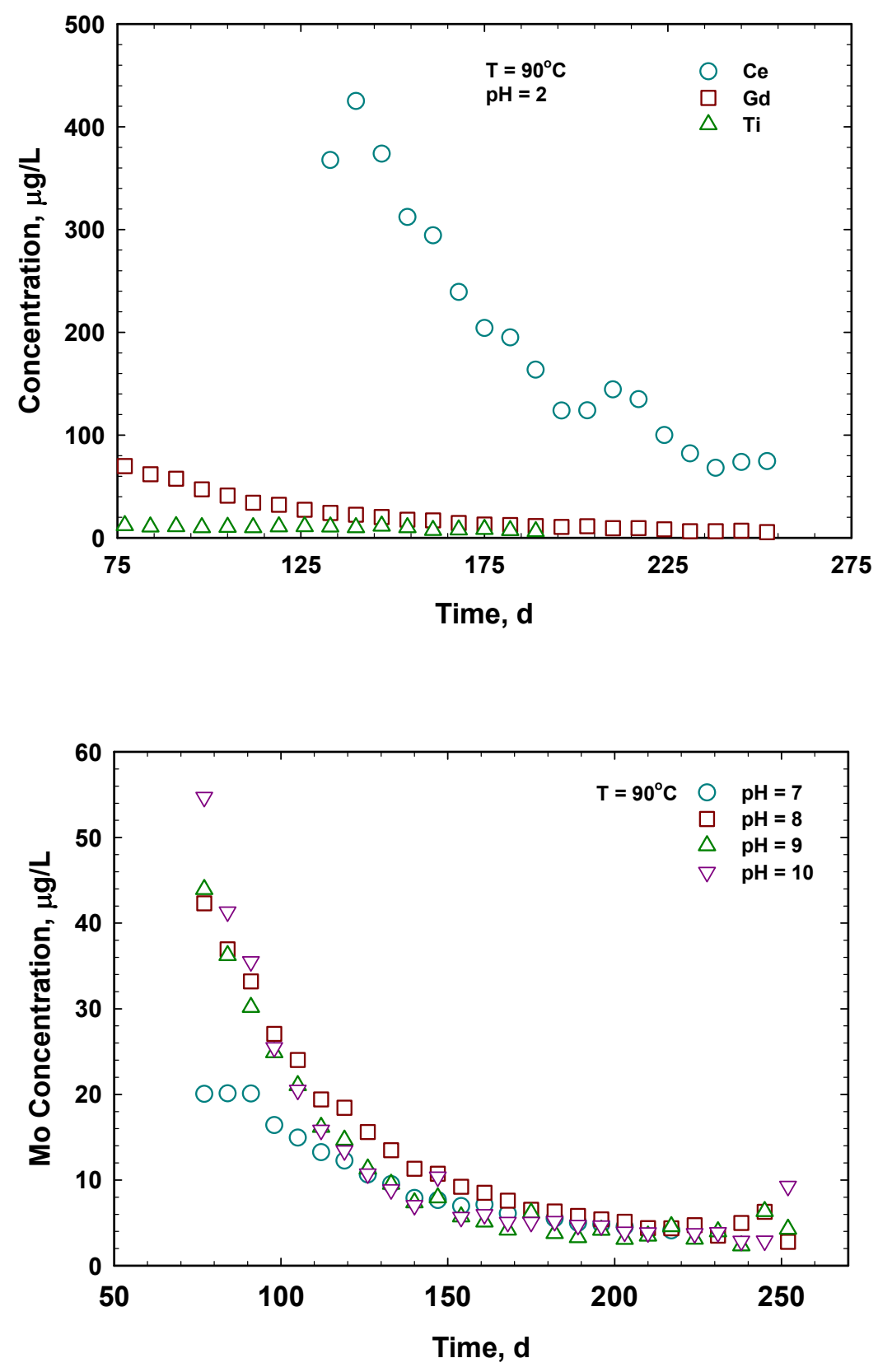

Figure 5.17. Plot of Element Concentrations Versus Time for the Zirconolite Ceramic at $90^{\circ} \mathrm{C}$. (A). Concentrations ( $\left.\mu \mathrm{g} / \mathrm{L}\right)$ of Ce, $\mathrm{Gd}$, and $\mathrm{Ti}$, and (B) Mo concentrations $(\mu \mathrm{g} / \mathrm{L})$ at various $\mathrm{pH}$ values. 
behavior. In Figure 5.20, dissolution rates with respect to Mo and $\mathrm{U}$ are constant across the $\mathrm{pH}$ interval of the experiments. Although rates based on $\mathrm{Pu}$ and $\mathrm{Ti}$ are indistinguishable from those of $\mathrm{Mo}, \mathrm{Gd}$, and $\mathrm{U}$ at $\mathrm{pH} 2, \mathrm{Pu}$ and Ti rates decrease by a factor of $\sim 100$ at higher $\mathrm{pH}$ values. Therefore, dissolution rates with respect to $\mathrm{Mo}$ and $\mathrm{U}$ are invariant with solution $\mathrm{pH}$, but rates based on $\mathrm{Ti}$ and $\mathrm{Pu}$ decrease by a factor of 100 at $\mathrm{pH}$ values higher than $\mathrm{pH}$ 2. These patterns are consistent with solubility control for Pu and Ti.

Dissolution rates between radioactive and non-radioactive specimens at $\mathrm{pH} 2$ are compared in Figure 5.21. Rates are based on Gd release, except where noted. At $\log _{10}(\mathrm{q} / \mathrm{S})$ values of less than -8 $(\mathrm{m} / \mathrm{s})$, the dissolution rates decrease in a manner consistent with reaction affinity control. The $\mathrm{U}$ release rate matches that of $\mathrm{Gd}$ for the ${ }^{239} \mathrm{Pu}$-bearing specimen in the Teflon reactor. In contrast, for $\log _{10}(\mathrm{q} / \mathrm{S})>$ $-8(\mathrm{~m} / \mathrm{s})$, the rates are constant, indicating that dissolution is at the forward rate of reaction. The indicated forward rate of dissolution is $1.7(4) \cdot 10^{-3} \mathrm{~g} /\left(\mathrm{m}^{2} \cdot \mathrm{d}\right)$. Significantly, the dissolution rates of the ${ }^{239} \mathrm{Pu}$-bearing specimens plot within the continuum of data. Note that the ${ }^{239} \mathrm{Pu}$-bearing zirconolite was tested in both the Teflon and the titanium reactors, which is strong evidence that the rates do not depend on the nature of the SPFT apparatus: the difference in rate between the two specimens can be interpreted as a consequence of the faster flow rate in the titanium reactor. It is also significant that the ${ }^{239} \mathrm{Pu}$-bearing zirconolite that was tested in the titanium reactor dissolves at the forward rate. Therefore, the rate of dissolution is invariant with not only reactor type, but Pu-loading as well.

One last feature of significance is the Ce-brannerite dissolution data. Fewer experiments with brannerite were performed than with zirconolite, but the available rate data are important. At fast $\log _{10}(\mathrm{q} / \mathrm{S})$ values $(>-7)$, brannerite dissolution rates are constant, but faster than the zirconolite forward rate. The apparent forward rate of dissolution of brannerite is $4.7(11) \cdot 10^{-3}$ to $7.3(17) \cdot 10^{-2} \mathrm{~g} /\left(\mathrm{m}^{2} \cdot \mathrm{d}\right)$. These data are consistent

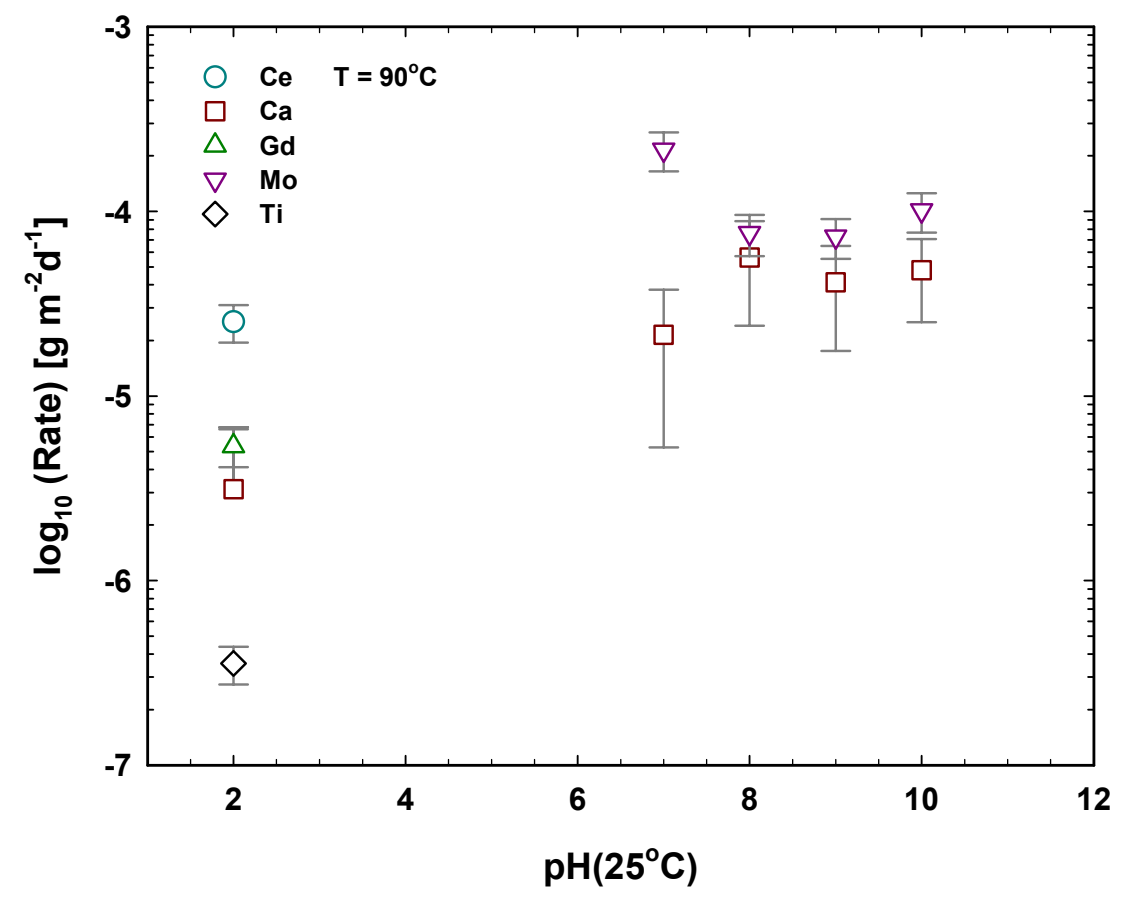

Figure 5.18. Plot of $\log _{10}($ Rate $)\left[\mathrm{g} /\left(\mathrm{m}^{2} \cdot \mathrm{d}\right)\right]$ Versus $\mathrm{pH}$ for a Zirconolite Ceramic at $90^{\circ} \mathrm{C}$ 
with previous work suggesting that brannerite dissolves faster than both zirconolite and pyrochlore (Lumpkin et al. 2000).
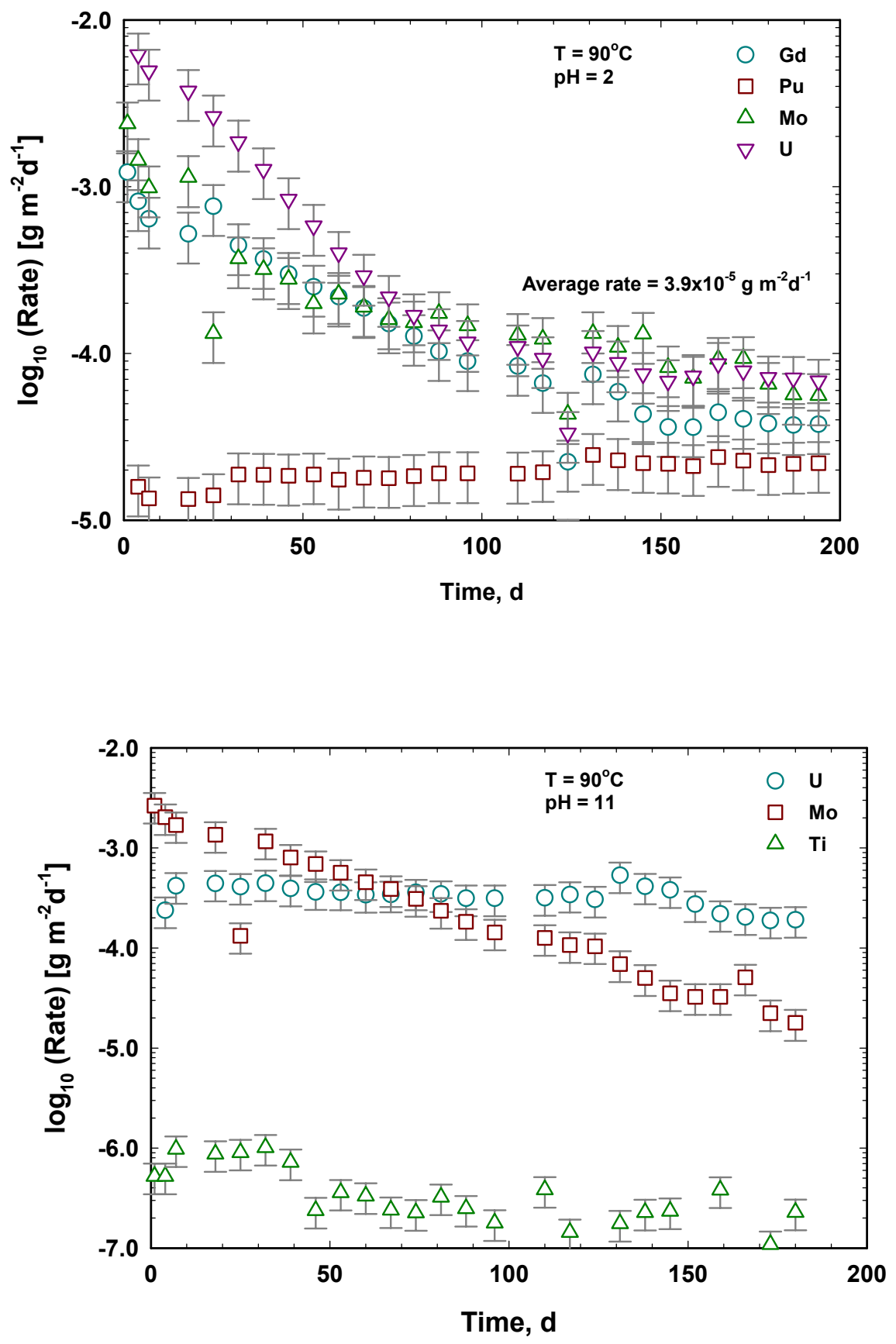

Figure 5.19. Plot of $\log _{10}($ Rate $)\left[\mathrm{g} /\left(\mathrm{m}^{2} \cdot \mathrm{d}\right)\right]$ Versus Time for ${ }^{239} \mathrm{Pu}$-Bearing Zirconolite Ceramic at $90^{\circ} \mathrm{C}$ and (A) $\mathrm{pH} 2$ for $\mathrm{Gd}, \mathrm{Pu}, \mathrm{Mo}$, and $\mathrm{U}$ and (B) $\mathrm{pH} 11$ for $\mathrm{U}, \mathrm{Mo}$, and $\mathrm{Ti}$ 


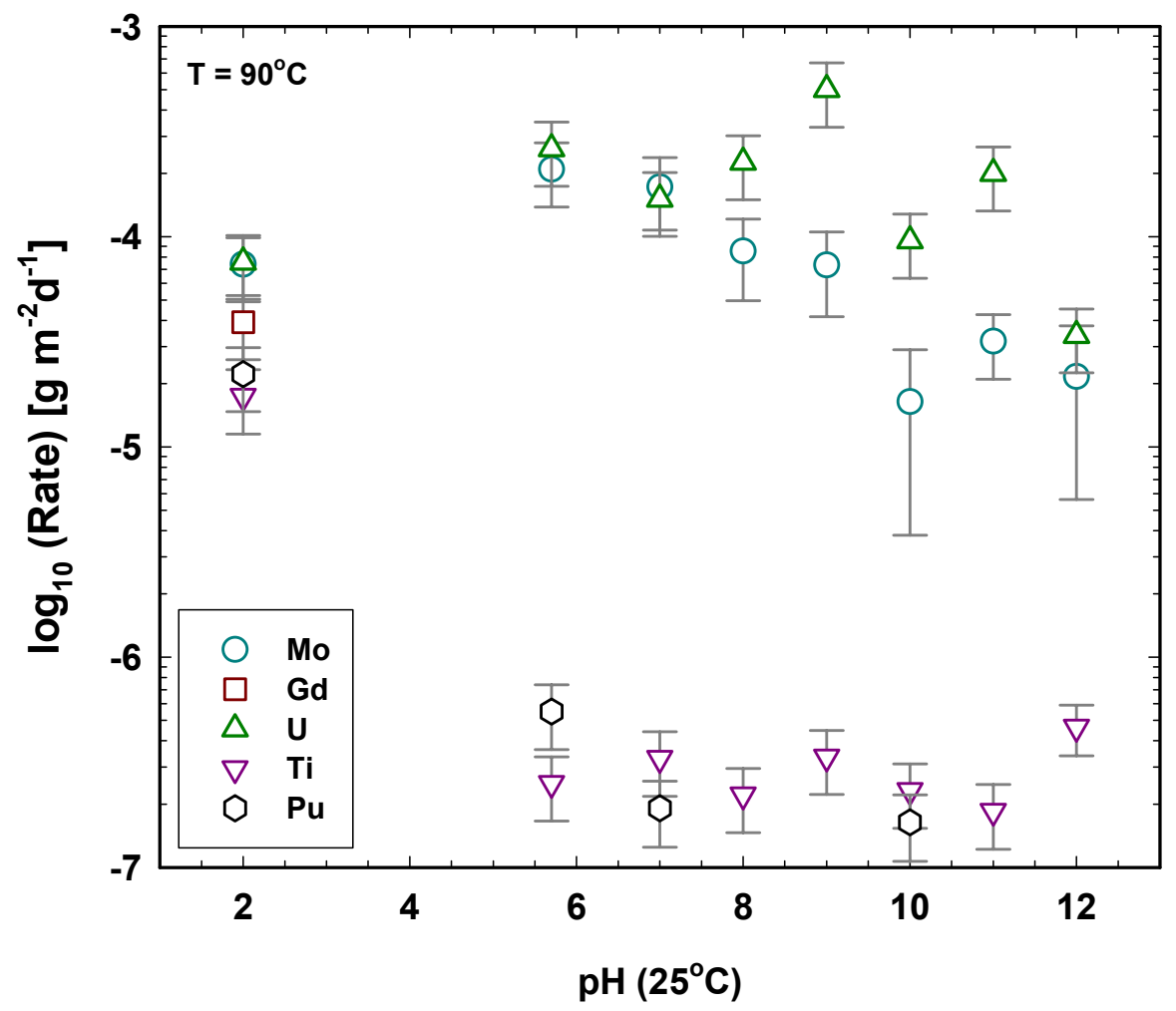

Figure 5.20. Plot of $\log _{10}($ Rate $)\left[\mathrm{g} /\left(\mathrm{m}^{2} \cdot \mathrm{d}\right)\right]$ Versus $\mathrm{pH}$ for ${ }^{239} \mathrm{Pu}$-Bearing Zirconolite Ceramic at $90^{\circ} \mathrm{C}$

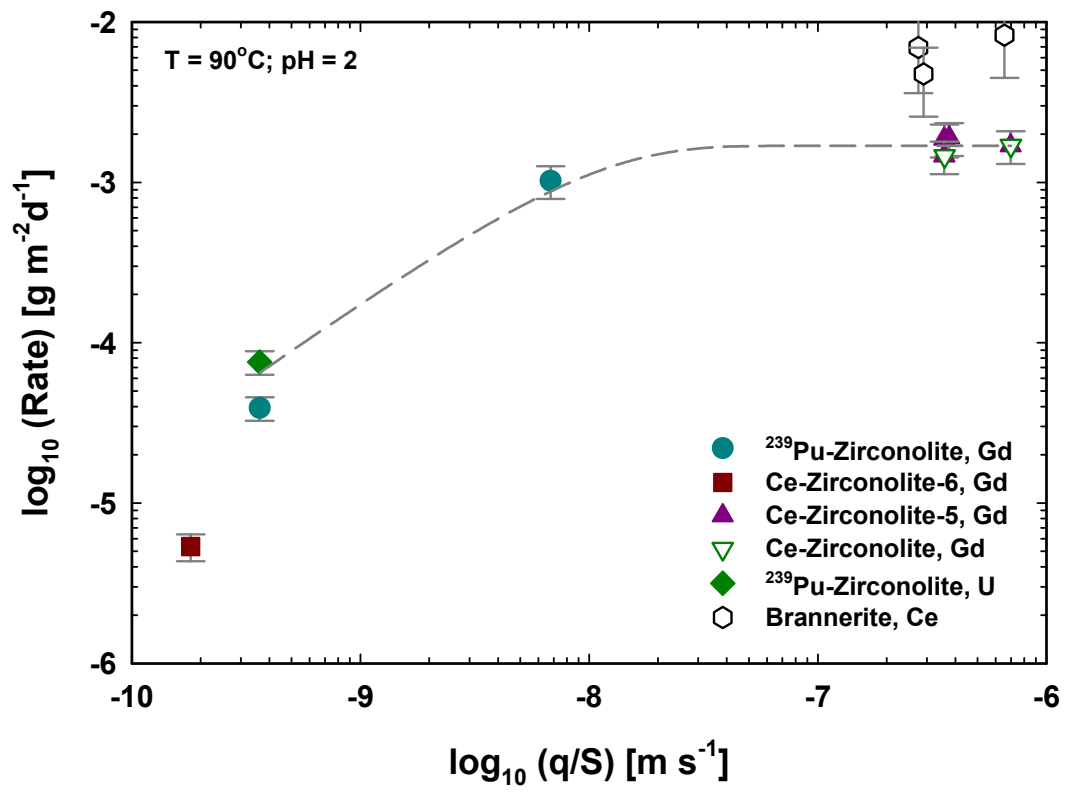

Figure 5.21. Plot of $\log _{10}($ Rate $)\left[\mathrm{g} /\left(\mathrm{m}^{2} \cdot \mathrm{d}\right)\right]$ Versus $\log _{10}(q / S)[\mathrm{m} / \mathrm{s}]$ at $90^{\circ} \mathrm{C}$ and $\mathrm{pH} 2$ for Brannerite and Zirconolite Specimens 


\subsection{Radiation-Damage Effects of ${ }^{238} \mathrm{Pu}$-Bearing Zirconolite-Rich Baseline and Impurity Baseline Ceramics}

In this section, we cover the remaining materials of the larger study in which specimens containing approximately 10 mass $\%{ }^{238} \mathrm{Pu}$ were used to determine the long-term effects of radiation induced damage from the $\alpha$ decay of ${ }^{239} \mathrm{Pu}$ in these titanate ceramics that would have been disposed of in the nuclear-waste repository at Yucca Mountain. These last two materials, zirconolite and impurity baseline ceramics, represent alternative materials that could result from various process feed streams at the Pit Disassembly and Conversion Facility.

\subsection{Preparations}

The target compositions are shown in Table 6.1.

Table 6.1. The Target Oxide Composition of the Impurity Baseline and Zirconolite-Rich Baseline Ceramics Used in this Study

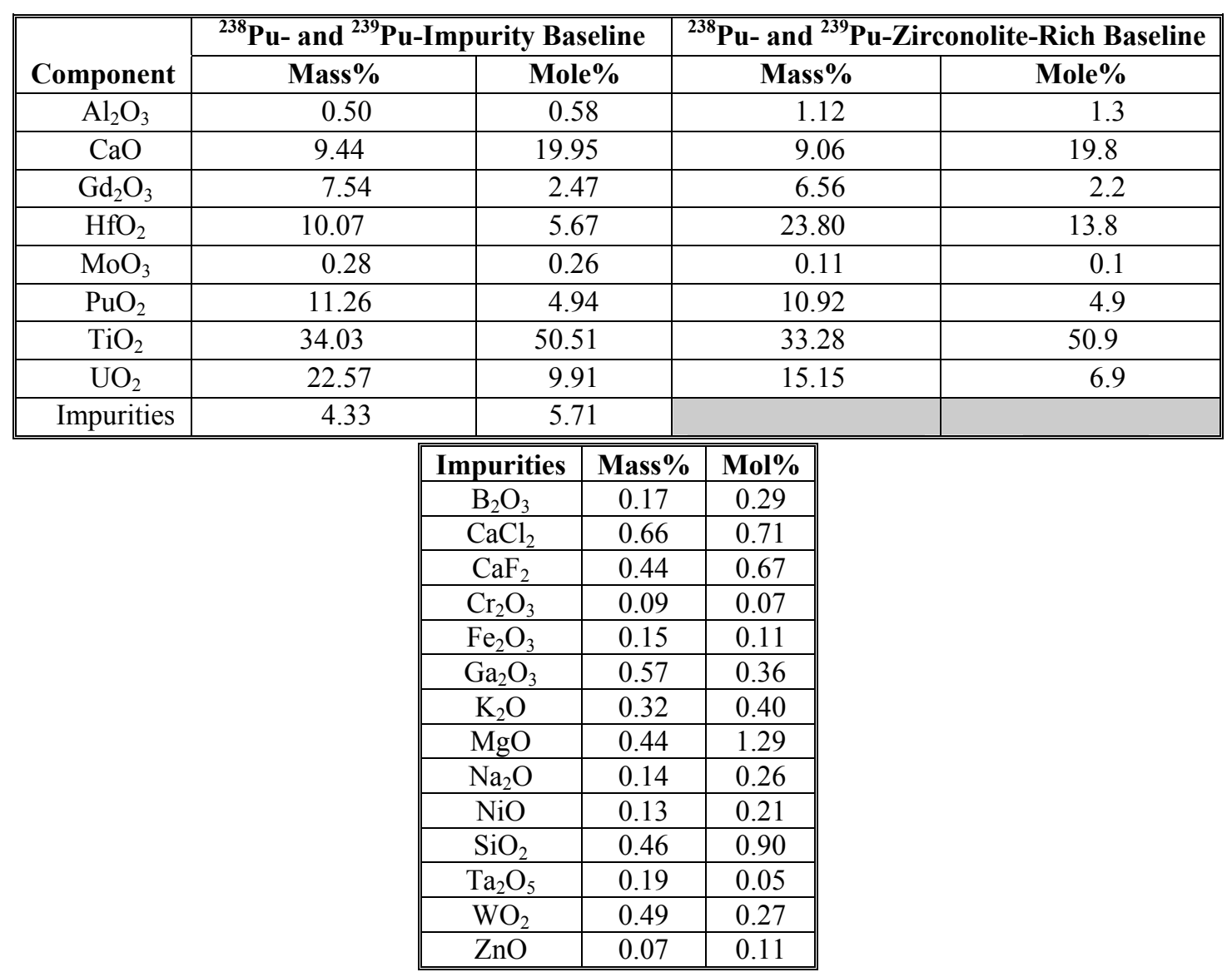




\subsection{Results and Discussion}

\subsubsection{Physical Appearance}

Photographs of typical zirconolite-baseline and impurity-baseline specimens are shown in Figure 6.1. The specimens were produced as right circular cylinders. The unpolished specimens have more surface flaws. These surface flaws, which presumably occur throughout the bulk of the specimen, result in low measured bulk densities. The flaws shown on the surface may or may not be interconnected, so that the densities measured with the He pycnometer may be affected. The source of the coloration is unknown. We noticed a general lightening of the impurity-baseline specimens with increasing temperature and with increasing time at all temperatures; initially the specimens were of uniform dark grey color.

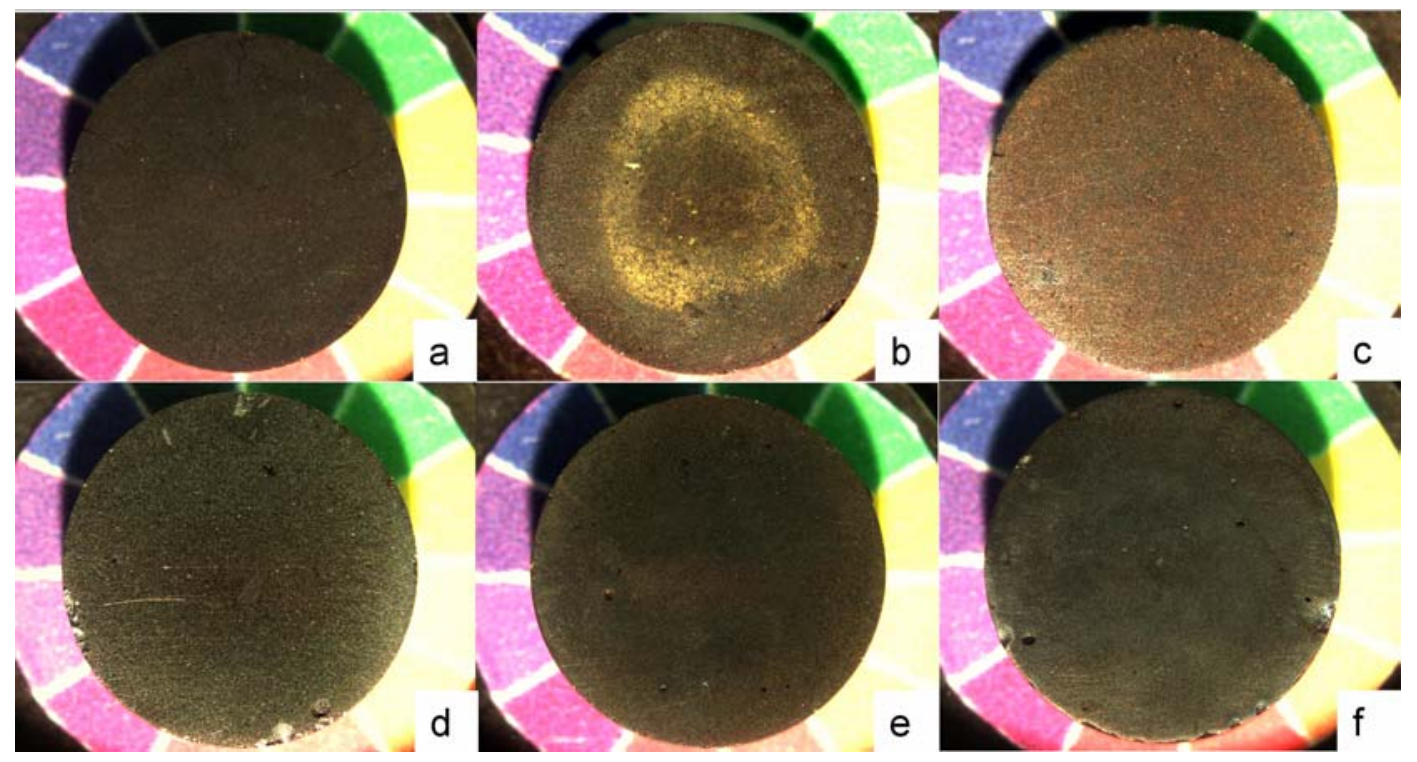

Figure 6.1. Pictures of Typical ${ }^{238} \mathrm{Pu}$-Bearing Zirconolite-Rich Baseline (a-c) and Impurity Baseline (d-f) Ceramics. Pictures a and $\mathrm{d}$ are of specimens stored at $20^{\circ} \mathrm{C}$; b and e $125^{\circ} \mathrm{C}$; and $\mathrm{c}$ and $\mathrm{f} 250^{\circ} \mathrm{C}$.

\subsubsection{Density Measurements}

Helium Pycnometer Results. The results of the He pycnometer measurements of the "true" density of the ${ }^{238} \mathrm{Pu}$ - and ${ }^{239} \mathrm{Pu}$-bearing zirconolite-baseline and impurity-baseline specimens are shown in Figure 6.2 and Figure 6.3. Although there is much scatter in the data, the density of the ${ }^{239} \mathrm{Pu}$-bearing specimens should not decrease to any extent. Therefore, the data were averaged, leaving out the high and low values, to get an average density of $5.560 \cdot 10^{3}$ and $5.516 \cdot 10^{3} \mathrm{~kg} / \mathrm{m}^{3}$ (dashed lines in Figure 6.2 and Figure 6.3; respectively). For the data from the ${ }^{238} \mathrm{Pu}$-bearing specimens, the data were least-squares fit to Equation 3.1.

The values are $\rho_{s}=6.01(4) \cdot 10^{3} \mathrm{~kg} / \mathrm{m}^{3}, b=0.41(8) \cdot 10^{3} \mathrm{~kg} / \mathrm{m}^{3}$, and $c=0.0033(18)$ for the data shown in Figure 6.2. It is unclear why the "true" density of the ${ }^{239} \mathrm{Pu}$-bearing zirconolite-rich baseline ceramic should be so much lower than the "true" density of the ${ }^{238} \mathrm{Pu}$-bearing ceramic, since the method of preparation was the same for both materials. The data indicate a significant amount of surface-connected 
porosity. The diameters of these specimens (see below) are larger than the corresponding ${ }^{238} \mathrm{Pu}$-bearing specimens, indicating a lower geometric density for the ${ }^{239} \mathrm{Pu}$-bearing ceramic specimens as well. Data from Figure 6.2 indicate a decrease of $6.3 \%$ in the "true" density of the ${ }^{238} \mathrm{Pu}$-bearing ceramic because of radiation induced damage after approximately $3 \cdot 10^{18} \alpha / \mathrm{g}$ have accumulated.

When performing the least-squares analysis for the ${ }^{238}$ Pu-bearing ceramics in Figure 6.3, we added the data point at zero time, which was the same as the ${ }^{239} \mathrm{Pu}$-bearing ceramics. The validity of this approach could be questioned, but, with the paucity of data, we felt that this was the only real choice when analyzing the data. Although the lines shown in Figure 6.3 are from a least-squares fit of the data to Equation 3.1, we do not report the values here because of the lack of sufficient data to support any conclusions from such a fit. Rather, we show the lines as a guide to the eye. From the data shown for both materials, there does not appear to be a significant dependence on the storage temperature. The "true" densities decrease by $6.3 \%$ for the zirconolite-baseline specimens and $9.9 \%$, $9.0 \%$, and $8.6 \%$ for the impurity-baseline specimens stored at $20^{\circ} \mathrm{C}, 125^{\circ} \mathrm{C}$, and $250^{\circ} \mathrm{C}$, respectively. An average value of $9.2 \%$ decrease in the impurity baseline "true" density should probably be used. The magnitude of the changes is likely caused by the increase in closed porosity as the individual grains swell and close access to what was open porosity and accessible to the He gas in the pycnometer. This conclusion will be strengthened by the results in the next section where the bulk swelling of the zirconolite-baseline specimens is incommensurate with the large changes in "true" density and from previous sections.

Geometric Densities. As seen in the picture of a typical specimen (Figure 6.1), there are chips on the edge of the specimens. This, combined with a $20-\mu \mathrm{m}$ wobble in the table (Strachan et al. 2004), caused a significant variation in the measured height of the specimen and a concomitant uncertainty in the calculated

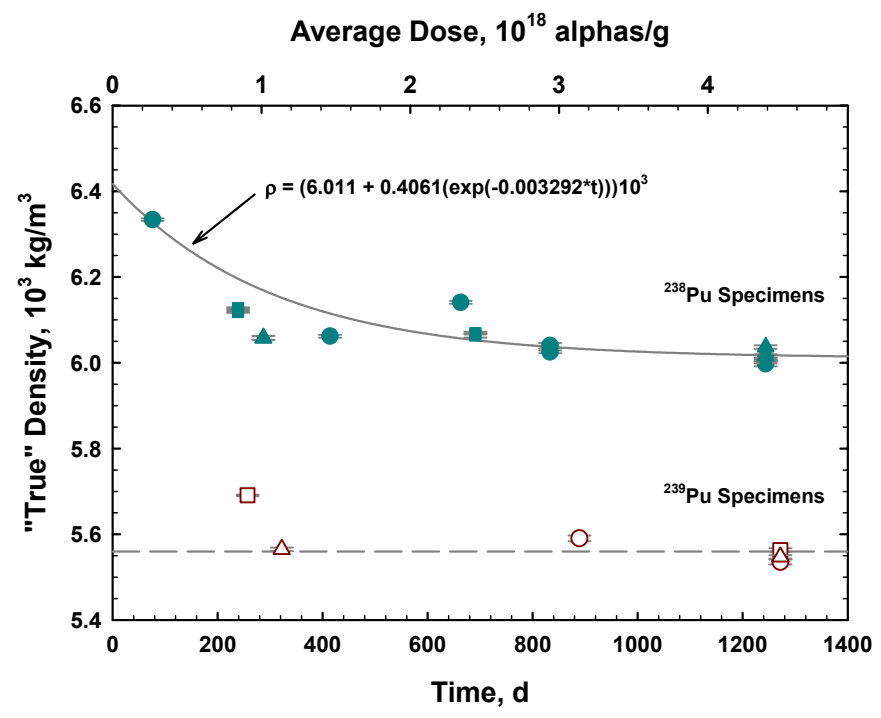

Figure 6.2. The Change in "True" Density with Increasing Radiation induced Damage for ${ }^{238} \mathrm{Pu}$ - and ${ }^{239} \mathrm{Pu}$-Bearing Zirconolite-Rich Baseline Specimens Stored at $20^{\circ} \mathrm{C}, 125^{\circ} \mathrm{C}$, and $250^{\circ} \mathrm{C}$. The solid line is a least squares fit to the ${ }^{238} \mathrm{Pu}$ data and the dashed line is from a linear least squares fit to the ${ }^{239} \mathrm{Pu}$ data.

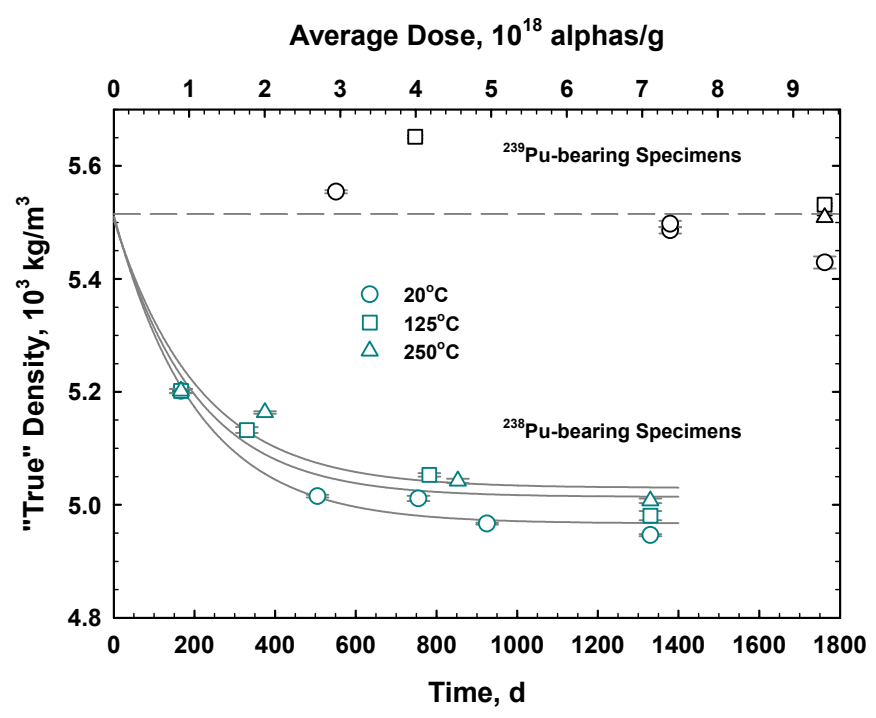

Figure 6.3. A Graph Showing the Change in the "True" Density for the ${ }^{238} \mathrm{Pu}$ - and ${ }^{239} \mathrm{Pu}$-Bearing Impurity Baseline Specimens 
geometric density of the specimen. Therefore, as a measure of the change in the geometric density, we show the change in diameter of the zirconolite-baseline specimens with increasing dose (Figure 6.4). Here the diameters of all the specimens stored at all temperatures are shown. There is no discernable difference between specimens stored at any temperature. The initial (day zero) measurement of the diameter, $9.98 \mathrm{~mm}$, was done with a hand-held micrometer. The majority of the ${ }^{238} \mathrm{Pu}$-bearing specimen data were fit to Equation 3.2.

Using the asymptotic value for the diameter of $10.08 \mathrm{~mm}$, we calculate a $0.98 \%$ increase from radiation induced swelling or a $2.6 \%$ decrease in the density of the specimens when approximately $3 \cdot 10^{18} \mathrm{\alpha} / \mathrm{g}$ have accumulated (900 days). This small decrease in the geometric density is inconsistent with the "true" density changes discussed above. The most probable explanation for this is that as the individual grains swell, they cause internal and surface-connected porosity to become isolated from the surface so that it cannot be accessed by the He gas in the pycnometer. This leads to a much more rapid change in the "true" density relative to the changes in the geometric density.

Although not shown in Figure 6.4, the average diameter for all the ${ }^{239} \mathrm{Pu}$-bearing specimens is 10.197(64) $\mathrm{mm}$. These data are consistent with the observed low "true" densities of these specimens, but inconsistent with data from the other ceramics studied for which the values were more similar to the ${ }^{238} \mathrm{Pu}$-bearing ceramics.

For the impurity-baseline specimens, the variation in the specimen diameters is shown in Figure 6.5. Again, the starting diameters of the ${ }^{238} \mathrm{Pu}$-bearing specimens, which averaged 10.30(1) $\mathrm{mm}$, were measured with a handheld micrometer. The diameters of the ${ }^{239} \mathrm{Pu}$ bearing specimens averaged to $9.98(1) \mathrm{mm}$. We then fit the data to Equation 2 to obtain the values for the parameters of $d_{0}=10.30(1) \mathrm{mm}$, $b=0.26(3) \mathrm{mm}$, and $c=0.0020(5) \mathrm{d}^{-1}$. More significant figures are given in Figure 6.5 to allow the reader to more accurately reproduce the fit to our data. This treatment of the data yields a value for the swelling of these specimens of $2.5 \%$. From this swelling, we calculate that there was a $7.1 \%$ decrease in the

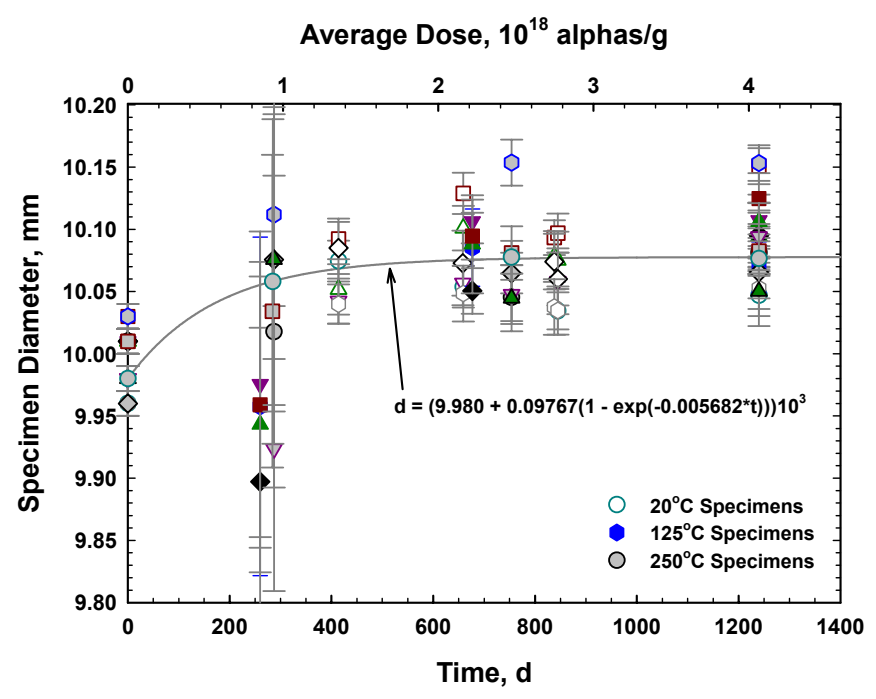

Figure 6.4. The Change in the Diameter of all ${ }^{238} \mathrm{Pu}$ Bearing Zirconolite-Rich Baseline Specimens with Increasing Alpha Dose

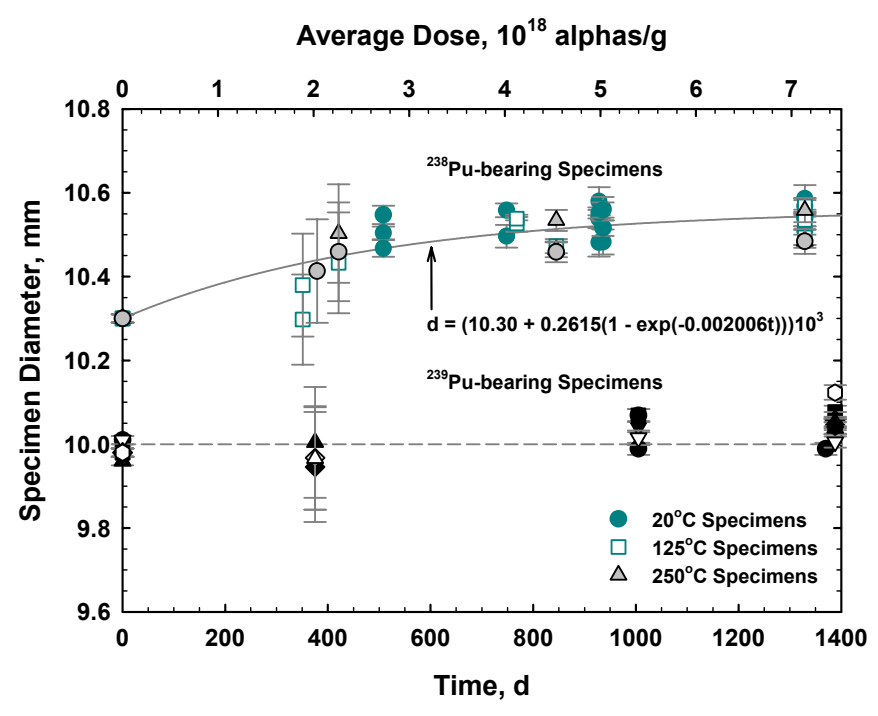

Figure 6.5. The Variation in the Diameters of the ${ }^{238} \mathrm{Pu}$ and ${ }^{239} \mathrm{Pu}$-Bearing Impurity Baseline Ceramic Specimens with Increasing Alpha Dose 
bulk density of these specimens. Saturation of the bulk swelling occurs after about $6.5 \cdot 10^{18} \alpha / \mathrm{g}$ have accumulated. The largest change in the "true" density was $-9.9 \%$ for the specimens stored at $20^{\circ} \mathrm{C}$. As determined for other specimens in this study, some open porosity was converted to closed porosity with increasing radiation induced damage.

\subsection{Scanning Electron Microscopy}

Two major phases were observed in a sample of the original (fully damaged) ${ }^{238} \mathrm{Pu}$-bearing zirconolite baseline ceramic that was stored at $20^{\circ} \mathrm{C}$ : zirconolite (dark gray veins) and pyrochlore (lighter grey material). However, these were not easily visible in the sample examined. A minor $\mathrm{HfTiO}_{4}$ phase was also present (white contrast in Figure 6.6). The EDS analyses of zirconolite and $\mathrm{HfTiO}_{4}$ are shown in Figure 6.7 and Figure 6.8, respectively.

The microstructure of the zirconolite baseline ceramic cannot be easily seen in Figure 6.6 because of SEM sample preparation problems. However, zirconolite veins can be seen as dark bands within the more abundant grey. These features were much more clearly visible in the ${ }^{239} \mathrm{Pu}$ analog of this composition (see Figure 6.9 and Figure 6.10).

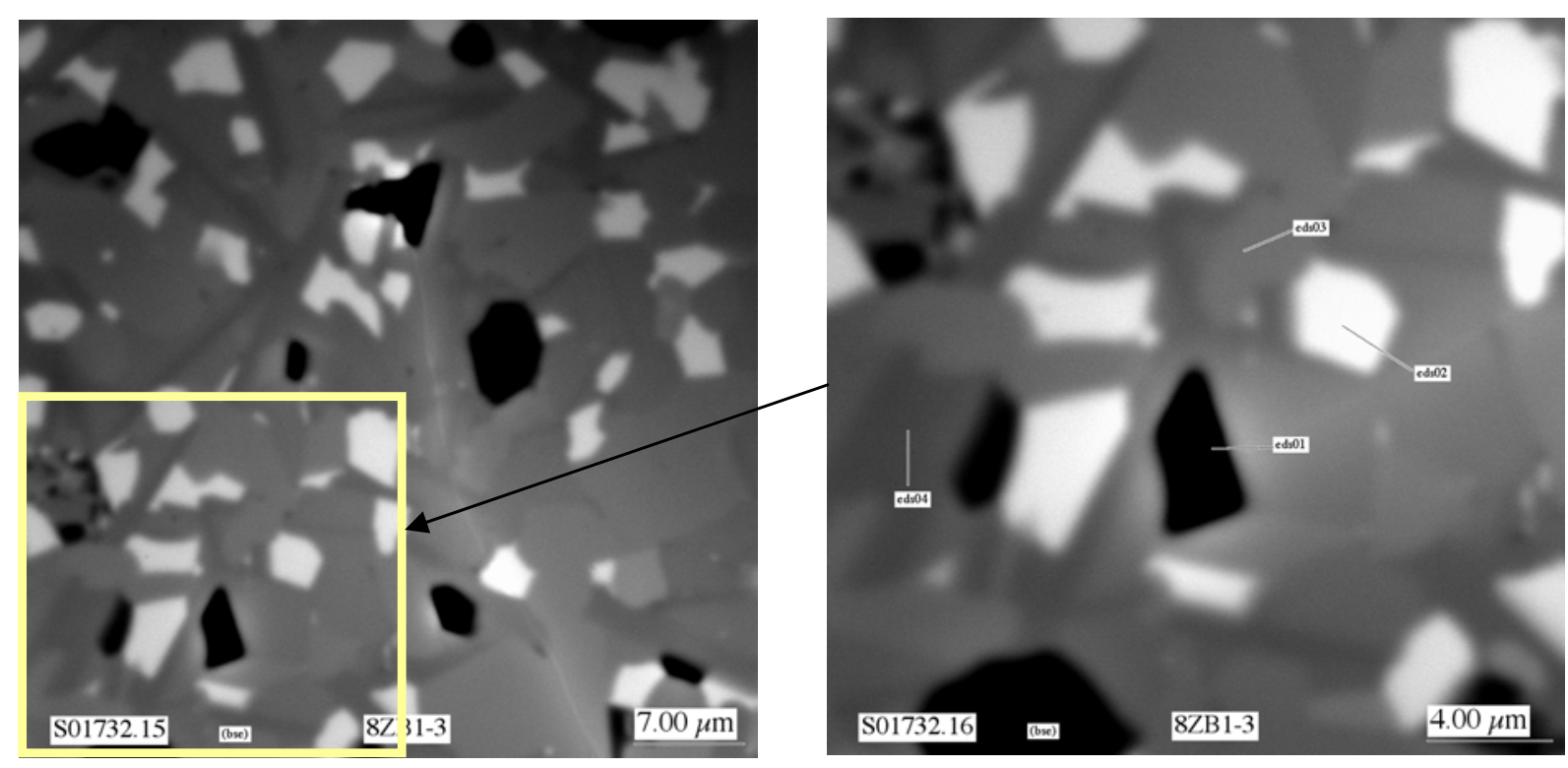

Figure 6.6. Backscattered Electron Image of ${ }^{238} \mathrm{Pu}$-Bearing Zirconolite Baseline Ceramic (stored at $20^{\circ} \mathrm{C}$; fully damaged). (B) Higher Magnification Showing Three Major Phases. The dark contrast may be due to pores in the ceramic. It is not possible to confirm the absence of pores with the collected images. 
The ${ }^{239} \mathrm{Pu}$-bearing ceramic analog also exhibited two main phases, zirconolite and pyrochlore (Figure 6.9 and Figure 6.10), similar to the ${ }^{238} \mathrm{Pu}$ ceramic. Veins of euhedral zirconolite crystals are clearly visible running through the pyrochlore in Figure 6.10. This suggests that the pyrochlore solidified after the zirconolite. As the pyrochlore crystallized, Pu-rich phases precipitated as inclusions. These inclusions were not observed within the zirconolite. This indicates that the melt becomes increasingly more concentrated in $\mathrm{Pu}$ during cooling until the remaining $\mathrm{Pu}$ is exsolved, forming actinide inclusions (Figure $6.9)$.

\subsubsection{X-Ray Diffraction}

Results from the XRD analyses from both ceramic materials are discussed in this section.

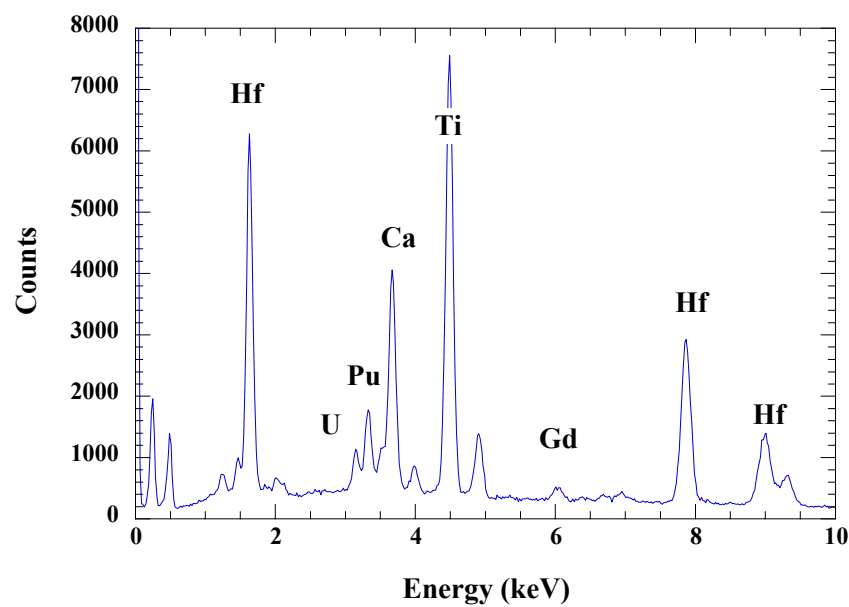

Figure 6.7. Zirconolite Composition

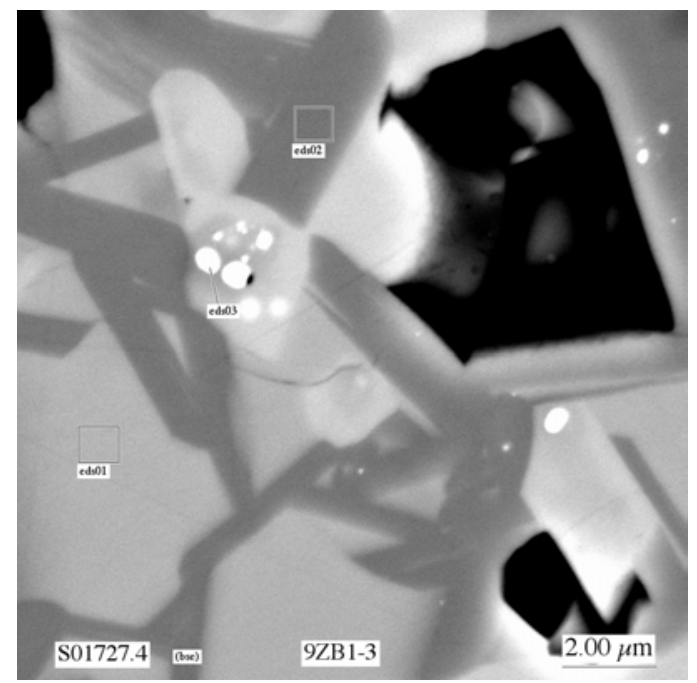

Figure 6.9. High Effective Atomic Number Particles in the Ceramic

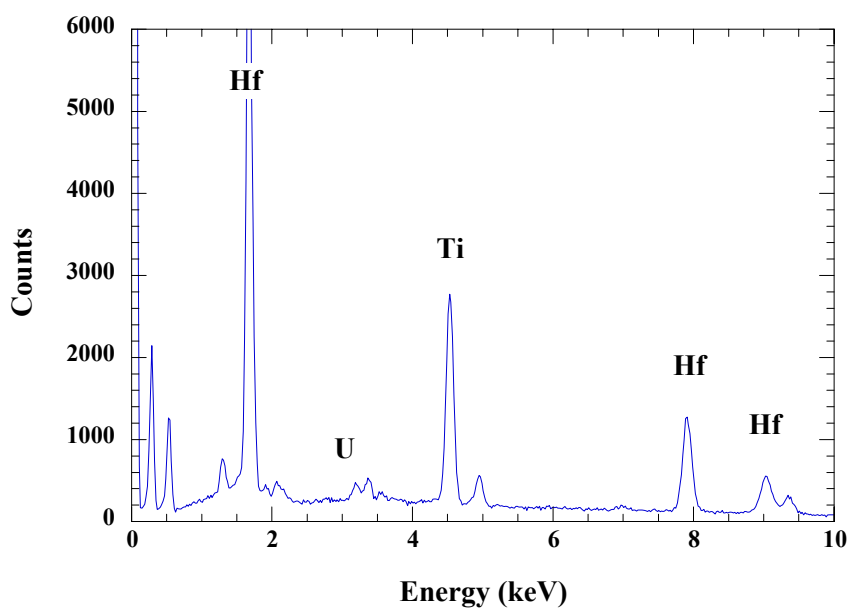

Figure 6.8. $\mathrm{HfTiO}_{4}$ Phase

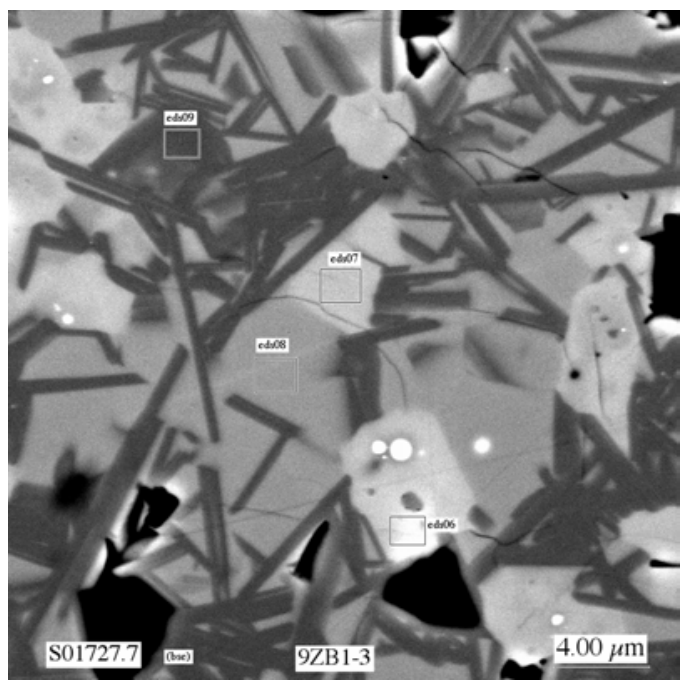

Figure 6.10. The Distribution of Phases in the Ceramic 


\subsubsection{Zirconolite Baseline Ceramic}

Results from the analyses of the XRD patterns from the ${ }^{239} \mathrm{Pu}$-bearing zirconolite-rich baseline specimens indicated that the material was comprised predominantly of zirconolite, pyrochlore, and brannerite (Figure 6.11). This phase assemblage did not change over the course of 1700 days nor was there any change in the phase assemblage at elevated temperatures. Over those 1700 days, we improved at obtaining the patterns, and we obtained a dedicated XRD unit, both of which explain the better signal-tonoise in the later patterns. The evolution of the XRD pattern with time (dose) for the ${ }^{238} \mathrm{Pu}$-bearing specimen is shown in Figure 6.12. The dose accumulated in this specimen was $4.4 \cdot 10^{18} \mathrm{\alpha} / \mathrm{g}$ over 1246 days. There is an additional phase in the ${ }^{238} \mathrm{Pu}$-bearing specimen, namely $\mathrm{PuO}_{2}$, and the specimen was not significantly affected by radiation induced damage (Chikalla and Turcotte 1973). Before preparing the batch of zirconolite-rich baseline material, radiolytic heating of the ${ }^{238} \mathrm{Pu}$-containing stock solution caused some evaporation that went undiscovered until after the ceramic was made. This excess $\mathrm{PuO}_{2}$ remained as an additional phase in the ceramic. Brannerite appears to have undergone significant radiation damage because only several diffraction peaks appear in the diffraction pattern. After an additional year of accumulated dose, the brannerite diffraction peaks largely disappeared. Of note is the presence of preferred orientation in some of the patterns. Some of the specimens have pits that occur on the surface, and these could also cause diffraction to occur at angles different than the majority of the specimen that is in proper alignment. Because these pits are not always in the same orientation when the specimen is remounted, the peaks do not always occur or occur with the same intensity. Fortunately, these errant diffraction peaks do not interfere with the overall interpretation of the diffraction pattern; they do make the use of the Rietveld method difficult. The phase that survives the longest, possibly because it contains less ${ }^{238} \mathrm{Pu}$ than the other pyrochlore, is zirconolite. The last diffraction pattern shows the presence of $\mathrm{HfTiO}_{4}$, which has an orthorhombic unit cell, zirconolite, and $\mathrm{PuO}_{2}$.

As noted by Wald and Offerman (1982b) and Strachan et al. (2002), 2003c), the expansion of the zirconolite monoclinic cell occurs predominantly along the c-axis with increasing radiation induced damage. This is most noticeable with the diffraction peak that occurs at $31^{\circ} 2 \theta$, which shifts to lower $2 \theta$ (Figure 6.12). Zirconolite does not seem to transform to pyrochlore as suggested by Wang et al. (1999c) because there is no characteristic (311) peak on the low $2 \theta$ side of the main diffraction peak (it would normally be found between the main zirconolite peak and the main $\mathrm{PuO}_{2}$ peak). Zirconolite appears to transform from the monoclinic cell to an amorphous phase as shown by the peaks between 50 and $54^{\circ} 2 \theta$ that change in relative intensity, but in a manner inconsistent with the ingrowth of a pyrochlore or fluorite phase (compare the patterns from the ${ }^{239} \mathrm{Pu}$-bearing and ${ }^{238} \mathrm{Pu}$ bearing specimens shown in (Figure 6.11 and Figure 6.12, respectively).

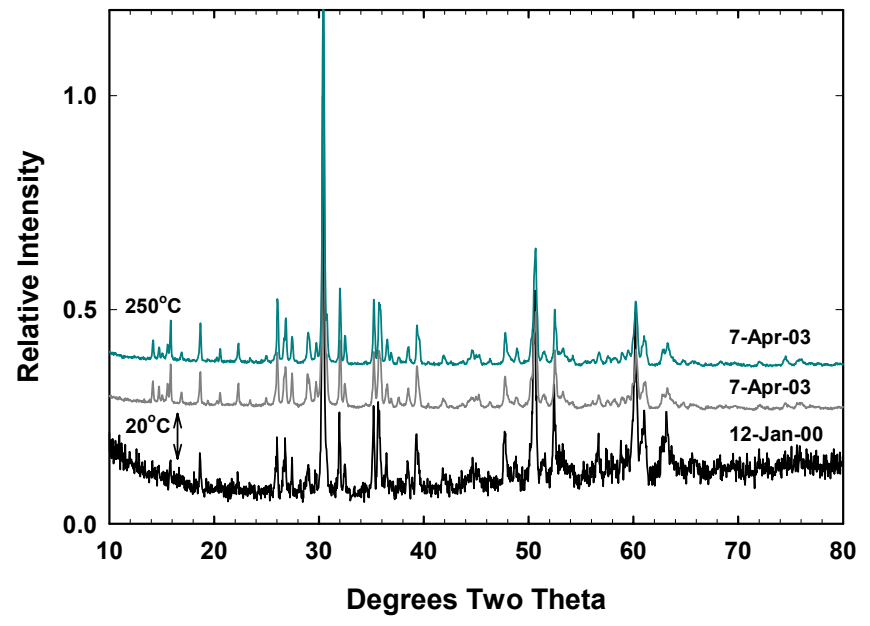

Figure 6.11. A Comparison of the XRD Patterns of the ${ }^{239} \mathrm{Pu}$-Bearing Zirconolite-Rich Baseline Ceramic Specimen from Early in the Study and at the End 


\subsubsection{Impurity Baseline Ceramic}

The ${ }^{239} \mathrm{Pu}$-bearing impurity baseline ceramic is composed of zirconolite, pyrochlore, brannerite, and rutile and shown in the diffraction patterns from the specimens (Figure 6.13). This figure shows that the phase character of the specimens did not change with time and temperature for over 1390 days of storage irrespective of storage temperature. Diffraction patterns from the ${ }^{238} \mathrm{Pu}$-bearing ceramic (Figure 6.14) showed that the brannerite phase was amorphous before the first pattern was obtained at 165 days after it was made $\left(0.9 \cdot 10^{18} \alpha / \mathrm{g}\right)$. As reported in previous sections, it appears that brannerite readily becomes amorphous with small amounts of radiation induced damage. This is consistent with the thermodynamic instability of brannerite (Helean et al. 2003). In the ${ }^{238} \mathrm{Pu}$-bearing specimens, there does not appear to be any significant rutile since there are no diffraction peaks of significance in the last pattern obtained in 2003 (Figure 6.13). The zirconolite phase remains identifiable in all but the last pattern taken. Remnants of the main peaks can still be seen in the last pattern taken in 2002 after 960 days during which time about $5 \cdot 10^{18} \alpha / \mathrm{g}$ were accumulated. In Figure 6.15 , we show in more detail the zirconolite unit cell and the persistence of the pyrochlore (311) diffraction peak. The relative intensities remain approximately constant.

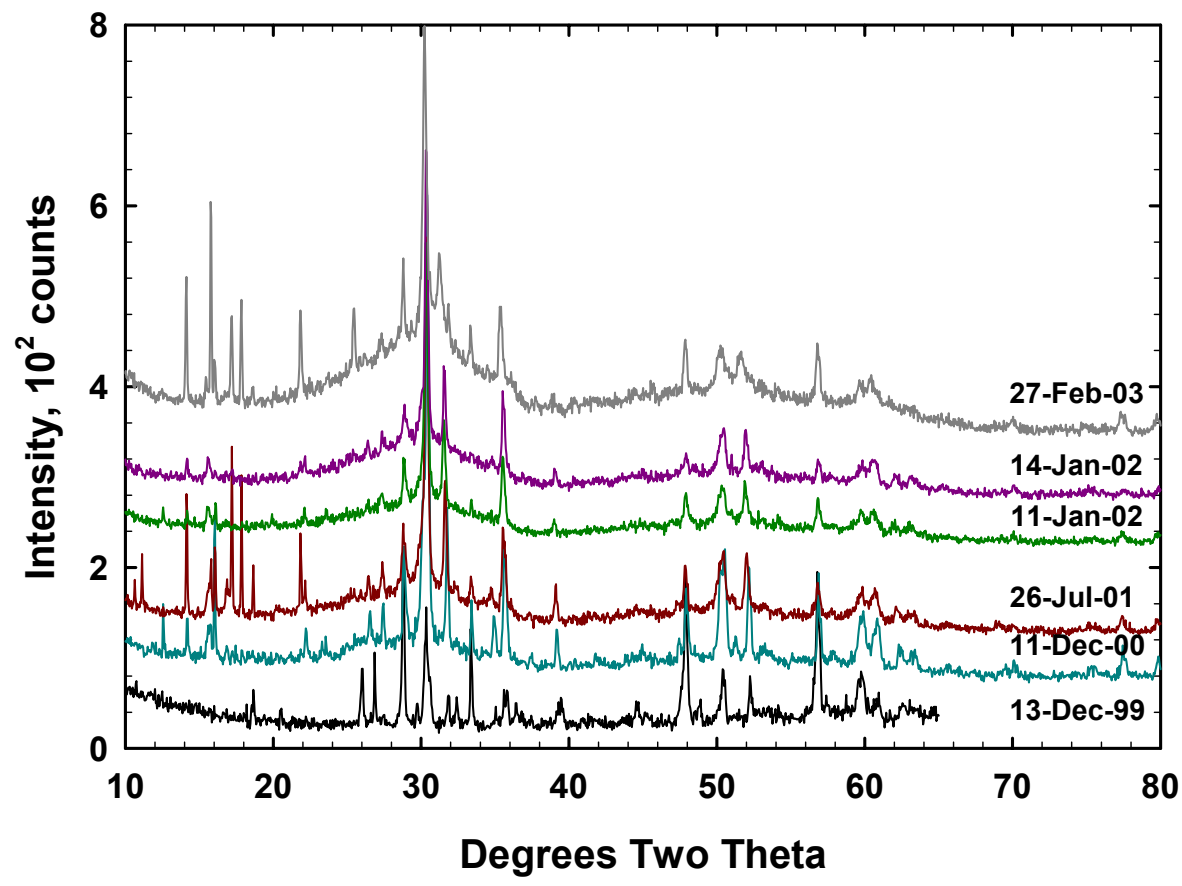

Figure 6.12. A Summary of the XRD Patterns from the ${ }^{238} \mathrm{Pu}$-Bearing Zirconolite-Rich Baseline Specimens 


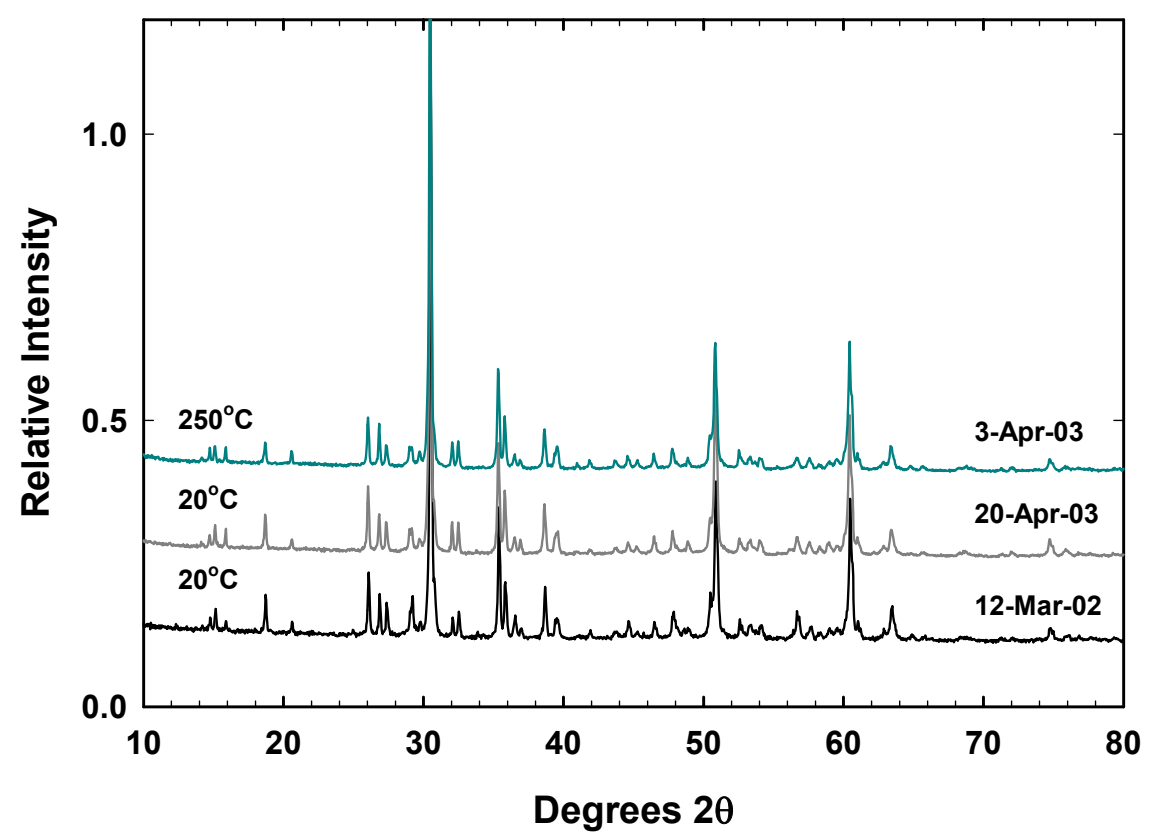

Figure 6.13. A Comparison of the XRD Patterns from the ${ }^{239} \mathrm{Pu}$-Bearing Impurity Baseline Ceramic Specimen from Early and at the End of the Study

\subsection{Transformations Induced by Radiation Damage}

From the work presented here and our previous papers on radiation-damage effects in these titanate ceramics, we conclude that, if the transformation from zirconolite to pyrochlore to fluorite to amorphous material occurs, it occurs only within unit cell dimensions of the collision cascade. Our results suggest that the transformation is from zirconolite or pyrochlore to an amorphous material without the intermediate fluorite phase. Lumpkin et al. (2001b) came to the same conclusion for heavy ion bombarded specimens of pyrochlore, brannerite, and columbite. For these particular phases, it may be that the distinction between the highly damaged zirconolite and pyrochlore and an intermediate fluorite phase is at best ambiguous and at worst not possible given the loss of relationship between Bragg diffraction and the disordered structure that gives rise to the observed XRD pattern (Howard and Sabine 1974). Considering the reverse experiment of starting with a completely amorphous titanate with the pyrochlore or zirconolite composition, one can consider the hypothetical experiment of adding undistorted unit cells into the otherwise amorphous milieu. At the start of the hypothetical experiment, one would predict an XRD pattern consistent with two broad maxima with d-spacings consistent with the average metal-metal and metal-oxygen distances or diffraction rings in a selected area diffraction pattern from a transmission electron microscope. As more crystallites of larger size are added, the diffraction patterns would be consistent with diffraction from cryptocrystalline material—broadened peaks — with only the most intense diffraction peaks emerging from these broad maxima or appearing in a selected area electron-diffraction pattern along with diffuse rings. For XRD patterns, this can be simulated with an XRD pattern simulator, such as that found in Jade, by starting with very small crystallites $(5 \mathrm{~nm})$ and incrementally making them larger (Figure 6.16). This exercise was performed for a mixture of pyrochlore and rutile where the size of the pyrochlore grais was varied and the size of the rutile crystals kept constant 
at $100 \mathrm{~nm}$ (Figure 6.16). A small amount of broadening was included for the small pyrochlore crystallites and less broadening with increasing size. No diffuse scattering was included in these simulations. For the small pyrochlore crystallites, it is not possible to distinguish between pyrochlore and fluorite. Thus, the maxima in both instruments would be indexed as fluorite because there are no other peaks from which to derive the other crystal symmetries. Adding more unit cells in this hypothetical experiment would lead to sharpened diffraction peaks and to the additional peaks from which the actual symmetry could be derived. Thus, we conclude that the progression of structure suggested by Wang et al. (1999c), Smith et al. (1997), and Ewing and Headly (1983) is probably incorrect for the zirconolites and pyrochlores that occur in the ceramics we studied. As Lumpkin et al. (2001) point out, the transition of one crystalline phase to another may be valid for compositions where the metals involved have radius ratios such that defect structures occur at elevated temperatures. This is true in spite of the relevance of the peak assignments when there is significant diffuse scattering.

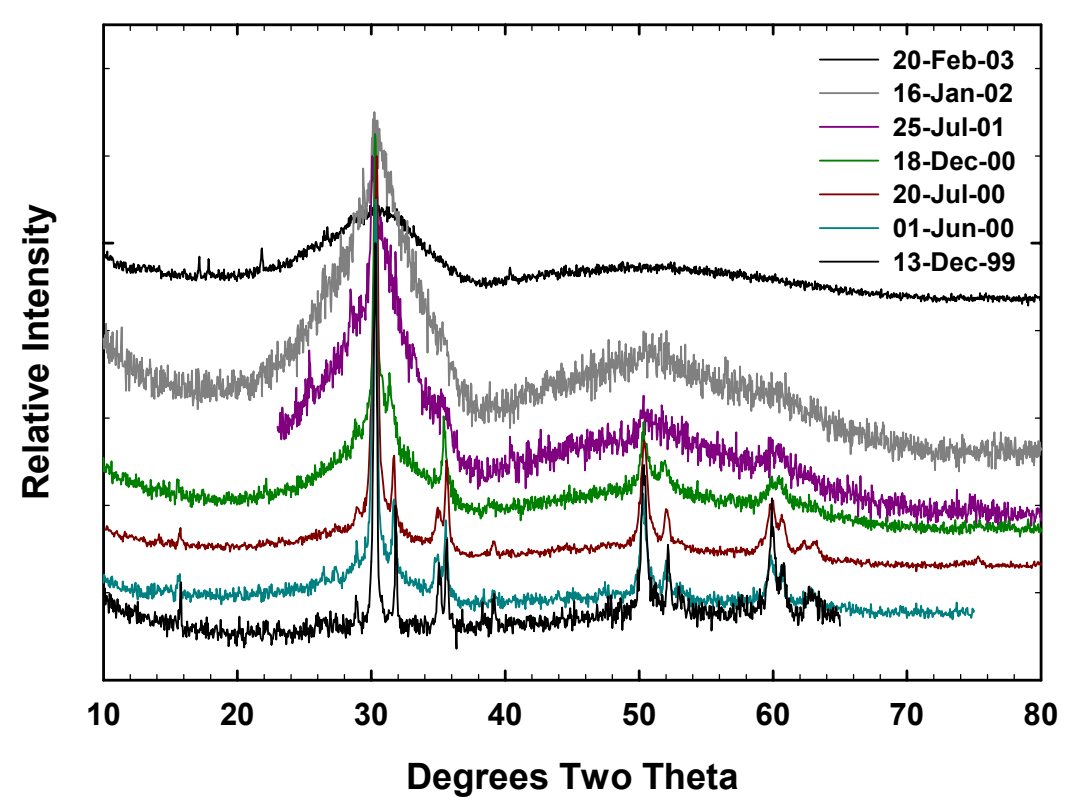

Figure 6.14. A Comparison of the XRD Patterns from ${ }^{238} \mathrm{Pu}$-Bearing Impurity Baseline Specimens Showing the Progress from Crystalline to Amorphous Structure with Accumulating Radiation Damage (the order of the patterns is the same as the order in the legend) 


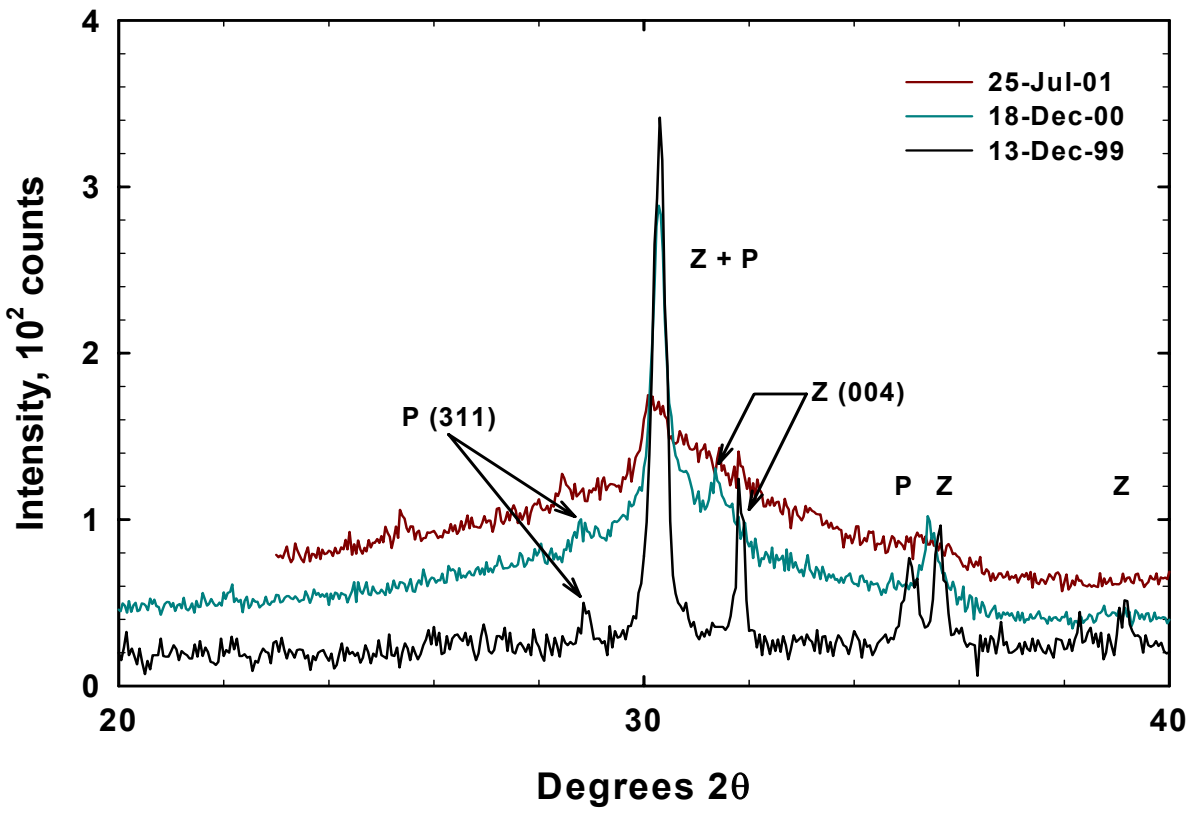

Figure 6.15. A Detail of the Three XRD Patterns from Figure 6.13 Showing the Changes in the Zirconolite and Pyrochlore Phases in the ${ }^{238} \mathrm{Pu}$-Bearing Impurity Baseline Ceramic (the Order of the Patterns Is the Same as in the Legend) 


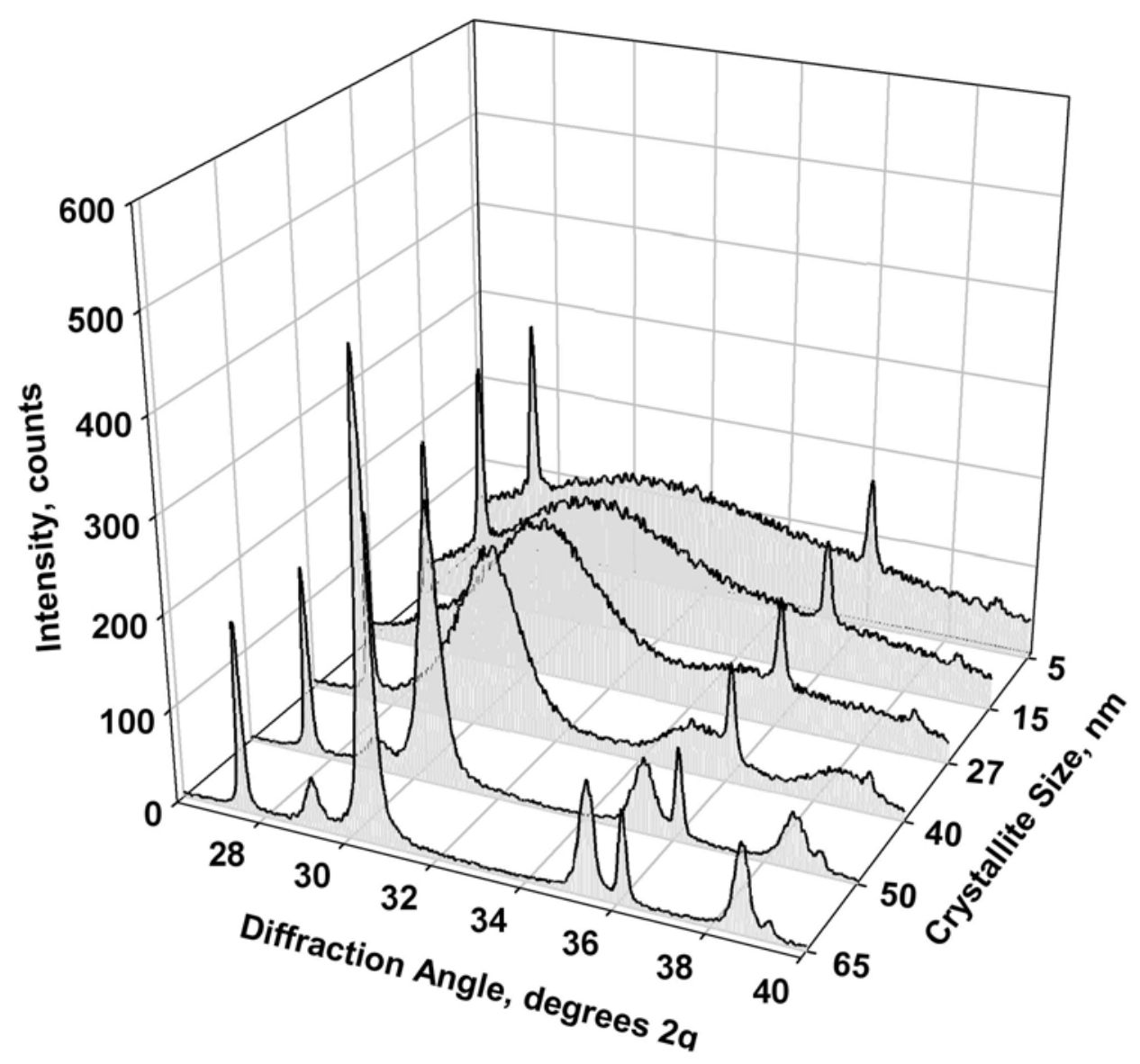

Figure 6.16. Simulated Pyrochlore and Rutile Diffraction Patterns Showing the Effect of Crystallite Size on the Capbility to Differentiate Between Pyrochlore and Flourite 


\subsection{Conclusions}

In this section, we discuss the conclusions from our research with five materials: pyrochlore, pyrochlorerich baseline, zirconolite, zirconolite-rich baseline, and impurity baseline. We made these materials in 1999 with approximately 10 mass $\%$ of either ${ }^{238} \mathrm{Pu}$ or ${ }^{239} \mathrm{Pu}$ and stored them at three temperatures, $20^{\circ} \mathrm{C}$, $125^{\circ} \mathrm{C}$, and $250^{\circ} \mathrm{C}$ in Ar-filled stainless steel containers. In mid-2002, selected ${ }^{238} \mathrm{Pu}$-bearing specimens were resintered at $1350^{\circ} \mathrm{C}$ for $2 \mathrm{~h}$. Specimens containing ${ }^{239} \mathrm{Pu}$ but otherwise of the same composition were prepared, tested, and characterized to provide results against which the results from the ${ }^{238} \mathrm{Pu}-$ bearing specimens could be compared. With an 87.7-year half-life, materials containing ${ }^{238} \mathrm{Pu}$ accumulate radiation induced damage from the alpha decay and atom recoil 275 times faster than from the same ceramics containing ${ }^{239} \mathrm{Pu}$ that would be disposed in a geologic repository. We determined the dimensions, the densities, the phase composition, and the dissolution rates in flowing water. Because of our experimental apparatus for dimension measurements and the edge defects on the specimens, the measurement of the specimen diameter was more reliable than the measurement of the height. Therefore, we calculated the changes in the geometric (bulk) density of the specimens assuming that the specimens swelled uniformly. Our results show that these materials remain viable immobilization forms for surplus weapons-grade $\mathrm{Pu}$ even when they become amorphous from the radiation induced damage.

Geometrically, these materials swell less than $10 \%$. Although the "true" density, which is the density exclusive of the porosity, decreased by a maximum of $16 \%$, the evidence suggests that open porosity is converted to closed porosity. Mechanically, the specimens we studied remained intact with no gross evidence of microcracking. However, we did not etch the specimens as one might have to do to provide sufficient relief to unambiguously detect the presence or absence of microcracking. While we were unable to estimate the critical temperature, we can conclude that it is in excess of $250^{\circ} \mathrm{C}$. Our results from single-pass flow-through dissolution tests indicate that there is no increase in the dissolution rate as these materials become amorphous.

\subsection{Pyrochlore}

We studied the effects of radiation induced damage in several specimens in which damage from the decay of ${ }^{238} \mathrm{Pu}$ accumulated for approximately 1100 days. These specimens consisted of two phases, a pyrochlore with the apparent chemical formula $\mathrm{Ca}_{1.13} \mathrm{Gd}_{0.22} \mathrm{Hf}_{0.12} \mathrm{Pu}_{0.24} \mathrm{U}_{0.40}\left(\mathrm{Ti}_{1.90} \mathrm{Hf}_{0.10}\right) \mathrm{O}_{7}$ and $\mathrm{Hf}$-rutile (containing $20 \%$ of the total $\left.\mathrm{TiO}_{2}\right),\left(\mathrm{Hf}_{0.1}, \mathrm{Ti}_{0.9}\right) \mathrm{O}_{2}$. Some of the initial specimens were sintered for an additional $100 \mathrm{~h}$ to coarsen the microstructure. This was done to determine if the coarser microstructure material was more susceptible to microcracking. After approximately 2 years, some of the original specimens that had become amorphous from damage accumulation were resintered to remove the ingrown radiation induced damage so that we could determine the changes that occurred at early times. The bulk dimensions swelled $2.6 \%$ for both the original and coarse microstructure specimens. The "true" densities of the original specimens decreased by approximately $6.8 \%$; the "true" densities of the coarsened microstructure ceramics decreased by up to $10 \%$. The larger change in the "true" densities of the coarsened specimens relative to the geometric densities occurs because open porosity is converted to closed porosity. The geometric density and the "true" density changes compared well, $7.4 \%$ and $6.8 \%$, respectively. A $3.8 \%$ increase in the unit cell volume for the pyrochlore phase in the specimens stored at $20^{\circ} \mathrm{C}$ was observed leading to a calculated decrease in the unit cell density of $3.7 \%$. 
Photomicrographs of the specimen that was originally stored at $20^{\circ} \mathrm{C}$ and was again stored at $20^{\circ} \mathrm{C}$ after resintering showed a uniformly dense material consisting of a pyrochlore and a rutile phase. Minor phases were also evident, but they could not be identified, either from the SEM or XRD results. The porosity was limited; no evidence for open porosity changing to closed porosity was discernable in the SEM photomicrographs. However, there was evidence for accumulation of a high or absence of low atomic number component(s) at the grain boundaries. Also noted was the tendency for rutile to exist at the triple points of the grains. Even at magnifications of $10000 \times$, there was no evidence for cracking in the material from radiation induced swelling. There was also evidence for compositional variability across pyrochlore grains. Although this variation could not be quantified with SEM/EDS, it would be consistent with the observation that zirconolite was stabilized after prolonged heating at $250^{\circ} \mathrm{C}$ and radiation induced damage accumulated.

Specimens that were resintered after being stored at ambient and $250^{\circ} \mathrm{C}$ each showed different phase assemblages. The XRD patterns from the specimens that had been stored at $20^{\circ} \mathrm{C}$ for about 2.5 years and then were resintered showed the presence of only pyrochlore and rutile $\left(\mathrm{TiO}_{2}\right)$. The expansion of the $\mathrm{a}_{0}$ unit cell dimension was determined to be $1.2 \%$ over approximately 400 days $\left(2.4 \cdot 10^{18} \mathrm{\alpha} / \mathrm{g}\right)$. The specimens that had been stored at $250^{\circ} \mathrm{C}$ before being resintered showed evidence of four phases, pyrochlore, rutile, and two zirconolites, at least one of which had preferred orientation, probably from the defects on the surface of the specimen. The ${ }^{238} \mathrm{Pu}$ appeared to be distributed amongst these phases differently as evidenced from the change in diffraction-peak intensity and broadening with increasing time. We concluded that one zirconolite had more ${ }^{238} \mathrm{Pu}$ than the other. This is in agreement with the SEM results, although we were unable to obtain a quantitative measure of the compositional variation. In the original specimens stored at $250^{\circ} \mathrm{C}$, there was some indication of an in-growth of zirconolite (Strachan et al. 2002). Pyrochlore and zirconolite phases are prone to lamellae formation (Buck et al. 1999) and it is possible that lamellae have formed in this material. Apparently, sintering this specimen at $1350^{\circ} \mathrm{C}$ for 2 hours was insufficient to restore the original pyrochlore phase, and the system was kinetically at a local minimum in the free energy because of the local arrangement of atoms from the radiation induced damage. This may simply be the result of slower quenching that occurs at higher temperatures in the displacement cascade, or it could represent a phase instability at $250^{\circ} \mathrm{C}$. For example, Helean et al. (2002) and Putnam et al. (1999a) showed that Ce-pyrochlore is metastable with respect to $\mathrm{CaTiO}_{3}, \mathrm{CeO}_{2}$, and $\mathrm{TiO}_{2}$. Therefore, we conclude that the radiation induced damage and storage at $250^{\circ} \mathrm{C}$ stabilized, perhaps kinetically, a mixture of pyrochlore and zirconolite. These phases become amorphous shortly after the zirconolite formed from the pyrochlore.

After we ended the experiments with the specimens that had been resintered and stored at $250^{\circ} \mathrm{C}$, we sintered them at $1390^{\circ} \mathrm{C}$ for 8 hours. The resulting XRD pattern consisted of diffraction from pyrochlore, rutile, and a single zirconolite with preferred orientation. The same result was obtained from the same specimen after it was sintered for an additional 24 hours at $1350^{\circ} \mathrm{C}$. These results suggest that, while there may be kinetic barriers to the reformation of pyrochlore from the new phase assemblage, it is also likely that chemical changes have occurred (e.g., oxidation state changes) so that zirconolite is one of the thermodynamically stable phases in these solids.

From the XRD patterns, there was an indication that Hf substituted for Ti in the structure. Some Hf substitution on the Ti site was needed to minimize the residuals in the Rietveld fit to the observed XRD patterns. To charge balance the chemical formula, some Hf was needed on the Ti site as well. Since Hf is 
included in the formulation as a neutron absorber to control criticality in these materials, and the chemistry of $\mathrm{Hf}$ and $\mathrm{Zr}$ are very similar, changing the formulation of the $\mathrm{Pu}$ immobilization form to force more $\mathrm{Hf}$ onto the Ti site might make this pyrochlore formulation more radiation resistant, but this is not needed. Some Zr-bearing pyrochlore compounds have been shown to resist very high doses without becoming amorphous (Wang et al. 1999a).

Dissolution rates of powdered and monolithic pyrochlore were determined in the Teflon SPFT apparatus; a single test of ${ }^{238} \mathrm{Pu}$-bearing pyrochlore was performed with the Ti-based apparatus. The data show that the dependence of the rate on solution $\mathrm{pH}$ is weak to non-existent, but rates are more strongly dependent upon the ratio of flow rate to sample surface area $(\mathrm{q} / \mathrm{S})$. On a plot of $\log _{10}(\mathrm{Rate})\left[\mathrm{g} /\left(\mathrm{m}^{2} \cdot \mathrm{d}\right)\right]$ versus $\log _{10}(\mathrm{q} / \mathrm{S})[\mathrm{m} / \mathrm{s}]$, dissolution rates show a dependence on $\log _{10}(\mathrm{q} / \mathrm{S})$ for values $<-7$. For values $>-7$, the dissolution rates are constant, indicating a forward rate of dissolution of $2.3 \cdot 10^{-3}$ to $5.6 \cdot 10^{-3} \mathrm{~g} /\left(\mathrm{m}^{2} \cdot \mathrm{d}\right)$. Significantly, the data from the ${ }^{238} \mathrm{Pu}$-bearing specimen lie amongst the data for the various pyrochlore specimens and close to the forward rate of dissolution.

From a physical and chemical point of view, the pyrochlore phase appears to be a viable phase in which to immobilize Pu. Although it would become X-ray amorphous in a relatively short time, approximately 300 years in the repository, the material would maintain its physical integrity with no observable microcracking over the time during which physical changes are predicted to saturate ( 950 years). The accumulated alpha dose (about $7.5 \cdot 10^{18} \mathrm{\alpha} / \mathrm{g}$ ) to the specimens studied in the work presented here is equivalent to approximately 970 years of storage of ${ }^{239} \mathrm{Pu}$-bearing pyrochlore ceramic waste form. Over the course of this radiation damage, the material swelled approximately $3 \%$, with most of the swelling occurring before $2 \cdot 10^{18} \mathrm{\alpha} / \mathrm{g}$ accumulated. Even in the case of the specimens stored at $250^{\circ} \mathrm{C}$ where zirconolite was formed with increasing radiation induced damage, there was no evidence of microcracking. Physically, the specimens remained intact. No evidence for microcracking was evident during the SEM examinations of this material. Radiation induced damage has no effect on the dissolution of this material. Thus, although pyrochlore is susceptible to radiation induced damage, the material remains viable as a material for immobilizing surplus weapons-grade $\mathrm{Pu}$.

\subsection{Pyrochlore-Rich Baseline}

In this section, we discuss the results from our radiation-damage experiments with ${ }^{238} \mathrm{Pu}$-bearing pyrochlore baseline titanate ceramic specimens. This ceramic is based on the formulation that was to be the target composition for production at the Plutonium Immobilization Plant for the immobilization of surplus weapons-grade Pu. These specimens contained four phases: pyrochlore, brannerite, zirconolite, and rutile. The specimen diameters swelled by $1.5 \%$, implying that the bulk density decreased by $4.4 \%$, and the changes appeared to be independent of temperature within the experimental uncertainty. The "true" densities decreased by more than the bulk densities at all temperatures. We conclude that some of the open porosity became closed porosity. The "true" densities after more than 1300 days $\left(7.3 \cdot 10^{18} \alpha / \mathrm{g}\right.$ or $\sim 980$ years when the dose comes from ${ }^{239} \mathrm{Pu}$ in the repository) of accumulated damage were $11 \%, 9.9 \%$, and $7.4 \%$ for the specimens stored at $20^{\circ} \mathrm{C}, 125^{\circ} \mathrm{C}$, and $250^{\circ} \mathrm{C}$, respectively. Although there was no significant temperature dependence of the macroscopic swelling, there was a temperature dependence of the "true" density and the unit cell dimensions. These observed differences further suggested that open porosity was converted to closed porosity as individual particles swelled. 
Results from the XRD analyses suggested that material becomes amorphous by $3.7 \cdot 10^{18} \alpha / \mathrm{g}$ or about 650 days for these materials. Results from the resintered specimens gave us a better understanding of how the individual phases change with radiation induced damage. The pyrochlore phase lattice parameter increased by $4.6 \%$ at $20^{\circ} \mathrm{C}$ over 675 days (approximately 500 years from ${ }^{239} \mathrm{Pu}$ ). At $250^{\circ} \mathrm{C}$, the cellvolume expansion was the same, but it took 1.6 times longer to achieve that expansion. This is consistent with a decrease in the cascade volume per alpha event that one expects because more damage is annealed at the higher temperature. The brannerite phase is the most sensitive to the effects of radiation damage, consistent with the metastability of the brannerite phase (Helean et al. 2003) and the relative thermodynamic stability of the pyrochlore and zirconolite phases (Helean et al. 2002). Since the rutile phase contains little, if any, $\mathrm{Pu}$ (Ebbinghaus et al. 1999), the small changes in the lattice parameters were likely caused by the radiation from the surrounding phases containing $\mathrm{Pu}$. The zirconolite phase in the pyrochlore-rich baseline material behaved differently with accumulated damage than zirconolites in other materials in that the major effect of radiation induced damage was to $a_{0}, b_{0}$, and $\beta$ and no significant change in $\mathrm{c}_{0}$. Examination of a sample of this material in the SEM did not provide any information that could be used to explain this difference.

Scanning electron microscope images suggest that zirconolite in the pyrochlore ceramics is embedded (as lamallae or veins) within the pyrochlore. This might indicate that the zirconolite crystallizes with a preferred orientation. This may be the reason why only specific axes were affected by the radiation effects. It is also clear from the SEM images that brannerite solidifies last during processing and has an ill-defined shape (anhedral). If this phase is poorly crystallized or had the shortest time to form, it may be less resistant to radiation effects than the other phases. The SEM images also indicate that undissolved plutonium-rich inclusions are usually present near the brannerite, possibly increasing the radiation field around it. The uranium in brannerite is also known to occur as U(V) (Stewart et al. 2002). This may have some effect on its radiation resistance.

The corrosion-resistance of pyrochlore-baseline specimens was tested in both a Teflon- and a Ti-based SPFT apparatus. Non-radioactive and ${ }^{239} \mathrm{Pu}$-bearing samples were tested in the Teflon SPFT apparatus and the ${ }^{238} \mathrm{Pu}$-bearing specimens in the Ti reactor systems. The ${ }^{238} \mathrm{Pu}$-bearing specimens included radiation damaged (X-ray amorphous) and resintered samples. Fast flow rates coupled with the Teflonfree apparatus minimized experimental artifacts, such as fluorine or buildup of radiolysis products in the leachate solution. Of special significance is our finding that there is NO difference in dissolution rate between the fully radiation damaged (original) and resintered specimens. These data appear to rule out the proposition that the magnitude of radiation induced damage influences dissolution rates of titanate ceramics. Our other findings indicate that dissolution rates are not dependent upon solution $\mathrm{pH}$, but are strongly dependent upon flow rate. The forward rate of reaction for pyrochlore-baseline is $4.2 \cdot 10^{-3}$ to $1.3 \cdot 10^{-2} \mathrm{~g} /\left(\mathrm{m}^{2} \cdot \mathrm{d}\right)$. The ${ }^{238} \mathrm{Pu}$-bearing specimens dissolve at near the forward rate of dissolution, thus placing an upper bound on the chemical durability of titanium pyrochlore-baseline materials.

Overall, the pyrochlore-baseline material appears to be a viable material for the immobilization of weapons-ready $\mathrm{Pu}$. Despite the mixture of phases and the low porosity, these specimens maintained their physical integrity over the course of this study during which the effects of radiation induced damage saturated, and the bulk volume swelled $4.4 \%$. No microcracking was observed. The photomicrographs show good adherence at the grain boundaries between phases that have isotropic and anisotropic swelling. No increase in the dissolution rate in water was noted. The physical and chemical properties of the 
pyrochlore-rich baseline material, as the other titanate materials that we have studied, are not adversely affected by the material becoming amorphous from radiation induced damage.

\subsection{Zirconolite}

Radiation induced damage effects on the crystal structure, dimensions, and density have been measured for zirconolite. The "true" density decreased with increasing dose. There was a rapid decrease in the "true" density of the specimens stored at $20^{\circ} \mathrm{C}$ between 0 and about 500 days. The "true" density data from $20^{\circ} \mathrm{C}$ and $125^{\circ} \mathrm{C}$ were fit to an exponential decay to a constant value. These results indicate that the "true" density decreases by $16 \%$ and $9.6 \%$ for the $20^{\circ} \mathrm{C}$ and $125^{\circ} \mathrm{C}$ data, respectively. There were insufficient data to make a similar determination for the "true" density of the specimens stored at $250^{\circ} \mathrm{C}$. The radiation induced swelling of the specimens was $1.7 \%$ or a calculated density decrease of $4.9 \%$. We conclude that the difference between the changes in the "true" densities and the bulk swelling result from changes in open porosity in the "true" density measurements. Open porosity was converted to closed porosity as individual grains of the specimen swelled in response to radiation induced damage. The XRD patterns show that the specimens consist of zirconolite, $\mathrm{HfTiO}_{4}$, and $\mathrm{TiO}_{2}$. There is a progressive loss of intensity and a general broadening of the diffraction peaks before the zirconolite becomes amorphous. There is no evidence for a progression from zirconolite to pyrochlore to fluorite before the material becomes amorphous. This is different than what is reported in the literature (Wang et al. 1999c). By 741 days $\left(2.6 \cdot 10^{18} \alpha / \mathrm{g}\right)$, the zirconolite is X-ray amorphous. This is well before time at which radiation induced swelling saturates, 900 days $\left(3.2 \cdot 10^{18} \alpha / \mathrm{g}\right)$; a time equivalent to nearly 700 years of $\alpha$-dose from ${ }^{239} \mathrm{Pu}$ in the repository.

Major phases identified with SEM included zirconolite, brannerite, and rutile. In these ceramics, zirconolite is a dominant phase and the characteristic elongated crystal growth was absent. This may allow the ceramic to become amorphous more rapidly; however, EDS analyses appeared to indicate that the $\mathrm{Pu}$ content in the zirconolite was relatively low in comparison to the brannerite phase. This supports the conclusion from XRD that brannerite becomes amorphous before zirconolite because of the occurrence of Pu-rich inclusions within the brannerite, which may possibly give brannerite a localized high-radiation field.

The chemical durability of ${ }^{239} \mathrm{Pu}$-bearing zirconolite was tested in both the Ti- and Teflon-based SPFT systems. Non-radioactive specimens, both powdered and monolithic, were tested exclusively in the Teflon reactors. As in the case of the pyrochlore and pyrochlore-baseline materials, zirconolite dissolution exhibits no dependence on solution $\mathrm{pH}$. The exceptions to this are the elements $\mathrm{Pu}$ and $\mathrm{Ti}$, which are released at a rate of $\sim 100$ times slower at $\mathrm{pH}$ values greater than 2 . These data are consistent with solubility control for $\mathrm{Pu}$ and Ti. Element release determined from tests in the Teflon vessel exhibit no difference in rate compared to the release obtained from the Ti reactor, once flow rate is taken into account. The forward rate of dissolution, determined from the specimen in the Ti reactor, is very close to the forward rate of dissolution determined from the entire set of zirconolite data. Our results demonstrate that zirconolite dissolution rates do not depend on either the reactor vessel composition or Pu-loading.

Although this material becomes amorphous at low doses, the specimens remained physically strong. To load the XRD specimen holder, the specimen had to be pushed against modeling clay to align it in the Xray beam. At no time did the material fracture or spall particles. Even after the radiation induced swelling saturated, the specimens remained physically intact with no evidence for microcracking as was 
noted by Clinard and coworkers $(1981 ; 1982 b)$. No increase in the low dissolution rate was noted in our experiments. Thus, the material remains physically a viable material for the disposition of surplus weapons-grade $\mathrm{Pu}$.

\subsection{Zirconolite-Rich Baseline and Impurity Baseline}

Radiation induced damage effects on the crystal structure, dimensions, and density have been measured for two immobilized $\mathrm{Pu}$ forms with baseline compositions - a zirconolite baseline and an impurity baseline. Both ceramics were composed of the phases zirconolite, pyrochlore, and brannerite; the zirconolite-rich baseline also contained excess $\mathrm{PuO}_{2}$ that resulted from a make-up error, (Hf,Ti) $\mathrm{O}_{2}$, and $\mathrm{HfTiO}_{4}$. There was a rapid decrease in the "true" density of the specimens with increasing dose at all storage temperatures. The "true" density data were fit to an exponential decay to a constant value equation. These results indicate that the "true" density decreases by $6.3 \%$ for the zirconolite baseline specimens with no observed temperature dependence and $9.9 \%, 9.0 \%$, and $8.6 \%$ for the impurity-baseline specimens stored at $20^{\circ} \mathrm{C}, 125^{\circ} \mathrm{C}$, and $250^{\circ} \mathrm{C}$, respectively. The radiation induced swelling of the zirconolite baseline specimens was $1.7 \%$ or a calculated bulk density decrease of $4.9 \%$. Dimensional swelling in the impurity-baseline specimens was $2.5 \%$ for a calculated decrease in the bulk density of $7.1 \%$. We conclude that the difference between the changes in the "true" densities and the bulk swelling result from changes in open porosity in the "true" density measurements. Open porosity was converted to closed porosity as individual grains of the specimen swelled in response to radiation induced damage. There is a progressive loss of intensity in the XRD patterns and a general broadening of the diffraction peaks. In the ${ }^{238} \mathrm{Pu}$-bearing specimens, brannerite appears to have become amorphous before the first XRD patterns were obtained. In both materials, zirconolite is the last phase to become amorphous, but it is unknown if this is because the zirconolite is more resilient to radiation induced damage as indicated in the literature or if this particular phase has less of the total $\mathrm{Pu}$ than do the other phases. Brannerite would be expected to have the least $\mathrm{Pu}$ based on the thermodynamic instability of $\mathrm{PuTi}_{2} \mathrm{O}_{6}$ (Helean et al. 2003). However, there must be sufficient Pu contained in this phase for it to become amorphous rapidly, or the phase is so sensitive to radiation induced damage that the radiation from the surrounding $\alpha$-bearing material causes the brannerite to become amorphous. There is no evidence for a progression from zirconolite to pyrochlore to fluorite before the material becomes amorphous. The SEM-EDS analyses indicate that plutonium is not incorporated into brannerite but occurs as undissolved inclusions in this phase. This is consistent with the conclusions of Lumpkin et al. (2001b) and different than what is reported by others Wang et al. (1999c), Smith et al. (1997), and Ewing and Headley (1983). These ceramics become amorphous before 930 days (approximately 700 years when the dose comes from ${ }^{239} \mathrm{Pu}$ in the repository) or an average dose of $5 \cdot 10^{18} \alpha / \mathrm{g}$ for the impurity baseline. Although zirconolite and $\mathrm{PuO}_{2}$ can be identified as crystalline phases in the zirconolite baseline ceramic, the material was largely amorphous at the end of the experiments (1246 days or an average of $4 \cdot 10^{18} \alpha / \mathrm{g}$; approximately 950 years from $\left.{ }^{239} \mathrm{Pu}\right)$.

Quality SEM data on the zirconolite baseline ceramic was not possible; however, the phase distribution in the ${ }^{239} \mathrm{Pu}$ ceramic was very similar to the ${ }^{238} \mathrm{Pu}$ ceramic in this case. There were significantly more lamellae structures in these ceramics compared to the pure zirconolite (see Section 6). Based on SEMEDS results, though not quantitative, it is likely that zirconolite becomes amorphous last because it has the least $\mathrm{Pu}$ of the phases capable of incorporating $\mathrm{Pu}$. 
Although these materials become amorphous at low doses, the specimens remained physically strong. To load the XRD specimen holder, the specimen had to be pushed against modeling clay to align it in the X-ray beam. Even after the radiation induced swelling saturated, the specimens remained physically intact with no evidence for microcracking as was noted by Clinard and coworkers (1981) and (1982b). Based on our results from the other ceramics in this study, no increase in dissolution rate is expected for these ceramics as they become amorphous from radiation induced damage. Thus, the material remains physically and chemically a viable material for the disposition of surplus weapons-grade $\mathrm{Pu}$.

\subsection{General Conclusions}

From the work summarized above, we have determined that radiation induced damage has little or no effect on the chemical durability of the titanate immobilization forms for surplus weapons-grade Pu. We measured the dissolution rates with a method that eliminated or relegated to insignificant the effects of radiolysis products on the dissolution rate. Furthermore, our analyses and results indicate that most of the reports of radiation damage on the dissolution rates of materials need to be repeated to verify the observed increases. Our results also indicate that less than $10 \%$ swelling is expected between the time these materials have been made and 700 years or more in the repository. While we did not perform strength measurements, our handling of the specimens and the insensitivity of the dissolution rate to radiation damage suggest that these materials remain strong even after the crystalline components have become amorphous. Thus, these materials remain as viable candidates for the immobilization of surplus weaponsgrade $\mathrm{Pu}$. 


\subsection{References}

ANSTO. 1999. Japan-Australia Co-Operative Program on Research and Development of Technology for the Management of High Level Radioactive Wastes, 1985 to 1998., ANSTO/E736, Australian Nuclear and Science Technology Organisation, Lucas Heights, Australia.

Begg BD, NJ Hess, DE McCready, S Thevuthasan, and WJ Weber. 2001. "Heavy-Ion Irradiation Effects in $\mathrm{Gd}_{2}\left(\mathrm{Ti}_{2-\mathrm{x}} \mathrm{Zr}_{\mathrm{x}}\right) \mathrm{O}_{7}$ Pyrochlores." Journal of Nuclear Materials 289: 188-193.

Begg BD, WJ Weber, R Devanathan, JP Icenhower, S Thevuthasan, and BP McGrail. 2000a. "Heavy-Ion Irradiation Effects in Pyrochlores." Ceramic Transactions 107: 553-560.

Begg BD, WJ Weber, R Devanathan, JP Icenhower, S Thevuthasen, and BP McGrail. 2000b. "Heavy-Ion Irradiation Effects in Pyrochlores." Ceramics Transactions 107: 553-560.

Buck EC, DB Chamberlain, and R Giere. 1999. "Intergrowth Structures in Synthetic Pyrochlores: Implications for Radiation Damage Effects and Waste Form Formulation." Mat. Res. Soc. Symp. Proc 556: $19-26$.

Burakov BE, and EB Anderson. 2001. Immobilization of Excess Weapons Plutonium in Russia: A Review of LLNL Contract Work, UCRL-ID-143846, Livermore National Laboratory, Livermore, California.

Burakov BE, EB Anderson, M Yagovkina, M Zamoryanskaya, and E Nikolaeva. 2002a. "Behavior of

${ }^{238} \mathrm{Pu}$-Doped Ceramics Based on Cubic Zirconia and Pyrochlore under Radiation Damage." Journal of Nuclear Science and Technology, Supplement 3: 733-736.

Burakov BE, EB Anderson, M Yagovkina, M Zamoryanskaya, and E Nikolaeva. 2002b. "Behavior of

${ }^{238} \mathrm{Pu}$-Doped Ceramics Based on Cubic Zirconia and Pyrochlore under Radiation Damage." In: Actinide 2001 International Conference, Japan, Atomic Energy Society of Japan.

Chen J, J Lian, LM Wang, RC Ewing, and LA Boatner. 2001. "X-Ray Photoelectron Spectroscopy Study of Irradiation-Induced Amorphizaton of Gd2Ti2O7." Applied Physics Letters 79(13): 1989-1991.

Chikalla TD, and RP Turcotte. 1973. "Self-Radiation Damage Ingrowth in ${ }^{238} \mathrm{PuO}_{2}$." Radiation Effects 19: 93-98.

Clinard FW. 1986. "Review of Self-Irradiation Effects in Pu-Substituted Zirconolite." American Ceramic Society Bulletin 65(8): 1181-1187.

Clinard FW, LW Hobbs, CC Land, DE Peterson, DL Rohr, and RB Roof. 1982a. "Alpha-Decay SelfIrradiation Damage in Pu-238-Substituted Zirconolite." Journal of Nuclear Materials 105(2-3): 248-256.

Clinard FW, CC Land, DE Peterson, DL Rohr, and RB Roof. 1982b. "Alpha Decay Self-Damage in Cubic and Monoclinic Zirconolite." In: Scientific Basis for Nuclear Waste Management, Boston, MA, Elsevier Science Publishing Company, Inc.

Clinard FW, DE Peterson, DL Rohr, and LW Hobbs. 1984. "Self-Irradiation Effects in Pu-238Substituted Zirconolite .1. Temperature-Dependence of Damage." Journal of Nuclear Materials 126(3): 245-254. 
Clinard FW, and DL Rohr. 1981. "Spontaneous Fragmentation of an Alpha-Active Ceramic -- a Mechanism for Dispersion of Solid Waste?" In: Scientific Basis for Nuclear Waste Management, Boston, MA, Plenum Press, NY.

Cochran SG, WH Dunlop, TA Edmunds, TH Gould, and LM MacLean. 1997. Fissile Material Disposition Program: Final Immobilization Form Assessment and Recommendation., Lawrence Livermore National Laboratory, Livermore.

Conradson SD. 1998. "Application of X-Ray Absorption Fine Structure Spectroscopy to Materials and Environmental Science." Applied Spectroscopy 52(7): 252a-279a.

DOE. 2002a. Amended Record of Decision for the Surplus Plutonium Disposition Program. Washington, DC, Office of the Federal Register.

DOE. 2002b. Report to Congress: Disposition of Surplus Defense Plutonium at Savannah River Site. Washington, DC, Department of Energy.

Dosch RG, AW Lynch, TJ Headley, and PF Hlava. 1981. "Titanate Waste Forms for High Level Waste an Evaluation of Materials and Processes." In: Scientific Basis for Nuclear Waste Management, Boston, MA, Plenum Press.

Ebbinghaus B, RA Van Konynenburg, ER Vance, A Jostons, RG Anthony, CV Philip, and DJ Wronkiewicz. 1995. "Status of Plutonium Ceramic Immobilization Processes and Immobilization Forms." In: Plutonium stabilization and immobilization workshop, US Department of Energy.

Ebbinghaus BB, GA Armantrout, L Gray, HF Shaw, RA VanKonynenburg, and C Cicero-Herman. 2000. Plutonium Immobilization Project: Baseline Formulation Report, UCRL-ID-133089 Rev. 1, Lawrence Livermore National Laboratory, Livermore, CA.

Ebbinghaus BB, C Cicero-Herman, L Gray, and HF Shaw. 1999. Plutonium Immobilization Project: Baseline Formulation, UCRL-ID-133089, Lawrence Livermore National Laboratory, Livermore, California.

Ebbinghaus BB, and OH Krikorian. 2001. Ternary Phase Diagrams That Relate to the Plutonium Immobilization Ceramic, UCRL-ID-143170, Lawrence Livermore National Laboratory, Livermore, CA.

Ewing RC, and TJ Headley. 1983. "Alpha-Recoil Damage in Natural Zirconolite (CaZrTi2O7)." Journal of Nuclear Materials. 119: 102-109.

Eyal Y, GR Lumpkin, and RC Ewing. 1987. "Natural Annealing of Alpha-Recoil Damage in Metamict Minerals of the Thorite Group." Mat. Res. Soc. Symp. Proc 84: 635-643.

Fortner JA, AJ Kropf, RJ Finch, AJ Bakel, MC Hash, and DB Chamberlain. 2002. "Crystal Chemistry of Uranium (V) and Plutonium (IV) in a Titanate Ceramic for Disposition of Surplus Fissile Material."

Journal of Nuclear Materials 304(1): 56-62.

Gieré R, C Hatcher, E Reusser, and EC Buck. 2002. "Element Partitioning in Pyrochlore-Based Ceramic Nuclear Waste Form." Mat. Res. Soc. Symp. Proc 713: 303-310. 
Helean KB, A Navrotsky, GR Lumpkin, M Colella, J Lian, RC Ewing, B Ebbinghaus, and JG Catalano. 2003. "Enthalpies of Formation of U-, Th-, Ce-Brannerite: Implications for Plutonium Immobilization." Journal of Nuclear Materials 320: 231-244.

Helean KB, A Navrotsky, ER Vance, ML Carter, B Ebbinghaus, OH Krikorian, J Lian, LM Wang, and JG Catalano. 2002. "Enthalpies of Formation of Ce-Pyrochlore, $\mathrm{Ca}_{0.93} \mathrm{Ce}_{1.00} \mathrm{Ti}_{2.035} \mathrm{O}_{7.00}$, U-Pyrochlore, $\mathrm{Ca}_{1.46} \mathrm{U}(\mathrm{IV})_{0.23} \mathrm{U}(\mathrm{VI})_{0.46} \mathrm{Ti}_{1.85} \mathrm{O}_{7.00}$, and Gd-Pyrochlore, $\mathrm{Gd}_{2} \mathrm{Ti}_{2} \mathrm{O}_{7}$ : Three Materials Relevant to the Proposed Waste Form for Excess Weapons Plutonium." Journal of Nuclear Materials 303: 226-239.

Hess NJ, BD Begg, SD Conradson, DE McCready, PL Gassman, and WJ Weber. 2002. "Spectroscopic Investigations of the Structural Phase Transition in $\mathrm{Gd}_{2}\left(\mathrm{Ti}_{1-\mathrm{x}} \mathrm{Zr}_{\mathrm{x}}\right)_{2} \mathrm{O}_{7}$ Pyrochlores." J. Phys. Chem. B 106: 4663-4677.

Howard CJ, and TM Sabine. 1974. "X-Ray Diffraction Profiles from Neutron-Irradiated Magnesium Oxide." Journal of Physics C: Solid State Physics 7: 3453-3466.

Icenhower JP, DM Strachan, MJ Lindberg, EA Rodriguez, and JL Steele. 2003. Dissolution Kinetics of Titanate-Based Ceramic Waste Forms: Results from Single-Pass Flow Tests on Radiation Damaged Specimens, PNNL-14252, Pacific Northwest National Laboratory, Richland, WA.

Kong LB, J Ma, W Zhu, and OK Tan. 2002. "Phase Formation and Thermal Stability of $\left(\mathrm{Zr}_{1-\mathrm{x}} \mathrm{ti}_{\mathrm{x}}\right) \mathrm{O}_{2}$ Solid Solution Via a High-Energy Ball Milling Process." Journal of Alloys and Compounds 335: 290-296.

Lukinykh AN, SV Tomilin, AA Lizin, AA Yelesin, AG Yakovenko, and AV Bychkov. 2002. Investigation of Chemical Resistance and Structural Restoration of Damaged Titanate Ceramics Designed for Actinides Disposal, SSC RF RIAR, Dimitrograd, Russia.

Lumpkin GR. 2001. "Alpha-Decay Damage and Aqueous Durability of Actinide Host Phases in Natural Systems." Journal of Nuclear Materials 289(1-2): 136-166.

Lumpkin GR, R Gieré, TE Payne, PJ McGlinn, and KP Hart. 2001a. "Partitioning of Actinides, Rare Earth Elements, and Other Trace Elements in Titanium-Rich Veins from Adamello, Italy." Mat. Res. Soc. Symp. Proc 663: 989-997.

Lumpkin GR, SHF Leung, and M Colella. 2000. "Composition, Geochemical Alteration, and AlphaDecay Damage Effects of Natural Brannerite." In: Scientific Basis for Nuclear Waste Management XXIII. RW Smith and DW Shoesmith, Eds. Materials Research Society, Warrendale, PA. 608:359-365.

Lumpkin GR, KL Smith, and MG Blackford. 2001b. "Heavy Ion Irradiation Studies of Columbite, Brannerite, and Pyrochlore Structure Types." Journal of Nuclear Materials 289(1-2): 177-187.

Lumpkin GR, KL Smith, MG Blackford, R Giere, and CT Williams. 1998. "The Crystalline-Amorphous Transformation in Natural Zirconolite: Evidence for Long-Term Annealing." Mat. Res. Soc. Symp. Proc 506: $215-222$.

Meldrum A, CW White, V Keppens, LA Boatner, and RC Ewing. 2001. "Irradiation-Induced Amorphization of $\mathrm{Cd}_{2} \mathrm{Nb}_{2} \mathrm{O}_{7}$ Pyrochlore." Physical Review B 63: 1-11.

Minervini L, RW Grimes, and KE Sickafus. 2000. "Disorder in Pyrochlore Oxides." J. Am. Ceram. Soc. 83(8): 1873-1878. 
Mitamura M, S Matsumoto, and MWA Stewart. 1994. Journal of the American Ceramics Society 77(9): 2255-2264.

Morgan PED, AB Harker, JF Flintoff, TM Shaw, and DR Clarke. 1984. "Developments in SRP "Composite" Defense Ceramic Radwaste Forms." In: Advances in Ceramics. GG Wicks and WA Ross, Eds. American Ceramic Society, Westerville, OH. 8:234-246.

Myers BR, GA Armantrout, CM Jantzen, A Jostsons, JM McKibben, HR Shaw, DM Strachan, and JD Vienna. 1998. Technical Evaluation Panel Summary Report: Ceramic and Glass Immobilization Options, UCRL-ID-129315, Livermore National Laboratory, Livermore, California.

Putnam RL, KB Helean, A Navrotsky, EC Buck, BB Ebbinghaus, HF Shaw, ER Vance, and MA Williamson. 1999a. Plutonium Immobilization Project: Limits of Thermodynamic Stability of Pyrochlore Waste Forms for Surplus Weapons Plutonium, UCRL-JC-13509, Lawrence Livermore National Laboratory, Livermore, CA.

Putnam RL, A Navrotsky, BF Woodfield, JL Shapiro, R Stevens, and J Boerio-Goates. 1999b. "Thermochemistry of Hf-Zirconolite, $\mathrm{CaHfTi}_{2} \mathrm{O}_{7}$." Mat. Res. Soc. Symp. Proc 556: 11-18.

Ringwood AE, V Oversby, M., and W Sinclair. 1980. "The Effects of Radation Damage on Synroc." In: Scientific Basis for Nuclear Waste Management, Boston, MA, Plenum Press.

Saripalli PK, BP McGrail, and DC Girvin. 2002. "Adsorption of Molybdenum on to Anatase from Dilute Aqueous Solutions." Applied Geochemistry 17(5): 649-656.

Smith KL, NJ Zaluzec, and GR Lumpkin. 1997. "In Situ Studies of Ion Irradiated Zirconolite, Pyrochlore and Perovskite." Journal of Nuclear Materials 250(1): 36-52.

Stewart MWA, ER Vance, A Jostsons, K Finnie, RA Day, and BB Ebbinghaus. 2002. "Atmosphere Processing Effects on Titanate Ceramics Designed for Plutonium Immobilisation." Mat. Res. Soc. Symp. Proc 713: 381-388.

Stokes MW, EL Hovis, EL Hamilton, and JB Fiscus. 1999. Plutonium Immobilization Canister Loading, WSRC-TR-00441, Westinghouse Savannah River Co., Aiken, SC.

Strachan DM, WC Buchmiller, WR Park, and JT Munley. 2004. "A Laser-Based Measurement Device for Highly Radioactive Specimens." Powder Diffraction Accepted for publication.

Strachan DM, HT Schaef, MJ Schweiger, KL Simmons, LJ Woodcock, and MK Krouse. 2003a. "A Versatile and Inexpensive XRD Specimen Holder for Highly Radioactive or Hazardous Specimens." Powder Diffraction 18(1): 23-28.

Strachan DM, RD Scheele, WC Buchmiller, JD Vienna, RL Sell, and RJ Elovich. 2000. Preparation and Characterization of ${ }^{238} \mathrm{Pu}$-Ceramics for Radiation Damage Experiments, PNNL-13251, Pacific Northwest National Laboratory, Richland, Washington.

Strachan DM, RD Scheele, JP Icenhower, AE Kozelisky, RL Sell, VL Legore, HT Schaef, MJ O'Hara, CF Brown, and WC Buchmiller. 2001. The Status of Radiation Damage Experiments, PNNL-13721, Pacific Northwest National Laboratory, Richland, WA. 
Strachan DM, RD Scheele, AE Kozelisky, and RL Sell. 2003b. Effects of Self Irradiation from ${ }^{238}$ Pu on Candidate Ceramics for Plutonium Immobilization, PNNL-14232, Pacific Northwest National Laboratory, Richland, WA.

Strachan DM, RD Scheele, AE Kozelisky, RL Sell, HT Schaef, MJ O'Hara, CF Brown, and WC Buchmiller. 2002. "Radiation Damage in Titanate Ceramics for Plutonium Immobilization." Scientific Basis for Nuclear Waste Management XXV 713: 461-468.

TRW. 1997. Degraded Mode Criticality Analysis of Immobilized Plutonium Waste Forms in a Geologic Repository, A00000000-01717-5705-00014 Rev 01, TRW Environmental Safety Systems, Inc., Las Vegas, Nevada.

USA. 2000. Agreement between the Government of the United States of America and the Government of the Russian Federation Concerning the Management and Disposition of Plutonium Designated as No Longer Required for Defense Purposes and Related Cooperation, United States State Department.

Vance ER, JN Watson, ML Carter, RA Day, and BD Begg. 2001. "Crystal Chemistry and Stabilization in Air of Brannerite, $\mathrm{UTi}_{2} \mathrm{O}_{6}$." J. Am. Ceram. Soc. 84(1): 141-144.

Volkov YF, AN Lukinykh, SV Tomilin, and AV Bychkov. 2001. Immobilization of Excess Weapons Plutonium in Russia, UCRL-ID-143846, Livermore National Laboratory, Livermore, California.

Wald JW, and P Offerman. 1982a. "A Study of Radiation Effects in Curium-Doped $\mathrm{Gd}_{2} \mathrm{Ti}_{2} \mathrm{O}_{7}$ (Pyrochlore) and $\mathrm{CaZrTi}_{2} \mathrm{O}_{7}$ (Zirconolite)." In: Scientific Basis for Nuclear Waste Management V. W Lutze, Ed., North-Holland, New York, New York:369-378.

Wald JW, and P Offerman. 1982b. "A Study of Radiation Effects in Curium-Doped Gd2Ti2O7 (Pyrochlore) and CaZrTi2O7 (Zirconolite)." Materials Research Society Symposium Proceedings 11: 369-378.

Wald JW, and WJ Weber. 1984. "Effects of Self-Radiation Damage on the Leachability of Actinide-Host Phases." Advances in Ceramics, Nuclear Waste Management 8: 71-75.

Wang SX, BD Begg, LM Wang, RC Ewing, WJ Weber, and KV Govindan Kutty. 1999a. "Radiation Stability of Gadolinium Zirconate: A Waste Form for Plutonium Disposition." J. Materials Research 14(12): 4470-4473.

Wang SX, LM Wang, RC Ewing, and KV Govindan Kutty. 1999b. "Ion Irradiation Effects for Two Pyrochlore Compositions $\mathrm{Gd}_{2} \mathrm{Ti}_{2} \mathrm{O}_{7}$ and $\mathrm{Gd}_{2} \mathrm{Zr}_{2} \mathrm{O}_{7}$." Materials Research Society Symposium Proceedings 540.

Wang SX, LM Wang, RC Ewing, and KV Govindan Kutty. 2000. "Ion Irradiation of Rare-Earth- and Yttrium-Titanate-Pyrochlores." Nuclear Instruments and Methods in Physics Research B 169: 135-140.

Wang SX, LM Wang, RC Ewing, GS Was, and GR Lumpkin. 1999c. "Ion Irradiation-Induced Phase Transformation of Pyrochlore and Zirconolite." Nuclear Instruments and Methods in Physics Research B 148: 704-709.

Weber WJ, and RC Ewing. 2002. "Radiation Effects in Crystalline Oxide Host Phases for the Immobilization of Actinides." Mat. Res. Soc. Symp. Proc 713: 443-454. 
Weber WJ, RC Ewing, CRA Catlow, T Diaz de la Rubia, LW Hobbs, C Kinoshita, H Matzke, AT Motta, M Nastasi, EKH Salje, ER Vance, and SJ Zinkle. 1998. "Radiation Effects in Crystalline Ceramics for the Immobilization of High-Level Nuclear Waste and Plutonium." Journal of Materials Research 13(6): 1434-1484.

Weber WJ, and H Matzke. 1986. "Radiation Effects in Actinide Host Phases." Radiation Effects 98: 9399.

Weber WJ, JW Wald, and H Matzke. 1985. "Self-Radiation Damage in $\mathrm{Gd}_{2} \mathrm{Ti}_{2} \mathrm{O}_{7}$." Materials Letters 3(4): 173-180.

Weber WJ, JW Wald, and H Matzke. 1986. "Effects of Self-Radiation Damage in Cm-Doped $\mathrm{Gd}_{2} \mathrm{Ti}_{2} \mathrm{O}_{7}$ and $\mathrm{Gd}_{2} \mathrm{Zr}_{2} \mathrm{O}_{7}$." Journal of Nuclear Materials 138: 196-209.

Wolery TJ. 1992. EQ3NR, a Computer Code for Geochemical Aqueous Speciation-Solubility Calculations: Theoretical Manual, Users' Guide and Related Documentation (Version 7.0), UCRL-MA110662 PT III, Lawrence Livermore National Laboratory, Livermore, California. 
PNNL-14588

\section{Distribution}

\section{Hardcopies}

No. of

Copies

OFFSITE

1 Lawrence Livermore National Laboratory

P. O. Box 808

Livermore, CA 94551

Attn: L. Jardine
No. of

Copies

\section{ONSITE}

9 Pacific Northwest National Laboratory

D. M. Strachan (5)

K6-24

R. D. Scheele (2)

P7-25

Information Release Office (2) K1-06

3 U.S. Department of Energy Richland Operations Office

Public Reading Room

$\mathrm{H} 2-53$

RL Docket File (2)

$\underline{\text { CDs }}$

No. of

No. of

Copies

Copies

\section{OFFSITE}

\section{OFFSITE}

2 Argonne National Laboratory

Building 205

9700 South Cass Avenue

Argonne, IL 60439-4837

Attn: David Chamberlain

\section{Alan Bakel}

3 Australian Nuclear Science and Technology

Organisation

PMB 1

Menai NSW 2234

Australia

Attn: L. Vance (3)

2 AWE Aldermaston

Reading, Bershire

RG7 4PR, United Kingdom

Attn: I. Donald (2)

1 California State University, Chico

Department of Geosciences

Chico, CA 95929-0205

Attn: W.M. Murphy

1 CEA/VRH

Marcoule BP17171

Bagnols-sur-Cèze 30207

France

Attn: T. Avocat

1 Embassy of Australia

1601 Massachusetts Avenue NW

Washington, DC 20036

Attn: K. Hart

2 Forschungszentrum Karlsruhe

Postfach 3640

D-76021 Karlsruhe

Germany

Attn: B. Kienzler

H. Matzke

Distr. 1 


\section{Distribution (Contd)}

\section{$\underline{\text { CDs }}$}

No. of

Copies

OFFSITE

9 Lawrence Livermore National Laboratory

P. O. Box 808

Livermore, CA 94551

Attn: W. Bourcier (1)

B. Ebbinghaus (1)

L. Jardine (5)

H. F. Shaw (1)

R. VanKonynenberg (1)

1 Lutze Consulting

3110 Birch Street NW

Washington, DC 20015

Attn: W. Lutze

1 Massachusetts Institute of Technology

77 Massachusetts Avenue

Cambridge, MA 02139-4307

Attn: L. W. Hobbs

2 University of California - Davis

One Shields Avenue

Davis, CA 95616

Attn: A. Navrotsky (2)

2 University of Cambridge

Department of Earth Sciences

Downing Street

Cambridge CB2 3EQ

United Kingdom

Attn: I. Farnan

G. Lumpkin

1 University of Michigan

Geological Sciences

1006 C Little

Ann Arbor MI 48109-1063

Attn: R. Ewing
No. of

Copies

OFFSITE

2 University of Sheffield

Western Bank

Engineering Materials

Sheffield S10 2TN

United Kingdom

Attn: W. Lee (2)

3 US Department of Energy, Headquarters

Forrestal (NN-62)

1000 Independence Avenue, S.W.

Washington, DC 20585

Attn: J. Bozik (3)

1 Westinghouse Savannah River Company

P. O. Box 616

Aiken, SC 29802

Attn: James Marra

1 V.G. Khlopin Radium Institute

28, 2-nd Murinsky Ave.

St. Petersburg 194021

Russia

Attn: B. Burakov

Distr. 2 


\section{Distribution (Contd)}

\section{CDs}

No. of

Copies

\section{ONSITE}

1 U.S. Department of Energy

Richland Operations Office

D. L. Biancosino K8-50

14 Pacific Northwest National Laboratory

W. C. Buchmiller

K6-24

E. C. Buck

P7-27

J. P. Icenhower

K6-81

A. E. Kozelisky

$\mathrm{P} 7-25$

D. E. McCready

K8-93

B. P. McGrail

K6-81

H. T. Schaef

K6-81

R. L. Sell

P7-25

D. M. Strachan (5)

K6-24

W. J. Weber

K8-93

Distr. 3 